ROUTLEDGE EXPLORATIONS IN ENVIRONMENTAL STUDIES

\title{
Fairness and Justice in Natural Resource Politics
}

Edited by

Melanie Pichler, Cornelia Staritz, Karin Küblböck, Christina Plank, Werner Raza and

Fernando Ruiz Peyré 


\section{Fairness and Justice in Natural Resource Politics}

As demand for natural resources increases due to the rise in world population and living standards, conflicts over their access and control are becoming more prevalent. This book critically assesses different approaches to and conceptualizations of resource fairness and justice and applies them to the analysis of resource conflicts.

Approaches addressed include cosmopolitan liberalism, political economy and political ecology. These are applied at various scales (local, national, international) and to initiatives and instruments in public and private resource governance, such as corporate social responsibility instruments, certification schemes, international law and commodity markets. In doing so, the contributions contrast existing approaches to fairness and justice and extend them by taking into account the interplay between political scales, regions, resources and power structures in 'glocalized' resource politics.

Various case studies are included concerning agriculture, agrofuels, land grabbing, water resources, mining and biodiversity. The volume adds to the academic and policy debate by bringing together a variety of disciplines and perspectives in order to advance both a research and policy agenda that puts notions of resource fairness and justice centre-stage.

Melanie Pichler is a Post-doctoral Researcher and Lecturer at the Institute of Social Ecology, Alpen-Adria-Universität Klagenfurt, Austria and an Associate of the International Political Ecology Research Group at the University of Vienna.

Cornelia Staritz is Senior Researcher at the Austrian Foundation for Development Research (ÖFSE), Austria and Research Associate at Policy Research in International Services and Manufacturing (PRISM), University of Cape Town, South Africa.

Karin Küblböck is Senior Researcher at the Austrian Foundation for Development Research (ÖFSE), Austria and Lecturer in Development Economics at the University of Vienna.

Christina Plank is a PhD candidate and Lecturer at the Department of Political Science, University of Vienna, Austria.

Werner Raza is Director of the Austrian Foundation for Development Research (ÖFSE), Austria.

Fernando Ruiz Peyré is Assistant Professor at the Institute of Geography, University of Innsbruck, Austria. 


\section{Routledge Explorations in Environmental Studies}

Water Politics and Spiritual Ecology Custom, environmental governance and development

Lisa Palmer

The Politics of Ecosocialism

Transforming welfare

Edited by Kajsa Borgnäs,

Teppo Eskelinen, Johanna Perkiö

and Rikard Warlenius

Peak Energy Demand and Demand Side Response

Jacopo Torriti

The Green Economy in the Gulf

Edited by Mohamed Abdelraouf

and Mari Luomi

Ecology, Sustainable Development and Accounting

Seleshi Sisaye

Environmental Change and the

World's Futures

Ecologies, ontologies and

mythologies

Edited by Jonathan Paul Marshall

and Linda H. Connor

Environmental Adaptation and Eco-cultural Habitats

A coevolutionary approach to society and nature Johannes Schubert
Complexity and Creative Capacity Rethinking knowledge transfer, adaptive management and wicked environmental problems Kelly Chapman

Contemporary Perspectives on Ecofeminism

Mary Phillips and Nick Rumens

Culture and Conservation

Beyond anthropocentrism

Eleanor Shoreman-Ouimet and

Helen Kopnina

The Governance of Sustainable Rural Renewal A comparative global perspective Rory Shand

Disasters and Social Resilience

A bioecological approach Helen J. Boon, Alison Cottrell and David King

Fairness and Justice in Natural Resource Politics

Edited by Melanie Pichler, Cornelia Staritz, Karin Küblböck, Christina Plank, Werner Raza and Fernando Ruiz Peyré 


\section{Fairness and Justice in Natural Resource Politics}

Edited by Melanie Pichler,

Cornelia Staritz, Karin Küblböck, Christina Plank, Werner Raza and Fernando Ruiz Peyré 
First published 2017

by Routledge

2 Park Square, Milton Park, Abingdon, Oxon OX14 4RN

and by Routledge

711 Third Avenue, New York, NY 10017

Routledge is an imprint of the Taylor \& Francis Group, an informa business

(C) 2017 Melanie Pichler, Cornelia Staritz, Karin Küblböck, Christina

Plank, Werner Raza and Fernando Ruiz Peyré

The right of the editors to be identified as the authors of the editorial matter, and of the authors for their individual chapters, has been asserted in accordance with sections 77 and 78 of the Copyright, Designs and Patents Act 1988.

All rights reserved. No part of this book may be reprinted or reproduced or utilized in any form or by any electronic, mechanical, or other means, now known or hereafter invented, including photocopying and recording, or in any information storage or retrieval system, without permission in writing from the publishers.

Trademark notice: Product or corporate names may be trademarks or registered trademarks, and are used only for identification and explanation without intent to infringe.

British Library Cataloguing-in-Publication Data

A catalogue record for this book is available from the British Library

Library of Congress Cataloging-in-Publication Data

Names: Pichler, Melanie, editor.

Title: Fairness and justice in natural resource politics / edited by

Melanie Pichler, Cornelia Staritz, Karin Kèublbèock, Christina Plank, Werner Raza and Fernando Ruiz Peyrâe.

Description: London ; New York : Routledge, 2016. I Series:

Routledge explorations in environmental studies I Includes

bibliographical references and index.

Identifiers: LCCN 2016008053| ISBN 9781138195950 (hbk) I

ISBN 9781315638058 (ebk)

Subjects: LCSH: Natural resources-Political aspects. I Environmental policy. I Environmental justice.

Classification: LCC HC85 .F353 2016 I DDC 333.7-dc23

LC record available at http://lccn.loc.gov/2016008053

ISBN: 978-1-138-19595-0 (hbk)

ISBN: 978-1-315-63805-8 (ebk)

Typeset in Sabon

by Wearset Ltd, Boldon, Tyne and Wear 


\section{Contents}

List of illustrations viii

Notes on contributors ix

Acknowledgements xii

1 Fairness and justice in natural resource politics: an introduction

MELANIE PICHLER, CORNELIA STARITZ,

KARIN KÜBLBÖCK, CHRISTINA PLANK, WERNER RAZA, AND FERNANDO RUIZ PEYRÉ

\section{PART I}

Conceptual approaches to resource fairness and justice

2 Liberal global justice and social science

SHMUEL NILI

3 What's democracy got to do with it? A political ecology perspective on socio-ecological justice

MELANIE PICHLER

4 Social costs and resource creation: essential elements of a political economy approach to resource fairness

WERNER RAZA

\section{PART II}

Empirical cases on resource fairness and justice

5 Integrated water resources management in Brazil: participatory approaches as a way to resource justice? 
vi Contents

6 Claims for local justice in natural resource conflicts: lessons from Peru's mining sector

MELANIE CONI-ZIMMER, ANNEGRET FLOHR, AND

ANDREAS JACOBS

7 Corporate social responsibility: a globally applicable tool to manage community-company relations in the extractive sector?

JOHANNA SYDOW

8 Increasing fairness in global value chains? Possibilities and limitations of fair trade standards for the agricultural and mineral sector

JUTTA KISTER AND FERNANDO RUIZ PEYRÉ

9 The soy-production fair(y) tale? Latin American perspectives on globalized dynamics, territoriality, and environmental justice

ROBERT HAFNER AND MARTIN COY

10 Greening the imperial mode of living? Socio-ecological (in)justice, electromobility, and lithium mining in Argentina AXEL ANLAUF

11 Foreign involvement in small-scale gold mining in Ghana and its impact on resource fairness

GORDON CRAWFORD AND GABRIEL BOTCHWEY

12 Elite capture and the development of natural resource linkages in Mozambique

LARS BUUR AND CELSO MARCOS MONJANE

13 The agrofuels project in Ukraine: how oligarchs and the EU foster agrarian injustice

CHRISTINA PLANK

14 Price risks and resource fairness in commodity trading: the cotton and coffee sectors in sub-Saharan Africa 
Contents vii

15 Responsibility for financing biodiversity conservation: an analysis of the Convention on Biological Diversity

INA LEHMANN

Index 


\section{Illustrations}

Figures

6.1 Local justice claims in resource conflicts

8.1 Cross-regional influences via standards in fair trade, schematic illustration

14.1 Futures prices, export prices, and farm gate prices for cotton (left) and coffee (right)

14.2 Intra-seasonal price risks and PRM for producers, local exporters, and international traders

\section{Tables}

9.1 Territoriality - comparison between Brazilian Mato Grosso and Argentine Chaco

9.2 Discourse - comparison between Brazilian Mato Grosso and Argentine Chaco

13.1 Agrofuel consumption in the EU 28 


\section{Contributors}

Axel Anlauf is a freelance social scientist in Germany. His research is guided by his interest in political ecology, resource extraction, social movements, and theories of global capitalism with a regional focus on Latin America.

Gabriel Botchwey is Lecturer and head of the Department of Political Science, University of Education in Winneba (Ghana). His research interests include state-society relations, public policy and administration, social policy, local and regional development, as well as environment and natural resource struggles.

Lars Buur is Associate Professor at the Institute for Society and Globalization, Roskilde University (Denmark). His research interests are productive sector development and industrial policy. $\mathrm{He}$ is currently coordinator of the Hierarchies of Rights research programme that explores the relationship between extractive investments and the rights of different parties.

Melanie Coni-Zimmer is a Research Fellow at the Peace Research Institute Frankfurt (Germany). Her current research interests include the role of non-state actors in international relations, privatized forms of governance, and conflicts around natural resources with a particular focus on the oil industry.

Martin Coy is Professor at the Institute of Geography, University of Innsbruck (Austria). His main research interests include geographical development research, urban geography, and sustainable development. Regionally, he focuses on Latin America (particularly Brazil and Argentina), France, Indonesia, and the Alpine region.

Gordon Crawford is Research Professor at the Centre for Trust, Peace and Social Relations, Coventry University (UK). His research examines issues of human rights, democracy, and development, especially in countries of the Global South, with a particular focus on empirical research in Ghana. Current research focuses on resource politics, food sovereignty, and participatory democracy. 
Annegret Flohr is Project Coordinator at the Institute for Advanced Sustainability Studies (IASS) in Potsdam (Germany) and an Associate Fellow at the Peace Research Institute Frankfurt (Germany). Her research focuses on natural resource governance. She has worked on the extractive sector in Peru and currently focuses on soil and land resources in Benin, Burkina Faso, Ethiopia, Kenya, and India.

Robert Hafner is a PhD candidate at the Institute of Geography, University of Innsbruck (Austria). His research focuses on human-environment relations, social-ecological conflicts, and environmental justice, predominantly in Latin America and particularly in Argentina.

Andreas Jacobs is an Associate Fellow of the Peace Research Institute Frankfurt (PRIF). His research interests include natural resource conflicts, local development dynamics, and impact assessment methodologies. His regional expertise is particularly comprehensive with regard to Sub-Saharan Africa.

Jutta Kister is a $\mathrm{PhD}$ candidate at the Institute of Geography, University of Innsbruck (Austria). Her research interests include global interlinkages, private standards, and power relations in alternative food chains, especially Fair Trade. Her regional foci are Latin America and Europe.

Karin Küblböck is Senior Researcher at the Austrian Foundation for Development Research (ÖFSE) and Lecturer for Development Economics at the University of Vienna (Austria). Her main research topics include development economics, investment policies, commodities, financial markets, and international financial institutions.

Ina Lehmann is a Research Associate at the University of East Anglia (Norwich, UK) and a PhD candidate at the University of Bremen (Germany). Her research interests include global justice as well as the legitimacy and legitimation of global governance. Empirically, her main focus is on environmental politics and biodiversity conservation.

Celso Marcos Monjane is PhD Fellow at Roskilde University (Denmark) and the University of Dar es Salaam (Tanzania). He is based at the University of Eduardo Mondlane in Maputo (Mozambique). His research interests include governance and development, especially related to natural resources.

Shmuel Nili is a $\mathrm{PhD}$ candidate in political science at Yale University (Connecticut, USA). His main research topics include collective agency and democracy, and tensions between realism and idealism in thinking about global reform.

Melanie Pichler is a Post-doctoral Researcher and Lecturer at the Institute of Social Ecology, Alpen-Adria Universität Klagenfurt (Austria) and an Associate of the International Political Ecology research group at the 
University of Vienna. Her research interests include political ecology, critical state theory, and the relationship between socio-ecological transformation and democracy, with a regional focus on South-East Asia.

Christina Plank is a $\mathrm{PhD}$ candidate and Lecturer at the Department of Political Science, University of Vienna (Austria) where she is a member of the International Political Ecology research group. Her research focuses on critical state theory and political ecology in Central and Eastern Europe with a particular focus on agricultural transformation in Ukraine.

Werner Raza is Director of the Austrian Foundation for Development Research (ÖFSE). His research areas include international trade, development economics, and development policy.

Fernando Ruiz Peyré is Assistant Professor at the Institute of Geography, University of Innsbruck (Austria). His research topics include rural and social geography, political ecology, lithium mining, and development geography with a regional focus on Latin America.

Tobias Schmitt is a Post-doctoral Researcher at the Institute of Geography, University of Hamburg (Germany). His main research interests include critical geography and postcolonial political ecology with a regional focus on Latin America and particularly Brazil.

Cornelia Staritz is Senior Researcher at the Austrian Foundation for Development Research (ÖFSE) and Research Associate at Policy Research in International Services and Manufacturing (PRISM) at the University of Cape Town (South Africa). Her research focuses on economic development, international trade, global value chains and production networks, private sector development, and commodity-based development.

Johanna Sydow is a policy officer for resource policy and the IT sector with the NGO Germanwatch in Berlin (Germany) and a visiting Research Fellow at the University of Sussex (UK). She conducted extensive field research in Ghana, Peru, and Ecuador on the social impact of large- and small-scale mining, especially on the implications of CSR and the role of local contexts and the criminalization of protest.

Bernhard Tröster is a Researcher at the Austrian Foundation for Development Research (ÖFSE) and PhD candidate in Economics at the Vienna University of Economics and Business (Austria). His research focuses on commodity markets, economic development, and international trade. 


\section{Acknowledgements}

This volume originates from the 1st Austrian Conference on International Resource Politics entitled Towards International Resource Fairness - Theories, Conflicts and Policies, which was held at the Centre for International Development in Vienna (C3) (Austria) from 4-6 December 2014. The conference was organized by the Austrian Foundation for Development Research (ÖFSE), the Department of Political Science at the University of Vienna, and the Institute of Geography at the University of Innsbruck. The conference was a joint activity of the Research Platform on Resource Fairness that these organizations initiated in 2013. Special thanks go to the over 100 participants of the conference for many insightful presentations and stimulating discussions, which laid the ground for the publication of this volume.

The editors wish to acknowledge the permission to reprint for two of the chapters. With Cambridge University Press, a longer version of the chapter by Shmuel Nili first appeared in the Review of International Studies, vol. 42, no. 1 (2016). With Berghahn Books, a similar version of the chapter by Johanna Sydow was first published in the volume The Anthropology of Corporate Social Responsibility, edited by Catherine Dolan and Dinah Rajak (2016). 


\title{
1 Fairness and justice in natural resource politics
}

\author{
An introduction
}

\author{
Melanie Pichler, Cornelia Staritz, \\ Karin Küblböck, Christina Plank, \\ Werner Raza, and Fernando Ruiz Peyré
}

\section{Approaching resource fairness and justice}

In March 2011, a devastating civil war started in Syria that forced more than four million people to flee their homes, mainly to the neighbouring countries of Jordan, Lebanon, Iraq, and Turkey (UNHCR, 2015). Little discussed in media reports, the worst drought in Syrian history, that forced over 1.5 million farmers to migrate from the countryside to the cities of Aleppo, Damascus, or Homs, preceded the civil war (Gleick, 2014; Meynen and Temper, 2014). Drought related water shortage, crop failure linked to climate change, and subsequent internal migration contributed to urban unemployment and social unrest in the advent of the civil war (Gleick, 2014). Historically, disputes over the (re)distribution of water resources have been an important line of conflict in one of the driest regions in the world, mainly through the construction and control of water infrastructure (at least 46 dams in the Tigris-Euphrates basin). Currently, hydrological control is also an important factor in war activities. In 2012, for example, Syrian rebels captured the Tishrin dam and in 2013 the Islamic State captured the Tabqa dam that serves as the most important source of irrigation for the surrounding farmlands in Syria and Iraq as well as of electricity supply for the second largest city of Aleppo (Gleick, 2014; Meynen and Temper, 2014).

In November 2013, the Supreme Court of the Republic of Ecuador fined the multinational petroleum corporation Chevron (formerly Texaco) 9.5 million US dollars as financial compensation for social and environmental damage in the Ecuadorian Amazon (Environmental Justice Atlas, 2015). Petroleum is Ecuador's most important natural resource and has brought wealth and prosperity to Ecuadorians and international companies. At the same time, petroleum extraction has been an important source for political mobilization of oil workers, Amazonian settlers, and indigenous peoples over the distribution of benefits from the nation's natural resources (Valdivia, 2008). Since 1964, the former Texaco Petroleum Company extracted crude oil from up to 350 oil wells on a 1.5 million hectare concession in 


\section{M. Pichler et al.}

the Amazon, spilling over 60 billion litres of toxic waste and 650,000 barrels of oil (Environmental Justice Atlas, 2015). The contamination of the land and the water led to the dispossession and marginalization of thousands of indigenous peoples and peasants dependent on forests, agricultural land, and the environment more generally as well as to serious health risks such as rising cancer rates, birth defects, and spontaneous miscarriages (Chevron Toxico, 2015).

In August 2015, about 1,500 climate activists occupied an opencast brown coal mine of the multinational energy corporation RWE in the German Rhineland to shut down one of Europe's biggest $\mathrm{CO}_{2}$ emission sites (Jordan, 2015). Globally, coal is the single biggest driver of climate change through the associated greenhouse gas emissions, and scientists argue that 80 per cent of coal deposits need to be kept in the ground in order to prevent the most devastating effects of climate change (McGlade and Ekins, 2015). In Germany, despite efforts in renewable energy production to drastically reduce $\mathrm{CO}_{2}$ emissions (German Renewable Energy Act), 45 per cent of electricity is still produced from coal (Statistisches Bundesamt, 2015). The temporary shutdown of the mine constituted an important focal point for the transnational climate movement in the run-up to the international climate negotiations in Paris and called on Germany's responsibility for global climate justice, that is, to immediately cut emissions from fossil fuels in line with international obligations (Darby, 2015).

These three examples illustrate the multiple causes and sites of resource conflicts and justice claims (e.g. local environmental destruction and health impacts, uneven distribution of natural resources and related benefits, climate change). At the same time, the examples shed light on the diverse forms of resistance to resource injustice as well as the instruments used to claim and access fairness and justice (e.g. legal means, migration, sabotage, occupation of extraction sites).

Although political, scientific, and media debates regularly refer to fairness and justice when it comes to resource politics, the applied conceptions and underlying meanings are diverse, vague, and often contradictory. In the academic literature, explicit conceptions of resource fairness and justice have been mostly advanced based upon liberal global justice and international (human rights) law. These approaches suggest an agreed-upon and universal understanding of justice that often fails to materialize in practice. Case studies from different social science backgrounds show that in concrete resource conflicts different notions of fairness and justice often compete with each other; that is, the very definition of justice is at stake. In other words, apart from economic (distributional) aspects, environmental and social concerns, questions of inclusion and democracy, references to sacredness, or cultural and aesthetic values may be brought forward (Martínez-Alier et al., 2010).

This edited volume on Fairness and Justice in Natural Resource Politics aims to contribute to the debate on resource politics from a fairness and 
justice perspective. The volume critically assesses different approaches to and conceptualizations of resource fairness and justice (e.g. liberal global justice, political economy, political ecology) and applies them to resource conflicts (e.g. conflicts over agriculture, biodiversity, mining, water) at various scales (local, national, international). In doing so, the contributions critically assess initiatives and instruments in public and private resource governance (e.g. Corporate Social Responsibility (CSR), private standards, international conventions, commodity derivative markets) and take into account the interplay between political scales, regions, resources, and power relations in glocalized resource politics.

\section{Historical development of resource politics}

Access to natural resources has been a contested political arena for centuries and a key motive for the expansion and consolidation of colonial rule in Latin America, Asia, and Africa. After decolonization, the unequal appropriation of resources and commodity earnings was increasingly put on the international agenda. In 1962, the UN Declaration on Permanent Sovereignty over Natural Resources stated that natural resources should be used in the interest of national development and the well-being of the people, subordinating foreign capital used for resource exploration to these conditions (United Nations, 1962). Furthermore, the UN Declaration for the Establishment of a New International Economic Order (United Nations, 1974) confirmed the full and permanent sovereignty of all states over their natural resources and the right of developing countries to form cartels and extend existing commodity agreements. National control over natural resources was seen as an important pillar in development strategies. Nationalization of extraction and production as well as requirements for foreign investors in resource sectors (e.g. know-how transfer and profit sharing) were widespread. Natural resources were meant to raise public revenues and contribute to the diversification of the economy with, however, often limited sustainable success.

Besides debates on resource sovereignty, the discussion on sustainable resource use and development started in the 1970s. The scenarios of the Club of Rome (Meadows et al., 1972) on the increasing scarcity of nonrenewable resources fuelled this debate. Their publication Limits to Growth challenged both population growth and the unlimited use of natural resources (especially land and fossil energy) that would lead to resource scarcity and environmental destruction within the next 50 to 100 years. In the run-up to the first UN environmental conference in Stockholm in 1972, the Club of Rome called for the establishment of international institutions to deal with these global problems and a radical change in unequal NorthSouth relations. Although the scenarios did not materialize in reality as predicted, resource scarcity, environmental destruction, and climate change have since then shaped and influenced (international) resource politics. 
The discovery of new raw material deposits, the oil price crises and the related fall in other commodity prices, as well as the debt crisis of the 1980s significantly weakened the position of resource-rich countries in international politics. Hence, resource-based development strategies and resource politics more broadly largely disappeared from the (international) agenda. In the following two decades, resource policies were shaped by a withdrawal of the state and the creation of favourable conditions for foreign investors (e.g. fiscal and financial incentives, investment protection measures). The pressure of international financial institutions and their Structural Adjustment Programmes (SAPs), as well as the global policy shift towards neoliberalism, contributed to these developments. In this context, the roles, rights, and responsibilities of states and corporations changed significantly. This can be seen in the development of international investment policies that shifted from protecting states to limiting their policy space and promoting foreign investors. From the perspective of most resource-rich developing countries, the impact of this policy shift on public revenue, local employment, diversification of the economy, and development more broadly was disappointing (Campbell, 2010; UNECA and AU, 2011; Besada and Martin, 2015).

From the turn of the millennium, natural resources have again become a key issue in local, national, and international politics. This is due to a number of factors, including the increasing demand for resources by emerging economies (most importantly, China), the generalization and intensification of resource-based modes of living (e.g. meat consumption, use of cars and electronics), the scarcity of some critical natural resources (e.g. magnesite, tungsten), and the (related) commodity price boom accompanied by high price volatility. Competition for access to and control of resources has thus intensified, and so have conflicts over the exploration, production, and consumption of natural resources and the distribution of economic, social, and environmental benefits and costs.

Current resource politics is dominated by diverse actors and strategies. Resource importers, that is, largely industrialized and emerging economies, are mainly motivated by resource security concerns and strive for 'undistorted' access to raw materials. For this purpose, several of these countries, such as the US, Japan, Korea, and the EU, have formulated raw material strategies in recent years (Küblböck, 2013; Mildner and Howard, 2013). In the case of the EU, access to raw materials has become a priority in negotiating trade agreements with non-EU countries. The EU has also used WTO accession negotiations to establish bans on export restrictions in the resources sector that go beyond WTO rules and has employed different instruments of development policy in order to promote access to raw materials (European Commission, 2013; European Commission 2014).

On the other hand, the competition for access to natural resources and the price boom of the 2000s have increased the political space for negotiation in resource-rich countries. Debates about the unequal distribution of 
benefits from natural resources and the potential of resource-based development in the Global South have intensified and governments have taken action to increase public revenue from the resource sector to improve its contribution to local economic development. Some have also initiated linkages and local content policies to further local added value and economic diversification (Küblböck, 2015; for Africa, see African Union, 2009; UNECA and AU, 2013). However, governments of resource-exporting countries too often implement resource policies without respecting the rights of affected local communities and fail to use resource revenues for social and productive investment. The recent commodity price decline has also challenged resource-based development strategies more generally, once more shifting the power away from resource exporting countries.

Transnational companies play a key role in extractive industries. In recent years, they have been increasingly subject to criticism and resistance against their business strategies and the social and environmental impacts of resource extraction. As a response, they developed CSR programmes in order to acquire or maintain their "social licence to operate" (Moffat and Zhang, 2014). A main challenge is the voluntary and often unilateral character of these activities and their diversion from the companies' core business that limit their transformative potential from the onset. At the trans- and international level, the general trend towards soft law and privatization of resource regulation has fostered voluntary self-regulatory initiatives to resource governance (e.g. roundtables, guidelines, certification schemes). However, as far as transparency of financial flows is concerned, the US and the EU have more recently introduced binding legislation on the disclosure of payments from companies to governments of resource-exporting countries (Küblböck, 2015).

The often dramatic environmental and social impacts of extractive industries and natural resource politics have intensified socio-ecological conflicts and encouraged social movements to reflect on alternatives to resource-based development and mechanisms for fairness and justice in resource politics. Especially in Latin America, social movements and civil society actors increasingly question the very basis of current resource extraction patterns in the context of capitalist production and development under the term post-extractivism (Monge et al., 2011; Gudynas, 2013). They stress that social and environmental costs are externalized while resource-based benefits accrue to a small group of people only. Most importantly, they criticize the fact that a majority of actors are excluded from decision-making processes in resource politics. These debates and struggles (e.g. on buen vivir in Latin America, Ubuntu in Africa, or climate justice in international climate politics) denounce existing power relations regarding the appropriation, control, and distribution of natural resources and call for alternative and democratic resource politics. 


\section{Major themes}

Academic research on fairness and justice in resource politics has so far mainly focused upon particular issues and case studies. These include, for example, the analysis of local resource conflicts (Selfa, 2004; Gross, 2007; Bebbington and Williams, 2008), resource geopolitics (Le Billon, 2004), regulatory instruments and initiatives (Campbell, 2010; Besada and Martin, 2015), or different resource-based value chains (Barrientos and Smith, 2007; Reed, 2009). Research has focused on justice implications for specific resources (e.g. Hunt and Haider, 2001 for forestry; Weinhold et al., 2013 for agriculture; Gross, 2014 for water; or Bryceson et al., 2014 for mining), analysed from specific disciplines and theoretical or conceptual approaches (e.g. Lawrence et al., 1997 from a legal perspective or Bullard, 1990 from an environmental justice approach). This volume brings together scholars from a variety of disciplines and combines and contrasts their approaches in order to advance both a research and policy agenda that puts notions of fairness and justice centre-stage. Three major themes are identified:

First, the contributions draw on different conceptualizations of resource fairness and justice. The first part of the volume introduces three conceptual approaches, namely liberal global justice, a political ecology and a political economy perspective on resource fairness and justice. In line with the disciplinary and institutional logics of knowledge creation, these approaches have been developed more or less in isolation from each other. Based on this insight, the volume promotes an exchange between different approaches to resource fairness and justice. Such an interdisciplinary approach highlights the different perspectives, interrelations, and contradictions between the disciplinary debates on resource politics. These conceptual approaches are referred to and partly built upon in the subsequent, more empirically focused chapters of the volume that deal with specific aspects or cases of resource conflicts, fairness/justice, and governance.

A liberal global justice perspective draws mainly on Rawlsian justice principles, and applies them to global natural resource management. Rawls ([1971] 2003) developed social justice from two basic principles: that is, the equal rights principle (referring to equal basic liberties) and the difference principle postulating that "social and economic equalities are to be arranged so that they are to the greatest benefit of the least advantaged" (266). Based on this originally national framework, liberal philosophers have conceptualized resource justice as a global challenge and call for the redistribution of natural resources based on an abstract moral justice 'compass'. The distribution of natural resources is seen as morally arbitrary over the earth's surface, resembling a natural resource lottery (Beitz, [1979] 1999). Accordingly, liberal global justice representatives call for an increase in foreign aid (Beitz, [1979] 1999), the introduction of a global resource dividend (Pogge, 2001), or other global funds (Hayward, 2006) to redistribute the economic benefits derived from excessive natural resource use. In this volume, Shmuel Nili 
introduces basic arguments of liberal global justice and contrasts some of the philosophical paradigm's assumptions with social scientific findings on natural resource production, consumption, and distribution.

In developing an abstract moral justice compass, liberal global justice neglects conflicts, power relations, and the historical development of current resource distribution patterns. A political ecology perspective on fairness and justice in turn emanates from conflicts over access to and control of nature and natural resources to reflect on explicitly political dimensions of resource justice. Therefore, political ecology challenges abstract redistribution principles and directs attention to questions of "who has the power to impose decisions on resource extraction, land use, pollution levels, biodiversity loss, and more importantly, who has the power to determine the procedures to impose such decisions" (MartínezAlier et al., 2010: 154). In other words, the redistribution of natural resources - among humans, social groups, and states - requires the inclusion of all potentially affected people and the control over decision-making power and problem-solving as well as the recognition of diverse modes of living (Schlosberg, 2004). In this volume, Melanie Pichler conceptualizes justice from a political ecology perspective that explicitly highlights power relations and inequalities and elaborates on the political dimensions of socio-ecological justice. In doing so, the chapter reverses the line of argument from abstract moral justice principles to socio-ecological conflicts as a starting point for thinking about resource justice.

Political economy approaches to resource fairness typically focus on the distribution of the economic benefits and costs of resource extraction (Barma et al., 2012; Morris et al., 2012). Furthermore, these approaches have analysed why resource abundance often does not promote economic development, referring to rent-seeking, the 'resource curse', or the 'Dutch disease' (Rosser, 2006; Collier, 2010). These (mainstream) approaches are lacking in some important dimensions. Usually, questions of power are marginalized, and the social and environmental costs of resource extraction are either sidelined or dealt with by neoclassical welfare economics, neglecting issues such as fundamental uncertainty and incommensurability. Furthermore, the analysis is typically centred upon the national level even though politics of scale has doubtlessly become more important in the era of globalization. In this volume, Werner Raza offers an alternative political economy approach to resource fairness, building on Fraser's theory of justice and extending it by Kapp's concept of social costs and a dynamic understanding of natural resource development inspired by the American Institutionalist School. Raza argues that resource politics should not only manage the short-term distribution of benefits and costs, but strive at building institutions that allow for a dynamic process of 'resource-creation' by way of economic diversification and technological upgrading.

Second, the chapters analyse resource conflicts at various scales as well as the interplay of global, national, and local dynamics in resource politics. 
The access, control, use, and distribution of natural resources are global challenges that are manifested in competition and conflicts on various scales as well as in diverse public and private initiatives to resource politics and governance. The focus on case studies and the analysis of justice claims raised in local resource conflicts are a well-established way of dealing with fairness and justice in resource politics (e.g. Syme et al., 1999; Smith and McDonough, 2001; Selfa, 2004; Gross, 2007). Since the 1980s, globalization processes have intensified the interplay of global and local dynamics through international trade and investment relations and their implications for transnational conceptions of fairness and justice. The phenomenon of geographical disjuncture of production and consumption sites has, however, been discussed since colonial expansion and the industrial revolution. For example, the Marxist ecologist John Bellamy Foster (1999) conceptualizes this spatial disconnect between production and consumption with the concept of the metabolic rift and Haberl et al. (2009) use the term 'teleconnections' derived from climate and land use research. In specifically highlighting power relations, Brand and Wissen (2013) introduce the concept of the imperial mode of living to point to "prevailing patterns of production and consumption that disproportionately rely on global labour power, resources and sinks" (690). The imperial mode of living mainly refers to practices in the Global North, but is increasingly spreading among the middle classes and elites in emerging countries.

In this volume, on a local case study level Tobias Schmitt critically assesses participation processes in water distribution conflicts in the context of integrated water resources management in the Brazilian state of Ceará. By applying Fraser's concept of social justice, the contribution challenges the assumed positive relation between existing participation mechanisms and social justice and points to dominant power relations and existing inequalities that current participation mechanisms fail to question. Also referring to Fraser's concept of social justice, Melanie Coni-Zimmer, Annegret Flohr, and Andreas Jacobs analyse a mining conflict in the Peruvian Moquegua region and the local justice claims put forward by the conflict parties. The chapter argues that the governance mechanism developed to respond to the mining conflict does not appropriately take into account local communities' justice claims, focussing mainly on recognition-based claims. Johanna Sydow compares the local perspectives on and reactions to the implementation of CSR mechanisms to manage company-community relations by the transnational company Newmont in mining conflicts in Peru and Ghana. While Newmont's CSR concept is highly standardized, the contribution finds that it has differing impacts at different sites, depending on local contexts, agency, and counter-conduct.

From a national perspective, Gordon Crawford and Gabriel Botchwey conceptualize resource fairness in the Ghanaian small-scale gold mining sector. They examine the impact of foreign involvement, particularly from China, in this sector and the consequences for resource fairness in terms 
of resource sovereignty, state revenue, distribution of benefits, and environmental degradation, finding irrevocable changes to indigenous mining practices and negative externalities. Lars Buur and Celso Monjane explore resource fairness in relation to linkage development programmes in Mozambique's extractive sector, stressing the importance of a political economy perspective. They show that linkage formation has been monopolized by the ruling elite, which is engaged in 'linkage patronage', leaving few avenues for a more fair distribution of potential benefits from natural resource exploitation.

Framing resource conflicts on an international level, Ina Lehmann analyses the Convention of Biological Diversity (CBD) and assesses responsibilities for financing biodiversity conservation from a normative global justice perspective. While the CBD generally reflects the normative argument that developed countries should bear most of the costs of biodiversity conservation, the chapter applies the contributor pays principle and the ability to pay principle to argue that more recent developments with regard to financing the international biodiversity regime have shifted responsibilities to developing countries and therefore countervail global justice principles.

Dealing with the interplay of various scales, Jutta Kister and Fernando Ruiz Peyré reflect on consumer-producer relations in fairtrade initiatives. The chapter discusses opportunities and limitations of private standards in supporting 'fairer' global value chains, comparing the well-established Fairtrade system for agricultural products with experiences of 'fair' standards in the mining sector. They focus on governance structures, power relations, and cross-regional influences in a qualitative actor-centred approach of value chain analysis. Robert Hafner and Martin Coy analyse the local consequences of export-oriented soy production in the Brazilian Mato Grosso and the Argentine Chaco. The contribution draws on an environmental justice perspective to argue that universal conceptions of fairness and justice need to incorporate regional characteristics and local perspectives. Axel Anlauf reflects on the imperial mode of living through the analysis of high-tech and green growth strategies in Europe (e.g. electromobility, smartphones, notebooks) and their consequences for lithium mining conflicts in Jujuy, Argentina. The chapter argues that without addressing power asymmetries, 'green' technologies do not promote socioecological justice as they rely on the exclusive access to resources and externalize costs to both marginalized actors and nature. Cornelia Staritz, Bernhard Tröster, and Karin Küblböck focus on the interplay between international and national dynamics through the analysis of price setting in global commodity trade. Global processes of financialization are connected to national market structures and local outcomes on the distribution of price risks in the coffee sector in Ethiopia and the cotton sector in Burkina Faso, Mozambique, and Tanzania. Christina Plank analyses the transnational implications of the agrofuels project driven by EU policies and national and foreign agribusiness interests for agrarian justice in Ukraine. 
Ukrainian oligarchs, highly intertwined with the Ukrainian state, increasingly capture large-scale agriculture through agrofuel exports to the EU with negative impacts on rural development.

Third, a crosscutting theme of the volume is the analysis of different actors, instruments and initiatives, as well as responsibilities in resource politics. In other words, the chapters refer to the question of who is responsible for guaranteeing and implementing resource fairness and justice. Since the neoliberal turn in the 1980s, responsibility for fairness and justice in resource politics has gradually shifted from states to markets. This shift from statebased government to market- and network-based governance was accompanied by a "denationalization" at both the subnational (through decentralization) and the supranational level (through economic integration and global governance mechanisms) (Jessop, 1997: 573-576). In resource and environmental politics, these transformations include, for example, the rise of private and mostly voluntary standards and certification schemes (e.g. Giovannucci and Ponte, 2005; Tallontire, 2007; Pichler, 2013; Küblböck, $2015)$ and the increasing delegation of state responsibilities to private enterprises, including service delivery and rule setting and implementation (Campbell, 2010) which is closely linked to a further weakening of state legitimacy. On the international level, these transformations are interlinked with the establishment of multi-level or global governance mechanisms in climate, biodiversity, or water politics (e.g. Conca, 2006; Okereke et al., 2009) where transnational companies often play a key role. These shifts in responsibility imply that fairness and justice claims tend to move away from central state institutions to direct negotiations between, for example, communities and companies in so-called multi-stakeholder processes.

In this volume, Schmitt elaborates on the exclusion mechanisms in decentralized River Basin Committees and Users' Commissions in Brazil that were introduced within the global framework of Integrated Water Resources Management. Coni-Zimmer et al. analyse justice implications through the installation of Dialogue Tables (Mesas de diálogo) in mining conflicts in Peru, usually set up between a local community, a company, and local government authorities. Sydow compares the different effects of standardized CSR initiatives of the mining company Newmont in the local contexts of mining regions in Ghana and Peru. Hafner and Coy highlight the increasing importance of voluntary certification schemes in Latin America's soy production, which is, however, predominantly an act of marketing rather than an actual improvement towards fairer production. In dealing with explicitly transnational phenomena, Kister and Ruiz Peyré assess the fairness assumptions and power relations in fairtrade standards in the agricultural and mining sector. Staritz et al. analyse the distributional effects of commodity price setting through derivative markets and contrast them with national price stabilization schemes. Also on a supranational level, Lehmann discusses financial responsibilities in international biodiversity governance. In explicitly challenging neoliberal 
governance, Crawford calls on the state to develop viable and effective institutions to guarantee national resource sovereignty for the benefits of all Ghanaian citizens. Buur and Monjane, in turn, show the problematic outcomes of national linkages and local content policies in the extractive sector in Mozambique that led to 'linkage patronage' by the ruling elite, stressing the importance of taking into account power relations and political economy aspects in implementing national policies. In a similar vein, Plank highlights moments of conflict and cooperation between the Ukrainian oligarchs and different EU actors with their common support for agribusiness decisively shaping the conditions for resource (in)justice and policies in Ukraine. The contribution also shows the responsibility of EU regulation (i.e. agrofuel policies) for transnational justice implications in other countries (i.e. Ukraine), a theme also taken up in Anlauf's chapter on the implications of the green growth strategies of the Global North on mining conflicts in Argentina.

In sum, the volume shows that the very conception of fairness and justice in natural resource politics is contested. Furthermore, although often referring to some abstract principles, fairness and justice are typically contextsensitive and developed in societal struggles. The contributions help to reach a better understanding of different concepts, notions, and perspectives of resource fairness and justice at the local, national, and international level in order to design adequate resource policies and governance mechanisms. The chapters also shed light on the power relations that shape resource politics and prevent these reforms. Hence, a multi-dimensional and multi-scalar perspective on resource fairness and justice is required, that includes economic, social, and environmental redistribution as well as questions of inclusion, representation, and recognition. Shifts in resource politics towards fairness and justice will not come about without resistance from powerful groups that benefit from current resource politics and will therefore only evolve from resource conflicts and struggles that question these power asymmetries and inequalities.

\section{References}

African Union (2009) 'Africa mining vision', www.africaminingvision.org/amv_ resources/AMV/Africa_Mining_Vision_English.pdf [accessed 14 January 2016].

Barma, N. H., Kaiser, K., Minh Le, T., and Vinuela, L. (2012) Rents to Riches? The Political Economy of Natural Resource-Led Development, The World Bank, Washington, DC.

Barrientos, S. and Smith, S. (2007) 'Do workers benefit from ethical trade? Assessing codes of labour practice in global production systems', Third World Quarterly, vol. 28, no. 4, 713-729.

Bebbington, A. and Williams, M. (2008) 'Water and mining conflicts in Peru', Mountain Research and Development, vol. 28, no. 3, 190-195.

Beitz, C. R. [1979] (1999) Political Theory and International Relations, Princeton University Press, Princeton, NJ. 


\section{M. Pichler et al.}

Besada, H. and Martin, P. (2015) 'Mining codes in Africa: emergence of a "fourth" generation?’, Cambridge Review of International Affairs, vol. 28, no. 2, 263-282.

Brand, U. and Wissen, M. (2013) 'Crisis and continuity of capitalist society-nature relationships: the imperial mode of living and the limits to environmental governance', Review of International Political Economy, vol. 20, no. 4, 687-711.

Bryceson, D. F., Fisher, E., Jonsson, J. B., and Mwaipopo, R. (2014) Mining and Social Transformation in Africa. Mineralizing and Democratizing Trends in Artisanal Production, Routledge, New York.

Bullard, R. (1990) Dumping in Dixie. Race, Class, and Environmental Quality, Westview Press, Boulder, CO.

Campbell, B. (2010) 'Revisiting the reform process of African mining regimes', Canadian Journal of Development Studies, vol. 30, no. 1-2, 197-217.

Chevron Toxico (2015) 'A rainforest Chernobyl', http://chevrontoxico.com/about/ rainforest-chernobyl/ [accessed 14 January 2016].

Collier, P. (2010) 'The political economy of natural resources', Social Research, vol. 77 , no. 4, 1105-1132.

Conca, K. (2006) Governing Water. Contentious Transnational Politics and Global Institution Building, MIT Press, Cambridge, MA.

Darby, M. (2015) 'Activists to halt diggers at RWE coalfields in Germany', The Guardian, 14 August, www.theguardian.com/environment/2015/aug/14/activistshalt-diggers-rwe-coalfields-germany [accessed 14 January 2016].

Environmental Justice Atlas (2015) 'Chevron-Texaco oil extraction and legal case, Ecuador', https://ejatlas.org/conflict/chevron-texaco-ecuador [accessed 14 January 2016].

European Commission (2013) 'On the implementation of the Raw Materials Initiative', COM (2013) 442 final, http://eur-lex.europa.eu/LexUriServ/LexUriServ. do? uri=COM:2013:0442:FIN:EN:PDF [accessed 14 January 2016].

European Commission (2014) 'Commission staff working document: on the implementation of the Raw Materials Initiative', SWD (2014) 171 final, http://register. consilium.europa.eu/doc/srv?l=EN\&f=ST\%2010457\%202014\%20ADD\%201 [accessed 14 January 2016].

Foster, J. B. (1999) 'Marx's theory of metabolic rift: classical foundations for environmental sociology', American Journal of Sociology, vol. 105, no. 2, 366-405.

Giovannucci, D. and Ponte, S. (2005) 'Standards as a new form of social contract? Sustainability initiatives in the coffee industry', Food policy, vol. 30, no. 3, 284-301.

Gleick, P. (2014) 'Water, drought, climate change, and conflict in Syria', Weather, Climate, and Society, vol. 6, no. 3, 331-340.

Gross, C. (2007) 'Community perspectives of wind energy in Australia: the application of a justice and community fairness framework to increase social acceptance', Energy policy, vol. 35, no. 5, 2727-2736.

Gross, C. (2014) Fairness and Justice in Environmental Decision Making. Water Under the Bridge, Routledge, New York.

Gudynas, E. (2013) 'Transitions to post-extractivism: directions, options, areas of action', in M. Lang and D. Mokrani (eds) Beyond Development. Alternative Visions from Latin America, Rosa Luxemburg Foundation, Quito, 165-188.

Haberl, H., Erb, K.-H., Krausmann, F., Berecz, S., Ludwiczek, N., Martínez-Alier, J., Musel, A., and Schaffartzik, A. (2009) 'Using embodied HANPP to analyze teleconnections in the global land system: conceptual considerations', Geografisk Tidsskrift-Danish Journal of Geography, vol. 109, no. 2, 119-130. 
Hayward, T. (2006) 'Global justice and the distribution of natural resources', Political Studies, vol. 54, no. 2, 349-369.

Hunt, L. and Haider, W. (2001) 'Fair and effective decision making in forest management planning', Society \& Natural Resources, vol. 14, no. 10, 873-887.

Jessop, B. (1997) 'Capitalism and its future: remarks on regulation, government and governance', Review of International Political Economy, vol. 4, no. 3, 561-581.

Jordan, J. (2015) 'The day we stopped Europe's biggest polluter in its tracks', Guardian, 27 August, www.theguardian.com/commentisfree/2015/aug/27/europesbiggest-polluter-protesters-lignite-mine-germany-direct-action [accessed 14 January 2016].

Küblböck, K. (2013) 'The EU Raw Materials Initiative. Scope and critical assessment', Briefing Paper, no. 8, ÖFSE, Vienna.

Küblböck, K. (2015) 'International commodity policy: from raw material imperialism to resource fairness?', in ÖFSE (ed.) Österreichische Entwicklungspolitik 2015: Rohstoffe und Entwicklung, ÖFSE, Vienna. English version available at www.oefse.at/fileadmin/content/Downloads/Publikationed/Oepel/Artikel2015/ International-commodity-policy.pdf.

Lawrence, R. L., Daniels, S. E., and Stankey, G. H. (1997) 'Procedural justice and public involvement in natural resource decision making', Society \& Natural Resources, vol. 10, no. 6, 577-589.

Le Billon, P. (2004) 'The geopolitical economy of "resource wars", Geopolitics, vol. 9 , no. 1, 1-28.

Martínez-Alier, J., Kallis, G., Veuthey, S., Walter, M., and Temper, L. (2010) 'Social metabolism, ecological distribution conflicts, and valuation languages', Ecological Economics, vol. 70, no. 2, 153-158.

McGlade, C. and Ekins, P. (2015) 'The geographical distribution of fossil fuels unused when limiting global warming to 2 [deg] C', Nature, vol. 517, no. 7, 533, 187-190.

Meadows, D. H., Meadows, D. L., and Randers, J. (1972) The Limits to Growth: A Report to the Club of Rome's Project on the Predicament of Mankind, Universe, New York.

Meynen, N. and Temper, L. (2014) 'Behind the veil of the Islamic State is a war for water', www.ejolt.org/2014/09/behind-the-veil-of-the-islamic-state-is-a-war-forwater/ [accessed 14 January 2016].

Mildner, S.-A. and Howald, J. (2013) 'Die Vereinigten Staaten von Amerika', in H. G. Hilpert and S.-A. Mildner (eds) Nationale Alleingänge oder internationale Kooperation? Analyse und Vergleich der Rohstoffstrategien der G20 Staaten, Berlin, 172-181.

Moffat, K. and Zhang, A. (2014) 'The paths to social licence to operate: an integrative model explaining community acceptance of mining', Resource Policy, vol. 39, 61-70.

Monge, C, Alayza, A., and Gudynas, E. (eds) (2011) Transiciones. Post Extractivismo y Alternativas al Extractivismo en el Perú, Centro Peruano de Estudios Sociales, Lima.

Morris, M., Kaplinsky, R., and Kaplan, D. (2012) 'One thing leads to another: promoting industrialisation by making the most of the commodity boom in SubSaharan Africa', www.prism.uct.ac.za/Downloads/MMCP\%20Book.pdf [accessed 16 July 2015].

Okereke, C., Bulkeley, H., and Schroeder, H. (2009) 'Conceptualizing climate 
governance beyond the international regime', Global Environmental Politics, vol. 9, no. 1, 58-78.

Pichler, M. (2013) “"People, planet \& profit”: consumer-oriented hegemony and power relations in palm oil and agrofuel certification', The Journal of Environment \& Development, vol. 22, no. 4, 370-390.

Pogge, T. W. (2001) 'Eradicating systemic poverty: brief for a global resources dividend', Journal of Human Development, vol. 2, no. 1, 59-77.

Rawls, J. [1971] (2003) A Theory of Justice, revised version, Harvard University Press, Cambridge, MA.

Reed, D. (2009) 'What do corporations have to do with fair trade? Positive and normative analysis from a value chain perspective', Journal of Business Ethics, vol. 86 , no. 1, 3-26.

Rosser, A. (2006) 'The political economy of the resource curse: a literature survey', IDS Working Paper, no. 268, Institute of Development Studies, Brighton.

Schlosberg, D. (2004) 'Reconceiving environmental justice: global movements and political theories', Environmental Politics, vol. 13, no. 3, 517-540.

Selfa, T. (2004) 'Mobilizing at the frontier: framing social justice claims in a natural resources management project in Rondônia, Brazil', Society \& Natural Resources, vol. 17, no. 1, 717-734.

Smith, P. D. and McDonough, M. H. (2001) 'Beyond public participation: fairness in natural resource decision making', Society \& Natural Resources, vol. 14, no. 3, 239-249.

Statistisches Bundesamt (2015) 'Energie. Erzeugung', www.destatis.de/DE/ ZahlenFakten/Wirtschaftsbereiche/Energie/Erzeugung/Erzeugung.html [accessed 14 January 2016].

Syme, G. J., Nancarrow, B. E., and McCreddin, J. A. (1999) 'Defining the components of fairness in the allocation of water to environmental and human uses', Journal of Environmental Management, vol. 57, no. 1, 51-70.

Tallontire, A. (2007) 'CSR and regulation: towards a framework for understanding private standards initiatives in the agri-food chain', Third World Quarterly, vol. 28 , no. $4,775-791$.

UNECA and AU (2011) Minerals and Africa's Development: The International Study Group Report on Africa's Mineral Regimes. Addis Ababa.

UNECA and AU (2013) Making the Most of Africa's Commodities: Industrializing for Growth, Jobs and Economic Transformation, UNECA, Addis Ababa.

UNHCR (2015) 'Syria regional refugee response', http://data.unhcr.org/syrian refugees/regional.php [accessed 14 January 2016].

United Nations (1962) 'Permanent Sovereignty over Natural Resources', General assembly resolution 1803 (XVII), http://legal.un.org/avl/ha/ga_1803/ga_1803. html [accessed 14 January 2016].

United Nations (1974) 'Declaration on the Establishment of a New International Economic Order', General assembly resolution 3201 (S-VI), www.un-documents. net/s6r3201.htm [accessed 14 January 2016].

Valdivia, G. (2008) 'Governing relations between people and things: citizenship, territory, and the political economy of petroleum in Ecuador', Political Geography, vol. 27, no. 4, 456-477.

Weinhold, D., Killick, E., and Reis, E. J. (2013) 'Soybeans, poverty and inequality in the Brazilian Amazon', World Development, vol. 52, 132-143. 
Part I

Conceptual approaches to resource fairness and justice 
This page intentionally left blank 


\title{
2 Liberal global justice and social science $^{1}$
}

\author{
Shmuel Nili
}

\section{Introduction}

My aim in this contribution is to ask how both the findings and the limitations of social science should inform the debate on global economic justice among liberal political philosophers. I shall focus on the central place that this debate has allocated to political and economic aspects of natural resource wealth. Furthermore, I shall also try to provide a broader introduction to some key liberal discussions of global justice.

In the process of pursuing this agenda, I will advance three main claims. First, I will show that social science research casts doubt on key premises of important liberal global justice theories. However, second, I will also suggest that empirical questions pivotal to these theories bring to the fore important limitations inherent to social science work on global issues. These limitations will lead me to argue, third, that new normative concerns should feature in liberal discussions about global justice.

I commence my argument with introductory remarks concerning the liberal debate on global justice (section 1). I emphasize the debate's enduring roots in John Rawls' (1999) ideas, particularly concerning (1) the moral arbitrariness of natural endowments, and (2) the significance of the socio-economic structures that form the background of interactions among agents. I move to introduce social science into the discussion, first by asking how it can inform Rawlsian claims, initiated by Charles Beitz (1979), concerning the moral arbitrariness of societies' natural resource endowments (section 2). I then ask a parallel question regarding Thomas Pogge's (2002) extension of the Rawlsian concept of a "basic structure" to global politics (section 3). Both Beitz's and Pogge's arguments turn out to hinge on causal claims that currently lack social-scientific support, but that also seem extremely difficult to evaluate through social-scientific tools. I therefore end by asking (in section 4) what should be our normative position concerning global reforms that hinge on social-scientific confidence that we not only lack at present, but also seem unlikely to attain in the future. 


\section{Global justice in liberal political philosophy}

Questions of economic justice across borders began to appear on the radars of liberal political philosophy only in the 1970s. This development - like many of the other developments that occurred in liberal political philosophy during and since that decade - was heavily indebted to John Rawls' work. In A Theory of Justice, Rawls (1999) seeks a public criterion of social justice that can regulate a liberal democracy's "basic structure" its "major institutions", including "the political constitution and the principal economic and social arrangements" (6). Rawls derives this criterion from the contractual thought-experiment of the "original position", the parties to which represent democratic citizens. These parties know "general facts about human society" (such as "the principles of economic theory [...], the basis of social organization and the laws of human psychology" (Rawls, 1999: 119)). However, a "veil of ignorance" deprives them of any knowledge of the particular individuals they represent and thus ensures that morally irrelevant (in Rawls' language, "morally arbitrary") features do not influence their decision. Rawls argues that, so situated, the parties will opt for two principles of justice over other alternatives (most importantly, utilitarian alternatives). The first principle demands that all citizens will be accorded equal basic rights and liberties. The second principle, alongside fair equality of opportunity in attaining "offices and positions" in society, contains Rawls' famous difference principle - the demand that "social and economic inequalities are to be arranged so that they are to the greatest benefit of the least advantaged" (Rawls, 1999: section 46).

Though explicitly designed for an idealized, "closed" (Rawls, 1999: 67) domestic society, Rawls' theory seemed to have at least two important global parallels. First, some philosophers have argued that global economic interdependence generates a global basic structure that is a subject of justice in much the same way as the domestic basic structure. Rawls held that the major institutions that comprise the domestic basic structure, such as a society's property and legal system, should be the main focus of a theory of justice, given their pervasive impact on individuals" "life prospects, what they can expect to be and how well they can hope to do" (Rawls, 1999: 6-7). Some of Rawls' main interlocutors have held that the same ought to be true, analogously, for global economic institutions. To introduce a key example, Thomas Pogge (2003), a prominent Rawls student and one of the pioneers of the global justice debate, has considered it simply

undeniable that, today and in the foreseeable future, there is a global institutional order that importantly affects the options and incentives societies and their rulers face in their relations with one another and even affects profoundly the domestic institutions and cultures of especially the smaller and weaker societies.

$(1751-1752)$ 
According to the ambitious version of this reasoning, if one endorses Rawls' domestic theory, one ought to replicate it globally and endorse $a$ global difference principle, holding that global inequalities ought to be arranged so that they are to the greatest benefit of the (globally) least advantaged (Pogge, 1994). According to the more minimal version (based on basic human rights), even if the demands of global justice fall short of a global difference principle, substantive duties of justice (rather than mere charity) still apply to the global economic order.

A second important global parallel that Rawls' interlocutors have drawn from his domestic theory concerns the idea of moral arbitrariness. At the domestic level, Rawls held that the "veil of ignorance" should prevent the distortion of justice by morally arbitrary features - that is, unchosen features that are irrelevant to the assessment of agents' moral worth, such as their birth into a certain social class and their natural talents. These features reflect nothing but a "natural lottery", and should therefore not be allowed to determine individuals' income and wealth (Rawls, 1999: 64). Charles Beitz (1979), another key figure in the global justice debate, has applied this idea to the global level, and argued that the different natural resource endowments of different societies, being a paradigmatic example of "the natural lottery", ought not to be allowed to determine societies' income and wealth. Insofar as Rawls (1999) regards "the distribution of natural abilities in some respects as a collective asset" (156), Rawlsians must similarly regard the global distribution of natural resources as a collective asset, and redistribute these resources in accordance with a global difference principle (Beitz, 1979: 137-143).

The enduring significance of Beitz's and Pogge's accounts is interesting from the perspective of social science, since both of these accounts seem initially, at least - amenable to social-scientific research. Accordingly, I now turn to examine how each of these arguments interacts with social science.

\section{Social science and the natural resource lottery}

Let us begin with Beitz's argument from a "natural resource lottery", and its relation to prevalent political norms regarding natural resource ownership. Sovereign peoples currently claim exclusive original rights to the value of natural resources found within their territories, and particularly to resources traded as commodities in global markets, from oil through coal to diamonds. According to this claim, all revenue from the oil within Canada's territory, for example, originally belongs to the Canadian people. The same claim could be made for every nation in the world: the people can legitimately transfer their rights over natural resources to internal or external actors, but only they are originally entitled to the value - to all of the value - of these resources.

One way to understand Beitz's view is to see it as challenging this prevalent idea of national ownership in the name of cosmopolitan ownership, 
according to which the earth's natural resources are, in some sense that has practical significance at present, the common property of humankind: "The fact that someone happens to be located advantageously with respect to natural resources does not provide a reason why he or she should be entitled to exclude others from the benefits that might be derived from them" (Beitz, 1979: 138). ${ }^{2}$ Such exclusion is morally problematic because

some areas are rich in resources, and societies established in such areas can be expected to exploit their natural riches and prosper. Other societies do not fare so well, and despite the best efforts of their members, they may attain only a meager level of well-being because of resourcescarcities.

(Beitz, 1979: 137)

This thought, in turn, gives rise to a "resource redistribution principle" redistributing natural resource wealth across nations in order to correct the accidental fact that "natural resources are distributed unevenly across the earth's surface" (Beitz, 1979: 137). Something like a resource redistribution principle will only achieve something significant, however, if Beitz's empirical claim is correct - that inequality in natural resource endowments is a significant contributor to global economic inequality. In turn, from the perspective of liberal normative individualism - that is, a perspective that sees only individuals as the ultimate units of moral concern - global economic inequality is a moral problem only insofar as it bears on individual prospects. This means that for Beitz's argument to work, it must be shown that inequalities in societies' natural resource endowments are a significant contributor to inequalities in the life-prospects of their individual members.

Yet, the problem is that it is in fact extremely hard to show that natural resource endowments make such a contribution. Individuals' life-prospects in today's world are, to be sure, dramatically influenced by their country of birth. But there is no evidence suggesting that individuals' prospects are positively correlated with the level of their country's natural resource endowments. In fact, the social science debate regarding societies' natural resource endowments focuses on the exact opposite claim - namely, that a negative relationship exists between resource abundance and individual prospects. As Leif Wenar (2008) notes, economists have repeatedly found that "many countries rich with natural resources are full of very poor people" (3). Poverty significantly correlates with natural resource wealth. Yet, there is practically no discussion of societal resource abundance as causing individual wealth or societal resource scarcity as causing individual poverty.

Those who believe that natural resource abundance tends to cause poor economic performance - a 'resource curse' - often emphasize two dynamics. The first dynamic, which has become known as the 'Dutch 
Disease', concerns the effects of natural resource exports on other sectors of a country's economy. Especially in already-poor countries that rely on foreign expertise, capital, and labour to extract resources, natural resource extraction does little to advance domestic skills, capital or labour, meaning that growth of natural resource exports only rarely has positive ripple effects advancing the growth of other parts of the country's economy. However, a growing resource sector does have negative effects on other sectors in a way that threatens the economy's performance. Thus, for example, natural resource revenue inflates the country's exchange rate, since it comes in the form of foreign currency. As a result, agricultural and industrial imports become more attractive, while the country's agricultural and industrial exports become less competitive. In such ways, a dominant natural resource sector can shrink other sectors of the economy, making it less diversified, and more dependent on (often volatile) global demand for a specific natural resource (Ross, 2012: 48-49). The second dynamic emphasized by proponents of the resource curse concerns the fact that poverty in resource-rich countries is typically connected to specific patterns of authoritarian rule and economic mismanagement. Here the thought is that the political and economic destitution of many societies can be traced partly to an abundance of natural resources that frees autocrats from the need to tax their population, and thus from the need to elicit its cooperation or develop the foundations of a viable economy. Instead, not shackled by democratic elections and rule of law (Maravall and Przeworski, 2003), resource-rich autocrats can systematically embezzle state revenue, buy off or forcibly silence potential or actual opposition, and neglect - often intentionally - the modernization and diversification of the country's economy (Ross, 2001).

The resource curse thesis has critics. However, these critics do not emphasize the idea that a positive link necessarily exists between a society's resources and its members' fortunes. Rather, their focus is quite different. A key ingredient of the resource curse connection between political and economic outcomes is (arguably) the idea that at least in the long run, authoritarianism hinders economic performance in comparison to democracy. If natural resource wealth harms economic growth, it will frequently do so indirectly, by promoting authoritarianism (Gerring et al., 2005: 336). It is only the last clause - the claim that natural resources necessarily promote authoritarianism - that the critics contest. But none of the critics focuses on arguing that natural resource abundance necessarily makes a contribution (let alone a significant one) to individuals' economic prospects. Rather, the main argument is that there is no significant link between resource endowments and individuals' prospects: social and political institutions are considered far more crucial.

At this point, a critic might raise the following objection. Even if it is the case that social and political institutions are much more significant determinants of economic prospects, it might still be true that, given 'good' social 


\section{S. Nili}

and political institutions, a significant increase in natural resources endowments translates into a significant improvement in individuals' economic circumstances (Beitz, 2005). There are several reasons why this objection misses the mark, but we can begin with just one. The objection is misleading in asking how would resource abundance influence individual prospects given 'good' institutions, since abundant natural resources will frequently produce self-reinforcing pressures against having such institutions from the outset - or at least, such pressures arise, as many scholars emphasize, if the institutions that exist prior to the discovery of natural resources are inimical to "accountability and state competence" (Robinson et al., 2006: 450; see also Boschini et al., 2007; Haber and Menaldo, 2011). Since in such circumstances natural resource abundance can cause vicious cycles, perpetuating 'bad' institutions, there are many countries with regard to which it seems irrelevant to simply assume 'good' institutions (Ross, 2012: 1). Moreover, once we focus exclusively on those countries that have favourable institutions preceding the discovery of natural resources, this only puts further emphasis on how institutions, rather than the morally arbitrary endowments of natural resources, are the source of natural resource wealth. If social and political institutions are far more crucial determinants of a nation's fortunes than its natural endowments, and if the former in fact shape whether the latter are a blessing or a 'curse', then the very idea that natural resource wealth is morally arbitrary receives a serious blow.

Finally, the more one emphasizes the decisive economic role of social and political institutions, the more one is likely to be sceptical of the claim that, setting institutions to one side, significant differences in countries' natural resource endowments translate into significant differences in their members' economic prospects. Not only is there no empirical backing for this claim, more fundamentally, it is not clear that such empirical backing could ever be provided. This is because it is extremely hard to show that abundant natural resources independently yield significant increases in citizens' economic prospects that the 'proper' institutions would not have obtained even without abundant natural resources. We may be able to see well-governed resource-abundant countries putting their natural endowments to good use in increasing the affluence of their citizens. But we cannot see - nor can we disprove the possibility - that these countries would have been able to similarly increase affluence through development of human capital, were they more resource-scarce. And this is a possibility that anyone who grants a decisive impact of social and political institutions on economic performance ought to take seriously. Suppose that a country with stable, accountable, and transparent institutions discovers valuable minerals at time $T$. Two generations later $(T+50)$, the ordinary citizens of the country are tangibly better off. How can we know whether they would not have been just as (or nearly as) better off at $T+50$ even if no natural resources were discovered at T? How can we disprove the possibility that the country's institutions would have led to the development 
of human capital that would have compensated for the lack of natural capital (see also Haber and Menaldo, 2011)?

In order to assess whether ordinary citizens of a resource-rich country with 'good' institutions would have indeed achieved a similar level of affluence even without abundant natural resources, social scientists would need to be able to assess what potential sources of revenue that are 'crowded out' by natural resource rent would come to the fore in its absence. Yet, it is far from clear that social scientists can construct reliable models here. Consider, for example, the case of Norway. The rise in the living standards of the ordinary Norwegian has centrally involved oil revenue, ever since Norway discovered oil in the late 1960s. If this rise was only possible due to the backdrop of institutions of the right kind, it does not seem implausible to think that these institutions would have generated a tangible rise in affluence even if there was no such resource-abundance - a rise based, as in the Japanese case for example, on the development of human capital. But it is not clear what social scientists can do to provide reliable answers regarding the fate of such a hypothetical Norway.

This point alerts us to two social-scientific problems that are particularly acute in the context of the global economy - the sheer number of potential causal levers involved, and the fact that we are not truly able to compare our world as a whole to any other world. Both of these problems, I will argue below, have significant implications for global political philosophy. In order to properly set up these problems, however, we need to go through an additional stage of our discussion. Having discussed what social science can say about Beitz's notion of a natural resource lottery, I now turn to ask what social science can say about Pogge's notion of a global basic structure.

\section{Social science and the global basic structure}

Since the beginning of the millennium, Pogge has been using the idea of a global basic structure to make the claim that global economic institutions ought to prevent the global poor from dropping below the threshold set by the Universal Declaration of Human Rights (UDHR). What makes this claim both dramatic and interesting from a social science perspective, however, is the nature of Pogge's concomitant moral accusation. Since the 1970s, scholars have conceived democracies' global duties primarily as positive duties to help the global poor (e.g. Singer, 1972; Patten, 2005). Yet Pogge argues that much before helping, citizens of affluent countries and particularly citizens of affluent democracies through our elected governments - are harming the world's deprived. Through global economic institutions, we not merely fail to help but actively contribute to 50,000 daily deaths from poverty related-causes (Pogge, 2007: 30).

This provocative claim has left few global justice theorists indifferent. Some supporters of Pogge's views, and even certain critics, have characterized 


\section{S. Nili}

his arguments as "groundbreaking" (Risse, 2005: 9). Others, however, insist that it is implausible to attribute to citizens of affluent countries such "barbaric" crimes (Cohen 2010: 28). Empirical issues are at the heart of the heated 'Pogge debate', and these issues will occupy us in a moment. Before we turn to them, however, we need to note two things. The first concerns the moral significance of the distinction between negative duties not to harm and positive duties to help. One reason why Pogge wishes to recast the problem of poverty as a matter of negative duties not to harm is that doing so prevents conflict between the demand to ameliorate poverty and "the grain of the Anglo-American moral and legal tradition, in which it is often denied that persons have duties to protect and aid other persons in distress" (Pogge, 1989: 34). Another reason, specifically with regard to global poverty, is that the negative duties strategy bypasses the dilution through distance that afflicts positive duties - that is, the idea that our positive duties to help become weaker the more we move "outward", away from our near and dear and to "distant" others (Pogge, 2010: 20-21).

Second, in order to see why these advantages of negative over positive duties depend on empirical considerations, we also need to note Pogge's actual argument connecting negative duties to poverty and global institutions. Pogge begins this argument by claiming that persons have negative duties to enact and comply with just institutions, since the full content of individual rights and duties cannot be known solely through rules of personal conduct, apart from institutions. Even if I wish merely to satisfy my negative duties not to violate your rights, I cannot do so outside of an institutional framework specifying what your full rights are and what is therefore actually required by my negative duties to respect them (Pogge, 2002: 137). This, in turn, means that my duty to enact and support just institutions can itself be understood as a negative one. Since we clearly "need shared institutions to avoid invading one another's freedom", we "have a negative duty to comply with such existing institutions, whenever noncompliance can succeed only if like non-compliance by others is constrained" (Pogge, 2002: 137). Once individuals have a negative rather than positive duty towards institutions, they also become right-bearers - and therefore also bearers of negative duties to respect rights - by virtue of cooperating with others under a shared coercive institutional order (Pogge, 2002: 64). Pogge believes this institutional understanding of rights and correlative duties must be replicated at the global level, among other things since he considers it evident, as noted above, that a coercive institutional global order exists. Specifically, Pogge sees global organizations, from the World Trade Organization (WTO) through the World Bank and the International Monetary Fund (IMF) to the Group of $8(\mathrm{G} 8)$, as the main foundations of this institutional order, skewing it in favour of the global rich against the global poor, in ways ranging from the rules allocating control over natural resources, through regulations of intellectual property rights, to "quotas, tariffs, anti-dumping duties, export credits, and huge 
subsidies to domestic producers [...] that poor countries are not permitted, or cannot afford, to match" (Pogge, 2007: 44). According to Pogge, global institutions limit the poor's access to UDHR provisions, thus sharing much of the blame for the poverty-related death toll that "matches, every three years, the entire death toll of World War II, concentration camps and gulags included" (Pogge, 2007: 30). Pogge insists that "minor modifications in the global order that would entail at most slight reductions in the incomes of the affluent" (Pogge, 2007: 30, my italics) will suffice to generate very different outcomes for the global poor, and secure their access to UDHR provisions. Our failure to engage in such reform violates our negative institutional duties of justice.

This background should make clear how Pogge wishes to connect global institutions, global poverty, and negative duties. This thesis, however, faces two key social-scientific problems, paralleling the issues that were apparent in our discussion of the natural resource lottery. The first problem is that there is a gap in social-scientific knowledge. Social scientists simply do not know enough about the impact that global rules have or might have on extreme poverty. Pogge himself, it is important to note, is keenly aware of this gap, emphasizing that evidence on the causal role of global institutions with regard to global inequality is "sorely lacking today" (2010: 181). Indeed, he explicitly sees his arguments as potential motivators for social scientists who might address the gap: "One practical aim of my work" as he put it recently, "is to stimulate more serious social-science research into the impact of global institutional design decisions upon the massive persistence of severe poverty" (Pogge, 2010: 181). However, just as in the case of the natural resource lottery, the second problem is that it is not clear that social scientists can fill the empirical gaps of the normative argument.

Pogge's argument hinges on the question of how extreme poverty would have evolved, had different global institutions been in place. Yet it is far from clear that social science can assess this huge counterfactual (Risse, 2005). Arguably, the most important difficulty here is what we might call the one world problem. We only have one set of global institutions in place at any given time. This means that we cannot compare existing global institutions to another set of global institutions while holding everything else constant. Pogge is again aware of the issue: "There being only this one world to observe, it is hard to obtain solid evidence about how the overall incidence of poverty would have evolved differently if this or that global factor had been different" (Pogge, 2002: 17). But how to solve the issue remains unclear, and in the lack of a solution, we remain unable to make confident judgments concerning the causal relationship between global institutions and poverty trends.

We can see this problem at play when we examine specific central issues, such as the relationship between global and domestic institutions. Arguably, in order for Pogge's argument to work, it must be the case that reforms in global institutions will significantly increase the likelihood of 
reforms in poor countries' domestic institutions. But it is far from obvious that this is indeed the case. In an essay titled 'Philosophy, Social Science, Global Poverty', Joshua Cohen (2010), for example, insists that there is "no reason to accept the claim" that

changes in global rules would suffice to lift most of the terrible poverty that so many people suffer from. In particular, I see no case for the claim that such changes will suffice holding domestic institutions fixed, and no reason to think that they will suffice by changing incentives and opportunities in ways that induce poverty-alleviating changes in domestic institutions.

My point here, however, is not to endorse Cohen's criticism as such. Rather, I merely wish to point out that it is extremely difficult for social science to construct reliable models that will support either Cohen's pessimism or Pogge's optimism regarding the causal force of global institutions. The enormous number of potentially confounding factors involved in the global economy poses structural difficulties towards creating such models.

More specifically, the combination between the one world problem and the ever-growing complexity of the global economy yields at least three obstacles to social-scientific analysis, all of which are evident when we ask how global institutions impact domestic ones. First, even if we could be confident that certain global institutions have a negative impact on the domestic institutions of poor countries, it is very hard to assess their relative weight in comparison to many other likely causes. Thus, for example, many global dynamics that are in principle independent of global institutions, and are not always completely amenable to institutional interventions (such as dramatic fluctuations in the supply and demand for certain valuable commodities), can themselves be a significant cause of institutional crises in poor countries. Yet it is hard to assess their relative weight in comparison to global institutional factors.

Second, and very much related, global institutional reforms necessarily interact with an extraordinary number of causal levers, which in turn interact amongst themselves in unknown and potentially undesirable ways. This makes the effects of global institutional changes extremely difficult to predict.

Finally, all of these problems are compounded by the fact that not only existing global institutions might be novel: certain proposals for global reforms might be even more novel - indeed, unprecedented. One of Pogge's reform proposals, for instance, involves ending the ability of odious regimes to borrow funds and sell natural resources in their peoples' name (Pogge, 2005). This proposal (which will also occupy us below) in effect requires an extraordinary number of countries - all of the world's 
democracies - to sanction a very large number of regimes. Predicting what would be the result of such reform is extremely difficult not only because of the number of factors that might be involved, but also because such a global policy has never been carried out before: We have even less comparative evidence to work with in such a case than we do in other global contexts. The combination of one world, multiple factors, and unprecedented change is especially difficult for social scientists to assess.

\section{What ought to be done? Reform under uncertainty}

All of this brings us to a practical question, which applies both to Beitz's proposal of global resource redistribution and to Pogge's charge of global harm: What ought global justice theorists to do when they not only lack social-scientific evidence that seems necessary to motivate certain reforms, but also face serious obstacles in attaining such evidence?

One answer that may initially seem appealing is that global justice theorists should retain the reform proposals that suffer from social-scientific uncertainty. The thought here would be that it is worthwhile to pursue some reforms even given deep uncertainty, whether because of the mere chance that they would achieve important gains for the world's poor and oppressed or because of the hope that these reforms would be worthwhile even if their benefits were limited. Thus, for instance, even if a global redistribution of natural resource wealth, or reform of the WTO, will not achieve much by way of combating global poverty, it would still achieve something.

I do not wish to deny that this strategy will make sense in some cases. But we should be cognizant of its important limitations. One limitation concerns, again, the distinctive structural circumstances of global politics, and specifically the structural problem of global collective action. In the enduring lack of a global sovereign, no state can have assurance that other states will join it in undertaking reforms meant to improve the condition of the world's poor and oppressed. This structural fact makes the deep uncertainty regarding the impact of many global reforms particularly burdensome, since it allows each state to excuse itself from initiating collective action. This is true even where there is reasonable certainty that joint efforts by multiple states will actually achieve important moral aims. Even under such happy circumstances, each state may try to exempt itself from initiating collective action - from leading by example - by claiming that, lacking credible commitment from other states, its solitary sacrifice would be ineffective. But when there is deep social-scientific uncertainty as to whether important moral aims will be realized even in the best-case scenario of full cooperation by a critical mass of states, it is especially easy for each state to provide moral excuses for its refusal to take action (Nili, 2014).

Moreover, alongside the issue of global collective action, there is also the matter of opportunity costs. Because there are always opportunity costs 
to prioritizing any given reform proposal over others, the mere hope that some reform might have limited benefits for the world's poor and oppressed is often not a sufficiently compelling empirical foundation on which to base a normative call for political action. In such a case, the normative political theorist (at least one who is practically inclined) is better off shifting focus elsewhere, to discuss moral principles related to different potential reforms that have a greater chance of making a tangible real world impact. Furthermore, a strategy that settles on the hope for limited global gains ignores not only practical but, for lack of a better term, ideational opportunity costs. There are ideational opportunity costs involved in pushing for reforms that rely on certain moral principles if other potential reforms that rely on conflicting principles can be more effective.

To make these claims (especially the latter) concrete, consider the conflicting moral principles underlying, on the one hand, Beitz's proposal for a global redistribution of natural resource wealth, and on the other hand, the various proposals made in recent years to end the essentially neocolonial practice under which dictators enjoy customary rights to sell their state's natural resources to any willing buyer (Pogge, 2002: Chapter 6; Nili, 2011a, 2011b; Wenar, 2011). There are clearly conflicting normative principles at play here: The reform of dictators' "resource privilege" (Pogge, 2001) emphasizes the idea of national ownership over natural resources, an idea that the Beitzian argument wishes to undermine. The key thought underlying recent philosophical discussions of dictators' trading privileges is that a state's resources belong to its people rather than to rulers, and that dictators (and corporations) who are transacting in state resources without obtaining proper consent from their people are therefore violating national property rights. Rather than contrasting the claim of national ownership with the claims of humanity as a whole, reform of dictators' trading privileges focuses on the contrast between the claims of sovereign peoples and the claims of those who wield effective political power. Insofar as the grounding rationales for these two proposals are in tension with one another, pursuing a global redistribution of natural resource wealth has a clear philosophical opportunity cost in undermining the normative case for national resource reform.

In light of these difficulties, I would like to propose, in lieu of a conclusion, an alternative normative strategy for dealing with the structural uncertainty of global social science. This strategy sees the problems of global social science as an important reason to examine normative arguments for global reform that are far more independent of empirical and predictive uncertainty. These arguments, in turn, focus on self-referring moral reasons that liberal polities have against entanglement in certain foreign practices.

Two examples should suffice to give a sense of what such self-referring reasons can look like. First, consider the divestment of almost all liberal 
democracies from Apartheid, culminating in the late 1980s. Divestment could have been justified through consequentialist reasoning, as a way to precipitate the collapse of the regime. But it is difficult to prove that Apartheid would not have collapsed at about the same time as it actually did, even if the regime were less isolated (as was desired, for example, by the Reagan administration preaching "constructive engagement") (Waldmeir, 1997). This difficulty provides a further reason to examine an alternative, self-referring moral perspective on disengagement from Apartheid. One might argue that liberal democracies had moral reasons pertaining to their own integrity to divest from a blatantly racist regime, independently of the social-scientific question as to whether divestment would be effective in precipitating Apartheid's demise.

A second example has to do, once more, with dictators' resource privilege. One way to see an end to dictators' ability to sell their peoples' natural resources is simply as a means to destabilize dictators' grip on power. But this perspective once again brings us to extremely complex social-scientific questions, such as whether even a wide-scale boycott of dictators' resource exports can indeed be effective in weakening them, instead of simply producing 'rallying behind the flag', and imposing costs primarily on the population, as the sanctions literature often warns. A selfreferring perspective, however, would emphasize the thought that democracies have a principled reason to end their own complicity in dictators' theft of their peoples' resources, independently of the social-scientific uncertainty over whether doing so will also destabilize the regime. One could argue that even if political and economic circumstances in most dictatorships will remain the same as a result of liberal democracies prohibiting natural resource transactions, such a prohibition would still be morally required, just as ending colonialism would have been morally required even if one could not prove that doing so would make the victims of colonialism better off (Ypi, 2013). To prevent misunderstanding, I should emphasize that taking seriously such principled reasons for global reform does not mean adopting an indifference towards the consequences of reform. Rather, the claim is that such reasons warrant independent attention: that the moral reasons for global reform are not exhausted by consequentialist considerations.

There are likely to be normative theorists who will find even this moderate approach to be overly self-absorbed and too removed from the practical needs of the world's poor and oppressed. But this likelihood only makes it all the more necessary to debate the normative questions that selfreferring moral arguments trigger. It is important, in particular, to discuss the way in which a society's global conduct may or may not derive from 'moral duties to itself', from its own integrity, or 'clean hands'.

Global justice theorists have yet to undertake such a discussion. Recognition of the deep limitations of global reforms dependent on (structurally limited) social science should provide an important reason to pursue it. 
It is worthwhile, in turn, to note both some of the practical pay-offs that will arise if the discussion will vindicate self-referring reforms, and the new kinds of normative questions that will have to take centre-stage in this discussion.

One important practical pay-off of self-referring global reforms is their dissolving of the aforementioned collective action problems endemic to international politics. Hinging reform of dictators' trading privileges, for instance, on the ability to destabilize them, also means making such reform dependent on successful collective action by multiple boycotting countries. If the goal is to destabilize the dictatorships basing their rule on natural resource revenue, each state can exempt itself from any duty to take solitary action by claiming ineffective sacrifice - pointing out that the moral gains from such action will be miniscule unless others join, but the cost (in terms of lost access to valuable resources) will be significant. Furthermore, were that state to act alone, it will only incur absolute and relative costs in relation to its competitors (Pogge, 2002: Chapter 5). Yet, when reform of dictators' trading privileges is justified through a prohibition on complicity in theft, such collective action excuses disappear. To take the analogy, one's duty not to steal from the person next door, for example, holds independently of the possibility that other neighbours will be stealing from that person (even if these neighbours are also competitors) as well as of the possibility that one's clean hands will not alter the neighbourhood's overall condition.

These advantages may still not convince those philosophers who have very strong intuitions against self-referring moral concerns. However, with normative political philosophy as with empirical social science, mere intuition is not enough. An actual in-depth discussion is necessary, and such discussion will have to cover multiple sets of questions.

One set of questions has to do with whether and why there is a difference in the moral force of self-referring moral reasons in different contexts. For instance, if, as I suspect is the case, many philosophers would be willing to concede that liberal democracies had a duty to divest from Apartheid for the sake of their own moral integrity, but far fewer philosophers will say the same about a duty to disengage from kleptocrats, what argument can justify this difference?

Another set of questions has to do with the relationship between personal and political morality. Philosophers who resist 'clean hands' global reforms will be hard-pressed to deny that when the agent in question is an individual person, the duty not to steal a victim's property, for example, is independent of what other agents do. What, then, (if anything) is different when the property belongs to a people and is effectively stolen by a corporation colluding with a dictator in a process legalized by a state? If my claims here have been cogent, then such questions should receive far more attention from global political philosophers. 


\section{Notes}

1 This essay is a revised and abbreviated version of an article from the Review of International Studies, vol. 42, no. 1 (2016). Thanks to Thad Dunning, Shan Ge, Lisa Herzog, Thomas Pogge, Michael Ross, and Ian Shapiro for comments and discussions. Thanks also to three anonymous RIS reviewers for helpful and generous feedback. Finally, I am particularly grateful to Elisabeth Wood and to participants at her comparative politics seminar at Yale for excellent critiques especially Consuelo Amat Matus, Alyssa Battistoni, Natasha Chichilnisky-Heal, Elizabeth Krontiris, and Paul Linden-Retek.

2 I am assuming here that Beitz has in mind, primarily if not solely, extractable natural resources.

3 Among other things, Cohen and Pogge provide radically conflicting estimates as to how much the elimination of protectionist trade barriers will (by itself, independently of other structural changes) benefit the global poor (Cohen, 2010: 27; Pogge, 2010: 182-184).

\section{References}

Beitz, C. (1979) Political Theory and International Relations, Princeton University Press, Princeton, NJ.

Beitz, C. (2005) 'Cosmopolitanism and global justice', Journal of Ethics, vol. 9, 11-27.

Boschini, A., Pettersson, J., and Roine, J. (2007) 'Resource curse or not: a question of appropriability', Scandinavian Journal of Economics, vol. 109, no. 3, 593-617.

Cohen, J. (2010) 'Philosophy, social science, global poverty', in A. Jaggar (ed.) Thomas Pogge and His Critics, Polity, London, 18-45.

Gerring, J., Bond, P., Barndt, W. T., and Moreno, C. (2005) 'Democracy and economic growth: a historical perspective', World Politics, vol. 57, no. 3, 323-364.

Haber, S. and Menaldo, V. (2011) 'Do natural resources fuel authoritarianism? A reappraisal of the resource curse', American Political Science Review, vol. 105, no. 1, 1-26.

Maravall, J. M. and Przeworski, A. (eds) (2003) Democracy and the Rule of Law, Cambridge University Press, Cambridge, UK.

Nili, S. (2011a) "Democratic disengagement": towards Rousseauian global reform', International Theory, vol. 3, no. 3, 355-389.

Nili, S. (2011b) 'Our problem of global justice', Social Theory and Practice, vol. 37, no. 4, 629-653.

Nili, S. (2014) 'Global taxation, global reform, and collective action', Moral Philosophy and Politics, vol. 1, no. 1, 83-103.

Patten, A. (2005) 'Should we stop thinking about poverty in terms of helping the poor?', Ethics \& International Affairs, vol. 19, no. 1, 19-27.

Pogge, T. (1989) Realizing Rawls, Cornell University Press, Ithaca, NY.

Pogge, T. (1994) 'An egalitarian law of peoples', Philosophy and Public Affairs, vol. 23, no. 3, 195-224.

Pogge, T. (2001) 'Achieving democracy', Ethics and International Affairs, vol. 15, no. $1,3-23$.

Pogge, T. (2002) World Poverty and Human Rights, Polity Press, Cambridge, UK. 


\section{S. Nili}

Pogge, T. (2003) 'The incoherence between Rawls's theories of justice', Fordham Law Review, vol. 72, 1739-1759.

Pogge, T. (2005) 'Recognized and violated by international law: the human rights of the global poor', Leiden Journal of International Law, vol. 18, no. 4, $717-745$.

Pogge, T. (2007) 'Severe poverty as human rights violation', in T. Pogge (ed.) Freedom from Poverty as a Human Right. Who Owes What to the Very Poor? Oxford University Press, Oxford, 11-53.

Pogge, T. (2010) 'Reply to critics', in A. Jaggar (ed.) Thomas Pogge and His Critics, Polity, London, 175-250.

Rawls, J. (1999) A Theory of Justice, Harvard University Press, Cambridge, MA.

Risse, M. (2005) 'Do we owe the poor assistance or rectification?', Ethics and International Affairs, vol. 19, no. 1, 9-18.

Robinson, J., Torvik, R., and Verdier, T. (2006) 'Political foundations of the resource curse', Journal of Development Economics, vol. 79, no. 2, 447-468.

Ross, M. (2001) 'Does oil hinder democracy?', World Politics, vol. 53, no. 3, $325-361$.

Ross, M. (2012) The Oil Curse, Princeton University Press, Princeton, NJ.

Singer, P. (1972) 'Famine, affluence, and morality', Philosophy and Public Affairs, vol. 1, no. 3, 229-243.

Waldmeir, P. (1997) Anatomy of a Miracle: The End of Apartheid, W. W. Norton, New York.

Wenar, L. (2008) 'Property rights and the resource curse', Philosophy \& Public Affairs, vol. 36, no. 1, 2-32.

Wenar, L. (2011) 'Clean trade in natural resources', Ethics \& International Affairs, vol. 25, no. 1, 27-39.

Ypi, L. (2013) 'What's wrong with colonialism', Philosophy and Public Affairs, vol. 41, no. 2, 158-191. 


\title{
3 What's democracy got to do with it?
}

\author{
A political ecology perspective on \\ socio-ecological justice ${ }^{1}$
}

\author{
Melanie Pichler
}

\section{Introduction}

Current notions of fairness and justice in resource politics are mainly influenced by liberal political philosophy. Such ideas adopt a Rawlsian understanding of distributive justice so as to develop a liberal cosmopolitan framework (Wapner, 1997; Beitz, 1999; Pogge, 2001, 2008; Held, 2002; Hayward, 2006; Nili, in this volume). This liberal approach conceptualizes resource production, distribution, and consumption as a global challenge and calls for the redistribution of natural resources based on an abstract moral justice 'compass' (Nili, in this volume). While such a framework supports the redistribution of natural resources from a global egalitarian perspective, it lacks an adequate conceptualization of the specific politicaleconomic and socio-cultural relations that characterize the current patterns of access, control, and distribution of natural resources. In other words, a liberal framework fails to link global justice principles with power relations, inequalities, and concrete socio-ecological conflicts.

Based on a political ecology perspective, this chapter develops a multidimensional conception of resource justice - that is, socio-ecological justice - that explicitly incorporates power relations and inequalities in the access to and distribution of nature and natural resources on different scales. Accordingly, such a conception explicitly stresses political dimensions of socio-ecological justice and links them to claims for a democratization of societal nature relations (gesellschaftliche Naturverhältnisse). In doing so, the chapter reverses the line of argument from abstract moral justice principles to socio-ecological conflicts as a starting point for resource justice.

As a heterogeneous and interdisciplinary research field, political ecology analyses the appropriation and control of natural resources (e.g. land, water) and links them to social configurations and power relations. Socioecological conflicts, then, evolve from unequal power relations and injustices that constitute the access to and control over resources (Bryant and Bailey, 1997: 38-39). So far, political ecology has rather implicitly than explicitly referred to principles and dimensions of justice and democracy (Bryant and Jarosz, 2004; for activist debates on environmental justice, see 
Schlosberg, 2004). I argue that a conceptualization of socio-ecological justice benefits from a link to democracy theories that - like political ecology research - emanate from conflict and contestation, therefore explicitly highlighting political dimensions of socio-ecological justice that exceed mere distributional aspects. In line with radical democracy theories (e.g. Chantal Mouffe, Jacques Rancière), I understand democracy not necessarily as a form of government with a specific set of criteria and indicators (e.g. elections, rule of law, and division of powers) but as an emancipatory process that builds on the historical genesis of social struggles. With regard to the control of natural resources, socio-ecological conflicts emphasize the challenge of existing societal nature relations based on enclosure, valorization, and a shrinking of the public sphere. Emanating from such a conflict-oriented, yet limited, perspective with regard to the specific qualitative relation between justice and democracy, I further elaborate on political dimensions for rearranging societal nature relations. These dimensions evolve both from social movements and activism as well as political theory.

The chapter proceeds as follows: The next section critically examines the assumptions of liberal global justice, and is followed by a section introducing political ecology. The understanding gained from these discussions helps to develop an understanding of socio-ecological conflicts that serves as a point of reference for the subsequent elaboration in the third section on democratizing societal nature relations. The fourth section, then, links socio-ecological conflicts to a conflictual understanding of democracy, which paves the way for an elaboration on some explicit political dimensions of socio-ecological justice in the final section.

\section{Challenging moral assumptions of liberal global justice}

The cosmopolitan liberal framework to global justice emanates from a Rawlsian theory of justice (Nili, in this volume). From a moral contractarian perspective, Rawls' theory is based on two principles. The equal rights principle demands "equal basic liberties" for all citizens (Rawls, [1971] 2003: 53) and the difference principle postulates that "social and economic equalities are to be arranged so that they are to the greatest benefit of the least advantaged" (Rawls, [1971] 2003: 266). Based on these basic and abstract principles, a number of liberal philosophers have applied this moral theory of justice to both the global sphere and the distribution of natural resources and environmental risks.

Charles Beitz ([1979] 1999) points to the uneven and morally arbitrary distribution of natural resources over the earth's surface that resembles a natural resource lottery. Accordingly, he calls for the global redistribution of these resources "that would give each society a fair chance to develop just political institutions and an economy capable of satisfying its members basic needs" (141). Based on these moral concerns for justice, the approach 
argues for an increase in foreign aid as a means for redistributive justice (Beitz, [1979] 1999: 172).

Emanating from similar assumptions, Thomas Pogge $(2001,2008)$ condemns affluent countries as mainly responsible for world poverty and the unequal distribution of natural resources. International organizations like the World Trade Organization (WTO), the International Monetary Fund (IMF), or the G7 reproduce the unequal distribution of natural resources and impose inequality on less-affluent countries (Pogge, 2001: 61). Accordingly, global institutional reform based on moral grounds is seen as a pressing means for global justice. As minor changes in the structure of the world order with modest economic losses for wealthier countries would already have substantial effects on poverty reduction and global justice, Pogge suggests a Global Resource Dividend (GRD), so that "those who make more extensive use of our planet's resources should compensate those who, involuntarily, use very little" (Pogge, 2001: 66).

Drawing on ecological economics, Tim Hayward (2006) uses the concept of ecological space to account not only for the unequal distribution of natural resources but for "all human interactions with the natural world - our use of resources and our environmental impacts" (359). Following global footprint calculations, he demands "globally equal per capita right to ecological space" (Hayward, 2006: 368) to be recognized, and calls - similarly to Pogge - for a global fund to redistribute the economic benefits derived from excessive natural resource use.

These conceptions of global justice share the following assumptions: First, a liberal global justice perspective suggests an ahistorical and universal 'compass' for global justice without addressing the genesis of resource injustices. Such injustices are linked to geopolitical constellations, colonial legacies, and globally uneven capitalist expansion, all of which call for a historicized perspective on justice principles. Second, liberal global justice focuses mainly on abstract distributional aspects of justice at the expense of other, more political dimensions. Accordingly, the concrete conflicts and struggles, power asymmetries and relations of inequality as well as the competing notions of justice disappear from the research scope. Third, cosmopolitan liberalism traces the reason for an unequal and unjust distribution of nature and natural resources back to unfair institutions, and lacks a more complex understanding of the socio-economic and political relations that constitute unequal resource appropriation and control. Furthermore, it does not provide a social scientific conceptualization of the role of (state) institutions for the control of natural resources. Fourth, the proposals for institutional reform and political strategy prioritize global, cosmopolitan institutions at the expense of more local or regional ones. At the same time, they neglect the interplay of different scales that may be explanatory for the obstacles and blockades of global institutional reform. Fifth, liberal global justice principles are based on individuals rather than on states, communities, or social groups. Accordingly, these analyses and 
suggestions disregard collective and therefore more political justice claims (e.g. of indigenous peoples, affected communities, workers, peasants) that exceed individual entitlements.

To summarize, cosmopolitan liberalism fails to relate global justice to unequal power relations and the political-economic patterns of current resource politics. In other words, while "theories of distributive justice offer models and procedures by which distribution may be improved, none of them thoroughly examine the social, cultural, symbolic, and institutional conditions underlying poor distributions in the first place" (Schlosberg, 2004: 518). Taking these conditions into account, I propose a conceptual understanding of justice that, instead of emanating from abstract and universal philosophical principles of justice, is founded upon concrete socio-ecological conflicts. A political ecology approach such as this highlights the political rather than the moral dimension of current socio-ecological conflicts and traces it to patterns of access to and control over nature and natural resources.

The following section briefly introduces the research field of political ecology and develops an understanding of socio-ecological conflicts that serves as a point of reference for the subsequent discussion on political and democratic dimensions of socio-ecological justice.

\section{Political ecology, power relations, and socio-ecological conflicts}

The basic tenets of political ecology highlight the socio-economic and political reasons for unequal resource distribution and the ecological crisis, and link them to unequal power relations that foster socio-ecological conflicts. Rather than focusing solely on apolitical and moral assumptions to lead (global) natural resource distribution, the heterogeneous research perspective shares an understanding of a reciprocal relationship between society and nature that "encompasses the shifting dialectic between society and land-based resources, and also within classes and groups within society itself" (Blaikie and Brookfield, 1987: 17). Political ecology analyses the appropriation of nature and natural resources as an explicitly political process that is linked to social relations of ownership and control (Neumann, 2005: 6). In capitalist societal nature relations, the accumulation of capital is a major driver of this appropriation process. In this context, the valorization of nature conceptualizes the complex process of enclosure that incorporates commonly held natural resources into the capitalist mode of production, and subsequently enables the accumulation of capital (Görg, 2004; Pichler, 2015: 511). This process of "accumulation by dispossession" (Harvey, 2005) draws boundaries around nature and territories, assigns ownership rights, defines the utilization of natural resources, and excludes actors with competing claims from these territories (Altvater, 1993; Vandergeest and Peluso, 1995; Brad et al., 2015: 101). The starting 
point for political ecology research, then, is "the appropriation of nature that is necessarily historical [...] and social (the appropriation of Nature is determined by social relations, particularly relations of ownership and control)" (Peluso and Watts, 2001: 27).

The complex process of resource appropriation and valorization is linked to power relations associated with the distribution of nature and natural resources. Based on Bryant and Bailey (1997), I conceptualize power as the "ability of an actor to control" (39) the access to nature and natural resources as well as the access of other actors to these resources. Power is, then, the control that one person, social group, or state has over the access to nature and natural resources of another person, social group, or state both in material (e.g. control of access to land, natural resources, and environmental risks) and symbolic terms (e.g. control of access to knowledge systems, and environmental discourses) (Bryant and Bailey, 1997: 39-42).

Power asymmetries associated with the appropriation of nature and natural resources foster socio-ecological conflicts to reclaim access and control over these resources (Hall et al., 2011: 170-171). ${ }^{2}$ According to Matthew Turner (2004), publicly expressed - compared to latent - socioecological conflicts serve "as important moments when underlying structures of power and real interests are most revealed" (864). The focus on conflicts, then, offers a conceptual starting point to elaborate on an understanding of justice that encompasses real world resource politics and the power relations associated with these politics.

From these basic assumptions, political ecology researchers have developed complementary conceptions of socio-ecological conflicts. In general terms, Turner (2004) associates "resource-related conflict [...] with both struggles to gain access to natural resources and struggles resulting from the use of natural resources" (864). Joan Martínez-Alier (2002: 70) describes the very field of political ecology as the study of ecological distribution conflicts: that is, conflicts over the distribution of environmental resources and/or services. From a postcolonial political ecology perspective, Arturo Escobar (2006) draws on this definition and highlights the economic, ecological, and cultural dimension of such distribution conflicts, incorporating not only economic distribution but also the neglect of ecological processes outside monetary terms and cultural domination. Together, these approaches show that socio-ecological conflicts combine both material (e.g. struggles over the redistribution of land) and symbolic dimensions (e.g. struggles over the cultural meaning of land) of resource appropriation and are mainly concerned with the unjust distribution of ecological benefits and risks. Injustice, from this perspective, however, does not refer to a universal understanding of justice. Rather, different notions of justice often compete with each other in concrete socio-ecological conflicts: that is, the very definition of justice is at stake.

These conceptions mostly refer to power relations and different dimensions of socio-ecological conflicts but neglect the institutional dimension 
of resource appropriation and control. In recent years, critical scholars, mainly in the context of the German-language debate on 'societal nature relations' (gesellschaftliche Naturverhältnisse), have combined political ecology with critical reflections on the role of the state in the appropriation and control of nature and natural resources (Brand et al., 2010; Brand and Wissen, 2012; Pichler, 2015). This research has shown that processes of valorization and accumulation depend on the materialization of (state) institutions and authorities. According to critical state theory and hegemony theory, (state) institutions are social relations that 'condense' power relations and conflicts regarding the appropriation, distribution, and control of land and natural resources in state structures and processes, that is, in laws, regulations, administrative procedures, or everyday practices. Conflicting interests materialize in (state) institutions through state strategies that are bundled in hegemonic projects (Gramsci, 1971; Poulantzas, [1978] 2000; Jessop, 1990: 268). In hegemonic projects, particular groups of actors are able to generalize their particular interests (e.g. exclusive use of natural resources through ownership rights) and embed them in institutional structures and processes. This generalization of interests is not necessarily enacted through coercion but through consensus, which means that the particular interests of a dominant group are accepted by the majority of other social groups (Gramsci, 1971: 161, see also Schmitt, in this volume). Hegemonic projects therefore require alliances between dominant groups (e.g. extractive industries) and subaltern groups (e.g. local communities, miners, plantation workers, indigenous peoples) as well as (material) concessions to (partially) meet the interests of the latter. These (material) concessions evolve from justice claims in the course of specific socio-ecological conflicts and may include, for example, the increase of wages, compensation for environmental harm, or the provision of social infrastructure such as housing, health care, and education.

Socio-ecological conflicts allow for the challenge and transformation of hegemonic relations and the rupture of institutions. However, the arguments illustrated above show that conflicts take place in or are structured through given constellations of power that are reflected through (state) institutions and practices, and that pre-structure the possibilities and conditions for justice claims in socio-ecological conflicts. Accordingly, Brand (2010) distinguishes conflicts within a hegemonic constellation and conflicts over a hegemonic project. Based on this distinction, many current socio-ecological conflicts evolve around material concessions within a given hegemonic constellation (e.g. compensation for past environmental and social harm, increase in wages, see Coni-Zimmer et al., in this volume) but do not tackle the very basis of unequal appropriation, distribution, and control of natural resources (see Schmitt, in this volume).

In sum, "Political ecology provides tools for thinking about the conflicts and struggles engendered by the forms of access to and control over 
resources" (Peluso and Watts, 2001: 24-25). (State) institutions support these unequal social relations but also provide a terrain to fight for alternative societal nature relations. Based on these political ecology assumptions, I start to converge from a moral universal (global) justice framework to more political dimensions of socio-ecological justice in linking conflicting societal nature relations to democratization processes.

\section{Socio-ecological conflicts and democratization}

Democracy is a contested term. Commonly accepted (static) perspectives conceptualize democracy as a form of government comprising, among other things, regular elections, division of powers, and the rule of law. More process-oriented models of democracy, in turn, emphasize the process of decision making and focus on the role of democratic institutions and the emergence of a public sphere. Deliberative democracy, for example, highlights discussion and dialogue as the foundational principles that lead to reasonable consensus and agreed-upon policies (Young, 2000: 21-25; Eckersley, 2004: 115-119). Whereas the consensual idea of deliberative democracy reveals important dimensions of justice (e.g. inclusion, political equality, and social learning), the above elaborated reflections on the contested access to and control over natural resources and the associated socio-ecological conflicts imply an equally conflict-oriented starting point for the conception of democracy:

In a society where there are social group differences and significant injustice, democratic politics ought to be a process of struggle. [...] Because disadvantaged and excluded sectors cannot wait for the process to become fair, because there are often so many contending interests and issues, oppressed and disadvantaged groups have no alternative but to struggle for greater justice under conditions of inequality.

(Young, 2000: 50)

A number of political theorists (e.g. Jacques Rancière, Chantal Mouffe) have elaborated on such a conflict-oriented and radical understanding of democracy. In the following, I refer to these theories and link them to the appropriation of nature and the analysis of socio-ecological conflicts. ${ }^{3}$

Against defining democracy as a form of society or government, Jacques Rancière $(1999,2009)$ conceptualizes democracy as a process of contestation through distinguishing between the police and politics. Police encompass the existing order of things, that is, "the organization of powers, the distribution of places and roles, and the systems for legitimizing this distribution" (Rancière, 1999: 28). Politics, in contrast, is associated with the disruption of this existing order and the struggle of those people and places that claim a share in the order of things: 
As soon as governments are obliged to represent themselves as instances of the common of the community, separated from the sole logic of relations of authority immanent to the reproduction of the social body, there is a public sphere, which is a sphere of encounters and conflicts between two opposed logics of police and politics. [...] The spontaneous practices of any government tend to shrink this public sphere, making it into its own private affair and, in so doing, relegating the interventions and sites of intervention of non-State actors to the private domain. Democracy, then, far from being the form of life of individuals dedicated to their private pleasure, is a process of struggle against this privatization, the process of enlarging this sphere.

(Rancière, 2009: 55)

Democracy (a term which Rancière mostly uses synonymously with politics) describes the enlargement of the public sphere and includes both the "recognition, as equals and as political subjects" of those that have had no part, and "the recognition of the public character of types of spaces and relations that were left to the discretion of the power of wealth" (Rancière, 2009: 55).

Applied to societal nature relations in general and natural resource politics more specifically, such a conceptualization of democracy refers to both the recognition of marginalized people and those outside the public sphere of conflict (e.g. indigenous people, peasants, landless, urban poor, and workers) as well as to the reopening of places (e.g. territories and natural resources subject to enclosure, valorization, and accumulation processes) for public contestation and democratic negotiation.

In a similar tradition, feminist scholar Val Plumwood (1995: 155-156) links the process of shrinking the public sphere and the failure to equally address issues of natural resources and the environment to a dualism of both public/private and nature/reason in liberal democracies. These separations exclude the household and the economy, as well as other people and places associated with 'nature', from political contestation. The political sphere is confined to a narrow set of social relations that leaves questions of justice in resource access and control to the private sphere of the market. Radical democracy, in turn,

would tend in the opposite direction, to maximise the recognition of political relationships and subjects and to recognise the plurality and pervasiveness of power relationships [...], as appearing for example in the sphere of gender relationships, in the household, in economic areas, in formations of knowledge, culture and identity, and in relationships with nature and animals.

(Plumwood, 1995: 156) 
With reference to Gramscian hegemony theory, Chantal Mouffe and Ernesto Laclau (1985) also introduce democracy as a struggle for the extension of the political into more areas of the social, emanating from a conflictual democratic framework. In her conception of the political, Mouffe (1993) explicitly criticizes Rawls' conception of justice for not taking into account the conflictual nature of politics and democracy that lead to a moral instead of a political conception of justice:

Conflicts, antagonisms, relations of power, forms of subordination and repression simply disappear and we are faced with a typically liberal vision of a plurality of interests [...]. To think politics in terms of moral language, as Rawls does, necessarily leads to neglect of the role played by conflict, power and interest.

(Mouffe, 1993: 49)

Accordingly, Mouffe's (2013) conception of democracy departs from the existing order of things that "is always the expression of a particular configuration of power relations" (2) and of what is deemed 'natural' in a certain period of time. Such a hegemonic order, however, is contested and the political indicates the "dimension of antagonism", that is, the terrain of political contestation and conflict essential for politics (Mouffe, 2013: 2). Democracy, then, is "the confrontation between conflicting hegemonic projects" (Mouffe, 2013: 17) that try to change the existing order and establish an alternative hegemony. Like Rancière, Mouffe directs her attention to the disruptive moment of politics as a major factor of democratic politics that "require[s] making a choice between conflicting alternatives" (2013: 3).

Explicitly elaborating on the relationship between democracy and socioecological conflicts, Erik Swyngedouw (2009) also draws on a conflictoriented conception of democracy. Democracy arises when, "in the name of equality, those who are not equally included in the existing sociopolitical order, demand their 'right to equality' ", disrupt the given order of societal nature relations, and claim a share in the ordering of things (Swyngedouw, 2009: 606). In democratic struggles and conflicts, the marginalized and excluded reject the given arrangements of ownership and control over nature and natural resources and claim a say in the reordering of these relations. Democracy, then, refers to a terrain for expressing socioecological conflicts, "for nurturing agonistic debate and disagreement, and, most importantly, for the naming of different possible socio-environmental futures" (Swyngedouw, 2010: 229).

A radical democracy perspective on socio-ecological justice emanates from specific conflicts that challenge existing societal nature relations and call for a rearrangement of these relations in the course of an alternative hegemonic project (Laclau and Mouffe, 1985), based on a more just and equal access to nature and natural resources. Such a conflict-oriented 
perspective on democracy can be substantiated with the above-mentioned political ecology perspective on the role of accumulation and valorization processes as well as (state) institutions for hegemonic projects. Accordingly, a radical democracy perspective on socio-ecological justice exceeds conflicts within the current hegemonic constellation of resource enclosure and valorization. Rather, it draws attention to conflicts that both challenge the root causes of current societal nature relations and demand a democratic control of nature and natural resources as well as the establishment of alternative institutions to enable this.

To start from such a conflict-oriented framework reveals a more realistic and political perspective on socio-ecological justice. At the same time, however, radical democracy as a mere challenge to existing relations of access to and control over nature runs the danger of focusing solely on deconstruction and contestation without elaborating more specifically on some substantial political dimensions for democratically rearranging societal nature relations.

\section{Political dimensions of socio-ecological justice}

The following section develops some political dimensions of socioecological justice with explicit focus on aspects of democratization. In doing so, I refer both to claims from social movements that deal with the appropriation of nature and natural resources as well as insights from political and democracy theory. The illustrations of the social movements literature deal with the activist concepts of environmental justice and food sovereignty.

Historically, the environmental justice movement emerged in the 1970s from the struggles against the unequal distribution of environmental risks (through the location of polluting industries and the dumping of toxic waste) to mainly black and poor neighbourhoods in the United States. Now-infamous examples and widely accepted origins for the movement include the dumping of toxic waste in Love Canal and a hazardous landfill in Warren County (Bullard, 1990; Schlosberg, 2003). The subsequently emerging antitoxics movement and the movement against environmental racism made a scandal of the disproportionate share of environmental risk that poor African-Americans were confronted with, and called for distributional justice, mainly through legal means (Schlosberg, 2003).

In recent years, activists and scholars have widened the urban and UScentred focus of the environmental justice movement to include global dimensions of justice (e.g. the discourse on climate justice) as well as socioecological conflicts in rural areas, mainly in the Global South. For example, Stallworthy (2009) elaborates on the global environmental justice implications of climate change and discusses multijurisdictional aspects of climate justice. Lohmann (2008) calls for climate justice against the background of the failure of carbon trading, and diverse networks around the world take 
climate justice to the streets and demand real changes in climate policies (Ende Gelände, 2015; Global Justice Ecology Project, 2015). Middleton (2012) also transcends the national scale and analyses the transnational dimensions of distributional and procedural environmental justice in energy trade between Laos and Thailand. The EJOLT project, in turn, has compiled a large database, including an atlas of environmental justice conflicts around the world, to systematize the common roots of diverse local environmental distribution conflicts (http://ejatlas.org/). Challenging the human-centred focus of the debate, Low and Gleeson (1998) differentiate between environmental justice and ecological justice to include non-human nature in the equation. Whereas environmental justice refers to the fair distribution of nature and natural resources among humans, ecological justice extends the question of justice to non-human nature. The 'Universal Declaration of the Rights of Mother Earth' (2010), for example, incorporates such an ecological justice concept.

Referencing the link between democracy and justice, environmental justice conceptions inspired by political ecology are not only concerned with distributional justice and the rule of law but likewise emphasize the political dimension of justice, referring to recognition and selfdetermination as major principles of justice:

Justice, to these movements, is not just simply about categorizing environmental goods, or debating whether they should be included in a calculus of distributive justice, rather, at issue is the preservation of a way of life that relates to nature in a particular way. It is selfdetermination that is most often raised here.

(Schlosberg, 2004: 529)

Whereas redistribution of environmental goods and bads has been a major concern, activists realized that such a redistribution "will simply not happen without a broader cultural recognition of the victims of environmental injustice and their inclusion in problem solving and policymaking” (Schlosberg, 2003: 94, italics added).

Similarly to environmental justice, the food sovereignty movement has evolved from diverse and transnational socio-ecological struggles for selfdetermination, with a specific focus on food production and agricultural politics (Patel, 2005, 2009; Wittman et al., 2010; Ehlert and Voßemer, 2015). The movement has critically assessed the food security approach proposed by UN organizations that has accompanied globalized and corporate food production and led to both the dispossession of peasants and other small-scale food producers as well as to the environmental destruction of livelihoods. The international peasant movement La Vía Campesina is the leading protagonist of the food sovereignty network and calls for the sovereign control of land, water, seeds, and natural resources (Vía Campesina, 1996). According to the movement, food sovereignty is 
"directly linked to democracy and justice" (Vía Campesina 1996, cited in Wittman et al., 2010: 3) as it challenges power politics and structural inequalities in the production and distribution of food and agricultural resources:

Critically, the definition of food security avoided discussing the social control of the food system. As far as the terms of food security go, it is entirely possible for people to be food secure in prison or under a dictatorship. [...] The first exposition of food sovereignty recognised this ab initio, that the power politics of the food system needed very explicitly to feature in the discussion.

(Patel, 2009: 665, italics added)

Although the concept remains unclear about the actual sovereign subject (nation states, communities, people, household) (Patel, 2005: 81-82), the food sovereignty movement stresses - similarly to environmental justice the social control over nature and natural resources instead of mere distributional dimensions that can too easily end up in authoritarian resource distribution without any attempt for democratic control.

Both the environmental justice and food sovereignty movement have evolved from the politicization of day-to-day conflicts over the access and control of natural resources and environmental risks. At the same time, these political concepts entered academic discourses and benefited from an exchange between research and activism. In the following, I discuss some political dimensions of socio-ecological justice that have emerged from political and democracy theory (Young, 1997; Schlosberg, 2003, 2004; Baumgärtner et al., 2006; Fraser, 2010; Petersen and Schiller, 2011; Tronto, 2013; see also Coni-Zimmer et al. and Schmitt, in this volume). Apart from distributional aspects, these include (1) the dimension of political representation, decision making or participation, (2) the dimension of cultural recognition or cultural meaning, and (3) the relational dimension of responsibility. Alongside the discussion of this democratic extension to justice, I also reflect on the scalar dimensions of socio-ecological justice and the interplay of different scales.

Political representation refers to the intrinsic link between democracy and justice and comprises both the 'who' and 'how' of socio-ecological justice. It therefore establishes the arena for the inclusion or exclusion in a political community and sets the rules and procedures for democratic contestation (Fraser, 2010: 16-18). In qualifying political injustice, Fraser distinguishes between misrepresentation and misframing (2010: 18-21). Whereas both dimensions exclude people from their right to democratic self-determination, the latter specifically elaborates on the spatial mismatch between those who democratically control rules and procedures and those who are affected by them. This 'deeper form' of misrepresentation is especially visible in globalization processes that distribute people and resources 
around the world without any adequate arena for democratic control outside the frame of the nation state:

Increasingly subject to contestation, the Keynesian-Westphalian frame is now considered by many to be a major vehicle of injustice, as it partitions political space in ways that block many who are poor and despised from challenging the forces that oppress them. Channeling their claims into the domestic political spaces of relatively powerless, if not wholly failed, states, this frame insulates offshore powers from critique and control. Among those shielded from the reach of justice are more powerful predator states and transnational private power, including foreign investors and creditors, international currency speculators, and transnational corporations. Also protected are the governance structures of the global economy, which set exploitative terms of interaction and then exempt them from democratic control.

(Fraser, 2010: 20)

In line with liberal global justice, such a transnational perspective on socioecological justice challenges the nation state as the arena of political representation. However, instead of proposing a universal global justice 'compass' that lacks any chance of realization, a politically and democratically oriented conception of justice derives from particular transnational conflicts. According to Robyn Eckersley (2004), an ecological democracy approach to justice starts from local socio-ecological attachments to improve the conditions for democratic control over nature and natural resources,

yet it is impossible to arrest the growing gap between those who generate ecological problems and those who suffer the consequences, along with the increasing dis-embeddedness brought about by the processes of economic globalization, without developing sympathetic solidarity with environmental victims wherever they may be located.

(Eckersley, 2004: 190)

A multidimensional perspective on justice therefore claims the "practical negotiation of principles in tension in response to particular transnational problems, rather than a priori" (Eckersley, 2004: 192). That is, transnational justice departs from concrete local, national or transnational socio-ecological conflicts and cases of injustice to struggle for more democratic and sovereign international relations to preclude abstract models of transnational distribution that too easily link with colonial and imperial trajectories of resource exploitation and control.

Besides political representation, cultural recognition refers to the recognition of identity and difference (e.g. culturally diverse modes of living) as a precondition for socio-ecological justice and the actual representation of 
people in decision-making procedures (Young, 1997: 153; Schlosberg, 2004; Fraser, 2010: 16). Against liberal justice principles that only refer to individual prospects as a basis for the evaluation of (economic) inequalities, recognition is concerned with both individuals and social groups (Young, 1990: 42-48; Schlosberg, 2004: 522). Cultural recognition challenges universalization claims of specific social groups related to historical trajectories of colonial domination and cultural imperialism, and demands the recognition of alternative forms of knowledge, economics, and value systems (Young, 1990: 58-60). With regard to the appropriation and control of nature and natural resources, the recognition of particular social groups (e.g. indigenous peoples or peasants) and their respective cultural practices, forms of knowledge, and ways of living (e.g. customary land rights, shifting cultivation, subsistence farming) has proven to be of utmost importance (Schlosberg, 2004).

The dimension of responsibility adds an explicitly reciprocal category between humans as well as between humans and nature - to the democratic dimensions of socio-ecological justice. In conceptualizing the link between care and democracy, feminist scholar Joan Tronto (2013) stresses responsibility as a foundational pillar of justice to balance the reciprocal principles of autonomy and dependency in social interactions (31). Whereas normative ideas of responsibility - especially in moral philosophy - describe responsibility as an individual and, eventually, voluntary and altruistic disposition vis-à-vis other individuals, an explicitly political conception of responsibility insists on the a priori relations among people in social life. That is, responsibility is "by nature relational, existing in the relationships among people [and between society and nature] rather than in individuals themselves" (Tronto, 2013: 50). A political reading of responsibility therefore stresses the "power allocation in exchanges about responsibility" (Tronto, 2013: 55). To add responsibility to a multidimensional conception of socio-ecological justice is to highlight the dependence between society and nature and to ask the basic democratic question of 'Who is responsible for deciding on what?' Responsible politics, then, require specifying "who will participate in the decision-making process" (Toronto, 2013: 57) and "what people will decide when they come together to allocate responsibility" (Toronto, 2013: 59), that is, what is actually open for political contestation. The latter question links responsibility to the abovementioned feminist critique of minimizing the public sphere through the exclusion of substantial domains of responsibility allocation (e.g. household, market, transnational sphere) from democratic contestation and control. Therefore, socio-ecological justice is about politically challenging unequally allocated responsibilities (e.g. environmental risks to future generations, pollution sites to marginalized people in the Global South) and about democratically negotiating responsibilities between people, social groups, and states as well as in relation to nature and natural resources - in specific socio-ecological conflicts. 
To sum up, a multidimensional conception of socio-ecological justice has to highlight the political and specifically democratic dimensions of self-determination and equality in the access to and control over nature and natural resources. This requires the recognition of diverse modes of living, the inclusion in and the control over decision-making power and problem-solving (that require representation), and the democratic allocation of responsibility to challenge the existing order, enlarge the public sphere, and only then enable the redistribution of nature and natural resources - among humans, social groups, and states. These struggles for democratic societal nature relations can, however, only evolve from socio-ecological conflicts on different scales that challenge historically evolved injustices and envision alternative and democratic socio-ecological futures.

\section{Conclusion}

Against a liberal framework of (global) justice, I have developed a multidimensional conception of justice that emanates from socio-ecological conflicts over the appropriation of nature and natural resources. "Justice, from this perspective, disappears from the terrain of the moral and enters the space of the political under the name of equality" (Swyngedouw, 2009: 605). Socio-ecological conflicts arise from the unequal access to and control over nature, and the exclusion of people and places from democratic control. Based on conflict-oriented democracy theories, I have argued that socio-ecological conflicts serve as a means for justice as they challenge the existing order of things - that is, the distribution and position of people and resources - and point to alternative socio-ecological futures.

With reference to the identified gaps and weaknesses of liberal global justice, a political ecology perspective on fairness and justice contributes to a focus on the political and democratic dimensions of socio-ecological justice that stress power relations and inequalities. First, the departure from specific socio-ecological conflicts challenges an ahistorical and abstract justice perspective. Second, the focus on democratically challenging existing societal nature relations emphasizes political dimensions of socio-ecological justice in addition to mere distributional aspects. These evolve from the combined and contested democratic principles of selfdetermination and equality that comprise the recognition of marginalized people and places, the sovereign control of decision-making processes, and the democratic allocation of responsibilities. Third, a political ecology perspective on resource conflicts develops a comprehensive and historical understanding of (state) institutions based on complex socio-economic processes of enclosure and accumulation that materialize in state strategies and hegemonic projects. Fourth, the elaborated socio-ecological justice conception questions the a priori location of justice claims on the global level even though natural resource flows and environmental crises 
phenomena definitely transcend existing borders. Rather, justice is founded upon concrete transnational realities and conflicts to struggle for more democratic and sovereign international relations that are cautious of reproducing colonial and imperial trajectories of foreign resource control. Fifth, the elaborated conception of justice not only locates justice claims and entitlements with individuals but includes social groups as important claimants of injustice based, for example, on class, gender, race, or ethnicity.

\section{Notes}

1 I would like to thank Brigitte Bargetz, Ulrich Brand, and Tobias Boos for valuable feedback on an earlier version of the manuscript. I also appreciate the comments from two reviewers of the chapter.

2 The term socio-ecological conflict highlights the complexity of dimensions at stake in conflicts over nature and natural resources and indicates that such conflicts always encompass, if only implicitly, the distribution of social and environmental concerns.

3 As in other democracy theories, socio-ecological concerns have been of negligible importance for existing conceptualizations of radical democracy.

\section{References}

Altvater, E. (1993) The Future of the Market. An Essay on the Regulation of Money and Nature after the Collapse of 'Actually Existing Socialism', Verso, London.

Baumgärtner, S., Faber, M., and Schiller, J. (2006) Joint Production and Responsibility in Ecological Economics. On the Foundations of Environmental Policy, Edward Elgar, Cheltenham.

Beitz, C. R. [1979] (1999) Political Theory and International Relations, Princeton University Press, Princeton, NJ.

Beitz, C. R. (1999) 'Social and cosmopolitan liberalism', International Affairs, vol. 75 , no. 3, 515-529.

Blaikie, P. and Brookfield, H. (1987) Land Degradation and Society, Methuen, London.

Brad, A., Schaffartzik, A., Pichler, M., and Plank, C. (2015) 'Contested territorialization and biophysical expansion of oil palm plantations in Indonesia', Geoforum, vol. 64, 100-111.

Brand, U. (2010) 'Konflikte um die Global Governance biologischer Vielfalt. Eine historisch-materialistische Perspektive', in P. Feindt and T. Saretzki (eds) Umwelt- und Technikkonflikte, VS Verlag für Sozialwissenschaften, Wiesbaden, 239-255.

Brand, U. and Wissen, M. (2012) 'Global environmental politics and the imperial mode of living: articulations of state-capital relations in the multiple crisis', Globalizations, vol. 9, no. 4, 547-560.

Brand, U., Görg, C., Hirsch, J., and Wissen, M. (2010) Conflicts in Global Environmental Regulation and the Internationalization of the State. Contested Terrains, Routledge, London. 
Bryant, R. and Bailey, S. (1997) Third World Political Ecology, Routledge, London.

Bryant, R. L. and Jarosz, L. (2004) 'Ethics in political ecology: a special issue of political geography', Political Geography, vol. 23, no. 7, 807-812.

Bullard, R. (1990) Dumping in Dixie. Race, Class, and Environmental Quality, Westview Press, Boulder, CO.

Eckersley, R. (2004) The Green State. Rethinking Democracy and Sovereignty, MIT Press, Cambridge, MA

Ehlert, J. and Voßemer, C. (2015) 'Food sovereignty and conceptualization of agency: a methodological discussion', Austrian Journal of South-East Asian Studies, vol. 8, no. 1, 7-26.

Ende Gelände (2015) 'Who we are', https://ende-gelände.org/en/we [accessed 10 November 2015].

Escobar, A. (2006) 'Difference and conflict in the struggle over natural resources: a political ecology framework', Development, vol. 49, no. 3, 6-13.

Fraser, N. (2010) Scales of Justice. Reimagining Political Space in a Globalizing World, Columbia University Press, New York.

Global Justice Ecology Project (2015) http://globaljusticeecology.org.

Görg, C. (2004) 'Inwertsetzung', in W. Haug (ed.) Historisch-kritisches Wörterbuch des Marxismus. Imperium bis Justiz. Band 6/II, Argument, Hamburg, 1501-1506.

Gramsci, A. (1971) Selections From the Prison Notebooks, International Publishers, New York.

Hall, D., Hirsch, P., and Li, T. M. (2011). Powers of Exclusion. Land Dilemmas in Southeast Asia, University of Hawai'ii Press, Honolulu, HI.

Harvey, D. (2005) The New Imperialism, Oxford University Press, Oxford.

Hayward, T. (2006) 'Global justice and the distribution of natural resources', Political Studies, vol. 54, no. 2, 349-369.

Held, D. (2002) 'Law of states, law of peoples: three models of sovereignty', Legal Theory, vol. 8, no. 1, 1-44.

Jessop, B. (1990) State Theory. Putting the Capitalist State in its Place, Polity Press, Cambridge, UK.

Laclau, E. and Mouffe, C. (1985) Hegemony and Socialist Strategy: Towards a Radical Democratic Politics, Verso, London.

Lohmann, L. (2008) 'Carbon trading, climate justice and the production of ignorance: ten examples', Development, vol. 51, 359-365.

Low, N. and Gleeson, B. (1998) Justice, Society and Nature. An Exploration of Political Ecology, Routledge, London.

Martínez-Alier, J. (2002) The Environmentalism of the Poor. A Study of Ecological Conflicts and Valuation, Edward Elgar, Cheltenham.

Middleton, C. (2012) 'Transborder environmental justice in regional energy trade in mainland South-East Asia', Austrian Journal of South-East Asian Studies, vol. 5, no. 2, 292-315.

Mouffe, C. (1993) The Return of the Political, Verso, London.

Mouffe, C. (2013) Agonistics. Thinking the World Politically, Verso, London.

Neumann, R. P. (2005) Making Political Ecology, Hodder Education, London.

Patel, R. (2005) 'Global fascism, revolutionary humanism and the ethics of food sovereignty’, Development, vol. 48, no. 2, 79-83. 
Patel, R. (2009) 'Food sovereignty', The Journal of Peasant Studies, vol. 36, no. 3, 663-706.

Peluso, N. and Watts, M. (eds) (2001) Violent Environments, Cornell University Press, Ithaca.

Petersen, T. and Schiller, J. (2011) 'Politische Verantwortung für Nachhaltigkeit und Konsumentensouveränität', Gaia-Ecological Perspectives for Science and Society, vol. 20, no. 3, 157-161.

Pichler, M. (2015) 'Legal dispossession: state strategies and selectivities in the expansion of Indonesian palm oil and agrofuel production', Development and Change, vol. 46, no. 3, 508-533.

Plumwood, V. (1995) 'Has democracy failed ecology? An ecofeminist perspective', Environmental Politics, vol. 4, no. 4, 134-168.

Pogge, T. W. (2001) 'Eradicating systemic poverty: brief for a global resources dividend', Journal of Human Development, vol. 2, no. 1, 59-77.

Pogge, T. W. (2008) World Poverty and Human Rights, second edition, Polity Press, Cambridge, UK.

Poulantzas, N. [1978] (2000) State, Power, Socialism, Verso, London.

Rancière, J. (1999) Disagreement. Politics and Philosophy, University of Minnesota Press, Minneapolis, MN.

Rancière, J. (2009) Hatred of Democracy, Verso, London.

Rawls, J. [1971] (2003) A Theory of Justice, revised version, Harvard University Press, Cambridge, MA.

Schlosberg, D. (2003) 'The justice of environmental justice: reconciling equity, recognition, and participation in a political movement', in A. Light and A. de Shalit (eds) Moral and Political Reasoning in Environmental Practice, MIT Press, Cambridge, MA, 77-106.

Schlosberg, D. (2004) 'Reconceiving environmental justice: global movements and political theories', Environmental Politics, vol. 13, no. 3, 517-540.

Stallworthy, M. (2009) 'Environmental justice imperatives for an era of climate change', Journal of Law and Society, vol. 36, no. 1, 55-74.

Swyngedouw, E. (2009) 'The antinomies of the postpolitical city. In search of a democratic politics of environmental production', International Journal of Urban and Regional Research, vol. 33, no. 3, 601-620.

Swyngedouw, E. (2010) 'Apocalypse forever? Post-political populism and the spectre of climate change', Theory, Culture \& Society, vol. 27, no. 2-3, 213-232.

Tronto, J. C. (2013) Caring Democracy. Markets, Equality, and Justice, New York University Press, New York.

Turner, M. D. (2004) 'Political ecology and the moral dimensions of "resource conflicts": the case of farmer-herder conflicts in the Sahel', Political Geography, vol. 23, no. 7, 863-889.

Vandergeest, P. and Peluso, N. (1995) 'Territorialization and state power in Thailand', Theory and Society, vol. 24, no. 3, 385-426.

Vía Campesina (1996) 'The right to produce and access to land', www.voice oftheturtle.org/library/1996\%20Declaration \%20of\%20Food \%20Sovereignty. pdf [accessed 28 July 2015].

Wapner, P. (1997) 'Environmental ethics and global governance: engaging the international liberal tradition', Global Governance, vol. 3, no. 2, 213-231. 
Wittman, H., Desmarais, A. A., and Wiebe, N. (2010) Food Sovereignty: Reconnecting Food, Nature and Community, Food First Books, Oakland, CA.

Young, I. M. (1990) Justice and the Politics of Difference, Princeton University Press, Princeton, NJ.

Young, I. M. (1997) 'Unruly categories: a critique of Nancy Fraser's dual systems theory', New Left Review, vol. 222, 147-160.

Young, I. M. (2000) Inclusion and Democracy, Oxford University Press, Oxford. 


\title{
4 Social costs and resource creation
}

\author{
Essential elements of a political \\ economy approach to resource \\ fairness $^{1}$
}

Werner Raza

\section{Introduction}

The concept of sustainable development has been popularized since the late 1980s as a way of synthesizing the seemingly juxtaposed exigencies of socio-economic development and protection of the natural environment (WCED, 1987). However, the debate on how to implement models of socio-economic development while safeguarding the stability of ecosystems for current and future generations has remained highly controversial and essentially unresolved (for an overview see Jacobs, 1999). The global ecological situation has worsened considerably since the Rio Summit in 1992, which was heralded by many - both in governments and civil society - as the beginning of the era of global environmental governance. The climate crisis has become much more acute, biodiversity loss has accelerated, and the exploitation of natural resources has substantially intensified, the latter caused by increasing demand from industrialized and, more recently, also high-growth emerging countries (see Dittrich et al., 2012). Against this background, the debate on how to reconcile socio-economic development with the ecological integrity of the planet has become more polarized. While with the UN 2030 Agenda for Sustainable Development, adopted by the UN General Assembly in September 2015, the concept of sustainable development has on paper become the guiding principle for the international development agenda of the coming decade, the trade-off between economic development and ecological sustainability has not been addressed, as indeed no consensus exists how to reconcile economic development with environmental protection.

Two poles have emerged in the recent debate on environmental sustainability: one calling for a socio-ecological transformation towards a degrowth society (see Jackson, 2009), and the other believing in the possibility of 'greening' capitalism or 'ecological modernization' via the monetization of nature and technological innovation without necessarily abandoning economic growth (Mol et al., 2009). Under the latter approach, the path towards ecological modernization is portrayed as a technical process supported by sound science and effective economic 
policy-making. Socio-ecological conflicts are typically seen as temporary and solvable via monetary compensation, the main impetus needed is determined political leadership by governments (e.g. OECD, 2011; UNEP, 2011). Against this, governments in the Global South stress their right to development and, hence, the priority of economic growth over environmental protection. The responsibility of implementing policies against climate change and other threats to the integrity of ecosystems is passed to industrialized countries, since the current state of environmental problems is attributed to the development trajectories of the industrialized countries during the last 200 years. Here again, environmental protection is implicitly understood as essentially a technical problem that can be resolved with appropriate policies.

In contrast, I shall argue in the remainder of this chapter that at the core of this debate lies a fundamental societal conflict - not just of short-term benefits and costs, but of modes of production and consumption. On the one hand, there is a conflict between actors in the Global North and South who argue in favour of continuing a growth-oriented development trajectory - complemented by selective environmental policies - and those that reject the idea of 'greening' capitalism and aim at breaking with the growth paradigm and establishing alternative economic and social models that reconcile human life with natural limits. On the other hand, there is a conflict within the 'developmentalist camp', that is, between social actors and governments in the Global North, who aim at maintaining the "imperial mode of living" of the advanced industrialized countries (Brand and Wissen, 2012), and actors in the Global South, particularly in the emerging economics, who strive towards levels of material welfare akin to the advanced industrialized countries by way of high-growth late development trajectories. With limited planetary resources, access to resources in order to maintain and pursue high growth trajectories becomes a matter of competition. Under these conditions, conceptions of what constitutes fairness in terms of access and utilization of resources is not straightforward, since all actors typically refer to some a priori plausible normative claims.

In this chapter I, first, give an overview of the debate on socio-economic development and environmental protection, juxtaposing environmentalist and developmentalist approaches that are both legitimated with normative claims. The profound differences between these approaches are the main reasons for the limited progress in international environmental politics. I challenge the discussion from a fairness perspective, as both perspectives tend to shy away from explicitly discussing lines of conflict at different levels which crucially impact on fairness outcomes. I proceed by, second, introducing an alternative framework for resource fairness based on the work of Nancy Fraser. Third, this framework is adapted for the purpose of resources with the help of two concepts from institutional economics in order to account for the peculiar qualities of resource extraction. These concepts are Karl William Kapp's notion of social costs and Erich 
Zimmermann's functional theory of resources. In the conclusion, I finalize the discussion by making suggestions on what would constitute steps towards a fairer distribution of the benefits and costs of resource extraction from the perspective of political economy. For matters of simplification, I follow Rawls (1958) in using the terms 'fairness' and 'justice' interchangeably.

\section{The debate on socio-economic development and environmental protection}

In the polarized debate on reconciling socio-economic development with environmental protection, two main poles have emerged. The one calls for a re-politicization of environmentalism and aims at a socio-ecological transformation towards alternative forms of post-capitalist societies (e.g. degrowth (Jackson, 2009); buen vivir (Acosta, 2015); solidarity economy (Miller, 2010)), based on models of development that steadily reduce their absolute intake of materials and energy and, concomitantly, their emissions and wastes. This would entail the establishment of different and more sustainable production models, a return to local and/or regional production and consumption systems, and the development of alternative consumption norms (Kallis et al., 2012; Kallis, 2015). The other pole believes in the possibility of 'greening' capitalism via the monetization of nature and technological innovation that is expected to dramatically increase energy and material efficiency. Here, the free market system as well as economic globalization is considered necessary for and compatible with economic growth (OECD, 2011; UNEP, 2011).

Based on these lines of thought, environmentalists argue that the economic development model of the Global North has to drastically change and should not be repeated by the countries of the Global South, as this would overstretch the ecological capacities of planet Earth, both in terms of natural resources needed as inputs to production processes and in terms of the absorption capacities of ecosystems. Nonetheless, some authors concede that in many countries of the Global South which are still plagued by high levels of extreme poverty, living standards and material well-being need to be increased, which entails some increase in economic production and, inevitably, environmental degradation. They further argue that degrowth in the Global North is not only an imperative, but can also provide ecological space in the Global South by, for instance, reducing destructive resource extraction by transnational corporations, leaving room for alternative cosmovisions and practices in the South (Kallis, 2015).

Proponents of the 'green economy' stress the importance of improving energy and resource efficiency by advances in technology. They call for market-based solutions to environmental problems, for instance, through the monetization of nature, and argue in favour of the promotion of 
research and innovation policies in order to facilitate a model of development that is less resource intensive and environmentally damaging than previous processes of economic production and consumption but retains the principal focus on improving material well-being via economic growth (UNIDO, 2015). These lines of arguments are met with criticism and resistance, respectively. Governments in the Global South, particularly in emerging economies, stress their right to development. Hence, environmentalist degrowth positions are mostly brushed aside as disguised Northern protectionism by Southern governments, whereas the proposals for a 'green economy' are challenged by requests for additional funding and technology transfer. Needless to say, industrialized countries' willingness to supply such funding has been notoriously low (Climate Change News, 2015).

In most cases, the right to development boils down to introducing and promoting a model of late capitalist development. While country-specific models differ with respect to sector specializations and policy orientations, the general prime objective is to achieve high rates of economic growth, hence, mimicking the prevailing growth orientation of industrialized countries. Obviously, this orientation has implications in terms of requirements for material and energetic inputs, atmospheric pollution, and, thus, environmental costs. Unsurprisingly, the rapid economic development of the BRICS countries (Brazil, Russia, India, China, South Africa) over the last 20 years has substantially increased global demand for raw materials and energy. In consequence, commodity-exporting countries have seen their revenues soar with prices reaching new heights at international commodity markets during the 2000s, although more recently prices have fallen again substantially. However, it is far from clear whether this - and earlier - resource bonanzas have contributed to sustainable economic development (see Staritz et al., in this volume). For sure, these developments have triggered responses from the European Union (EU) and other industrialized countries. For fear of losing out, in particular to China, the EU and other industrialized countries have formulated raw material strategies, which seek to maintain access to cheap raw material supplies for their respective manufacturing industries (Küblböck, 2014).

With political priorities firmly based on economic development, any international responsibilities for safeguarding the environment are usually rejected by the governments of emerging and developing countries. The basic ethical argument is that developmental imperatives carry a higher social weight in situations of extreme poverty than any environmental considerations. Frequently, this line of argument is accompanied by the suspicion that environmental causes are raised by Western interests in order to stymie the economic development of the Global South so as to maintain exploitative centre-periphery relationships. If there exists any responsibility for global environmental issues, it rested with the industrialized countries, as global environmental degradation is overwhelmingly the 
by-product of the latter's model of economic development during the last 200 years. This argument is supported by the work of social movements and critical scholars, who have argued that the economic development model in the capitalist centres has been based on relations of unequal ecological exchange (Bunker, 1985; Hornborg, 2011) and has resulted in ecological debt vis-à-vis the peripheral countries of the Global South (Acción Ecológica, 1999; Goeminne and Paredis, 2010).

This struggle between environmentalism and developmentalism is taking place within a shifting international context, which as a tendency is weakening established mechanisms of global governance. The international governance architecture built up under US hegemony since World War II is in a process of decline. The global governance euphoria of the 1990s has given way to a more sober recognition of the dawn of a multipolar world order, where political interests have become more heterogeneous and a new geopolitics of at least partial rivalry for spheres of influence, if not hegemony, is unfolding (Raza, 2010). The main new actors are large emerging national states, with the BRICS countries and China in particular taking a leading role. But second-tier powers like Turkey and Indonesia have also increased their international economic and political influence. Those emerging economies are essentially adopting models of state-led capitalism, with a marked emphasis on nationalistic discourses and, often, state repression. The legitimizing basis of the respective political classes in these countries rests on the promise of rapid increases in the material welfare of its populations and, particularly, its incipient urban middleclasses. As policies of redistribution of wealth and income are usually strongly contested and difficult to implement, the focus is on high economic growth. Not dissimilar from some industrialized countries, especially the US, these emerging countries are very sceptical of binding themselves to international commitments, which impede their ability to pursue precisely these pro-growth policies. This represents a primary explanation as to why progress in international environmental, and, in particular, climate policies has become so protracted during the last 15 years, the recent conclusion of a climate accord in Paris in December 2015 notwithstanding. A similar situation characterizes other multilateral fora like the World Trade Organization (Raza, 2010). The latter are less and less able to impose conditions of Northern hegemonic powers upon the Global South, but are confronted with resistance and strong articulation of interests of new emerging powers. Concomitantly, other forms of international cooperation have emerged recently. These are marked by a higher degree of informality, like the G20, and are characterized by variable institutional geometries, for example, bilateral and regional trade agreements like the Trans-Pacific Partnership (TPP) or the Transatlantic Trade and Investment Partnership (TTIP). A third variant of new international organizations is set up under the leadership of emerging powers, particularly China, such as the BRICS Bank or the Asian Infrastructure Investment. 
Consequently, normative approaches like cosmopolitan liberalism (see Nili, in this volume; Pogge, 2001; Pogge and Barry, 2006), which advance global principles of justice with regard to natural resources, find it difficult to implement these principles for lack of appropriate global governance mechanisms. Instead, they are confronted with a situation where diverse actors - for example, Northern as well as Southern environmentalists, green growth optimists, pro-growth developmentalists - refer to normative claims as well as human rights principles in order to legitimize their perspective. While Northern as well as Southern environmentalists cite the rights of future generations and the rights of nature, respectively, in order to contest the legitimacy of a universalized model of capitalist development, or contrariwise of 'green' capitalism, Southern (as well as Northern) developmentalists refer to individual as well as collective social and economic rights of, essentially, present generation people(s) in order to defend their focus on high-growth strategies. Apparently, though perhaps to varying degrees, all sides acknowledge that economic development has environmental repercussions, at the national as well as international level. However, the question of who has to bear the responsibility for avoiding and/or mitigating this environmental burden remains severely contested.

Thus, we are trapped in a situation, where all sides hold claims based on normative grounds, which are all legitimate and ethically defendable. I argue that if my outline of the general debate is accurate, then a political solution based on an exchange of normative arguments will not be reached, since all sides are convinced of the validity of their respective positions. However, I argue that the dualistic accounts of Northern versus Southern interests, and developmental versus environmental positions, respectively, turn a blind eye to more intricate, but crucial, aspects of the debate on resource fairness. These relate in particular to (1) the distribution of the social and environmental costs and benefits of resource extraction at the local level, traditionally side-lined by developmentalism, (2) the distribution of benefits and costs of resource exploitation and resourcebased development at the national level, traditionally neglected by environmentalism, as well as (3) the institutional architecture of resource politics, and in particular commodity trade, at the international level, often not properly accounted for by either environmentalists or developmentalists. Hence, we need a reframing of our analytical approach which allows us to focus on these neglected dimensions of resource fairness and which transcends the usual Westphalian territorial framework.

\section{An outline of an alternative framework for resource fairness}

In the latest exposition of her theory of justice, Fraser (2010) rightly proceeds from the fundamental insight that any system of justice is by its very nature governed by institutions, both at the subnational, national, and international level. Thus, any approach to fairness cannot be restricted to 
the national level as has been common under the Keynesian-Westphalian state system, which reserves the discussion of issues of justice to the members of the respective national polity. The framing of justice thus needs to consider fairness at various territorial scales. Hence, the debate about justice cannot stop at treating the usual substantive questions about the 'what' of justice, but needs to concern itself with "second-order, metalevel questions" (Fraser, 2010: 15) concerning the frame of justice, that is, questions that deal with the 'who' and the 'how' of justice.

Furthermore, although fairness in the economic sphere is centred on questions of economic redistribution, that is, under which circumstances groups and individuals enjoy particular entitlements to the results of economic production, Fraser (2010) points to two other dimensions of justice. The first is recognition, that is, the question whether economic, ethnic, religious, or gender status lead to discrimination with regard to the recognition of rights in society. In the context of resource politics, the rights of local communities (e.g. indigenous populations) are a case in point. The second dimension refers to representation, that is, whether the rights of particular individuals or groups are represented in the polity. This could refer to persons without full citizenship rights that are thus not allowed to participate in decision making even though they are affected by national regulations. The denial of political rights to migrants in the host country is an obvious example of such misframing. Related to resource extraction activities, fairness of representation refers to affected people being (un)able to participate in respective decision-making processes. Another case in point are the obligations that a parent company (and its executive management) might hold under national law vis-à-vis the operations of its subsidiaries in third countries. Such issues of extraterritorial obligations have been neglected for a long time, and only more recently been debated (Amnesty International, 2014; Saage-Maß, 2014).

Thus, by applying Fraser's three-dimensional conceptualization of justice, we are able to develop a justice framework at various territorial scales. The two guiding principles for a democratic process of re-framing are the "all-affected" and the "parity of participation" principles (Fraser, 2010). While the first principle states that all those individuals and groups that are affected by a measure or activity should be entitled to participate in the collective decision process, the second principle posits that there must not be any discrimination between the affected parties with regard to their rights of participation and co-decision. While the usual modes of justice in the Westphalian state system are centred upon both the national level and the question of redistribution, the resource challenge involves the local, the national, and the international level, and is also based upon the misrecognition as well as the misrepresentation of certain actors in institutional arrangements which are decisive in determining the distribution of benefits and costs of resource appropriation. Thus, it is of paramount importance that institutional arrangements are assessed against the 
benchmark of whether they attribute parity of participation to all those individuals or groups that are affected by an activity or measure. Instead of taking the national setting with its established procedures for granted, a concept of justice in the current conjuncture needs to problematize precisely this conventional wisdom and asks who should be treated as a subject of justice in a given situation, and at which scale a process of justice should be located so as to safeguard a fair treatment of all the stakes involved (see also Pichler, in this volume, for a further elaboration of Fraser's concept of justice).

At the local level, fairness with regard to resource exploitation refers in particular to the distribution of social and environmental costs and benefits that resource extraction confers upon the local population, which often involves issues of misrecognition and misrepresentation. For example, the cultural specificity of indigenous communities, that is, their particular cosmovision and social relations to nature, might not be recognized by a government or company for fear of representing an obstacle to resource exploitation that cannot be made commensurable by way of ordinary means of economic redistribution. The lack of representation of local communities might effectively foreclose any proper process of negotiation with government or the corporate sector. In addition, interests might not be homogenous among local communities, with the capacities of some sub-groups or individuals to participate in decision-making processes curtailed by lack of resources or of social status (see Schmitt, in this volume). Thus, adequate representation and recognition depend on appropriate processes of economic, social, and political empowerment of disadvantaged sub-groups of a local community.

At the national level, fairness refers to the distribution of the benefits and costs of resource exploitation among the national population at large - for example, in how far the social costs are compensated by the polluters, or the extent to which benefits are shared by the general public via taxation and redistribution mechanisms and/or by maximizing the value added and the employment of resource-based production through creating economic linkages, respectively (see Buur and Monjane, in this volume). Again, issues of misrecognition and misrepresentation might render any settlement biased - for instance, in the case that local and regional communities are underrepresented in the political system at the national level, or in the case that minorities are denied appropriate cultural autonomy, which constrains their legal rights to participate in political processes.

At the international level, fairness refers to how value-addition and rentsharing are organized along the international value chain. This is governed by both transnational corporations, which define the structure of the valuechain from extraction to processing and marketization, and institutional arrangements such as trade and investment policies, regulation of international commodity markets, and the intellectual property rights regime. These arrangements determine (1) the conditions of access to and utilization of resource deposits, (2) the trading and pricing of commodities and 
the allocation of risk with regard to price fluctuations, and (3) the terms under which technological knowledge for resource extraction and processing is made available. Again, questions of misrepresentation play an important role at this level. For instance, do those affected by the operations of international commodity exchanges, such as small-scale miners or farmers, have a stake in the formulation of the terms and procedures upon which these exchanges operate (see Staritz et al., in this volume)?

\section{Two extensions of a concept of resource fairness}

The particular heuristic value of Fraser's concept lies in three basic features: (1) its emphasis on the multi-scalar nature of any concept of justice in the present conjuncture, (2) the insistence on the three dimensions of justice (redistribution, recognition, representation), and (3) the radical democratic proposition that all those affected by a measure/activity ought to have the right to participate in political processes on a par with social peers. In this section, I aim at extending the conceptual framework by two elements. First, I discuss if the economic value of resources is correctly evaluated by the market, by referring to a line of thought originating in the work of institutional economist Karl William Kapp and his notion of social costs. Second, I problematize the notion of resources, as it is conventionally used in most discussions, even in critical social science, by referring to the work of Erich Zimmermann and Clarence Ayres.

\section{Social costs as an intrinsic feature of capitalist accumulation}

Kapp (1950), being one of the early institutional economists who took an active interest in environmental concerns, is best known for his work on social costs, which differs fundamentally from the mainstream treatment of social costs in welfare economics. For Kapp (1950), it was obvious that the

political history of the last 150 years can be interpreted as a revolt of large masses of people (including small business) against social costs. It is doubtless true that the steady increase of protective social legislation, the enforcement of minimum standards of health and efficiency, the prohibition of destructive practices in many fields of production, the concern with air and water pollution, or even the efforts of farmers, businessmen and labor to peg the prices of products and services, reflect, at least in part, an attempt to restrain destructive methods of production and exploitation of resources.

(Kapp, 1950: 15)

Thus, the notion of social costs includes what we would consider the environmental costs of production. However, far from being a rare byproduct or 'externality' of economic processes, as economic orthodoxy 
would like to make us believe, Kapp considered social costs an integral component of every economic process in capitalism:

In so far as social costs are the result of the minimization of the internal costs of the firm it is possible to regard the whole process as evidence of a redistribution of income. By shifting part of the costs of production to third persons or to the community at large producers are able to appropriate a larger share of the national product than they would otherwise be able to do.

(Kapp, 1950: 15)

Thus, every economic process changes the distribution of benefits and costs between the affected parties, and it is in the active interest of the private enterprise to shift as many negative effects as possible upon the general public. Consequently, "the fact that problems of social costs raise issues of income redistribution makes them matters of political economy and political power" (Kapp, 1950: 15). An important implication of this line of reasoning is of course that market prices are never 'correct' in the sense of neoclassical theory, that is, a pure reflection of supply and demand conditions. Prices are always the outcome of a process of social and political struggle, where the distribution of power and resources ultimately conditions price-setting. Markets are thus institutional phenomena, a proper understanding of which necessitates an analysis of the typically asymmetrical constellation of social forces and interests of parties involved in and meeting on markets (see also the more recent institutionalist literature, e.g. Hodgson, 1988, 1998).

Kapp was quite sceptical as to whether one could fully internalize social costs into market prices, as welfare economics propose (the classic reference is Pigou, 1920). Such an internalization would imply a capacity to correctly monetize all the present and future social costs of a productive activity, which in the face of fundamental uncertainty and cultural dependency of all valuation is usually not possible (Heidenreich, 2006). Thus, there are no easy technical fixes to the problem of social costs. Instead, decisions about any economic activity, including, for example, the decision to exploit a particular natural resource, are by necessity problems of social choice. They depend not only on a proper analysis of the likely social benefits and costs of that activity, but need a process of political deliberation. Here Fraser's framework is of particular value, as it provides criteria against which to assess the fairness of this respective political process.

The extent to which it will be possible to internalize social and environmental costs into commodity prices thus largely depends on the relation of social forces at various scales. At the local level, affected communities might demand mitigation measures or social investments from companies in order to compensate for the loss of economic opportunities. Depending 
on its negotiating position, at the national level the government might charge royalties or demand other benefits including technology transfer from extractive companies, the deployment of which might then contribute to mitigating social costs or increase long-term economic benefits. Social costs, however, might not necessarily be compensable by monetary payments, but grounded in basic social rights, which make them incommensurable with monetary compensation. Kapp recognized that such situations demand more radical solutions. In the case of resources, such a situation might emerge if, for instance, an extractive site happens to bear religious value for a local community. In such circumstances, other solutions (e.g. abstention from the exploitation of the resource in that particular place) might have to be found. Similarly, in such a situation, issues of Fraserian re-framing might emerge. It might be argued that national sovereignty over resources might not have precedence over the rights of indigenous people to a particular territory to which they attribute a sacred status. Such conflicts might not be readily solvable at all, but lead to an impasse, as has been the case with the resistance of the U'wa people in Colombia against the extraction of oil in their territory. This and many other resource conflicts are mapped in the Environmental Justice Atlas (Ejolt, n.d.).

At the international level, another important mechanism to determine the extent to which social costs are accounted for in price-setting are commodity derivative markets. These constitute the central pricing mechanism for international commodity trade, in particular, the leading commodity exchanges in Europe and the US. Pricing significantly depends on the institutional configuration of these markets. Terms of access to these markets, the dissemination of information, as well as the trading procedures and strategies of diverse actors on these markets co-determine prices and their development over time. Unsurprisingly, the functioning of international commodity derivative markets has been controversially discussed ever since their beginnings in the late nineteenth century and their development to global benchmarks in the 1980s and 1990s. Earlier efforts by the newly independent states of the Global South in the 1960s and 70s to design alternative pricing mechanisms, in the end unsuccessful, were reflective of the quest to not only increase revenues from resource extraction but to stabilize prices. Price volatility exacerbated by speculative interests and the emergence of new classes of financial investors on commodity derivative markets has become a primary area of concern (Staritz et al., in this volume; Ederer et al., 2013). Again, a political economy approach to justice would ask to what extent the interests of diverse actors, including producers and consumers, are taken into consideration in establishing and re-regulating the institutional architecture of commodity derivative markets, and in how far the procedures prevalent on those markets are conducive to the stated goals, that is, price determination that is reflexive not only of demand and supply conditions, but fair in its assessment of the social and environmental cost of production. The recent literature on 
'ecologically unequal exchange' (Jorgenson and Rice, 2007; Jorgenson and Clark, 2009) and on 'ecological debts' (Srinivasan et al., 2008; Goeminne and Paredis, 2010) has provided broad and convincing evidence that social costs are notoriously absent from the pricing mechanisms in international commodity trade. Obviously, in addition to questions of how to correct for such negligence of social and environmental costs in economic policy, this raises questions with regard to the governance structure of international commodity markets. Though typically regulated by some - nota bene - national authority, many commodity exchanges are controlled by a club of powerful private financial actors, or have been, as in the case of over-the-counter transactions, not regulated at all. Issues of recognition and representation are thus of particular relevance at the international level too.

\section{Resources as a process of creation}

The second element in the extended conceptual framework for resource fairness calls into question the very notion of 'resources' as it is used in politics as well as in most of the social science literature. Typically, the term 'natural resource' is understood to refer to some material substance, which by implication is assumed to be provided by nature. Thus, typically it is supposed to be fixed and finite in quantity. Once humankind has started to consume the stock of that resource, the eventual depletion of the resource is basically a matter of time. Most of the discourse on resource politics, including on resource fairness, begins from this implicit assumption. American institutionalist authors, in particular Erich Zimmermann and Clarence Ayres, have, however, questioned this understanding, and have proposed an alternative, dynamic conceptualization, summarized in the phrase: "resources are not, they become" (Zimmermann, 1972: 16; see also Schmitt, in this volume). Hence, what makes some material substance found in nature a resource is that human ingenuity has devised a particular way of using this resource for some determinate social end. This process of fashioning some material or non-material stuff in a form usable and serviceable to humans is determined by the state of science and technology (De Gregori, 1987). Thus, it is the immaterial aspect of human knowledge that defines the resource character of a particular substance. In effect, the state of scientific and technological knowledge, as well as cultural bounds, determine the amount of resources humans have at their disposal. While the stock of a particular resource gradually depletes, technological innovation eventually leads to the creation of new resources, as indeed the fact that certain resources are currently used is already the result of some previous advance in knowledge. For instance, the utilization of lithium as a resource has become feasible because of advances in battery technology and the recent push propelled by environmental concerns to introduce electric cars on a grand scale (see Anlauf, in this volume). Similarly, rare earths only 
became a critical resource for EU raw materials policy once their utilization in electronic equipment such as mobile phones became technically feasible (as well as necessary) and the electronics industry came to be considered a major driver of growth in advanced economies.

The resources a society uses at a given time are therefore linked to its level of technological development. As long as technological innovation continues, possibilities for the further creation of new resources exist and the total stock of available resources is neither fixed nor finite. Obviously, this conceptualization may seem out of tune with central dogmas of the environmental discourse, which have since the early 1970s time and again stressed the finite nature of resources on planet Earth. This is not the place to engage in an in-depth discussion on this controversy. Suffice to say that I do not subscribe to some naïve belief in technological progress that solves all environmental concerns (as 'green economy' concepts suggest). However, for the purpose of this discussion on resource fairness, the institutionalist account of 'resourceship' conceptualizes resources as a dynamic social relation. A resource-rich country today may be poor tomorrow, in the event that, for example, its main export commodity is not in demand anymore thanks to some technological substitution process. Think of the fate of countries exporting natural rubber, once it had become possible to produce rubber synthetically in the early twentieth century. The country may also be poor in the sense that although it possesses the material resource, it does not possess the technical knowledge of utilizing the resource. Thus, although it might be able to sell the resource on the global market, the long-term effect of resource exploitation on a particular commodity-exporting country is largely determined by social forces outside of its own influence. Resource politics therefore should not be restricted to a static vision of resources, with its focus on maximizing current monetary flows (e.g. sales prices, public income), but use the resource endowment as a basis for improving its productive capabilities over time. Thus, industrial policy conceived in a broad sense, including education, science, and innovation policy, becomes crucial. In addition, fields such as trade and investment policies merit closer attention, since it is via these policies that the conditions for investors to operate in a host country, the privileges they enjoy, and the duties they have to comply with, are conditioned. Thus, the policy autonomy of host governments to implement conditions upon investors that aim at maximizing the economic benefits of resource extraction to the national economy depends on how trade and investment policies are designed. Similarly, international agreements bind countries to implement stringent standards of intellectual property protection, which typically make the acquisition and usage of innovative technology more expensive.

Unfortunately, and in spite of corroborating insights of structuralist economic thinking since the mid-twentieth century (e.g. Prebisch, 1950, 1980), most resource-dependent countries of the Global South have (again) neglected these dimensions of a comprehensive resource politics during the 
recent commodity price boom. Instead, most of them focused on maximizing short-term monetary gains from resource exploitation, which were used to a considerable extent for social investments, particularly by leftwing governments in Latin America (Brand and Dietz, 2013). I do not contest that this practice of neo-extractivism by Latin American governments like Bolivia or Ecuador constitutes an advance in comparison to previous extractivist regimes, also from a fairness perspective. However, despite notable efforts towards economic diversification and resource-led industrialization, (e.g. the African Mining Vision (AfDB et al., 2009) and the work of the 'Making Most of Commodities' project (Kaplinsky and Farooki, 2012; Morris et al., 2012)), it remains to be seen how resource dependent countries cope with the bust-phase of the current commodity super-cycle which started in mid-2014.

\section{Conclusion}

I have outlined in this chapter a conceptualization of resource fairness that builds upon Fraser's theory of justice and adds two components taken from institutional economics. With the concept of social costs, I have argued that resource extraction, like any other productive activity under capitalism, systematically changes not only the distribution of wealth and income, but often has broader implications for communities and their cultures. Private enterprise has rarely ever an incentive to fully compensate an affected community for any social costs it suffers, if that were possible at all in the light of issues of incommensurability of value. Consequently, market prices usually do not reflect the full social cost of production. The struggle over the distribution of the benefits and costs of resource extraction is therefore necessarily political in nature and takes place simultaneously at various territorial scales. It is not only a struggle over questions of redistribution of benefits and costs, but is inextricably linked to questions of recognition of different cultural values and of equal representation of all social actors affected in the institutions that govern resource politics. Furthermore, I have highlighted the importance of broadening the scope of resource politics upon the basis of an alternative reading of the term 'resource'. The conceptual core of this term refers to the scientific and technical knowledge that gives humans the capacity to use a particular material substance found in nature for a defined economic purpose for example, the production of particular goods and services. 'Resource' is therefore a dynamic and open concept, the creation of resources proceeds with advances in science and technology. The necessary complement to a static notion of resource policy, which focuses on the maximization of monetary benefits of resource extraction and the prevention of social costs, is therefore a focus on fostering the innovative capacities of an economy through industrial policy. The latter must, of course, be subjected to democratic control and reflect the social preferences of a society. 
Only such a comprehensive approach toward resource policy can help to eventually overcome the structural constraints of resource dependency. Lastly, at the international level, trade and investment policies and commodity trading schemes need to be redesigned in order to account for the interests of all affected stakeholders of resource extraction, production, and consumption.

Fair alternatives to current resource politics are, however, not easily found. Apart from earning windfall profits in the recent commodity price boom that were more ( $a k a$ social investment and industrial diversification) or less ( $a k a$ luxury consumption and real estate bubbles) wisely reinvested, most resource-exporting countries have not targeted the root causes of resource dependency. That owes to the prevailing institutional structure of the international economy in general and of commodity trade in particular, both of which have shielded core countries and the corporate sector from more fundamental reforms of international commodity trade. Besides, it also relates to power constellations in resource-exporting developing countries, where the economic and political elites profiting from resource extraction prevent a structural transformation of the economy (Rosser, 2006; Collier, 2010; Barma et al., 2012).

Nonetheless, the wholesale critique of neo-extractivist development models currently en vogue in the critical academic discussion, particularly in Latin America (e.g. Lang and Mokrani, 2013), and the related promotion of 'post-extractivism' (Gudynas, 2013) or buen vivir as an alternative to capitalist development (Acosta, 2015), are both too critical of the neoextractivist development models of the left-wing governments in Latin America and too utopian in their expectation that an alternative way of life beyond the large-scale exploitation of natural resources is possible and indeed desired by broad groups in developing countries, particularly urban populations. Against this, I would propose an approach to resource fairness that takes the concepts of social costs and of resources in a dynamic sense, aiming at the continuous advancement of productive capabilities centre-stage. On this basis, a fair resource politics calls for a just distribution of benefits and costs and aims at the recognition and representation of all affected parties in resource politics at the local, national, and international level. Thus, in a sense, I call for a democratic politics of resource creation precisely in order to overcome the prevailing extractivist models in the Global South, and for a fundamental reform of international resource politics.

\section{Note}

1 I acknowledge very useful suggestions by and discussions with Karin Küblböck and Cornelia Staritz. I also appreciate the detailed comments from two reviewers of the chapter. 


\section{References}

Acción Ecológica (1999) 'No more plunder, they owe us the ecological debt!', Bulletin of Acción Ecológica 78 (October), Acción Ecológica, Quito.

Acosta, A. (2015) Buen Vivir: vom Recht auf ein gutes Leben, oekom Verlag, München.

AfDB, AUC, and UNECA (2009) Africa Mining Vision, Addis Ababa.

Amnesty International (2014) 'Injustice incorporated: advancing the right to remedy for corporate abuses of human rights', www.amnesty.org/download/ Documents/8000/pol300012014en.pdf [accessed 15 January 2016].

Barma, N. H., Kaiser, K., Minh Le, T., and Vinuela, L. (2012) Rents to Riches? The Political Economy of Natural Resource-Led Development, The World Bank, Washington, DC.

Brand, U. and Dietz, K. (2013) 'Dialektik der Ausbeutung. Der neue Rohstoffboom in Lateinamerika', Blätter für deutsche und internationale Politik, November, 75-84.

Brand, U. and Wissen, M. (2012) 'Global environmental politics and the imperial mode of living: articulations of state-capital relations in the multiple crisis', Globalizations, vol. 9, no. 4, 547-560.

Bunker, S. G. (1985) Underdeveloping the Amazon: Extraction, Unequal Exchange, and the Failure of the Modern State, University of Chicago Press, Chicago, IL.

Climate Change News (2015) 'US, Japan and Canada miss Green Climate Fund donation deadline', www.climatechangenews.com/2015/04/30/us-japan-andcanada-miss-green-climate-fund-donation-deadline/\#sthash.eCcUXo53.dpuf [accessed 12 January 2016].

Collier, P. (2010) 'The political economy of natural resources', Social Research, vol. 77 , no. 4, 1105-1132.

De Gregori, T. R. (1987) 'Resource are not; they become: an institutional theory', Journal of Economic Issues, vol. 21, no. 3, 1241-1263.

Dittrich, M., Giljum, S., Lutter, S., and Polzin, C. (2012) 'Green economies around the world? Implications of resource use for development and the environment', SERI, Vienna.

Ederer, S., Heumesser, C., and Staritz, C. (2013) 'The role of fundamentals and financialisation in recent commodity price developments - an empirical analysis for wheat, coffee, cotton, and oil', ÖFSE Working Paper, no. 42, Vienna.

Ejolt (n.d.) 'Environmental Justice Atlas', http://ejatlas.org [accessed 13 January 2016].

Fraser, N. (2010) Scales of Justice. Reimagining Political Space in a Globalizing World, Polity, Cambridge, UK.

Goeminne, G. and Paredis, E. (2010) 'The concept of ecological debt: some steps towards an enriched sustainability paradigm', Environment, Development and Sustainability, vol. 12, no. 5, 691-712.

Gudynas, E. (2013) 'Transitions to post-extractivism: directions, options, areas of action', in M. Langand and D. Mokrani (eds) Beyond Development. Alternative Visions from Latin America, Rosa Luxemburg Foundation and Transnational Institute, Ecuador and Amsterdam, 165-188.

Heidenreich, R. (2006) 'Political democracy and social costs: reading K. W. Kapp's “political economy” today', in W. P. Elsner, P. Frigato, and P. Ramazzotti (eds) 
Social Costs and Public Action in Modern Capitalism: Essays Inspired by Karl William Kapp's Theory of Social Costs, Routledge, London, 41-55.

Hodgson, G. (1988) Economics and Institutions: A Manifesto for a Modern Institutional Economics, Polity Press, Cambridge, UK.

Hodgson, G. (1998) 'The approach of institutional economics', Journal of Economic Literature, vol. 36, March, 166-192.

Hornborg, A. (2011) Global Ecology and Unequal Exchange: Fetishism in a ZeroSum World, Routledge, London.

Jackson, T. (2009) Prosperity Without Growth. Economics for a Finite Planet, Earthscan, London.

Jacobs, M. (1999) 'Sustainable development as a contested concept', in A. Dobson (ed.) Fairness and Futurity: Essays on Environmental Sustainability and Social Justice, Oxford University Press, Oxford, 21-45.

Jorgenson, A. K. and Clark, B. (eds) (2009) 'Special issue: ecologically unequal exchange in comparative perspective', International Journal of Comparative Sociology, vol. 50, no. 3-4.

Jorgenson, A. K. and Rice, J. (2007) 'Uneven ecological exchange and consumption-based environmental impacts: a cross-national investigation', in A. Hornborg, J. R. McNeill, and J. Martínez-Alier (eds) Rethinking Environmental History: World-system History and Global Environmental Change, AltaMira Press, Lanham, 273-288.

Kallis, G. (2015) 'The degrowth alternative', www.greattransition.org/publication/ the-degrowth-alternative [accessed 9 January 2016].

Kallis, G., Kerschner, C., and Martínez-Alier, J. (2012) 'The economics of degrowth', Ecological Economics, vol. 84, 172-180.

Kaplinsky, R. and Farooki, M. (2012) Promoting Industrial Diversification in Resource Intensive Economies. The Experiences of Sub-Saharan Africa and Central Asia Regions, UNIDO, Vienna.

Kapp, K. W. (1950) Social Costs of Private Enterprise, Harvard University Press, Cambridge, MA.

Küblböck, K. (2014) 'Can "undistorted access" lead to inclusive development? The EU Raw Materials Initiative and possible effects upon resource-based development in Africa', Austrian Journal of Development Studies, vol. 30, no. 2, 89-105.

Lang, M. and Mokrani, D. (eds) (2013) Beyond Development. Alternative Visions from Latin America, Rosa Luxemburg Foundation and Transnational Institute, Ecuador and Amsterdam.

Miller, E. (2010) 'Solidarity economy: key concepts and issues', in E. Kawano, T. Masterson, and J. Teller-Elsberg (eds) Solidarity Economy: Building Alternatives for People and Planet, Center for Popular Economics, Amherst, MA, 25-42.

Mol, A., Sonnenfeld, D., and Spaargaren, G. (eds) (2009) The Ecological Modernisation Reader: Environmental Reform in Theory and Practice, Routledge, London.

Morris, M., Kaplinsky, R., and Kaplan, D. (2012) 'One thing leads to another: promoting industrialisation by making the most of the commodity boom in Sub-Saharan Africa', www.commodities.open.ac.uk/8025750500453F86/(http Assets)/BD21378EADE7D48080257A63004EEA9A/\$file/MMCP\%20Book\%20 (Final).pdf [accessed 9 January 2016].

OECD (2011) Towards Green Growth, OECD Publishing, Paris. 
Pigou, A. C. (1920) The Economics of Welfare, Macmillan, London.

Pogge, T. (2001) Global Justice, Blackwell, Malden, MA.

Pogge, T. and Barry, C. (2006) Global Institutions and Responsibilities: Achieving Global Justice, Blackwell, Malden, MA.

Prebisch, R. (1950) The Economic Development of Latina America and its Principal Problems, United Nations Department of Economic Affairs, New York.

Prebisch, R. (1980) 'Biosphere and development', CEPAL Review, no. 12, 69-83.

Rawls, J. (1958) 'Justice as fairness', The Philosophical Review, vol. 67, no. 2, 164-194.

Raza, W. (2010) 'Global Economic Governance: globale wirtschaftliche Machtverschiebungen und ihre Implikationen auf Entwicklung', in ÖFSE (ed.) Österreichische Entwicklungspolitik 2009: Krisen und Entwicklung, Vienna, 11-20.

Rosser, A. (2006) 'The political economy of the resource curse: a literature survey', IDS Working Paper, no. 268, Institute of Development Studies, Brighton.

Saage-Maaß, M. (2014) Unternehmen zur Verantwortung ziehen: Erfahrungen aus transnationalen Menschenrechtsklagen, European Center for Constitutional and Human Rights e.V., Berlin.

Srinivasan, U. T., Carey, S. P., Hallstein, E., Higgins, P. A. T., Kerr, A. T., Koteen, L. E., Smith, A. B., et al. (2008) 'The debt of nations and the distribution of ecological impacts from human activities', Proceedings of the National Academy of Sciences, vol. 105, no. 5, 1768-1773.

UNEP (2011) 'Towards a green economy: pathways to sustainable development and poverty eradication', www.unep.org/greeneconomy [accessed 9 January 2016].

UNIDO (2015) Industrial Development Report 2016. The Role of Technology and Innovation in Inclusive and Sustainable Industrial Development, UNIDO, Vienna.

WCED (1987) Our Common Future. Report of the World Commission on Environment and Development, United Nations, New York.

Zimmermann, E. W. (1972) Zimmermann's World Resources and Industries, third edition, edited by W. N. Paech and J. A. Constantin, Harper and Row, New York. 
This page intentionally left blank 
Part II

Empirical cases on resource fairness and justice 
This page intentionally left blank 


\title{
$5 \quad$ Integrated water resources management in Brazil \\ Participatory approaches as a way \\ to resource justice?
}

\author{
Tobias Schmitt
}

\section{Introduction}

For Nancy Fraser (2007), one of the most important critical theorists in social sciences, justice essentially "requires social arrangements that permit all to participate as peers in social life" (20). According to her concept of justice, people cannot participate on a par with others - with equal voices - as long as economic structures and institutionalized hierarchies of cultural value deny equal opportunities for all members of the political community. Therefore, the redistribution of material resources, goods, and wealth as well as the recognition of all members as equal - while recognizing their ethnic, racial, sexual, and gender differences - are two basic aspects for social justice. Recently, Fraser conceptually enlarged her notion of justice by adding the political dimension of representation to the economic and cultural dimension of social justice. Consequently, representation raises the question of who is involved and who is excluded, not only in terms of participation processes but also in the context of establishing institutional framework and decision-making rules (Fraser, 2001, 2007). While Fraser comprehensively elaborates on different dimensions of justice, these theoretical considerations do not indicate how such claims can be reached in terms of practical implementation, especially on a local level.

In such practical terms, the (re)distribution of water plays an essential role in debates over resource justice. Water is not only an important substance for almost all human activities (agriculture, industrial production, energy production, recreational activities, etc.) but a fundamental essence to sustain life itself and is considered as the most strategic natural resource of the twenty-first century (Lehn and Parodi, 2009). In past decades, traditional forms of government have been continuingly expanded and replaced by more flexible and participatory forms of governance (Demirovic and Walk, 2011; Newig, 2011: 485). The main player in such a governancerelated paradigm shift in the water sector was the World Water Council (WWC) comprising members from the private sector (multinational water corporations), intergovernmental organizations (UN, World Bank), governments, academic institutions and professional water associations 
(Linton, 2010: 212). The integration of all parties affected, the improvement of administrative efficiency regarding complex environmental problems, and the increase of the legitimacy of decision-making processes comprise some of the aims of the environment governance doctrine. Thus, the implementation of participation processes became an essential part of this new governance architecture. By integrating all stakeholders and generating a compromise between all interests, participation - grounded in the promise of sustainability - was considered to be able to manage the (re)distribution of resources. Thus participation "is marketed as a way to establish more justice in the world and is presented as a universal value" (Barreteau et al., 2010).

Is the demand for more participation, however, sufficient to reach what Fraser (2007) calls more resource justice? What are the explicit and implicit assumptions and presuppositions of the resource management approach? What are the dominant epistemologies and discursive settings in which this approach is framed? How are participation processes structured, do they extend existing power relations and how far do they contribute to reproducing them?

To answer these questions, I analyse the implementation of an Integrated Water Resources Management (IWRM) system in the state of Ceará, Brazil, referring to Fraser's approach of social justice informed by a political ecology perspective. In the first section I will reflect on some general assumptions of the concept of water management on a more global and abstract level. To do so, I will show that the designation of water as a 'scarce resource' is not a given fact but a socially produced discourse and structured entity. This dominant and westernized understanding of water excludes other non-western narratives and it is, furthermore, an essential ingredient for framing water as an economic good and the development of resource management as the dominant water policy approach. Subsequently, I will analyse some practical experiences of participation processes in water resource management on a local scale. These considerations are mainly taken from fieldwork in the state of Ceará (Brazil) between 2008 and 2009, where I participated in meetings and trainings of the Water Basin Committee of the Lower Jaguaribe River and conducted interviews with members of the committee and water users who were not involved in the participation process. Based on the empirical findings, emphasis is put on Fraser's notions of redistribution, representation, and recognition to show that the IWRM in the state of Ceará mainly serves as an instrument to (re)produce existing power relations and prevalent inequalities instead of initiating emancipation.

\section{The constitution of resources and scarcity}

The starting point of my reflections on resource justice is Erich Zimmermann's (1951) famous quote: "Resources are not; they become" (15). Seen 
from this angle, a resource is not an objective substance outside the human sphere, it is a result of epistemologies, discourses, social values, and necessities. The production of resources can be understood as a social transformation of a specific entity of the material world with its own biophysical qualities into a natural resource. This occurs due to historically specific social needs, through symbolic meanings, discursive constructions, and available technologies in relation to the dominant mode of production. In this process, the non-human (and even the human) nature is conceptually divided into separate parts and receives its social meaning through being labelled as a resource (Schmitt, 2013: 82). David Harvey (2007), for instance, defines natural resources as "a cultural, technical and economic appraisal of elements and processes in nature that can be applied to fulfil social objectives and goals through specific material practices" (147). These social objectives and goals, however, are never fixed. They are always dynamic and changeable entities that depend on social power relations as well as on their inherent gender, class, and race relations. Thus, the production of resources is a genuinely social process that reproduces the dominant epistemologies and the socially accepted forms of knowledge (Linton, 2010).

Not only resources, but also their availability and scarcity are socially produced. To define a natural resource as scarce always depends on modes of production and consumption as well as on existing knowledge and techniques. Scarcity is mediated by social values, political institutions, and economical regulations. Rare earth elements, for example, are actually not as rare as their name suggests. In fact, they became rare because of the expansion of increasing demand for high-tech products (e.g. smartphones, solar panels, LED screens) resulting in an exponentially growing industrial demand. Their scarcity is also the result of the necessary efforts to extract them and of the geopolitical dimension of China being the dominant supplier. Therefore, the limits of natural resources crucially depend on the societal relations to nature: "To say that scarcity resides in nature and that natural limits exist is to ignore how scarcity is socially produced and how 'limits' are a social relation within nature (including human society) rather than some externally imposed necessity" (Harvey, 2007: 147).

To raise questions about possibilities and dimensions of resource justice is not only to elaborate on the concepts of fairness, justice, or equality, but is also about accepting resources as a given fact and natural basis for human life and economic activity. Labelling (non-human and human) materiality as a resource has far-reaching implications in terms of how we perceive and conceptualize human-nature interactions and how we discuss questions of (fair) access, utilization, distribution, and disposal. Understanding a river as a unity with its surroundings - instead of a line in the landscape or as a water resource - is far more than just naming it differently. It is a different way of thinking about, understanding, and acting towards and with the environment. In his speech at the conference of the 
people of the São Francisco Vale and the semi-arid region in Brazil, Marcos Sabaru, a leader of the indigenous community of Tingui-Botó, highlighted their understanding of a river as follows:

In our vision, the vision of the indigenous people, a river doesn't exist, a human being doesn't exist, an animal doesn't exist, plants don't exist. It is all just one thing. For us, [...] the river is a sacred residence; it is a source of life, a source of nutrition. Sometimes it bothers me when people are talking about the river and using words like water resource. I don't think that we should only talk about a river as water. We should talk about a river as people; we should talk about a river as shore, as humans, as fish. [...] We should understand that all of this is just one thing. We shouldn't talk about the water and forget about the people, the animals, the shores, forget about the faith.

$(\text { Recording } 1)^{1}$

If water is considered as sacred and socially embedded, as an integral part of the environment and the human sphere, it is respected and treated in a very different way than if it is considered simply as a resource. Conceiving water as a resource already starts the process of abstraction and exploitation, and likewise transforms it into a manageable and tradable commodity (Linton, 2010: 215). By speaking of nature as a resource, "nature has been clearly stripped of her creative power; she has turned into a container for raw materials waiting to be transformed into inputs for commodity production" (Shiva, 2007: 206). Framing questions about fairness and justice within the discourse of recourse scarcity, therefore, already pre-defines the way in which the problems and possible solutions are conceptualized.

\section{The international framing: water as a finite resource with economic value}

The idea of water as being a scarce resource and an economic good was introduced with the 'Dublin Principles' published at the Dublin conference on Water and the Environment in 1992. On the eve of the Earth Summit in Rio de Janeiro, the conference was the most important international meeting on water where general principles for the water sector were determined and universalized.

The four Dublin principles state that

1 Freshwater is a finite and vulnerable resource, essential to sustain life, development, and the environment [...]

2 Water development and management should be based on a participatory approach, involving users, planners, and policy-makers at all levels $[\ldots]$ 
3 Women play a central part in the provision, management and safeguarding of water [...]

4 Water has an economic value in all its competing uses and should be recognized as an economic good. (ICWE, 1992: 4)

The emphases on the finite and vulnerable character as well as the economic value of the 'resource water' do not represent neutral representations of an existing reality. They have rather to be considered as a result of political negotiation processes with specific impacts on global water management. They have served as a precondition for the commodification and commercialization of water and provided the rationale for the marketed claim of a demand-oriented supply strategy comprising aspects of efficiency and profitability (Budds, 2004; Bakker and Bridge 2008; Swyngedouw, 2008). As a result, an Integrated Water Resources Management (IWRM) was claimed to be "the only viable way [...] for sustainable water use and management" (Rogers and Hall, 2003: 30).

As stated in the second principle, the introduction of a participatory approach became a key element for successful IWRM. By integrating all stakeholders, participatory decision-making processes are conceived to gather all interests in order to reach a compromise that is supposed to be beneficial for everyone. Participation, therefore, has become a precondition for resource fairness and justice in the water sector. However, a participatory process is neither neutral nor free of prerequisites and uneven power relations, nor does it guarantee an equal inclusion of all interests. Hence, participatory processes do not automatically contribute to social justice but must be analysed carefully regarding their contribution to change or stabilize existing power relations and inequalities.

\section{Integrated water resources management in the state of Ceará, Brazil}

The advent of IWRM as a global blueprint for the water sector constituted the international background for the introduction of a new water legislation in the state of Ceará. When the integrated water resources management system (Sistema Integrado de Gestão dos Recursos Hídricos) was enacted in Ceará in 1992, the state became a model region regarding the implementation of the new paradigm of IWRM throughout Brazil.

This development can only be understood in its particular climatic circumstances and political context. Ceará is a semi-arid region, where precipitations occur mainly in the rainy season (January to June) while in the dry season (July to December) water supply is secured through underground aquifers, dams, and rivers. In addition, periodical droughts in the region have an enormous impact on the poor rural population as they are normally not connected to a public water supply system. Their water demand is covered by (irregular) rain fall, the access to local dams and 
rivers, and water distribution through tank trucks organized by local state authorities (Frischkorn et al., 2003: 87-89). In this special context, the location of dams (normally built on private properties but financed by public funds), the access to the water from a dam or a river, and the purpose of its use (e.g. human needs, small agriculture, agribusiness) represent highly contested and politicized political issues. While the hinterland of the state (Sertão) was considered as the poorhouse of Brazil and farmers traditionally used the pastures for cattle breeding and cotton production (especially during the American Civil War), its use and perception have changed in the 1990s. This shift was introduced by an enormous and material expansion of the water infrastructure (dams, river transposition, canals, wells, etc.) and the arrival of national and international corporations in the fruit production sector. Instead of being seen as a developmental obstacle, the natural conditions of Ceará with high temperatures and the possibility of selective irrigation turned out to be a considerable advantage for the agribusiness (Oliveira, 1981: 47; Elias, 2006: 34). This led to the installation of big monocultures destined for export, multiplied the water demand in the region, and therefore increased competition for water.

Looking back, one could say that the political circumstances in the state of Ceará in the late 1980s paved the way towards a new policy program. After more than 20 years of dictatorship and nepotism, a well trained and young elite of businessmen took over government in Ceará in 1986. Their understanding of good governance was based on the principles of an effective corporate management. Together with a team of consultants, scientists, and engineers - and in close cooperation with the World Bank (who also financed the programme) -, they established technical, juridical, and institutional instruments to introduce a water resource management system guided by the principles of integration, decentralization, and participation (Parente and Arruda, 2002).

The main instruments introduced by IWRM consisted of water resource plans, user licences and bulk water tariffs, and participatory water management processes. The River Basin Committees (Comitê de Bacia Hidrográfica) and the Users' Commissions (Comissão de Usuários) are the main bodies of these participatory water management processes. The committees are responsible for the watershed level and support the execution of the water policy, approve the water resource plans, and transfer information concerning water policy. The users' commissions are grouped around specific reservoirs and decide on the quantity of water being discharged from them (Formiga-Johnsson and Kemper, 2008; Taddei and Gamboggi, 2011: 13-14). 


\section{Participation and social justice in integrated water resources management}

The decentralized and participatory river basin management was introduced in Ceará to overcome the structures of clientelism and to re-shape the distribution of water in a more democratic way. The integration of various stakeholders in the decision-making process and management of the water resources was supposed to minimize potential conflicts by searching for consensual solutions (COGERH, 2015). Besides this aspect, the participatory process aimed to increase the acceptance and the legitimacy of the water policy. Even the World Bank states that participatory processes are without any doubt a key factor for the social acceptance of water policies (Pereira et al., 2005: 71). Less clear, however, is whether participatory processes can lead to more than just an increase in the acceptance of water policies and can structurally contribute to increased social justice. Based on a transfer of Fraser's social justice concept to the local level of a river basin, the following sections therefore analyse whether the participatory processes led to an extended representation of the stakeholders, a higher recognition of the different members and their framing of water politics, and a (better) redistribution of water and decision-making power.

\section{Representation}

Public participation can be defined as "the involvement of individuals and groups that are positively or negatively affected by or interested in a proposed intervention, for example, a project, program, plan or policy, that is subject to a decision-making process" (Enserink et al., 2007). Bearing this in mind, the main questions concerning the representation of a participatory process are: Who are the legitimate stakeholders to take part in the process? Are they all able to participate or, if not, what prevents them from participating? Do the stakeholder groups represent the affected population or, if not, what are the biases and political logics inscribed in the process?

The introduction of IWRM in Ceará was a top-down project initiated by the local state and the World Bank and did not (or only partially) result from a civil society struggle (Gutiérrez, 2006: 188). The composition of the river basin committees is defined by law determining that the committees are composed of representatives of the municipal government $(20$ per cent), state and federal government agencies (20 per cent ), organized civil society (30 per cent), and water users (30 per cent) (COGERH, 2015). The category 'water users' involves everyone who has a legal right to extract water. According to this framework, a water user can be a transnational fruit company with very high water consumption, representatives of irrigation projects, or farmers. On the other hand, people without any direct 
access to water resources like rivers or reservoirs are explicitly excluded as water users. They are just represented by organizations of the civil society (e.g. agricultural workers union, NGOs) or by representatives of the municipalities. Such a composition of the committees means that about 800,000 to one million dryland producers - or 80 per cent of the rural population in Ceará have no direct representation in the committees. They are excluded from decision-making processes despite their legitimate interest and - possibly - right to change current water politics in a region where access to water is essential for survival - especially in the dry season (Taddei, 2005: 126; Ballestero, 2006: 319).

Besides the formal barriers that exclude potential participants, there are also practical obstacles that affect the various stakeholder groups differently. For a company, the possibility to participate in the meetings is much easier than for a small farmer who may not afford to spend one day off the field during harvesting season. Living in the outback implies a lot of effort and expenses to travel to a committee meeting. Access to participatory processes is thus basically dependent on the availability of resources like mobility, time, and money which are unequally distributed among different stakeholders (Schmitt, 2013: 315).

Whether the committees adequately represented the rural population was one of the main questions of the survey 'Marca d'Àgua', where 626 members of 14 different river basin committees in Brazil were interviewed. The results give a solid overview of the composition of the committees. It shows that 67 per cent of the members earn ten times the minimum income or more, 80 per cent completed a higher education class (curso superior), 75 per cent are older than 40 years, and 79 per cent are male. In particular, the presidential and vice-presidential positions of the committees - both positions having more representational power and authority regarding decision making - are usually occupied by male members (Empinotti, 2010: 181; Frank, 2010; 48; Gutiérrez, 2010: 121). This means that a male, formally educated, economically better-off position dominates the committees, which obviously does not represent the rural population.

\section{Politics of framing}

Misrepresentation is not only a result of unequal participation opportunities of different stakeholders. It also originates from the framing of decision-making processes. Who sets the agenda and connected procedures and who is entitled to establish decision-making rules which are important benchmarks for the evaluation of the process (Fraser, 2007: 24)?

Initially, the river basin committees were designed as advisory and decision-making bodies. However, sharp criticism from the committees on the official water policy in Ceará led to an open conflict with the State Council for Water Resources (CONERH) in 2001. As a consequence, the state council revoked the formal decision-making power of the committees. 
Even though the CONERH usually approves the decisions of the committees, there is no binding commitment in case of any conflicts, effectively reducing the committees to consultative bodies (Taddei, 2005: 316-317; Taddei and Gamboggi 2011: 24).

In many interviews, various members of the water committees criticized a lack of autonomy. The committees neither have their own executive board nor their own funds. They can only operate with the approval of Ceará's Water Resources Management Company (COGERH). The COGERH staff decides, for example, the place and time of committee meetings, schedules the agenda, facilitates the discussions, records the meetings, and provides the minutes. Only the COGERH is able to calculate the allocation scenarios for the reservoirs - one of the most important tasks of the committees (Schmitt, 2013, 315-317). A former member of the board of the river basin committee of Baixo Jaguaribe stated:

There is a false participation, a domination by COGERH, a control by this institution. It masters the knowledge and the techniques [...]. When we won the board of the river basin committee, our intention was this: to be autonomous.

(Interview 2)

The election of the river basin committee of Baixo Jaguaribe in 2003 resulted in a board that was critical towards the state's official water policy. During their presidency (2003-2005), the limited possibilities of shaping Ceará's water policy became evident. Through the withdrawal of funds for additional activities of the board - for example, the organization of information events in different municipalities, the production of a booklet about the conditions of the water resources, or the exchange with other committees - the COGERH undermined attempts to question the official water policy. These experiences show that participation processes should be equipped with their own budget and autonomous decision-making power in order to translate representation processes into political practices.

\section{Recognition}

Another important aspect of social justice refers to the notion of recognition. The composition of the committees, with mainly male and middle class members, already indicates a misrecognition of certain social groups that are not perceived as legitimate stakeholders in the participation process. Furthermore, mechanisms of (mis-)recognition can be found inside the committee structures as well. In particular, the disrespect of other forms of knowledge and languages conceptually prevent the recognition and participation of all stakeholders as peers.

Since the discussions in the committees mainly centre on changes in the water legislation and decisions about water allocation, the language used 
in the meetings is merely a technical one. Scientific and technical knowledge appear as a precondition for participation while other forms of knowledge (e. g. local and traditional knowledge) are devalued. 31 per cent of the members interviewed by the survey 'Marca d'Água' declared that technical knowledge is the most important skill for the participation process. As a matter of fact, 67 per cent considered the uneven distribution of technical knowledge to be the main obstacle for the process, and 18 per cent indicated that they did not always feel free to express their opinions in the meetings (Florit and Noara, 2010: 97).

The access to and the use of expert knowledge became decisive not only for the possibilities of participating in the process, but also for the presentation of individual positions. When members of the committees raise their voice for the first time during a meeting, they are invited to mention their name and position. While farmers normally introduce themselves with their name and the municipality they come from, state or company representatives usually add their function and profession (e.g. engineer, agronomist). This seems to legitimize their own position while it devaluates the position of others through introducing a social taxonomy from legitimate to illegitimate voices.

Thus, an establishment of roles and a production of identity take place through the participation process. The division of the participants into certain categories can be considered as an external "interpellation" - a term taken from the French philosopher Louis Althusser - to certain positions (Bröckling 2012: 134). Such attributions are internalized and reproduced through self-designation during the meetings. At the same time, the externally and internally designated positions are inscribed in existing power relations. For example, the self-designation as 'engineer' comes along with a more powerful position than the occupational title 'peasant'. These categorizations have impacts on self-perception and esteem, talking behaviour, the willingness to achieve a compromise, and the use of resistance strategies. Furthermore, these mechanisms function not only within the committee, but also develop a power effect outside the consensus space. If the members of the committee agree on a compromise, they do so as representatives of a certain interest group. Thus, they need to advertise and ensure compliance with the compromise, which provokes a reinforcement of the identification with the committee and its operation.

The organization of special training (curso de capacitação), where the historical, institutional, and legal foundations of water management are discussed, is an instrument to compensate for the knowledge bias between the members of the committee. This training is supposed to foster knowledge transfer and empowerment of all stakeholders. However, since these courses are normally given by representatives of public water agencies, they strive for the participation of the members in a preconceptualized way instead of critically discussing the management model 
itself. Accordingly, the COGERH refused an attempt by the committees to open the training to 'other experts', as one member of the board criticizes:

We won the election and we began to think of the training. As we started to conceptualize the training, thinking of the contents, what would be the training for the new members, the state began to react. And I realized: wow, but we do not have autonomy? We cannot decide who the advisors that come to train the people are? Because: Who were the technicians that came to train the members of the committee? Members of the SRH [the public water resources office], the COGERH; which are the state. So we thought that these technicians came with the government discourse, they came to make the trainings, but they did not appear with the criticality we wanted, because in my view, the state has an economic and exploitative vision of the water resources, you know? So we realized that there was a discourse of the participatory management, of an integrated water resources management, but in practice we saw something completely different. And when was it revealed? When the state wanted to patronize, which means to command, to coordinate the board of the committee, when we did not have freedom to think.

(Interview 3)

Therefore, this training does not serve as spaces to challenge existing structures, to construct alternative decision-making structures, or to produce new knowledge. They rather contribute to confirm the importance of technical knowledge and reproduce and strengthen dominant practices, positions, and power relations.

\section{Redistribution}

The idea of resource justice in the water sector is closely linked to a more equitable distribution of water resources. Participation is supposed to distribute the scarce resource water more equally to all stakeholders, by taking all interests into account. The decisions about the outflow of a reservoir could thereby serve as a good example to analyse the possibilities and limitations of such participation processes. But it also raises the question of whether greater social justice can be reached by a redistribution of resources without a redistribution of power.

The Santo Antônio de Russas reservoir is located in the basin of the lower course of the Jaguaribe river in the northeast of Ceará. It provides water for the non-perennial Palhano river. The main task of the users' commission of that reservoir is the determination of the amount of water to be released from the reservoir. Thus, there is a permanent conflict between the interests of the water users of the upper and the lower course of the river. While the main interest of the cultivators of the upper course 
is water security, that is, to maintain a sufficient amount of water in the reservoir to secure water flow during the whole year, the water users of the lower course demand a higher water discharge to guarantee that the water reaches their land.

As indicated before, the COGERH prepares the meetings of the commission and pre-structures the decision-making process. COGERH calculates, based on strong legal regulations, different scenarios for the water outflow of the reservoir. This means that the members of the commission can only decide between these previously defined scenarios. However, even the scenario with the highest water outflow (calculated in $\mathrm{m}^{3} / \mathrm{s}$ ) does not provide the downstream farmers with enough water during dry season. Yet, at the same time, it would be possible to divert water from a big irrigation canal nearby. It is technically feasible to provide the Palhano river with a sufficient amount of water - this is just not the priority of the state's water policy. The water is rather used to supply the 3.6 million people in the metropolitan region of Fortaleza and the industrial complex of the Port of Pecém.

Representatives of the municipality of Palhano and downstream water users have been urging the users' commission and the committee of the Baixo Jaguaribe for years to discuss procedures and mechanisms that would fundamentally change water distribution instead of only voting between pre-defined scenarios. So far, nothing has changed. Representatives of the COGERH argue that the task of the users' committee is limited to the management of water in the reservoir whereas the public water company CAGECE is responsible for water supply for the rural population. When asked about the possibility of changing the situation, a COGERH staff member said: "We are just following the law [...]. Unfortunately, things are like that. We should not act irresponsibly when the dam does not have the capacity. We have to work with the present facts" (Interview 4).

\section{The construction of hegemony}

The examples mentioned above illustrate that the users' commissions and the river basin committees have the right to decide on some aspects of the water policy in the river basin, but only in a strict framework and under predefined conditions. Structural changes such as the democratization of the access to water, the construction of small and decentralized water infrastructures, or the reform of the unequal property structure are not considered relevant parts of the agenda. Hence, the main function of the participatory process consists in the management of the dominant water politics which results in the stabilization of dominant power relations and existing inequalities. In this sense, the participation processes are part of new governance structures that re-produce and sustain existing hegemony. The Gramscian concept of hegemony refers to the fact that environmental governance is not only established by coercion, (e.g. laws, regulations, restrictions) but by convictions, the raising of consciousness, and the 
establishment of consensus (Sauer, 2011: 119; Pichler, in this volume). Apart from being a top-down policy approach, the IWRM is a process of integration of - what is supposed to be - all stakeholders and of producing a consensus. The production of a collectively accepted knowledge and the adaptation of the management structures are mainly fostered by the training. The logic of the participation process pre-structures and predetermines the achievement of a compromise and its compliance. The example of the Palhano river shows that the representatives of the municipality can indeed submit their demands to the committee and try to reach a majority. If they fail, however, they have to accept the decision. Not to accept the decision of the committee would exclude them from the participatory process and, thus, from social consent (Schmitt, 2013: 326).

The observations of the river basin committees reveal that the actual participation process falls short of the promise to represent all interests, as formal and informal barriers prevent equal participation. Yet, the assumption of equal stakeholders with similar skills and knowledge impedes a more critical discussion of the existing knowledge and power relations. The incorporation of the various stakeholders is supposed to increase the acceptance and legitimacy of the official water politics, and potential opponents are integrated in the participatory process and subjugated under the paradigm of consent. Social distinction and struggles are being calmed, if not pacified, by their integration into the participation process, since different interests are, at least formally, taken into account (Brand, 2011: 267f.; Jessop 2011: 55).

The integration of resistant actors has to be analysed in the context of the history of north-eastern Brazil. From the 1950s to the military coup of 1964, rural workers and peasants organized themselves in peasant leagues (ligas camponesas) to change their living conditions and to overcome unequal land ownership structures. Together with the communist party and parts of the Catholic church, they became a major force in the north east so that even the Brazilian government considered the region as a powder keg (Oliveira, 1981: 107; Costa, 2005: 58). While this movement was silenced during the military regime, some practices of resistance continued. They range from the occupation of land and barrages, the blockade of streets, the violent opening of floodgates, to the unauthorized extraction of water from reservoirs and rivers. The implementation of the consensus-orientated participation model, however, further delegitimized these practices.

The fear of absorption and the various experiences of failure in changing water policies in the state of Ceará through the participation process led to a withdrawal of various social movements from the river basin committee of Baixo Jaguaribe. They considered the risk of legitimizing a water policy that strengthens social inequalities instead of opening possibilities for transformation. If the committees are not conceived as spaces of empowerment, they prefer not to be part of the participation process: 
Either we organize the application of participatory methodologies with a popular language so that people know what they are doing or in what they are participating or we leave the process. We will not legitimize their process. [...] If a community does not have the power in the committee to destine projects for the distribution of water, we will leave and organize the people. We will develop projects; we will pressure the city hall $[\ldots]$. You have to create other ways to $[\ldots]$ empower the people, for that they create autonomy.

(Interview 5)

With the departure of a number of representatives of the social movements and the occupation of the vacant seats by professional 'experts', the social and political diversity of the committee, and eventually its democratic legitimacy, decreased. Since then, the meetings of the water committees have been considered less contested and more efficient (Taddei and Gamboggi, 2011: 25). Thus, it seems that the participation process has evolved into an efficient water management process where existing water policies are legitimized. It does not constitute - at least for now - a terrain for resistance or for the implementation of more social justice.

\section{Conclusion}

If social justice - according to Nancy Fraser - depends on the distribution of material goods, the recognition of social differences, and the broad representation of stakeholders, then the introduction of participation mechanisms in the water sector might be an instrument to implement a more just allocation of water. The analysis of participatory water management processes in Ceará, however, has shown that without taking into account underlying power relations, different epistemologies, forms of knowledge and articulation, as well as differences in class and gender, these participation processes fail to contribute to social justice.

Framed in the discourse of resource scarcity, the participation process of the IWRM in Ceara is limited to the act of deciding about water allocation and does not open up new societal nature relations:

Although it does perhaps integrate the interests of different stakeholders, IWRM is still water resources management. Stakeholders and participants are thereby consulted but not so as to elicit how different players may relate to water in ways other than as a resource whose natural disposition is to be managed.

(Linton, 2010: 241)

This management approach in the water sector - and in fact the participatory framework more generally - actually strengthen the idea of an economically efficient water use and the dominant forms of water distribution. 
Alternative forms of knowledges and concepts of relating to water, different modes of production and lifestyle, or attempts to reorganize the access to land and water are thereby excluded. In particular, the subtle power of the consensus paradigm makes participation mechanisms the perfect tool for the production of hegemony and aligned actors. The experiences of 'stakeholders' of the social movements in Ceará showed that the engagement in participatory processes can even lead to restricted opportunities for action and the weakening of social struggles instead of the expansion of their policy shaping power.

In sum, the analysis of participation opportunities in the water sector of Ceará showed that without challenging and re-framing existing discourses and power relations, participatory processes in most cases lead to a stabilization of dominant power networks and inequalities. Consequently, the redistribution of resources has to be linked to the redistribution of power relations that are always disputed and contested.

\section{Note}

1 All quotations from recordings and interviews were translated from Portuguese to English by the author.

\section{References}

Bakker, K. and Bridge, G. (2008) 'Regulating resource use', in K. R. Cox, L. Murray, and J. Robinson (eds) The Sage Handbook of Political Geography, Sage, Los Angeles, 219-233.

Ballestero, A. (2006) 'Construcción del espacio político a través de las prácticas locales: Bajo Jaguaribe y la política de recursos hídricos de Ceará', in D. Elias and R. Pequeno (eds) Difusão do Agronegócio e Novas Dinâmicas Socioespaciais, Banco do Nordeste do Brasil, Fortaleza, 307-325.

Barreteau, O., Bits, P. W. G., and Daniell, K. A. (2010) 'A framework for clarifying "participation" in participatory research to prevent its rejection for the wrong reasons', Ecology and Society, vol. 15, no. 2, www.ecologyandsociety.org/vol. 15/iss2/art1/ [accessed 26 October 2015].

Brand, U. (2011) 'Global Governance als ordnungswissenschaftliches Konzept (zwischen-)staatlichen Regierens im globalisierten Kapitalismus - und alternative Vorstellungen', in A. Demirović and H. Walk (eds) Demokratie und Governance: kritische Perspektiven auf neue Formen politischer Herrschaft, Westfälisches Dampfboot, Münster, 257-278.

Bröckling, U. (2012) 'Der Ruf des Polizisten: die Regierung des Selbst und ihre Widerstände', in R. Keller, W. Schneider, and W. Viehöver (eds) Diskurs, Macht und Subjekt, VS Verlag, Wiesbaden, 131-144.

Budds, J. (2004) 'Power, nature and neoliberalism: the political ecology of water in Chile', Singapore Journal of Tropical Geography, vol. 25, no. 3, 322-342.

COGERH (Companhia de Gestão dos Recursos Hídricos) (2015) 'Comitês de Bacias Hidrográficas', http://portal.cogerh.com.br/apresentacao [accessed 27 October 2015]. 
Costa, L. F. A. (2005) O sertão não virou mar. Nordestes, globalização e imagem pública da nova elite cearense, Annablume, Fortaleza, São Paulo.

Demirović, A. and Walk, H. (eds) (2011) Demokratie und Governance. Kritische Perspektiven auf neue Formen politischer Herrschaft, Westfälisches Dampfboot, Münster.

Elias, D. (2006) 'Ensaios sobre os espaços agrícolas de exclusão', Revista NERA, vol. 9 , no. 8, 29-51.

Empinotti, V. (2010) 'Gênero, recursos hídricos e tomadas de decisão: o papel das mulheres nos organismos de bacia brasileiros', in R. N. Abers (ed.) Água e Politica: Atores, Instituições e Poder nos Organismos Colegiados de Bacia Hidrográfica no Brasil, Annablume, São Paulo, 161-190.

Enserink, B., Patel, M., Kranz, N., and Maestu, J. (2007) 'Cultural factors as codeterminants of participation in river basin management', Ecology and Society, vol. 12, no. 2, www.ecologyandsociety.org/vol.12/iss2/art24/ [accessed 27 October 2015].

Florit, L. F. and Noara, C. T. (2010) 'Visão de mundo: desenvolvimento, meio ambiente e democracia nos comitês de bacias hidrográficas no Brasil', in R. N. Abers (ed.) Água e Política: Atores, Instituições e Poder nos Organismos Colegiados de Bacia Hidrográfica no Brasil, Annablume, São Paulo, 69-104.

Formiga-Johnsson, R. M. and Kemper, K. E. (2008) 'Institutional and policy analysis of decentralization on water resources management in Ceará state: the case of Jaguaribe river basin', www.anppas.org.br/encontro4/cd/ARQUIVOS/ GT12-380-879-20080512234646.pdf [accessed 27 October 2015].

Frank, B. (2010) 'Formação e experiência: os organismos de Bacia Hidográfica são capazes de lidar com a complexidade da gestão e recursos hídricos?', in R. N. Abers (ed.) Água e Política: Atores, Instituições e Poder nos Organismos Colegiados de Bacia Hidrográfica no Brasil, Annablume, São Paulo, 39-68.

Fraser, N. (2001) 'Recognition without ethics?', Theory, Culture \& Society, vol. 18 , no. 2-3, 21-42.

Fraser, N. (2007) 'Re-framing justice in a globalizing world', in T. Lovell (ed.) (Mis)Recognition, Social Inequality and Social Justice. Nancy Fraser and Pierre Bourdieu, Routledge, London, 17-35.

Frischkorn, H., Araújo, J. C., and Santiago, M. M. F. (2003) 'Water resources of Ceará and Piauí', in T. Gaiser, H. Frischkorn, M. Krol, and J. C. Araújo (eds) Global Change and Regional Impacts, Springer, Berlin, 87-94.

Gutiérrez, R. A. (2006) 'Between knowledge and politics: state water management reform in Brazil', PhD thesis, Johns Hopkins University, Baltimore, MD.

Gutiérrez, R. A. (2010) 'Governo municipal e gestão de bacia hidrográfica no Brasil', in R. N. Abers (ed.) Água e Política: Atores, Instituições e Poder nos Organismos Colegiados de Bacia Hidrográfica no Brasil, Annablume, São Paulo, 107-157.

Harvey, D. (2007) Justice, Nature and the Geography of Difference, Blackwell, Cambridge, UK.

ICWE (International Conference on Water and Environment) (1992) The Dublin Statement and Report of the Conference, International Conference on Water and the Environment, Dublin.

Jessop, R. (2011) “"Regieren + Governance im Schatten der Hierarchie”: Der integrale Staat und die Herausforderungen der Metagovernance', in A. Demirović and H. Walk (eds) Demokratie und Governance: Kritische Perspektiven auf neue Formen politischer Herrschaft, Westfälisches Dampfboot, Münster, 43-72. 
Lehn, H. and Parodi, O. (2009) 'Wasser - elementare und strategische Ressource des 21. Jahrhunderts', Umweltwissenschaften und Schadstoff-Forschung, vol. 21, no. 3, 272-281.

Linton, J. (2010) What is Water? The History of a Modern Abstraction, UBC Press, Vancouver.

Newig, J. (2011) 'Partizipation und neue Formen der Governance', in M. Groß (ed.) Handbuch Umweltsoziologie, VS Verlag, Wiesbaden, 485-502.

Oliveira, F. (1981) Elegia Para uma Re(li)gião: SUDENE, Nordeste, Planejamento $e$ Conflitos de Classe, Paz e Terra, Rio de Janeiro.

Parente, J. and Arruda, J. M. (2002) A Era Jereissati: Modernidade e Mito, Edições Demócrito Rocha, Fortaleza.

Pereira, J. G., Arrobas, D. L. P., Noronha, L. C., and Pereira, L. P. (2005) Transferência de Água Entre Bacias Hidrográficas, Banco Mundial, Brasilía.

Rogers, P. and Hall, A. W. (2003) Effective Water Governance, Global Water Partnership, Stockholm.

Sauer, B. (2011) 'Governance als frauenpolitische Chance? Geschlechterkritik aktueller Debatten um Staatstransformation', in A. Demirović and H. Walk (eds) Demokratie und Governance: Kritische Perspektiven auf neue Formen politischer Herrschaft, Westfälisches Dampfboot, Münster, 106-130.

Schmitt, T. (2013) 'Dürre als gesellschaftliches Naturverhältnis. Eine politische Ökologie der Wasserknappheit im Nordosten Brasiliens', PhD thesis, University of Innsbruck, Austria.

Shiva, V. (2007) 'Resources', in W. Sachs (ed.) The Development Dictionary, Zed Books Ltd, London, 206-218.

Swyngedouw, E. (2008) 'Wasser, Geld und Macht', in Wasserkolloquium (ed.) Wasser: Kommerzialisierung eines öffentlichen Gutes, Karl Dietz, Berlin, 27-44.

Taddei, R. (2005) 'Of clouds and streams, prophets and profits: the political semiotics of climate and water in the Brazilian Northeast', PhD thesis, Columbia University, New York.

Taddei, R. and Gamboggi, A. L. (2011) 'Marcas de uma democratização diluída: modernidade, desigualidade e participação na gestão de águas no Ceará', Revista de Ciências Sociais, vol. 42, no. 2, 8-33.

Zimmermann, E. W. (1951) World Resources and Industries. A Functional Appraisal of the Availability of Agricultural and Industrial Resources, Harper and Brothers, New York.

\section{List of interviews and recordings}

Recording 1: Marcos Sabaru, leader of the indigenous community of Tingui-Botó, Juazeiro, February 2008.

Interview 2: Francisco Rosângelo Marcelino da Silva, member of the Water Basin Committee of the Lower Jaguaribe River, Limoeiro do Norte, August 2009.

Interview 3: Francisco Rosângelo Marcelino da Silva, member of the Water Basin Committee of the Lower Jaguaribe River, Limoeiro do Norte, August 2008.

Interview 4: Representative of COGERH, Limoeiro do Norte, August 2009.

Interview 5: Francisco Rosângelo Marcelino da Silva, member of the Water Basin Committee of the Lower Jaguaribe River, Limoeiro do Norte, August 2008. 


\title{
6 Claims for local justice in natural resource conflicts
}

\author{
Lessons from Peru's mining sector
}

\author{
Melanie Coni-Zimmer, Annegret Flohr, and \\ Andreas Jacobs
}

\section{Introduction $^{1}$}

Scholarly analysis has, in the past, rarely focused on the role that diverging notions of justice play in the evolution of natural resource conflicts. The consequence of this is a lack of systematic knowledge about the justice claims that actors involved in natural resource conflicts put forward. This is surprising considering that, upon closer inspection, justice claims advanced by affected actors are easily identifiable within any particular resource conflict. Be it the population in the Niger Delta claiming a greater share of oil revenues or an end to the contamination of fragile local ecosystems, or workers of the Marikana mine in South Africa protesting for higher wages and full rights for a particular union, almost all local claimmakers invoke ideas of justice as a basis for their demands.

In International Relations, the disregard for considering justice in the context of natural resource conflicts is best illustrated in literature dealing with the causes of civil war. Notable overlaps exist between the concept of justice and the concept of grievance within the so-called greed versus grievance debate (Collier and Hoeffler, 2004; Basedau and Lay, 2009; Collier et al., 2009). However, this literature generally conceptualizes natural resources as an essential element of the greed paradigm rather than as a grievance-related explanation for civil wars. In contrast, disciplines such as political theory and philosophy have long identified the exploitation and distribution of natural resources as a central point of contention in achieving (global) justice (Beitz, 1979; Pogge, 2002; Wenar, 2008; Nili, in this volume). These scholars have, however, mostly been interested in developing abstract principles of justice; as such, when they do mention empirical justice claims made by actors, it is primarily for illustrative purposes.

Social anthropologists and scholars engaged in development and regional studies, on the other hand, have frequently conceded analytical priority to justice considerations. Their explanations for the root causes and/or dynamics of ongoing resource conflicts often highlight locally perceived grievances publically expressed in terms of justice (Latouche, 1997: 137-139; Ferguson, 2006: 35-38). Despite having this focus, work done 
by scholars in these disciplines and research fields apparently does not differentiate between different types of justice claims in any systematic manner.

This chapter analyses justice claims by local communities along with the governance initiatives that have emerged in response to these claims. We ask whether these governance initiatives adequately respond to local justice claims and identify the significance of misperceptions or misinterpretations of justice claims made by the actors involved in given conflicts. The chapter demonstrates the importance of distinguishing between various types of justice claims in order to achieve a better understanding of conflict dynamics and increase our knowledge of the governance mechanisms used to address them.

In order to analyse local justice claims more systematically, we propose a threefold conceptualization of justice based on the work of Nancy Fraser (2009), which analytically covers distribution, recognition and representation-related claims (section 2, see also Schmitt, in this volume). We argue that the disentanglement of these different justice claims is important as the misperception of particular claims by addressees - such as corporations, state actors, or international organizations - might lead to governance initiatives that prove not only insufficient for satisfying local demands but could even further exacerbate the conflict dynamics.

We apply this argument to a mining conflict in Peru, where numerous local conflicts exist in the context of large-scale mining projects (section 3). These conflicts have generally emerged between corporations and the affected communities, though they also invariably involve state institutions. A common response has been to install Dialogue Tables (Mesas de Diálogo) to reach a compromise between parties to the conflict. The case study presented here focuses on the conflict between the population of Ilo, in Peru's Moquegua region, and the Southern Copper Corporation mining company. The analysis is based on field research carried out between June and August 2013, including interviews conducted with various stakeholders and participant observation in Mesa sessions. ${ }^{2}$ Our empirical analysis shows that the mesa de diálogo in Ilo has not been successful because of its inadequacy in addressing the local justice claims. While Southern Copper Corporation's discourse focused on voluntary (financial) contributions to local communities, representatives from these communities emphasized the past damages caused by Southern, principally striving for (official) recognition of the company's guilt. Hence, compromise-oriented policy instruments such as dialogue tables prove to be ill-suited for dealing with claims where recognition rather than compensation is at stake.

\section{Local resource conflicts}

According to the Heidelberg Institute for International Conflict Research, the year 2014 witnessed 96 inter- and intra-state political conflicts relating 
to natural resources, raw materials, or the profit generated therefrom. Among these, 63 involved violence and nine passed the threshold of war (HIIK, 2015: 18). ${ }^{3}$ The Observatory of Mining Conflicts in Latin America, in comparison, counted 209 ongoing mining conflicts across the continent as of November 2015, directly affecting 313 local communities (OCMAL, 2015a). Many of these conflicts have the potential to erupt into violence if not properly addressed. This also holds true for the probably much higher number of local natural resources conflicts worldwide (OCMAL, 2015b).

Local resource conflicts are commonly characterized by the centrality of justice claims made by various actors. The claims that local communities from developing countries make tend to stand out in this regard as the socio-economic and metaphysical well-being of the majority of local community members frequently relies on (free access to) the local environment and associated resources such as water, land, and forests (Martínez-Alier, 2009; Hahn, 2010). By being - or perceiving themselves as being - increasingly cut off from their livelihood conditions due to resource exploitation projects, local communities often rise up and demand justice. Conflicts are subsequently triggered by the unequal distribution of costs and benefits that either create new conflicts between local communities and other actors (such as extractive corporations) or aggravate pre-existing conflicts among community members and between communities from the larger area. Numerous studies have shown that resource extraction projects tend to lead to a variety of negative socio-environmental impacts for local communities, particularly those which depend on subsistence agriculture (e.g. Kok et al., 2009; Greve, 2011). For example, ecological conditions - such as the availability of water and fertile soil - are prone to be affected by resource exploitation; at the same time, substantial increases in migrant workers may challenge local markets and social settings. Furthermore, the unequal distribution of benefits and the subsequent justice claims are connected to financial profits generated from resource extraction. Whether already underway or predicted for the future, state actors, along with local communities, commonly associate resource extraction projects with the generation of significant profits. These profits, in turn, are frequently distributed to specific stakeholders - primarily extractive companies and their financial and political backers - in a way that other actors (particularly local communities) perceive as highly unjust (MiningWatch Canada, 2013).

Typical conflict constellations involve the state, extractive companies, and local communities. The state, for its part, sets the regulatory framework and has economic interests in large-scale projects. The state is often perceived as siding with companies and as intervening in favour of economic interests (e.g. through regulatory action or the use of force against its own population).

In particular, large-scale extractive projects in weak zones of governance are often not only controversially discussed but have the potential to 
escalate into violence. Extractive corporations - often with global operations - are powerful actors who possess superior technical knowledge and have financial and other resources at their disposal. Weak states are particularly dependent on these capacities, a condition that negatively influences their bargaining power. When conflicts erupt on the local level, communities often end up directly approaching corporations - or even a transnational public - since state institutions are either absent or perceived as weak and biased towards the companies. Moreover, companies are, rightfully, deemed as having the financial and other capacities to mitigate the community's grievances. In order to receive more just benefits, locally rooted opposition movements often seek assistance from local, national, and global NGOs. These organisations, in turn, release public statements that convey empirically identifiable justice claims.

\section{Conceptualizing local justice claims}

Justice claims can be defined as claims for an entitlement (Welch, 1993; Müller, 2010). ${ }^{4}$ Justice claims are not an objective assessment but are based on the perceptions held by different actors. Hence, these claims express what actors believe they are entitled to (Welch, 1993: 19). While justice claims may entail the formulation of positive ideas about justice-related principles, we assume that complaints related to perceived injustices are central in the statements made by local communities involved in resource conflicts. As Amartya Sen (2009) has argued, while people often possess "a strong sense of injustice" (2), they may neither agree on the reason for this injustice nor on any ideas or principles for a perfectly just situation.

Justice claims can be "self-referential (i.e. the actor perceiving the injustice would be the aggrieved party) or other-referential (i.e. the actor perceives an injustice suffered by someone else)" (Welch, 1993: 19). In the case of local resource conflicts, self-referential justice claims are generally made by communities and their representatives. Other-referential justice claims could, for instance, be made by civil society actors, such as NGOs, on behalf of the affected communities.

One important objection to analysing justice claims is that actors might strategically make use of the justice theme to mask inherently instrumental objectives (Müller, 2010: 5). For example, local communities could use justice claims to mask their greed. Some scholars have, however, argued that justice arguments possess a different character (Welch, 1993: 20-21, 40-41): An experience of injustice may, for instance, trigger "a unique emotional response", and thus increase the likelihood of violent reactions (Welch, 1993: 20). Moreover, the justice motive only refers to benefits that people perceive as entitlements; as such, any argumentation for the pursuit of these benefits tends to be "categorical and deontological rather than utilitarian" (Welch, 1993: 21). Due to the methodological difficulties in differentiating between 'real' and 'pretended' rationales held by local 


\section{M. Coni-Zimmer et al.}

communities - or NGOs that claim to speak on their behalf - it proves useful to analyse more than just written or oral statements when inferring justice claims. In order to increase our understanding of these claims, contextual knowledge about conflicts along with data sources - such as observations made during field research - must likewise be taken into account. There are, however, no distinct criteria for distinguishing between 'real' and 'pretended' rationales - we have been well aware of this issue in the context of our research. Justice claims made by local communities need to be understood and carefully scrutinized within their context (Welch, 1993: 42).

For systematizing the empirical analysis, we conceive of justice claims as being sent by local communities and/or representative organizations (senders) to other involved actors (addressees) (see Figure 6.1). Senders assume that these addressees have a say in the ongoing conflict and are, in turn, able to provide governance. Following the work of political theorist Nancy Fraser (2005, 2009), we distinguish between three types of justice claims: (1) claims for redistribution, (2) claims for recognition, and (3) claims for representation.

\section{Redistribution}

Claims for (re)distribution are a major issue both within nation states and beyond territorial borders (Wuppertal Institut für Klima, Umwelt, Energie,

\section{Justice claims \\ Demanding distribution, recognition, and/or representation}

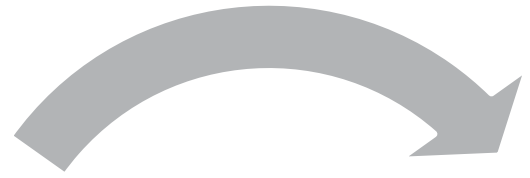

Senders

Local communities

(or organizations representing them)
Addressees

Companies, governments, civil society organizations, or others

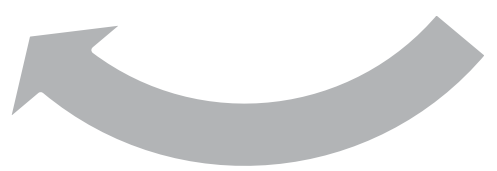

Governance initiatives

Located on local, national, and/or global levels

Figure 6.1 Local justice claims in resource conflicts (source: authors' own illustration). 
2006; Fraser, 2009). As large-scale resource extraction almost always negatively affects local communities, the latter most probably perceive an entitlement to some material benefits resulting from natural resource extraction on their land. The specific demands of local communities are an empirical question; they may demand some form of direct monetary compensation, ask for education or health services, or insist on jobs with the extractive companies.

\section{Recognition}

Recognition is a basic human need; hence, misrecognition has the potential to become a major source of frustration and conflict (Wuppertal Institut für Klima, Umwelt, Energie, 2006; Fraser, 2009: 14). As such, local communities might, first and foremost, demand respect and recognition from the state and/or corporations as comprising a group, including the acknowledgment of their existence and a serious consideration for their interests. ${ }^{5}$ Demands for recognition are often linked to claims for redistribution and representation as the recognition of a group by the state and corporations is a virtual precondition for achieving representation and redistribution. Beyond the aim of gaining this sort of recognition, claims may also involve admissions of the harms inflicted on a community. More fundamentally, claims may refer to recognizing particularities such as the differing ways of life adhered to by specific groups.

\section{Representation}

Justice claims can also be made with regard to "the opportunity of representation and equality before the law" (Daase and Humrich, 2011: 6). These claims relate to a procedural dimension of justice and aim at including certain groups in decision making on societal issues. Debates related to free, prior, and informed consent (FPIC) serve as a prime example as they are one of the main outcomes of struggles by local communities claiming self-determination and participation in decision making in the context of major resource extraction projects (Oxfam, 2010). In general, these demands may focus on claims for consultation or on gaining more formal decision-making rights from the state. Extractive companies can also become the targets of representation claims. They may, for example, ensure that community representatives have a strong say in the design and implementation of core business activities and various social programmes that most major companies conduct nowadays.

Although the disentanglement of distinct justice claims is essential, the relationship between the three dimensions is contested in theory and may also be blurred in the real world (Fraser and Honneth, 2003). Questions concerning the redistribution of material resources, for instance, almost inevitably have ramifications for questions of recognition as 
resources can only be distributed to actors who are recognized as possessing legitimate stakes in a given conflict. Likewise, if particular local communities demand inclusion in political processes, this may indicate justice claims that are related to both representation and (some form of) recognition. Nevertheless, we argue that the analytical distinction between the three dimensions is useful as a heuristic tool but the question of which dimension is most crucial in a given situation can only be answered by making use of empirical evidence.

\section{Governance initiatives as a response to justice claims}

Addressees of local justice claims can comprise a diverse set of actors. State actors intuitively come to mind since they bear prime responsibility for the population on their territory. State representatives are usually responsible for awarding contracts and licences to corporations and they provide the regulatory framework within which extractive projects are conducted. For developing countries in particular, extractive corporations are obvious targets of local justice claims as they are often much more visible to the affected communities than state actors. Justice claims made by local communities can, however, also be addressed to other actors, such as international organizations, development agencies, local and international NGOs, or even the corporations' home countries.

Generally speaking, addressees of local justice claims may react in different ways: They can attempt to ignore local demands or they can choose to provide local communities with the demanded benefits. Alternatively, addressees can try to convince communities that they have misconceived the scope or content of the perceived entitlements (Welch, 1993).

In recent years, a range of governance initiatives has emerged in response to resource conflicts including the Extractive Industries Transparency Initiative that promotes transparency in the oil, gas, and mining industry, the recent Open Contracting Partnership, aimed at publishing extraction contracts made between governments and companies, or the Kimberley Process, seeking to curb the trade of conflict diamonds (Darby, 2010; Carbonnier et al., 2011). In addition to their participation in a broad range of multi-stakeholder initiatives, transnational corporations are also recognized as important local governance actors, as they implement social responsibility and community development programmes or provide basic social services to the communities in which they operate (see Sydow, in this volume). The common feature of governance initiatives that involve the private sector is that they are usually voluntary in nature, that is, neither states nor corporations are legally bound to follow particular procedures or provide certain benefits. In terms of substance addressed by the initiatives, most of them are focused on issues of transparency whereas regulations of corporate behaviour that go beyond reporting requirements are rare. 
When responding to local communities' justice claims, addressees are likely to engage according to their own conceptions of justice. Whenever senders and addressees of justice claims share similar notions of justice, it is likely that the latter will design and implement governance initiatives that attempt to address injustices as perceived by the local communities, thereby contributing to the mitigation of local conflict dynamics. In contrast, when local communities and governance actors adhere to differing notions of justice, resource conflicts are more likely to occur and escalate. The following analysis does not focus on conceptions of justice held by addressees but rather on governance initiatives used to respond to senders' local justice claims. Given the prevalence of natural resource conflicts in developing countries, we expect empirical analyses to uncover serious justice gaps, meaning that governance initiatives do not respond to and satisfy local justice claims. This is based on the assumption that the latter - that is, corporations and state actors - probably adhere to substantially diverging notions of justice, which implies that their governance initiatives will not satisfy local demands. Alternatively, addressees may very well misperceive local justice claims and thus fail to address these claims adequately. In some cases, corporations might also knowingly misinterpret or fail to recognize claims made by communities if they are deemed too far-reaching or costly. The consolidation and/or escalation of conflict dynamics - rather than their mitigation - is a probable consequence of either case.

\section{Governing justice claims in mining conflicts in Peru}

\section{Natural resource conflicts in Peru}

Mining is the most important sector of the Peruvian economy. While its contribution to GDP ranged from 5 to 7 per cent between 2005 and 2011, its share of export revenues amounted to 50 to 60 per cent, while its contribution to tax revenues was 14 per cent in 2013 (CopperAcción, 2013). Copper and gold are by far the most important mining products in Peru. In 2014, 543 mining operations were carried out with an additional 440 in the exploration phase (Minem, 2014).

While highly important to the economy, mining is also highly controversial in public discourse in Peru and many of the hundreds of mining operations have caused conflicts on the local level, often manifesting in protest and blockades and not rarely erupting in violence. One of the reasons that mining conflicts in Peru have received a degree of notoriety is that they are unusually well documented. As of August 2015, Defensoria del Pueblo (2015) documented 142 social-environmental conflicts, out of which 94 were mining conflicts. ${ }^{6}$ These conflicts have been characterized by a set of typical characteristics that closely relate to Peru's political history. The largest portion of mineral extraction is taking place in the 
Andes, where the Andean inhabitants of indigenous origin (so-called campesinos) have experienced political and economic marginalization throughout Peru's history. When mining projects arrive in these Andean communities, the conflicts that arise regularly centre on the competition for scarce land and water resources, on environmental impacts, and the distribution of material benefits generated through mining (Bebbington and Williams, 2008). These conflicts often manifest in the form of protests and street blockades or attempts to forcefully enter mining compounds in order to bring operations to a halt (Arellano-Yanguas, 2011).

Formally speaking, the Peruvian state has devised a relatively broad set of policies and institutions for dealing with mining conflicts. The law requires comprehensive Environmental and Social Impact Assessments (ESIA) - including public hearings of affected communities - to be conducted before a mining project is licensed. A number of governmental agencies are tasked with overseeing mining projects to enforce environmental and social regulations. A national revenue redistribution scheme, titled Canon Minero, is also in place. This scheme prescribes the imposition of a tax that mining companies pay to the central government. Once received, part of the tax revenue is redistributed to the regions and districts in which the tax-paying mine operates. As a result, mining communities rank among the richest areas in Peru (Arellano-Yanguas, 2011). As for indigenous communities, Peruvian law permits a so-called Consulta Previa, that is, the right for these communities to be heard before any mining operation licence is conferred in their territory (Schilling-Vacaflor and Flemmer 2015; Flemmer and Schilling-Vacaflor, 2016). While these policies and institutional frameworks have the potential, in theory, to address or even prevent the emergence of conflicts, the problem - as is so often the case in countries with strong extractive sectors - lies in the implementation of these laws that requires strong governmental institutions.

While Peru is not necessarily a state with weak levels of governance, national institutions are not present throughout the entire territory, with institutional presence particularly limited in the Andes (Arellano-Yanguas, 2011). Furthermore, Peru's economy remains dependent on revenues from the mining sector, leading the government to strive for an investmentfriendly climate wherever it can. Consequently, the competencies of environmental authorities have been reduced time and again (Echave, 2015). When conflicts do erupt between local communities and mining companies, the government is often perceived as siding with the company rather than with the community. The police or military forces frequently forcefully repress anti-mining protests and make excessive use of violence (Misereor, 2013).

Against this background, the government has recently embarked on a policy of dialogue as a priority instrument for addressing mining conflicts. Since 2010, the so-called Mesas de Diálogo (Dialogue Tables) have been installed across the country whenever mining conflicts emerge. The mesas 
are designed as multi-stakeholder processes that involve the conflict parties - usually a mining company, a local community, and government authorities - and strive to settle the conflict through negotiation and compromise (Presidencia del Consejo de Ministros, 2013). The following subchapters will scrutinize one of the many dialogue processes in order to assess their potential for addressing local justice claims.

\section{Southern Peru Copper and the people of Ilo: misperceiving recognition as distribution}

The dialogue table under scrutiny was installed to deal with a conflict between the Southern Copper Corporation and the population of Moquegua. Civil society organizations (CSOs) in the port city of Ilo comprise the most outspoken sector of this local population, and their claims mostly involve environmental pollution resulting from the company's smelter and refinery operations (Grupo Iniciativa Anticorrupcion Ilo 2012; Scurrah 2013; Mesa de Diálogo de Ilo (n.d.)). Unless otherwise indicated, all empirical data used in the following subchapters was collected through participant observations during mesa sessions between June and July 2013.

\section{The conflict between Southern Copper and the town of Ilo}

The Southern Copper Corporation is one of Peru's oldest mining companies. It operates two large open-pit copper mines in the southern part of the country: the Cuajone project in the Moquegua region and the Toquepala project in Tacna. Additionally, Southern owns a copper smelter and refinery in the port city of Ilo. Copper production in Toquepala and refining in Ilo began as early as 1960 . The Cuajone mine, operational since 1976, still ranks 19th on the list of the world's largest copper mines and the Ilo smelter ranks 13th (International Copper Study Group, 2014: 12, 18 ). Due to both its sheer size and its long history in Peru, Southern is often seen and portrayed as a corporation with very privileged access to political decision-makers. Southern benefitted from tax exemptions granted by Peru's military government (1968-1980) while environmental regulations otherwise applicable to more recent mining projects have not been enforced on Southern for many years (Scurrah, 2013: 6-7).

Southern's operations have been the subject of severe social conflicts for almost six decades. Though this subchapter exclusively focuses on the conflict between Southern and the population of Ilo - whose CSOs have always been among the most vocal protagonist in conflicts with the company - the mining conflict operates on various levels and involves different communities across Peru's southern regions of Moquegua and Tacna.

Two specific issues have been central throughout the decades of struggle in Ilo and the Moquegua region. First, Southern has always held exclusive 
water-use rights for several of the most valuable fresh water sources in the Moquegua region, which happens to be located at the outskirts of the Atacama, the world's driest desert. As a result, the company has been able to satisfy its enormous water demand at no cost while the city of Ilo has increasingly faced water shortages (Balvín Diaz, 2004; Scurrah, 2013). Second, Ilo was heavily affected by the smelting facility's emissions. Southern's continued operations using technical standards from the 1960s resulted in extreme levels of air pollution in the city, which was repeatedly confirmed by various governmental authorities. Although the capture of 99 per cent of sulphur dioxide emissions in copper production has long been the standard elsewhere, Southern operated without any emission controls in Ilo for 35 years (Boon et al., 2001: 219). As early as 1968, a national law required Southern to begin reducing its emissions but was later repealed after a change in government. As recently as 1998 Southern completed an upgrade for capturing 33 per cent of emissions, still leaving them at levels that a WHO investigation deemed dangerous to human health (Boon et al., 2001: 219). The complete modernization of its operations that brought emissions controls up to current technological standards was only completed in February 2007 (Southern Copper, 2007).

Complaints about these emissions and their impacts arose just months after the smelting facility in Ilo had begun operations in 1960 (Scurrah, 2013: 6). In fact, Ilo's vibrant CSOs emerged as a result of this very conflict. These organizations have led many street protests and have repeatedly tried to use Peruvian state institutions to forward their claims. For example, they sought administrative investigations by responsible authorities, such as the national water authority (Autoridad Nacional del Agua, ANA) and the environmental monitoring agency (Organismo de Evaluación y Fiscalización Ambiental, OEFA). They have filed lawsuits in Peru and even took their claims to the United States when US investors still held a majority share in Southern (Interview 1). In the course of these struggles, the organizations built valuable human capital, since technical expertise was needed to provide evidence of the dangerous levels of emissions and their impacts on air quality, human health, or agricultural production (Interview 2; Scurrah, 2013: 40).

In 2007, when Southern completed the modernization of its facilities, the CSOs based in Ilo achieved their primary objective of significantly reducing harmful emissions. Justice claims against Southern did not, however, subside as a result. On the contrary, Ilo's population subsequently demanded material compensation for 46 years of uncontrolled emissions (LABOR, 2006; Mesa de Dialogo de Ilo, n.d.).

From an analytical perspective, it is reasonable to classify this demand for compensation as a recognition-related justice claim. At first sight, the local claims undoubtedly aimed at (re-)distribution: Ilo's population now demanded material benefits to compensate for past damages to their lives. At the same time, however, the people of Ilo also demanded the official 
acknowledgement of their suffering and the subsequent recognition of the company's wrongdoings. Hence, recognition was particularly important to the local actors. This became evident in many personal and written exchanges in which CSOs complained that company representatives, among other things, showed "a lack of respect for the people of Ilo when alleging that there had been no environmental impacts of the metallurgical operations" (Interview 3).

\section{The governance response: $a$ mesa de diálogo}

Mesas de diálogo have become popular all across Peru over the past decade. They are one of the most important policy instruments for the central government in response to the many social conflicts revolving around mining projects throughout the country (Presidencia del Consejo de Ministros, 2013). On the initiative of the new regional government led by Manual Vizcarra in 2012, a new mesa was established to deal with the conflicting issues involving Southern in the Moquegua region. This initiative complemented two other, closely related, mesa processes: In Moquegua itself, the regional government had successfully concluded a mesa with the incoming mining company, Anglo American, while local communities in the Tacna region successfully negotiated a new deal with Southern (Interviews 1, 2, and 4). The mesa with Anglo not only succeeded in securing an extraordinarily high social contribution from the company to the region, but also - and more importantly - resulted in significant changes in the mining company's operational plans, particularly with regards to its water use management plans (Interviews 5 and 6; Scurrah 2013; see also Elliott 2013). As a result of the mesa, Anglo's operations would greatly reduce the company's reliance on freshwater resources that have competitive uses in local agriculture. The mesa with Southern in Tacna, for its part, was primarily lauded for the social contribution that Southern agreed to pay in exchange for the expansion of its Toquepala mine. Following these recent and proximate examples, Martin Vizcarra, at that time the regional president of Moquegua, proposed an analogous process with Southern and succeeded in securing its implementation (Interview 2; Scurrah, 2013).

The institutional design of the Southern mesa resembled the model that has been rolled out all across Peru. It was created by a ministerial resolution and is tripartite in nature, incorporating government representatives along with CSOs and the company (Presidencia del Consejo de Ministros, 2013). The mesa has likewise adopted some regional particularities copied from the Moqeuguan mesa with Anglo. Among these regional specificities was the regional government's very strong role in the proceedings. More precisely, the plenary was led by the regional president, who had also presided over the mesa with Anglo and was seen to have personally contributed to its success (Flohr, 2014). The Southern mesa met regularly 
between October 2012 and April 2014. Its mandate was broadly formulated as "analysing the hydrological, environmental, and mining problems with Southern in the region of Moquegua" (Mesa de Diálogo, 2012: 1, authors' own translation).

\section{Misperceived justice claims}

The mesa had a broad mandate to "analyse" a variety of issues related to the conflict with Southern. ${ }^{7}$ From its first plenary sessions, however, it became evident that the demand for compensation for environmental damages would be a central issue for many mesa participants, particularly civil society representatives (Grupo Iniciativa Anticorrupcion Ilo, 2012). The latter regularly raised this concern at plenary sessions, often resulting in heated confrontations with representatives from Southern. The company's representatives highlighted the fact that this topic was not part of the mesa's mandate and that they were not ready to discuss the issue. Southern argued that a claim for compensation was totally ill-founded as its operations had always complied with the applicable laws. Hence, the alleged past environmental impacts were no longer a matter for discussion since large investments into upgrading the refinery and smelting facility to current technical standards had solved the problem (Interviews 7 and 8).

For the people of Ilo, the technological upgrade was insufficient for correcting the past harm they had suffered, and they therefore continued to demand compensation. While both social contributions and compensation entail a transfer of money, compensation also responds to claims for justice through recognition (of past harm inflicted) while social contributions do not. Consequently, the conflict between Southern and the community in Ilo was reinforced rather than mitigated. Any time this topic emerged, the discussions at the mesa would stall. For Southern, discussing the issue of compensation was completely off the table; for the people of Ilo, compensation was their primary demand. The controversy was clearly understood as an issue of justice, specifically justice as a form of recognition. This is evident in light of the statements made during mesa sessions where citizens of Ilo reacted with indignation to propositions by Southern to make a (financial) 'social contribution' to the region of Moquegua in exchange for a continued 'social licence to operate'. Ilo representatives frequently intervened to clarify that, in their view, any such discussion about a social contribution was meaningless unless a debate about 'compensation' for the environmental and health impacts the people had suffered from Southern's operations in the past was started.

The fact that the people of Ilo demanded compensation instead of a contribution indicates that this was a matter of justice as recognition (as victims of mistreatment at the hands of Southern) rather than justice as distribution - even though material benefits would ultimately be distributed one way or another. However, the nature of this local justice claim 
was misperceived by most of the mesa participants and by Southern's representatives in particular. According to the latter, the mesa in the Moquegua region was a mistake in the first place as the company did not plan to make changes in their Moqugua operations and was therefore not obliged to secure any form of societal consent. In Southern's view, the only reason that the people of Ilo demanded a mesa in Moquegua related to the fact that the company had agreed to pay a social contribution in Tacna and Moquegua sought to receive the same benefits. As the company argued, the contribution in Tacna was due to an expansion it planned for its Toquepala operations; since the company did not plan any expansion in Moquegua, there was no need to negotiate a benefit-sharing agreement with the locals.

As is evident in the above analysis, attempts to resolve the long-standing conflict pertaining to Southern's operations - and its past emissions in particular - through a mesa de diálogo were ill-conceived from the start. The Peruvian Mesas are, by their very nature, meant to facilitate collaborative processes that bring about compromise solutions through multi-stakeholder dialogue. Such an instrument could not address the central claim of the population of Ilo - compensation of past damages. Claims for compensation are invariably confrontational rather than dialogue-oriented. One side believes it has been unduly harmed by the other, while the other side is unlikely to voluntarily acknowledge and act upon this claim.

Indeed, even if the party inflicting damage accepted its responsibilities and 'voluntarily' paid compensation, this outcome would still most likely not satisfy the party making the claim. This owes to the fact that claims for compensation inherently imply claims for rectification or punishment. Claim-makers want the accused parties to be faulted and publicly punished by a super-ordinate third party; this is the only outcome that would suffice to satisfy their recognition-related demands. In formal legal systems, courts, for example, provide this form of recognition (and often impose some type of compensation), particularly in criminal proceedings that result in identifying guilt. For cases in which a proceeding is sought by one party, out-of-court settlements are often not an option since the recognition-related claims remain unfulfilled without a formal identification of guilt - despite the pecuniary result being very similar.

In fact, the people of Ilo were seeking an official and ideally legal identification of Southern's wrongdoing, which could not have come from Southern itself. In this sense, the mesa, with its collaborative proceeding, was an inappropriate venue for the compensation claim from the very beginning. Even if two thirds of its tripartite structure were ready to publically recognize Southern's 'guilt', the company would have always refused. This deficiency of the mesa as a governance instrument for the mining conflict was apparently overlooked by all the parties involved. The regional government knew that the past damages done by Southern would be a central issue and even so installed the mesa. The Ilo-based CSOs expected 
that their claim for compensation would finally be heard. Southern apparently believed that it could use the mesa to secure its social licence to operate without dealing with compensation claims. ${ }^{8}$

\section{Conclusion}

Justice claims are ubiquitous in local conflicts involving natural resources. In this chapter, we sought to present an analytical framework for studying such conflicts. This framework departs from the justice claims made by local communities defined as perceived entitlements. The framework differentiates among three dimensions of justice: justice as distribution, representation, and recognition. The assumption is that empirical analyses reveal serious gaps in justice between local communities - as senders of these claims - and their addressees - be they corporations, state actors, or others. Consequently, addressees may simply decline local claims or their governance activities will not satisfy the senders. Alternatively, addressees may misperceive the nature of local justice claims and therefore fail to properly address them. The consolidation and/or escalation of conflict dynamics is a likely consequence in either case.

This argument was illustrated through a case study of a local mining conflict in Peru. In this conflict, the population of the port city of Ilo in Peru's Moqeugua region had been protesting against the operations of the mining company Southern Copper and its metallurgical complex in Ilo for decades. The population demanded that Southern assume responsibility for the environmental and health impacts it had inflicted on Ilo. While the community demands compensation for these impacts, attempts at resolving the conflict have regularly failed since they do not take the justice dimension inherent in a claim for compensation into account: seeking compensation for past damages involves a recognition-based claim. All attempts at resolving the conflict, including the most recent multi-stakeholder dialogue process, have, however, resulted in Southern offering the community a social contribution, at best - which resembles a distribution-based claim.

The proposed framework for studying empirical justice claims can be applied to local conflicts in different countries and in relation to various types of natural resources. A result of further research could be the identification of similarities and differences of justice claims. To what extent are justice claims - similar in regard to their content and addressees - put forward by local communities in different regions of one country or across several countries? To what extent do justice claims have regionally or culturally specific characteristics? What can account for the similarities and differences identified? Further empirical research might also highlight cases in which local justice claims have more comprehensively been addressed and indicate whether this has led to more effective mitigation of the underlying resource conflicts. 


\section{Notes}

1 The authors would like to thank Mara Funda for her highly professional research assistance.

2 The authors are immensely thankful to all stakeholders in Moquegua who supported this work by contributing their first-hand insights.

3 According to the revised definition of the HIIK (2015), a political conflict

is a positional difference, regarding values relevant to a society - the conflict items - between at least two decisive and directly involved actors, which is being carried out using observable and interrelated conflict measures that lie outside established regulatory procedures and threaten core state functions, the international order or hold out the prospect to do so.

4 The approach chosen is in line with the Just Peace Governance research programme at the Peace Research Institute Frankfurt, where the empirical investigation of justice claims and justice-related conflicts is one of the main objectives (see Müller, 2010; Daase and Humrich, 2011; Poppe and Wolff, 2013).

5 Note, in this context, that the very implementation of resource extraction projects may contribute to processes of identity and group formation in the first place.

6 Note that the marked difference between the Peru-specific figures presented in this section and the world-wide, as well as Latin America-specific, figures presented above seems to primarily result from an unfortunate interplay of discrepancies in definitions, different ways of counting, and severe data gaps.

7 Indeed, the very mandate of the mesa regularly became the topic of fierce debate. During the sessions, Southern would often point out that the mesa was overstepping its competencies when it went beyond an 'analysis' of the problems and sought accords on possible solutions.

8 At the time of writing (September 2015), the Southern mesa in Moquegua was ongoing because a technical commission, named 'social contribution', had been unable to work out a compromise. Though field research for this chapter was last conducted in 2013, the misperception of justice claims presented here is likely to remain the principal reason that the mesa participants remain unable to produce a mutually acceptable resolution for the local mining conflict up to the present day.

\section{References}

Arellano-Yanguas, J. (2011) 'Aggrevating the resource curse: decentralisation, mining and conflict in Peru', Journal of Development Studies, vol. 47, no. 4, 617-638.

Balvín Diaz, D. (2004) 'Agua, minería y contaminación', http://bvs.per.paho.org/ texcom/cd048433/balvin.pdf [accessed 1 December 2015].

Basedau, M. and Lay, J. (2009) 'Resource curse or rentier peace? The ambiguous effects of oil wealth and oil dependence on violent conflict', Journal of Peace Research, vol. 46, no. 6, 757-775.

Bebbington, A. and Williams, M. (2008) 'Water and mining conflicts in Peru', Mountain Research and Development, vol. 28, no. 3, 190-195.

Beitz, C. R. (1979) Political Theory and International Relations, Princeton University Press, Princeton, NJ. 
Boon, R. G. J., Alexaki, A., and Becerra, H. E. (2001) 'The Ilo clean air project: a local response to industrial pollution control in Peru', Environment and Urbanization, vol. 13, no. 2, 215-232.

Carbonnier, G., Brugger, F., and Krause, J. (2011) 'Global and local policy responses to the resource trap', Global Governance, vol. 17, no. 2, 247-264.

Collier, P. and Hoeffler, A. (2004) 'Greed and grievance in civil war', Oxford Economic Papers, vol. 56, no. 4, 563-595.

Collier, P., Hoeffler, A., and Rohner, D. (2009) 'Beyond greed and grievance: feasibility and civil war', Oxford Economic Papers, vol. 61, no. 1, 1-27.

CopperAcción (2013) Actualidad Minera del Perú, no. 171, www2.congreso.gob. pe/sicr/cendocbib/con4_uibd.nsf/8B706E253E43C8D505257C1B006E6047/\$FI LE/171_AMP_Agosto_2013.pdf [accessed 2 October 2015].

Daase, C. and Humrich, C. (2011) 'Just peace governance: research program of the Peace Research Institute Frankfurt', PRIF Working Papers, no. 1, www.hsfk.de/ fileadmin/downloads/PRIF_WP_01.pdf [accessed 28 February 2013].

Darby, S. (2010) Natural Resource Governance: New Frontiers in Transparency and Accountability, www.transparency-initiative.org/wp-content/uploads/2011/05/ natural_resources_final1.pdf [accessed 3 December 2015].

Defensoria del Pueblo (2015) 'Adjuntía para la prevención de conflictos sociales y la gobernabilidad', www.defensoria.gob.pe/conflictos-sociales/conflictosportipo. php [accessed 1 October 2015].

Echave, J. de (2015) 'Auf der Suche nach Auswegen: in Peru spaltet der Bergbau das Land', Südlink, vol. 173, 22-23.

Elliott, H. (2013) 'Mining and development in the Andes: the Quellaveco Project in Peru and Anglo American's approach', Lecture at the School of Advanced Study, University of London, 4 March, www.youtube.com/watch?v=vLCrktp SG-o [accessed 30 November 2015].

Ferguson, J. (2006) Global Shadows: Africa in the Neoliberal World Order, Duke University Press, Durham, NC.

Flemmer, A. and Schilling-Vacaflor, A. (2016) 'Unfulfilled promises of the consultation approach: the limitations to effective indigenous participation in Bolivia's and Peru's extractive industries', Third World Quarterly, forthcoming.

Flohr, A. (2014) 'Natürliche Ressourcen, lokale Konflikte und Dialog als Antwort: das Beispiel Peru', HSFK Report, no. 11, www.hsfk.de/fileadmin/downloads/ report1114.pdf [accessed 1 December 2015].

Fraser, N. (2005) 'Reframing justice in a globalized world', New Left Review, vol. 36, 69-88.

Fraser, N. (2009) Scales of Justice: Reimagining Political Space in a Globalizing World, Columbia University Press, New York.

Fraser, N. and Honneth, A. (2003) Redistribution or Recognition? A PoliticalPhilosophical Exchange, Verso, London.

Greve, J. (2011) 'Die dunkle Seite des Rohstoff-Booms: wie der Bergbau die Menschenrechte untergräbt', Blätter für deutsche und internationale Politik, vol. 8, no. $11,71-80$.

Grupo Iniciativa Anticorrupcion Ilo (2012) 'Indemnización o compensación de Southern: al momento se percible falta de unidad y poca predisposición para formular propuestas', http://grupoiniciativaanticorrupcionilo.blogspot.de/2012/10/ indemnizacion-o-compensacion-de.html [accessed 1 October 2015]. 
Hahn, H. P. (2010) 'Ethnologische Perspektiven auf Armut', Entwicklungsethnologie, vol. 18, nos 1 and 2, 113-128.

HIIK (Heidelberg Institute for International Conflict Research) (2015) Conflict Barometer 2014, www.hiik.de/de/konfliktbarometer/pdf/ConflictBarometer_2014. pdf [accessed 7 August 2015].

International Copper Study Group (2014) 'The world copper factbook', www.icsg. org/index.php/component/jdownloads/finish/170/1997 [accessed 2 October 2015].

Kok, A., Lotze, W., and Jaarsveld, S. van (2009) 'Natural resources, the environment and conflict', www.accord.org.za/downloads/reports/Natural_Resources_ Conflict.pdf?phpMyAdmin=ceeda2df659e6d3e35a63d69e93228f1 [accessed 11 April 2013].

LABOR (2006) 'Report of the forum panel "Medio ambiente y compensación por daños"', www.labor.org.pe/?p=469 [accessed 1 October 2015].

Latouche, S. (1997) 'Paradoxical growth', in M. Rahnema and V. Bawtree (eds) The Post-Development Reader, Zed Books, London, 135-142.

Martínez-Alier, J. (2009) 'Social metabolism, ecological distribution conflicts, and languages of valuation', Capitalism Nature Socialism, vol. 20, no. 1, 58-87.

Mesa de Diálogo (2012) 'Sesion nro. 02: Acta de reunion del grupo de trabajo multisectorial "Mesa de diálogo para analizar la problemática hídrica, ambiental, minera y las propuestas de desarrollo del Departamento de Moquegua", http:// regionmoquegua.gob.pe/web13/file/dialogo/act_002_2012_mesa.pdf [accessed 2 October 2015].

Mesa de Diálogo de Ilo (n.d.) http://mesadedialogoilo.blogspot.de/ [accessed 2 October 2015].

Minem (2014) 'Perú: País minero. Principales unidades en producción y proyectos en exploración', www.minem.gob.pe/minem/archivos/file/Mineria/PUBLICACIONES/ MAPAS/2014/MAPA(Alta).pdf [accessed 1 October 2015].

MiningWatch Canada (2013) 'Mining and development: how much will it cost us to clothe the naked emperor?', www.miningwatch.ca/blog/mining-and-developmenthow-much-will-it-cost-us-clothe-naked-emperor [accessed 8 April 2014].

Misereor (2013) Menschenrechtliche Probleme im peruanischen Rohstoffsektor und die deutsche Mitverantwortung, www.misereor.de/fileadmin/publikationen/ studie-rohstoffe-menschenrechte-in-peru.pdf [accessed 3 December 2015].

Müller, H. (2010) 'Justice and peace: good things do not always go together', PRIF Working Papers, no. 6, http://hsfk.de/fileadmin/downloads/PRIF_WP_06.pdf [accessed 12 March 2014].

OCMAL (Observatorio de Conflictos Mineros de América Latina) (2015a) 'Mapa de conflictos mineros, proyectos y empresas mineras en América Latina', http:// mapa.conflictosmineros.net/ocmal_db/ [accessed 30 November 2015].

OCMAL (Observatorio de Conflictos Mineros de América Latina) (2015b) Conflictos Mineros en América Latina: Extracción, Saqueo y Agresión: Estado de Situación en 2014, www.conflictosmineros.net/agregar-documento/publicacionesocmal/conflictos-mineros-en-america-latina-extraccion-saqueo-y-agresion-estadode-situacion-en-2014/download [accessed 30 November 2015].

Oxfam (2010) Guide to Free, Prior and Informed Consent, www.culturalsurvival. org/sites/default/files/guidetofreepriorinformedconsent_0.pdf [accessed 3 December 2015].

Pogge, T. W. (ed.) (2002) World Poverty and Human Rights: Cosmopolitan Responsibilities and Reforms, Polity Press, Cambridge, UK. 
Poppe, A. and Wolff, J. (2013) 'The normative challenge of interaction: justice conflicts in democracy promotion', Global Constitutionalism, vol. 2, no. 3, 373-406.

Presidencia del Consejo de Ministros (2013) Institucionalizando el Diálogo a un Año de Gestión: Experiencias y Aportes de la ONDS - PCM, http://onds.pcm. gob.pe/publicaciones/Publicacion_Anual.pdf [accessed 1 October 2015].

Schilling-Vacaflor, A. and Flemmer, R. (2015) 'Conflict transformation through prior consultation? Lessons from Peru', Journal of Latin American Studies, vol. 47 , no. $4,811-839$.

Scurrah, M. (2013) 'Mining conflicts and institutional innovation in the Moquegua and Tacna regions of southern Peru', paper presented at the Congress of Latin American Studies Association, Washington, DC, 29 May-1 June.

Sen, A. (2009) The Idea of Justice, Belknap Press of Harvard University Press, Cambridge, MA.

Southern Copper (2007) 'Southern Copper Corporation completed the modernization of its Ilo smelter', press release, 1 February, www.southernperu.com/ENG/ invrel/INFDLPressRelease/pn010207.pdf [accessed 30 November 2015].

Welch, D. A. (1993) Justice and the Genesis of War, Cambridge University Press, Cambridge, UK.

Wenar, L. (2008) 'Property rights and the resource curse', Philosophy \& Public Affairs, vol. 36, no. 1, 2-32.

Wuppertal Institut für Klima, Umwelt, Energie (2006) Fair Future: Begrenzte Ressourcen und globale Gerechtigkeit, C. H. Beck, Munich.

\section{List of interviews}

Interviews were conducted in addition to participant observation at mesa sessions. All interviewees were promised anonymity.

Interview 1: Focus group discussion with Ilo civil society, 1 July 2013.

Interview 2: Civil society member, Lima, 1 May 2013.

Interview 3: Written communication with civil society member, Ilo, on file with the author.

Interview 4: Representative of regional government, Moquegua, 28 June 2013.

Interview 5: Representative of Anglo American, Global Headquarters, 18 April 2013.

Interview 6: Representative of Anglo American, Peruvian Headquarters, 7 June 2013.

Interview 7: Representative of Southern Copper Corporation, Moquegua, 28 June 2013.

Interview 8: Representative of Southern Copper Corporation, Ilo operation, 9 July 2013. 


\title{
7 Corporate social responsibility \\ A globally applicable tool to manage community-company relations in the extractive sector? ${ }^{1}$
}

\author{
Johanna Sydow
}

\section{Introduction}

When I arrived in New Abirem, Ghana in August 2009, the multinational mining company Newmont had not yet started its operations. It was establishing alternative livelihood programmes, community administered development funds, and trainings for affected communities. Newmont was, it seemed, welcomed by the community, considered more responsible than other mining companies operating in Ghana. Newmont's Corporate Social Responsibility (CSR) programmes, administered through a newly established NGO, were praised by different local institutions as being unique and extensive. Meanwhile, at the global level, the US-based mining company, one of the world's leading gold producers, is part of the UN Global Compact and the Voluntary Principles of Human Rights and Security, which set certain standards that engaged corporations have to meet.

In 2010 in Peru, where Newmont has been extracting gold since 1993, I encountered a very different picture of corporate-community dynamics. Community relations with Newmont were marked by deep mistrust and open contestation. Like in Ghana, Newmont had established an NGO, when it began operations in the early 1990s, to manage its CSR issues and community relations. Yet, as we will see, the NGO in Peru was seen in a rather different light - more as an instrument of corporate interests than a vehicle of community upliftment - to the one newly set up in Ghana.

CSR, which this chapter examines more closely in the context of Newmont's operations in Ghana and Peru, has become common practice within the extractive sector over the past two decades and is the focus of an increasing body of academic literature. Scholarly perspectives concerning its impacts are often diametrically opposed. While some see CSR optimistically as a way of humanizing business (Matten and Crane, 2003), many doubt that CSR prevents the negative social and environmental impact of multinational enterprise (Gilberthorpe and Banks, 2012). Going a step further, some argue that CSR grants the company more control and power over the government and local community (Rajak, 2011). This chapter will further investigate this argument, elaborating on the capacity of CSR as a 
standardized strategy and set of corresponding technologies to exercise corporate power and discipline in very different local contexts.

According to Ferguson (1994), the application of a standardized programme is possible if the problem addressed is de-contextualized and discursively transformed into a technical problem. Through this decontextualization, power structures are made invisible, and poverty causes and 'development measures' are de-politicized. Consequently, Ferguson argues, in the context of development operations, which he describes as "anti-politics" machines, highly political agendas can be implemented without seeming to be political. CSR in the extractive sector is promoted as this kind of standardized solution (Rajak, 2011: 18). In this sense, CSR can provide mining companies with a depoliticizing mechanism such as this, to veil or contain the underlying and emerging issues of inequality and marginalization - for example, in the case of displacement and resettlement of local populations. Questions of fairness of the implemented measures fade into the background and are quietened by the argument of development. Such questions could refer to the process of implementation and outcome. Fairness in regard to process can mean that possible consequences of operations are outlined, all relevant stakeholders are included in decision-making processes, weak stakeholders receive special support, and possible results of participatory processes are accepted. Only if a process is perceived as being fair, there can be a 'fair' and acceptable outcome. In any case, the perception of resource fairness varies from social positions and different local contexts.

My analysis shows how Newmont approaches local communities on different continents in a standardized way. Following its one global model developed in abstraction from the particular contexts of operations, it aims for standardized, manageable outcomes. Scott (1998) argues that a state, to a large extent, gains power over its citizens - as corporations do over surrounding populations (Ferguson, 2005) - by making society administrable through the simplification of qualitative matters into measurable units. From this perspective, people are uniform, measurable units without any specific skills or experience (Scott, 1998: 346). Thus, a standardizing view on communities would provide the company with more control. Ferguson (1994) also argues that these standardized solutions often fail to achieve the targeted development result, but still have an (unintended) side effect. It is an influential "instrumental effect" (Ferguson, 1994: 256), which enables the exercise of power over the target population. This power is a "bureaucratic power" (Ferguson, 1994: 274) exercised through the administration of development projects over the surrounding population. Instead of working with the state, CSR works in the "spaces where the state fails to deliver" which "creates opportunities for new unintended consequences to flow from CSR interventions" (Sharp, 2006: 220).

Yet, the ethnographic evidence presented here from Newmont's operations in Ghana and Peru show that standardized methods do not necessarily produce standardized effects of control. Newmont had been present 
in Peru for much longer than in Ghana, but was not able to adjust its standardized concepts to the local context and to make use of instrumental effects. Its grand CSR concept could not prevent huge protests against its new mining project 'Conga'. Indeed, violent clashes with the police led to a temporary suspension of the venture (Osterman and Wilson, 2012).

While Scott (1998) and Ferguson $(1994 ; 2005)$ give great insight into the workings of power, which will be particularly useful in the discussion of Newmont's techniques, they neglect the relevance of counter-conduct. As I will show, they fundamentally underestimate the agency of local actors. Based on my ethnographic fieldwork at Newmont's site of operations in Ghana (July-October 2009) and Peru (November 2010), I set out to examine the power and limitations of corporate techniques alongside the perspectives and agency of local actors, through a comparison of local responses to standardized corporate techniques. In Ghana, my core data include extensive field notes from participatory observation and 14 semistructured interviews with different employees of the mining company, affected and non-affected local inhabitants, members of the district assembly and other local institutions in the context of Newmont's preparation for a new mining operation in New Abirem, as well as with activists, NGOs, and government bodies outside of the place of operation. Moreover, participatory observation from the three months of research, official documents, newspaper articles, and 40 additional interviews at four different mining sites broadened my understanding of the mining sector in Ghana. In Peru, I analysed the company-community relations on the basis of participatory observation, ten semi-structured interviews with local and international NGOs, the NGO responsible for Newmont's CSR programme, community leaders, and other community members affected by planned mining operations in Cajamarca and surroundings as well as international news, blogs of activists, and social media sites.

The comparative angle of one company operating at two different places across two continents serves as a unique basis to better comprehend the dynamics of standardized tools in different contexts. Moreover, the different stages of the two operations - one being an expansion of a longstanding project, the other being a prospective operation far away from other operations of the same company - reveals how a temporal dimension, the stage of operation, influences corporate strategies as well as local response. The comparison between two different continents with supposedly differing discourses on the benefits and risks of mining, a difference in experience with mining, differing legal frameworks, and different networks available will show that standardized techniques cannot always adequately deal with complexities at the local level nor fully absorb counter-conduct and the agency of local actors. Ultimately, I challenge the conception that standardized techniques of governance yield a standardized effect of domination and argue instead that local specificities, agency, and counterconduct shape the effects of corporate techniques. 


\section{J. Sydow}

\section{The power and function of CSR: the academic debate}

Much academic work has been published on the social and environmental impacts of mining across different disciplines reaching back to colonial times (Lentz, 2008). Even though the risks of resource extraction are well known (Sachs and Warner, 1997), mining is still promoted as a key driving force for development (Akabzaa, 2000). While some scholars see this issue as a matter of resource and revenue management, more critical voices have emerged that question resource-based economies and resource extraction in general, especially in Latin America (Gudynas, 2012).

\section{CSR discourse}

In response to this general critique, CSR programmes have emerged in the extractive sector (Gilberthorpe and Banks, 2012: 185). However, CSR itself has become the focus of an increasingly polarized literature. On the one hand, we find authors who welcome the emergence of CSR and endorse initiatives like the Global Compact as the foundation for voluntary engagement in environmental issues and human rights (Cetindamar and Husoy, 2007). Others go so far as to argue that companies should step into the empty space which governments fail to develop and correct this failure (Hopkins, 2012). Gifford and Kestler's (2008) study on Newmont in Peru views CSR as a medium to earn the 'social licence' to mine, providing an adequate mechanism to control the behaviour of corporations. On the other hand, many see this development more critically, arguing that CSR is a façade that helps companies to formally satisfy different expectations, while maintaining practices which are strongly decoupled from the rhetoric of compliance (Hiß, 2006). In this sense, CSR distracts from the demands for stronger regulations (Cetindamar and Husoy, 2007). Some authors go further, arguing that CSR is a tool that shapes "social relations and projects according to a particular set of corporate interests and values" (Rajak, 2011: 12). Rajak points to a discursive power that lies with CSR, which is often dismissed. This provides companies with a "moral mechanism through which their authority is extended over the social order" (2011: 13). By creating cohesion and local bonds with actors of the community, companies can gain strength. Thus CSR, rather than being a philanthropic and altruistic act, offers mining companies a way to increase their agency and control. This insight is the starting point of my analysis.

Among the studies which examine CSR as a corporate tool to manage company-community relations, a few key studies highlight the way in which companies use social programmes to achieve control at the local level. Kapelus (2002) identifies different corporate strategies to stay in "good stead with potential financiers and local elites" (291). He shows how a company gains control by limiting participation to symbolic participation. A so called 'divide and rule' strategy monitored by Sawyer (2004) 
is the creation of allies and inequality through the strategic implementation of social programmes. These studies give detailed insight into the power of CSR to channel local actors' behaviour, while also revealing the common corporate logic and techniques in diverse contexts. Nevertheless, as Arellano-Yanguas (2011: 634) argues, companies are not always successful at eliminating conflicts over their operations through their CSR programmes, and other factors also play an important role. Indeed, as this chapter shows, CSR does not always achieve its intended ends and yield the expected benefits to companies.

\section{Global yet local}

According to Rajak (2011), "the power of CSR [...] lies, to a great extent, in its capacity to claim global applicability (underwritten by supposedly universal market values)" (218). Thus, CSR is promoted as a universally applicable and locally adjustable tool that is implemented by globally active companies like Newmont in different local contexts. Different institutions and standards, like the international protocol of Voluntary Principles on Security and Human Rights provide a scheme into which local CSR programmes are meant to fit (Gilberthorpe and Banks, 2012). Thus global norms shape the content and processes of CSR, not least by ensuring a respectable global image, which is important for multinational companies when ensuring future investments. This construction of CSR implies that global schemes can be designed in abstraction of local specificities but capture, adjust to, and deal with local structures in a more or less predictable way. It implies that standardized CSR can shape, control and keep its 'community' content by abstracting from cultural and historical differences and so on.

There is little academic literature that systematically analyses and compares the reaction of communities to similar corporate techniques by the same company in different national contexts in order to examine the assumption of their global applicability. Consequently, there is a lack of understanding of their limits and if and to what extent contextual factors, as opposed to standardized strategies, influence local inhabitants' reaction towards mining operations. When set alongside Li's (2009) study of a Newmont mine in Peru, my study of Newmont's community engagement in Ghana and Peru makes clear that despite the major geographical, social, environmental, political, and economic differences, the company deploys the same toolkit and technologies in its attempt to manage the community. At the same time, the ethnographic evidence presented in this chapter reveals how Newmont's claims to universal applicability are highly problematic and how contextual factors, in particular the agency of local actors, have a huge impact on its effects. 


\section{J. Sydow}

\section{Community relation management: the concept of Denver}

Newmont's multinational corporation's management of corporate responsibility is highly centralized and standardized. The "ultimate oversight responsibility for the management of community relationships lies with the Board of Directors [...] in Denver" (Smith and Feldman, 2009: 17). The company's standards are developed according to the management goals and global standards like the Global Compact, Extractive Industry Transparency Initiative (EITI), or ISO 14001 and then deferred to the regional offices to be implemented.

This task is based on a good amount of global thinking and reduction of complexity by abstraction. Experiences from certain selected mine sites are gathered, generalized, and then transformed into strategies with intended universal applicability. This is seen clearly in Newmont's Community Relation Review, which was demanded by a shareholder's meeting in 2007 in response to protests that started to hamper Newmont's operations (Smith and Feldman, 2009: 1). The review offers general "lessons learned". In the following years, these have become criteria according to which the different mining sites are evaluated in an annual letter to the company's shareholders.

One such "lesson learned" is dealing with the implementation of a better monitoring system for community relations at the regional level. It results from the identification of a gap between implemented programmes and Newmont's global standards on the paper. The external reviewers related this gap to the weakness of its reporting scheme for social relations. They argue that in order to "establish effective systems of accountability, Newmont will need to develop key performance indicators and metrics for community relations performance" (Smith and Feldman, 2009: 133). Inevitably, the processes of measurement and evaluation themselves have a significant impact on the object of evaluation (Scott, 1998: 348), as community relations are transformed into numbers in order to produce the necessary standardization and therefore better 'manage performance'.

An essential element of the global corporate standard is the establishment of local Consultative Committees and Social Responsibility Forums, prescribed by the head office to all its operations in order to manage diverse and potentially unpredictable situations. The Social Responsibility Forum is celebrated as a best practice mechanism for participatory community investment and concern management to be implemented at the different sites. Here, the company seeks to enable a degree of local agency but within a controlled realm. By bureaucratizing and institutionalizing the interface between community and company, new structures are implemented to exercise power.

The following section moves on to explore the implementation of different elements (community concern management, participatory investment, engagement with the government at different levels, creation of local 
jobs and business opportunities) of the global company-community relations standard generated in Denver at the company's local operational sites in Ghana and Peru. In doing so, I show that, while Newmont approaches its community relations in a standardized way, the very same CSR tools and standardized strategies do not lead to standardized effects of domination.

\section{Ghana: the application of a global concept in a local context}

The Chief of Abirem in the Eastern Region, Nana Amo Kyeretwie I [...] has admonished the NGOs to allow the company to engage in fruitful negotiations with the communities in the Newmont Akyem Project area for mining to commence for the benefit of the people and the country as a whole.

(Daily Graphic, 2009)

In the context of the Structural Adjustment Programmes around 1983, a mining law with extremely low environmental and social standards and favourable foreign direct investment conditions was implemented in Ghana. The ensuing mining boom led to immense and violent resettlements, water pollution, and conflicts between large- and small-scale miners resulting in violent clashes between local communities and both private and public security forces (Akabzaa, 2000). In this context, the NGO Wassa Association of Communities Affected by Mining (WACAM) was founded, supporting local communities in disputes with mining companies. In 2009, during my research in New Abirem (Eastern region) approximately $120 \mathrm{~km}$ from the location of these incidents, the mining company Newmont was preparing its second project in Ghana, the first being located around $200 \mathrm{~km}$ from New Abirem in Brong Ahafo region.

While waiting for the approval of its Environmental Impact Assessment, the company's local CSR personnel devoted their attention to building up key strategic relations with specific community actors. Due to future resettlement and compensation issues, the management of community relations is paramount for the company in the early stages of an operation. In this context, Newmont established two institutions with elected representatives to enable broad community support following its global standard of participatory community investment and concern management: a Social Responsibility Forum (SRF) and a Consultative Committee (in the form of a Compensation Negotiation Committee, CNC). Within the SRF, elected community representatives, the chief, members of the district assembly, and Newmont representatives came together to discuss ways to improve the communities, focusing primarily on infrastructural investment and development, such as the renovation or construction of schools. In this way, expectations that the mine would bring about development to the communities were raised. 


\section{J. Sydow}

The task of the CNC, following the same principles of election, was to negotiate the amount Newmont would pay in compensation for crop, land use, and property loss. In line with the standard, elected community representatives, Newmont's representatives, and the community chiefs established procedural rules for the negotiation. External observers from the district assembly and other institutions were invited, but at the same time the objectives of the CNC forbid the reporting of decisions as well as recording or note-taking without permission. Through the implementation of this CNC, following globally applied principles of representative democracy, Newmont avoided multiple individual negotiations, instead aiming for a collective solution, namely a standardized price for everybody's land, crops, and property.

Yet, the standardized treatment of people, land, and property was perceived as unfair by some of the farmers, who wanted to negotiate the price themselves and who saw the standardized method as failing to account for the complexity of local structures and different value of plants in the fields. They doubted that the chiefs were negotiating in the interest of the communities and some indigenous farmers did not want to be represented by settler farmers. However, despite these conflicts of interest, by implementing the CNC, Newmont effectively forestalled many individual conflicts and transferred the responsibility for price negotiations to the representatives. This sharing of responsibility, also described by Li (2009) in Peru, suggests that local communities are participating in shaping the future. It is a side effect which empowers Newmont to achieve formal legitimacy for the established price and the compensation practice. At the same time, the individual agency of farmers is decreased in comparison to individual negotiations.

Newmont stated at the time that it did not know where people would be resettled. Thus, the representatives did not know the extent to which they would actually be affected while negotiating in the committee. The emphasis was on monetary compensation, which, in comparison to what people normally earned, seemed substantial. Thereby, attention was drawn to what farmers would get, and away from what they would lose. This attempt to obscure the actual future impact for every individual effectively depoliticizes the highly contentious processes of compensation and resettlement. It conceals potentially unfair and disadvantageous outcomes for certain local actors. It can be interpreted as a strategic form of (dis)information politics.

\section{Local employment, business opportunities, and strategic information}

A key element of Newmont's CSR strategy is a set of measures designed to create local employment and business opportunities (Smith and Feldman, 2009: 97). By founding an NGO, called Olives, that provided alternative 
livelihood programmes, it refers to one of its core values, sustainability. At that early stage of operation not many jobs were yet available, but people envisioned a job in the near future. Those who worked with the mine were seen to earn a comparatively large amount of money. For many, the loss of farmland seemed to be redeemed by these fascinating probabilities, dismissing the risk of unfair outcome. Some people, such as the chiefs, had already been promised work by the company and in response Newmont received their support. By constantly referring to its high sustainability and commitments to participatory approaches, Newmont aimed to establish an image distinct from other companies. It successfully targeted the unlinking of its operations from negative environmental and social impacts that people had heard about from other places such as Obuasi and Prestea.

\section{Politics of de-politicization}

Newmont's special involvement of members from the district assembly and chiefs in the CNC and SRF corresponds to a standard of involvement with the government of all levels from the headquarters in Denver. As the chiefdom in Ghana is a traditional structure parallel to the governmental system, Newmont has to engage with the chiefs when adjusting its standards to the local context. Traditional chiefdom was strongly enhanced during colonial time as it served the British to execute indirect rule (Lentz, 2008). Newmont builds on this structure or even enhances it. A calculated effect of this is that chiefs react with reciprocity towards the company and try to keep resistance low. This led to the fact that chiefs openly stated that they did not want NGOs like WACAM to come to the Akyem area. Representatives of the NGO FIAN (Food-First Information and Action Network) were even detained by chiefs when they came to the communities without permission.

Newmont also uses these chief-company relationships to project discourses of accountability and transparency back onto critical NGOs. In this manner, Newmont tries to disqualify accusations against the company in order to hide the political dimension of its own operations. In 2009, the NGO FIAN (working together with WACAM) channelled a complaint against Newmont (Ghana) through the Office of the United Nations High Commissioner for Human Rights (OHCHR). Shortly after, newspapers quoted the chiefs stating that Newmont was very welcome and doing great work, they also stated that WACAM was lying and they did not want any more interference with this organization (Daily Graphic, 2009; Kofoya-Tetteh, 2009). According to WACAM, a chief openly admitted in an interview with a journalist that Newmont paid them money for carrying out this media campaign. Newmont confirmed on its website that it promised chiefs an allowance of US $\$ 8,000$ for all extra work upcoming in 


\section{J. Sydow}

the context of the mine (Newmont, 2009). Hence, it tried to silence the accusation of bribery by showing transparency.

Whilst, in my interviews, doubts were raised with regard to Newmont's sustainability at the project site, nobody openly talked about the disagreement with the company. At the mine site, a virtual consensus emerged amongst informants, all hoping that the company would start operations quickly, so contributing to a general feeling that the majority supported the mine. More critical or dissenting actors were geographically distant from the mine site and dispersed, so that they mostly did not even know of each other, precluding the possibility of any organized dissent.

With its CSR concept, Newmont managed to create a widely recognized image of being different from other companies, generating widespread popular support for the mining operations. In this context, the traditional structure of chiefdom was instrumentalized by the company in order to keep resistance low. The prospect of work, compensation payments, and local improvements stemming from the SRF were, for many, powerful inducements, despite potential losses of land and livelihoods as well as likely environmental damage.

\section{Peru: the limits of standards}

In 2012, hundreds of people marched through the streets of Lima protesting against Yanacocha's mainly Newmont-owned new venture, Conga, in the highlands of Peru, close to its other operations. Some weeks later, local protests led to a violent clash with the police, resulting in several deaths, the temporary suspension of the project, and a state of emergency (Osterman and Wilson, 2012). A key question running through this chapter is, then, how did the very same techniques of CSR that proved so powerful in enlisting local consent in Ghana fail to do the same and even contribute to dissent and resistance in Peru.

Mainly Newmont-owned and present in Cajamarca since 1992, Yanacocha is one of the most influential mining companies in Peru (Bury, 2004: $80)$. Much like Ghana, Peru has a history of mining dating back to colonial times and possesses legal and favorable conditions for FDI and low environmental legislation (Arellano-Yanguas, 2008: 18-19). Thorp (2012) argues that the extraction processes "influenced the early shaping of institutions" (113), now seen to be weak at all levels of government. Internationally, Peru ranks very low in terms of security, political stability, and socio-economic agreements and ranks high on conflicts over land on indigenous issues (Arellano-Yanguas, 2008: 1).

Conflicts harm the profits of operation and put the viability of large planned investments at risk. In response to this situation, mining companies, in collaboration with the national government and 
international institutions, are trying to apply international prescriptions to the Peruvian context.

(Arellano-Yanguas, 2008: 23)

\section{CSR in the local context: an attempt at de-politicization}

Similar to Olives in Ghana, the mine established an NGO named Association los Andes Cajamarca (ALAC) in 2004. Its activity of funding programmes of other regional NGOs can be seen as a kind of participatory investment, as money is distributed to various local organizations. Both in reach and finance, it is far more extensive than in Ghana. However, several actors I interviewed described Newmont's financing as a dangerous way of securing reciprocal behaviour and of defending the corporate idea. Several organizations and individuals criticized ALAC's role in the development of conservation plans of hiring the experts necessary to secure the outcome of the study. To declare certain zones within the concession as conservation areas is an attempt by the regional government to regain control over the territory through land-use management. In trying to influence these studies, Newmont tries to prevent this regaining of control.

ALAC is furthermore accused of influencing election results by financing special activities for favoured candidates, or by giving certain benefits to a community to create social pressure. The outcome of an election can be crucial for the mining company, as the mayor plays a decisive role in the process of land use management.

According to the global standards from the headquarters in Denver, ALAC also focuses on local employment and business opportunities, in the form of local entrepreneurial capacity and income generation. It supports agricultural and agro-industrial production and introduces microcredit systems. According to an employee of ALAC, these programmes teach the value of money. This is a powerful tool as compensation mechanisms will only work if people willingly hand over certain rights to the company in exchange for cash. Only then can it be perceived as a fair deal. Moreover, local inhabitants observed that Newmont uses the promise of employment as a tool to silence participants in land-use management workshops. Hence, it tries to prevent the use of new bureaucratic structures to decrease corporate power.

One of ALAC's enterprises is institutional capacity-building conforming to the global standard of government engagement. According to an employee of ALAC, this involves the implementation of a new system of planning and budgeting, which can lead governments to plan huge investments, making it indispensable to support the mine to be able to pay back the debt. Many actors see this close relationship as compromising the impartiality of the government.

Corresponding to the standard of community concern management and far more extensive than in Ghana, Newmont has implemented different 
modes of public participation and community consultations in the context of its planned expansion, the Conga project, since 2007 (Newmont, 2012). However, these methods were perceived as symbolic participation. Participants were able to ask questions and to comment, but their influence was not clear and in no case could they stop a project from being approved $(\mathrm{Li}$, 2009: 232).

With its CSR programmes, Yanacocha portrays itself as efficient as well as socially and environmentally responsible (Arellano-Yanguas, 2008: 23). As in Ghana, the company points to its modern techniques in the context of water management and builds water reservoirs. By arguing that this will provide more water than before, Yanacocha tries to transform the accusation of being water-greedy to being the very provider of water itself (Bebbington et al., 2013: 329-330).

\section{Politicization and growing distrust}

Despite all these efforts to command local consent and support, several key events have derailed attempts to negotiate a working relationship between the company and the community. In 2000, a truck providing the company with mercury spilled several tons outside the village of Choropampa. The way Newmont dealt with this accident and the ongoing health impacts at the place of the accident led to a significant loss of credibility and support. Mistrust ran high and the mine was accused of repeatedly making bilateral promises that go unfulfilled (Smith and Feldman, 2009: 51). When Yanacocha wanted to expand its operations to the mountain Cerro Quillish, which provides the whole city of Cajamarca with water, even people employed by the company protested, according to a local actor. This finally led to the suspension of the expansion. Yanacocha's new mining venture, Conga, which is much bigger than all its previous projects, would similarly affect the lakes that provide the surrounding communities with water and was eventually also suspended due to protests.

Mining is seen by many, having experienced it in the surrounding area, to imply a move from a healthy environment towards a greater dependency on money. The presence of the mine in the surroundings of Cajamarca has led to a reduced access to natural and social resources. The increasing availability of capital and human resources for some actors led to immense social inequality. Many families have been left without capital after low compensation payment (Bury, 2004). These experiences have politicized the presence of the mine to a great extent and make power structures visible again. Questions concerning fairness of outcome and dependency become core issues shaping the relationship of local inhabitants regarding the mine. 


\section{Protests}

Defying the kind of 'divide and rule' effects of CSR that worked so well in Ghana, the widespread mistrust has led to intensified scrutiny of corporate discourses and techniques as well as to more organized forms of activism in Peru. Local activists inform potentially affected communities with detailed presentations about the scope and impact of the planned operations, showing the risk of the operation for the supply of water and thus dismantling the discourse of the corporation. Due to (communicated) experience from other operations and mistrust towards the government, the fear for loss of water access is so high that people are willing to risk their lives in protest (Bebbington et al., 2013: 326). With the changes in law in recent years, the criminalization of the protest facilitated and legalized the use of force by police (Chérrez et al., 2011: 133). This made it more likely for protests to escalate into violent clashes.

Twice the protests have led to the suspension of a mining project, when, as a result, the site was declared an area of conservation $(\mathrm{Li}, 2009)$. This can motivate other protests. Whereas the identification of potential conservation zones is seen as a technical task, the decision to then pursue it is political, as observed by local NGOs. When government officials opt for mining instead of conservation, protest can be one way in which the affected population express their desire for a non-mining alternative. As the NGO WACAM laments in Ghana, the possibility to establish no-go zones does not exist.

A crucial factor enabling a strong protest movement is, among others, a historical one. As one of the activists pointed out, old structures like the rondas campesinas (peasant rounds) that emerged as communal selfdefence against cattle theft in the 1970s (Gitlitz, 1998: 24-26), are now used to mobilize the affected communities. Their participants are involved in multiple modes of resistance beyond street protests (RPP, 2013). In July 2013, ronderos decided to punish everybody who sold their land to the company (La Republica, 2013a, 2013b). With possible support from rondas campesinas, actors around the mines in Cajamarca have more independence from their elected leaders and a notably less hierarchical structure in relation to them than their Ghanaian counterparts have toward the chiefs. Thus, it is far more difficult for the corporation to effectively ally and to break resistance.

While inequality was just as much an outcome of Newmont's community investment programme in Ghana, in Cajamarca it provided a rallying point for protest directed toward the company. In this process, new solidarities across social and ethnic boundaries were created (Mi Mina Corrupta, 2013), which in turn reinvigorated the protest movement internally (Kirsch, 2013: 362). Meanwhile, environmental and regional discourses of post-extractivism promoted by national and international NGOs provided legitimacy and moral support to the protest externally (Gudynas, 
2012; Mi Mina Corrupta, 2013). While, in the past decade, a reprimarization of exports has taken place in many countries of Latin America, a discourse on alternatives to the extractivist model and a necessary change towards less resource-based and export-driven economies has emerged in Latin America's academia and NGOs (Gudynas, 2012). In Ghana, a similar discourse did not exist at the time.

Despite its extensive CSR apparatus, the company was not able to depoliticize its already politicized operations in Peru as the company lost much credibility. Once created, mistrust is difficult to reverse. Although implementing the same strategies in Peru as in Ghana, Newmont could not make use of bureaucratic power and depoliticizing effects. Ultimately, the standardized techniques did not lead to favorable instrumental effects for the mining company. Meanwhile, the persistent mistrust led to scrutiny of Newmont's behaviour and a resistance to the ways in which the company's development discourse and intervention devalued current modes of living.

\section{Conclusion}

"What gets measured gets managed" argued one of Newmont's CEOs in the context of its community relations management. This statement reveals the mining company's objective to control its community relations worldwide through the implementation of standardized, global CSR concepts, the success of which can be measured through quantifiable metrics. Global norms like the UN Global Compact signed by Newmont, frame, endorse, and validate their engagement in these standardized techniques of CSR.

This chapter examined the implementation and impact of these standardized CSR concepts in different local and regional contexts in the extractive sector. In contrast to much research conducted in this area, the chapter explored the limits of these corporate techniques in influencing companycommunity relations. The comparative approach based on ethnographic data involved both a temporal and geographical dimension, challenging the conventional wisdom of globalized corporate practice and revealing the specificities of local responses to standardized techniques. I showed that local specificities, a temporal dimension, and particularly agency and counter-conduct, neglected by Ferguson (1994), have shaped the effects and explain the limitations of these techniques. Ultimately, I argue that standardized technologies of governance do not yield standardized effects of domination.

Newmont's expansion plans were widely accepted or even welcomed in Ghana, while they resulted in violent conflicts and their suspension in Peru, although Newmont applied the same strategy. At both places, Newmont used its CSR concept strategically to shape social relations in a way that benefits corporate interests. Government involvement at all levels was used by Newmont to influence political processes and to take advantage of bureaucratic power. Furthermore, job policies were used to create reciprocal 
relationships. Participatory investment was implemented in both countries but depoliticized Newmont's operations significantly less in Peru compared to Ghana, even though it was used to a greater extent. In Ghana, community concern engagement resulted in criticism of its standardizing outcomes but still secured a broad acceptance, whereas it was perceived as a corporate manoeuvre in Peru. Factors which have shaped the reaction of local actors to Newmont's standardized techniques include: community organization (e.g. chiefs versus elected mayors), previous experience with the mining corporations, visible threats to livelihoods (e.g. water shortage), discourses on the role of mining, political structures, and experiences of the power of protest. These factors inhibit the fact that the use of CSR quietens the discussions on fairness of resource extraction and its outcomes.

In Peru, the project was in the vicinity of Newmont's already ongoing operations, where Newmont itself admits that its own mistakes created huge mistrust in community members. Consequently, local actors examined corporate techniques very closely which, to a certain extent, prevented their instrumental effects. Hence, CSR could not redeem mistrust created by the corporation's misbehaviour. Injustice was perceived, for example, regarding access to and control over water sources, self-determination concerning the mode of living and choice of livelihood, inclusion in and control over decision making, and interference of the corporation in political processes. Unity building on social structure and experience of successful protest became the biggest weapon against the company.

In Ghana, the local population did not have previous negative experiences with Newmont as its other operation was located far away. Consequently, the corporation could establish a discourse of being sustainable, participatory, and different compared to other mining corporations. It could raise hopes that mining would bring about desired development. Newmont could thereby depoliticize the operations to a large extent. Fairness of process and outcome in regard to compensation, among others, was questioned by different individuals. However, these questions did not shape corporate-company relations at large. De-politicization was promoted by the rather hierarchical community structure which made it more difficult for effective and organized protest to emerge.

In sum, this chapter showed that global concepts have limited power to de-politicize mining operations and to control social relations in the interest of corporations. They are not universally applicable tools for corporate control as they cannot be adapted identically to local complexities throughout the world. On a global scale, there are variances in social structure, political processes, and in local-historical context that these standards cannot fully account for. While global standards are mostly disconnected from local history, people's reactions are not. Severe environmental and social impacts can make standardized monitoring systems reach their depoliticizing and 'managerial' limits. 


\section{Note}

1 A similar, yet more extensive version was published first in D. Rajak and C. Dolan (2016) The Anthropology of Corporate Social Responsibility, Berghahn Books, New York.

\section{References}

Akabzaa, T. M. (2000) Boom and Dislocation: The Environmental and Social Impacts of Mining in the Wassa West District of Ghana, Third World NetworkAfrica, Accra.

Arellano-Yanguas, J. (2008) 'A thoroughly modern resource curse? The new natural resource policy agenda and the mining revival in Peru', www.ids.ac.uk/ idspublication/a-thoroughly-modern-resource-curse-the-new-natural-resourcepolicy-agenda-and-the-mining-revival-in-peru [accessed 17 December 2012].

Arellano-Yanguas, J. (2011) 'Aggravating the resource curse: decentralisation, mining and conflict in Peru', Journal of Development Studies, vol. 47, no. 4, 617-638.

Bebbington, A., Humphreys Bebbington, D., Hinojosa, L., Burneo, M. L., Warnaars, X., and Bury, J. (2013) 'Anatomia del conflicto: la negociación de las geograficas de la industria extractiva en los paises andinas', in A. Bebbington (ed.) Industrias Extractivas: Conflicto Social y Dinámicas Institucionales en al Región Andina, Instituto de Estudios Peruanos, Lima, 321-349.

Bury, J. (2004) 'Livelihoods in transition: transnational gold mining operations and local change in Cajamarca, Peru', The Geographical Journal, vol. 170, no. 1, 78-91.

Cetindamar, D. and Husoy, K. (2007) 'Corporate social responsibility and environmentally responsible behavior: the case of The United Nations Global Compact', Journal of Business Ethics, vol. 76, 163-176.

Chérrez, C., Padila, C., Ottan, S., and Yumbla, M. R. (2011) 'Cuando tiemblan los derechos. Extractivismo y criminalizacion en America Latina', www.biodiversidadla.org/Objetos_Relacionados/Extractivismo_y_criminalizacion_en_America_ Latina [accessed 20 October 2012].

Daily Graphic (2009) 'Chiefs worried about propaganda against Newmont Project', Daily Graphic, 15 September.

Ferguson, J. (1994) The Anti-Politics Machine: 'Development', Depoliticization, and Bureaucratic Power in Lesotho, University of Minnesota Press, Minneapolis, MN.

Ferguson, J. (2005) 'Seeing like an oil company: space, security, and global capital in neoliberal Africa', American Antropologies, vol. 107, no. 3, 377-382.

Gifford, B. and Kestler, A. (2008) 'Toward a theory of local legitimacy by MNEs in developing nations: Newmont mining and health sustainable development in Peru', Journal of International Management, no. 14, 340-352.

Gilberthorpe, E. and Banks, G. (2012) 'Development on whose terms? CSR discourse and social realities in Papua New Guinea's extractive industries sector', Resources Policy, vol. 37, no. 2, 185-193.

Gitlitz, J. (1998) 'Decadencia y superviviencia de las rondas campesinas del Norde del Perú', www.cepes.org.pe/debate/debate28/02_Articulo.pdf [accessed 15 September 2013].

Gudynas, E. (2012) 'Der neue progressive Extraktivismus in Südamerika', in T. Lambert (ed.) Der neue Extraktivismus: eine Debatte über die Grenzen des Rohstoffmodells in Lateinamerika, FDCL-Verlag, Berlin, 144-164. 
Hiß, S. (2006) Warum übernehmen Unternehmen gesellschaftliche Verantwortung? Ein soziologischer Erklärungsversuch, Campus Verlag, Frankfurt/Main.

Hopkins, M. (2012) Corporate Social Responsibility and International Development: Is Business the Solution? Earthscan, London.

Kapelus, P. (2002) 'Mining, corporate social responsibility and the "community": the case of Rio Tinti, Richard Bay Minerals and Mbonambi', Journal of Business Ethics, vol. 39, no. 3, 275-296.

Kirsch, S. (2013) 'Los conflictos sobre las industrias extractivas: una visión comparativa desde afuera', in A. Bebbington (ed.) Industrias Extractivas: Conflicto Social y Dinámicas Institucionales en la Región Andina, Instituto de Estudios Peruanos, Lima, 349-369.

Kofoya-Tetteh, K. (2009) 'Akyem Kotoku chiefs, communities support Newmont', Daily Graphic, 26 August.

La Republica (2013a) 'Cajamarca: Rondas prohibirán vender tierras a empresas mineras’, 30 July, www.larepublica.pe/30-07-2013/cajamarca-rondas-prohibiranvender-tierras-a-empresas-mineras [accessed 10 September 2013].

La Republica (2013b) 'Archivan caso contra Gregorio Santos por el delito de apología a la rebelión', 16 August, www.larepublica.pe/16-08-2013/archivancaso-contra-gregorio-santos-por-el-delito-de-apologia-a-la-rebelion [accessed 14 September 2013].

Lentz, C. (2008), Ethnicity and the Making of History in Northern Ghana, Edinburgh University Press for International African Institute, London.

Li, F. (2009) 'Documenting accountability: environmental impact assessment in a Peruvian mining project', PoLAR: Political and Legal Anthropology Review, vol. 32, no. 2, 218-236.

Matten, D. and Crane, A. (2003) 'Corporate citizenship: towards an extended theoretical conceptualization', ICCSR Research Paper Series, no. 4, 1-21.

Mi Mina Corrupta (2013) 'Cajamarca: paro indefinido contra la expansión minera', http://minacorrupta.wordpress.com/tag/rondas-campesinas/ [accessed 15 September 2013].

Newmont (2009) 'Letter from Newmont to Nana Kwandwo Amo II', www. newmont.com/sites/default/files/Afo-su_0.pdf [accessed 4 May 2009].

Newmont (2012) 'Citizen participation fact sheet l', www.newmont.com/sites/ default/files/u 87/Citizen \% 20Participation \% 20Fact $\% 20$ Sheet $\% 2004 \% 2015 \% 20$ 12\%20Final.pdf [accessed 31 August 2013].

Osterman, C. and Wilson, C. (2012) 'Peru protest against Newmont leaves one dead, leader detained', Reuters, 4 July, www.reuters.com/article/2012/07/05/usperu-newmont-idUSBRE86402820120705 [accessed 24 October 2012].

Rajak, D. (2011) In Good Company: An Anatomy of Corporate Social Responsibility, Stanford University Press, Stanford, CA.

RPP (2013), 'Cajamarca: ronderos retiran primera tranquera en el proyecto Conga', RPP NOTICIAS, 20 August, www.rpp.com.pe/2013-08-20-cajamarcaronderos-retiran-primera-tranquera-en-el-proyecto-conga-noticia_623785.html [accessed 15 September 2013].

Sachs, J. and Warner, A. (1997) 'Natural resource abundance and economic growth', NBER Working Paper Series, no. 5,398, National Bureau of Economic Research, Cambridge, MA.

Sawyer, S. (2004) Crude Chronicles: Indigenous Politics, Multinational Oil, and Neoliberalism in Ecuador, Duke University Press, Durham, NC. 


\section{J. Sydow}

Scott, J. C. (1998) Seeing Like a State: How Certain Schemes to Improve the Human Condition Have Failed, Yale University Press, New Haven, CT.

Sharp, J. (2006) 'Corporate social responsibility and development: an anthropological perspective', Development Southern Africa, vol. 23, no. 2, 213-223.

Smith, G. A. and Feldman, D. (2009) 'Community relationships review. Global summary report', www.beyondthemine.com/pdf/CRRGlobalSummaryFULLEnglishFINAL.pdf [accessed 16 August 2013].

Thorp, R. (2012) 'The challenges of mining-based development in Peru', in R. Thorp, S. Battistelli, J. C. Orihuela, and M. Paredes (eds) The Developmental Challenges of Mining and Oil, Palgrave Macmillan, Basingstoke, 110-130. 


\title{
8 Increasing fairness in global value chains?
}

\author{
Possibilities and limitations of fair \\ trade standards for the agricultural \\ and mineral sector
}

\author{
Jutta Kister and Fernando Ruiz Peyré
}

\section{Introduction}

Collapsing sewing factories in Bangladesh, the sickening use of agrochemicals in agroindustry, or mercury contaminated mining in Africa - there are many examples where social and ecological aspects are being ignored in global value chains. Economic relations, including the relocation of production processes, become increasingly complex and responsibility is externalized. Most companies still put maximizing profits first, despite the consequences for humans and the environment.

Standards and certification mechanisms that go beyond the level of national legislation have been developed to secure environmental and labour protection in transnational trade relations. We raise the argument that standards, defining minimum criteria for products or companies, are drawn up in the region of consumption - usually in the Global North. Therefore, we look behind the power and governance structures of global value chains in order to analyse the underlying mechanisms of the creation of standards and the definition of minimum criteria. In particular, we highlight the fact that these chains are embedded in the social environment of the consumer region. The process can also be influenced by group actors such as social movements or value-based consumer groups, among others. This opens up pathways for a redesigning of global value chains towards increased resource fairness and politics.

While the "Fairtrade' system (FLO) is a well known and widely accepted 'fair' standard for mainly agricultural products, our aim is to determine whether this form of certification mechanism is also applicable to the mineral sector. Experiences with fair trade certifications in the mining sector are few and, due to the complexity of the value chain, even considered impossible in the early 1990s (Brown, 1993). Using the Global Value Chain (GVC) and Global Production Network (GPN) frameworks, we analyse similarities and differences along the structure of the value chains in agriculture and mining in order to show different starting points towards 'fairer' trading. 
We begin with a brief description of recent developments in global trade and its consequences for global inequality, also highlighting the functioning of private standards in global trade. Second, we describe the experiences of 'fairer' trading initiatives in the agricultural and mineral sector. We compare the GVC/GPN structure in order to analyse similarities and differences to understand which value chain structures are necessary preconditions for the successful implementation of 'fairer' standards. Our focus is on governance structures and power relations in a qualitative actor-centred approach of value chain mapping. Finally, the conclusion summarizes the challenges of strengthening fair trade to increase fairness in resource supply.

\section{Global trade, inequalities, and standards}

Companies increasingly act and compete internationally. Raw materials, semi-manufactured, and final goods circulate globally (Bathelt and Glückler, 2002; Giese et al., 2011), that is, value chains increasingly expand beyond national borders. Simultaneously, national governments and supranational organizations (like the EU) (re-)define their geopolitical strategies to secure access and control over natural resources worldwide. Under these conditions, global trade has reinforced global inequality (see Wade, 2004).

The current characteristics of the global market help transnational companies to avoid assuming responsibility for the social and ecological consequences of production, processing, and trading. This aspect is made possible through the general lack of regulation in international trade and by the transmission of responsibility to subsidiary companies (Ungericht, 2010: 59). Usually, developing countries have - also as a result of international deregulation processes - less strict legislation and public standards. The misconduct of single participants in the value chain as well as widely tolerated 'bad practices' (like agrochemical residues forbidden in the country of consumption, child labour, or fraudulent product declaration) have the potential to discredit whole market areas, recurrently leading to scandals reported in media. They are often the cause of consumers demanding more transparency and control of production and manufacturing processes, eventually leading to an increasing number of public and private standards (Dannenberg, 2012). Public standards are constituted by governments, national or international regulation bodies, like the EU trading or national hygienic standards. Private standards are set up by nongovernmental actors such as companies or producer associations. Big buying companies have the governance power to implement standards for their suppliers, establishing their own minimum requirements (Gereffi et al., 2005; Schamp, 2008). Today, in order to establish ecological, social, or fair trade initiatives, hybrid governance networks emerge by bringing together public and private or business and non-business actors (Schulz and Bailey, 2014; Schulz and Affolderbach, 2015). ${ }^{2}$ 
Standards aim to attain improvements in transparency and quality, as well as environmental and labour protection. In doing so, they are capable of raising consumers' trust. In general, standards open up possibilities for producers in the Global South to participate in markets with high demand for products that are not permanently or only seasonally available in the Global North or that can be offered more cheaply (Bernzen and Dannenberg, 2012). Once established, standards have to be controlled. We distinguish between product and corporate certification. In general, every stakeholder involved in the value chain has to be certified and controlled periodically. Depending on the number of actors involved, this process becomes complex.

Challenges and critiques are raised from the consumers' side related to the difficulty of distinguishing between the numerous varieties of standards claiming sustainability. Additionally, some standards are criticized for lax control mechanisms. Some authors perceive private standards in global trade as trade barriers, especially for small-scale producers, who are excluded from the value chain due to high financial and technical requirements for certification (Brown, 2005; Nadvi, 2008; Dannenberg, 2012).

\section{Value chain approaches as useful frameworks}

Due to the global division of labour, the number of participants involved in production processes and the geographical distance between these participants has increased (Gereffi et al., 2005). From an economic geographical perspective, the production, processing, and trading of different goods of global demand has been analysed within concepts of chains and networks. The GVC approach focuses on the relations between the actors in a value chain and their control over transactions (Gereffi and Korzeniewicz, 1994; Gibbon et al., 2008). It is often used to analyse economic linkages between the North and the South (Schamp, 2008). The GPN approach includes the social embeddedness of the actors as well as the political and social framework in the analysis of power relations (Henderson et al., 2002; Coe et al., 2008; Franz and Hassler, 2010). ${ }^{3}$

The method of value chain mapping helps to visualize the production process by describing who is doing what and where (Figure 8.1). Politics, legislation, NGOs, and consumer groups in the market region influence public opinion (e.g. moralistic values or religious concepts) using awareness raising, political campaigns, and lobbyism. The discourses around conditions of production and trading influence consumers in their lifestyle and consuming practice, as well as retailers and wholesalers in their decision making. In this process, NGOs and groups of civil society laid common ground for the definition of social and ecological requirements beyond the business-to-business standards (Raynolds, 2000).

Hence, the standard is generated and permanently influenced by its embeddedness in the market region. As a result, standards are oriented 


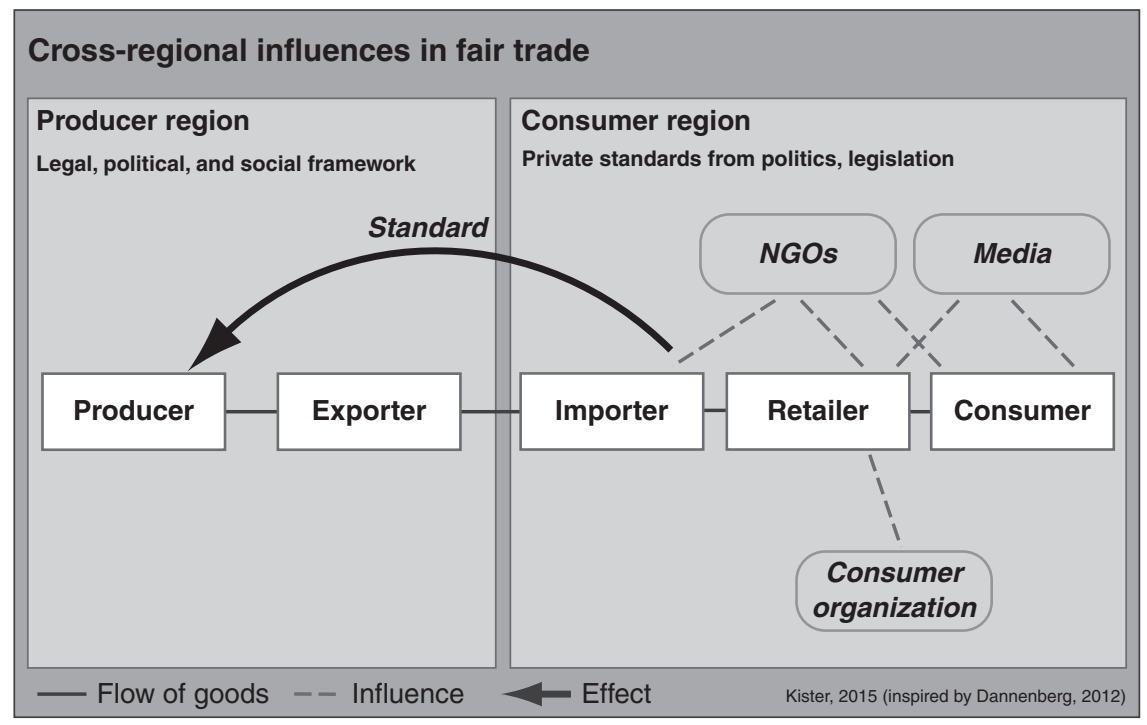

Figure 8.1 Cross-regional influences via standards in fair trade, schematic illustration.

towards the social realities of the respective region they are developed in and for - the "consumer region" (Morgan et al., 2006). However, the standard becomes effective in a totally different region - the "producer region". This is how the consumer region and their regional surrounding exert "cross-regional influences" throughout the standard (Dannenberg, 2012).

A multi-level perspective is necessary for the analysis of cross-regional influences. While private standards become effective on a global level, the consumer region and its social environments are influencing producers in their region. Bridge (2013) defines "Certification Territories" where "control by actors in the Global North [extends] over sites in the Global South, facilitated by a narrative of protecting vulnerable subjects in the context of a weak state" (123). In the producer region standards become effective quite locally.

\section{The conceptualization of 'fairness' in global trade and value chains}

What are the potentials of GVC and GPN approaches for analysing fairness in global trade transactions and relations between actors involved? In the contemporary frameworks in economic geography, categories like 'solidarity', 'fairness', or 'justice' are not conceptualized. They may be analysed when they become effective in the relationships between the actors 
involved in the chain. On the one hand, we can take a closer look at governance structures and power relations in the chains: on the other hand, the social and political embeddedness of the actors involved in the network may be used as a source of information. To identify fairness, consumerproducer relations - in our case formalized through fair trade standards are under scrutiny in this chapter.

As governance power is a precondition to implement standards, it is recommended to shed light on the interests behind the creation of standards. In conventional trading, powerful lead firms are able to enforce standards on their suppliers. In fair trade, however, power relations are characterized by lead firms that are willing to share their power and create relationships in a cooperative partnership. In many cases, financial and technological assistance is offered to producers willing to get certified.

Various scholars have tried to include a fairness perspective in the analysis of global trading. Earlier work of Renard (1999) sees fair trade as a niche in the world market. The niche has opened up because new sets of values have been developed in parts of society. In her concept, these normative implications are referred to as "qualities" of a commodity. In contemporary studies, in opposition to "conventional chains" that build up the mainstream market, "alternative chains" are constructed around topics such as organic food, fair trade, or regional trade (e.g. "alternative food systems"4). This binary view is criticized by post-structuralist researchers such as Gibson-Graham (2006), who rather speak of a "diverse economy".

The "convention theory" gives a stimulating contribution to the understanding of normative aspects of fairness (e.g. Morgan et al., 2006; Ponte, 2009). The demands of specific social groups, defined by their value-based consumers' behaviour, are considered as decisive for the constitution of alternative value chains. The characteristics of the value chain (power relations, modes of processing, handling of nature, etc.) are oriented on the requirements, raised by the social group. Furthermore, there are concepts of "moral geography" as in the works of Smith (2000) and Goodman et al. (2012) analysing food networks. Goodman (2004) detects a "moral economy" where discourses and moral values of a society gain special attention and Fridell (2007) speaks of "market-driven social justice".

We have to keep in mind that - following the concepts of economic geography - normative 'fairer' GVC/GPN implicates guidelines defined by the demanding end of the chain. Conceptualizing fairness is normative, but fairness is not universally defined by all actors in the GVC/GPN. Therefore, fairness is related to perspectives, dependent on subjective perception and social embeddedness of the actor or actor group (e.g. geographical origin, social discourses, shared values, personal background). The (utopian) claim of universal fairness would need an integrated discourse and negotiation with all actors involved to define 'common' standards. 


\section{Global initiatives on 'fair' trading standards}

In the scientific debate, little attention has been paid to making a link between fair trading initiatives in different resource sectors. This section presents and compares certification mechanisms in the agricultural and mineral sector that could be referred to as 'fair'. While there do exist adequate certification mechanisms in the agricultural sector, respective mechanisms in the mineral sector are still scarce. In the following, we present the Fairtrade standard for agricultural products as an example for a certification scheme associated with fairness. In comparison, we show several initiatives from the mineral sector directed towards fairness.

\section{Fairtrade standard in the agricultural sector}

The Fairtrade standard is known as a strict international business-toconsumer standard for food and several non-food-products. It is developed and reviewed by the Fairtrade Labelling Organizations International e. V. (FLO) and third party-controlled by FLOCERT. Fairtrade allows the consumer to take an informed decision based on the label on the product and is often seen as an instrument for market-based development cooperation. FLO offers certification criteria for mostly food products produced by small-scale farmers in the Global South. South-South trading and mixed products (e.g. chocolate, biscuits) have played an ever-increasing role in the certification scheme as well. These products are given market access by fair trade in order to improve the livelihoods of disadvantaged peripheral producer groups. $^{5}$

Today, two dominant forms of trading practice exist: the chain of traditional alternative import organizations and the licensed processing and retailing where conventional companies use the Fairtrade label (Hutchens, 2009). Against this background, power shifts from Global South to North have been observed in recent years (Kister, 2013). The fair trade market is showing fast growing sales rates especially in the mainstream supermarket segment, and powerful actors are engaging in the fair trade sector by selling certified products or producing own-brand products with certified raw ingredients. A growing number of mixed and highly processed products are designed to meet consumers' preferences. As a consequence, more value-adding steps (like processing, branding, and marketing) are located in the consumer region, and the proportional share of producers' power in the value chain declines (Kister, 2013). Conventional retailing and wholesaling companies are able to reduce prices and additional services to the minimum standards defined. They refuse to make contracts covering several cropping seasons, which limits the possibilities for the producers to make social and ecological investments. By contrast, traditional fair trade importers rely on their founding values and even exceed minimum criteria compared to FLO standards, establishing long-term partnerships that go 
beyond formal contracts. One of the positive effects of these partnerships is planning security for the producers, which encourages social and environmental community projects and promotes mutual exchange of information and quality improvement measures.

On an international scale, fair trade is revealed to be a heterogeneous social movement mainly motivated by the idea of changing the world trading system through an alternative form of trading (Raynolds, 2012). Goods should be traded under equal terms, producers and buyers forming a long-term relationship, and providing security for the producers. The small-scale producers in the Global South should be given market access. By paying more than world market prices and a social premium, Fairtrade should contribute to the rural community's development.

The fair trade movement experienced an international harmonization after the Second World War. The movement was institutionalized by founding several national import organizations and further supra-national umbrella organizations (Gendron et al., 2009). This laid common ground for the implementation of the Fairtrade label in the early 1990s. Today, Fairtrade has attained equal participation of producers and importers in international bodies. An important milestone has been the global harmonization of the definition of fair trade in 2001:

Fair Trade is a trading partnership, based on dialogue, transparency and respect, that seeks greater equity in international trade. It contributes to sustainable development by offering better trading conditions to, and securing the rights of, marginalized producers and workers - especially in the South. Fair Trade Organizations, backed by consumers, are engaged actively in supporting producers, awareness raising and in campaigning for changes in the rules and practice of conventional international trade.

(WFTO and FLO, 2009)

It is part of Fairtrade's self-definition to influence institutions, politics and social discourse through educational awareness-raising programmes, public campaigns, and advocacy work (Low and Davenport, 2005). Public opinion also puts pressure on conventional retailers to adapt their practices.

The definition of fairness within the fair trade movement is constantly contested (Renard, 2003; Raynolds, 2009, 2012). Broome (1990) describes fairness as a negotiation process that navigates between the deserts formulated by the actors involved; the "desert" differs from the objectively recognized "needs" of the actors. Between desert and need the agreement has to be discussed. In fact, the vision of what producers see as fair (or just) clearly differs from the vision of what import organizations, consumers, or volunteers in 'worldshops' in the market region would define as fairness. Consumers might have a rather idealistic, simplified notion of the producer's life and the labour behind the product (Wright, 2009). While 


\section{J. Kister and F. Ruiz Peyré}

producers are expected to modify their organizational structures into a form required by the standard, they strongly prioritize measures that improve economic security and social welfare, enabling investments in work equipment and assistance in urgent social community projects (e.g. capacity building, health, or infrastructure).

Today, Fairtrade faces several challenges. The strategy of redefining criteria to align with market expansion is widely rejected by small-scale producers, as they fear losing their unique selling proposition and expect to get played off by larger producers. This expansion measure has been criticized as dilution of criteria by producer groups as well as by alternative traders. The split of Fair Trade USA is the most visible consequence (Jaffee and Howard, 2015). Other, more industry-friendly sustainability certification schemes such as UTZ certified or Rainforest Alliance are putting pressure on Fairtrade. These schemes are competing in certifying the conventional market in the Global North. At the same time, producer groups from the Global South are lobbying for higher prices and for keeping Fairtrade preserved for small-scale farming. In particular, the Latin American producer network CLAC is challenging Fairtrade by establishing its own certification scheme, called Small Producer's Symbol (Clark and Hussey, 2016). Thus, the fair trade movement is keeping its heterogeneous character between contested interests.

\section{Initiatives to 'fairness' in the mineral sector}

Public awareness is crucial for the successful implementation of standards. In the case of mineral products, the progress towards certification standards has been quite delayed (Childs, 2008: 207). The starting point for the increasing awareness of consumers and sellers about the origin of products and the social conditions surrounding production processes can be traced back to the late 1990s, when several campaigns connected mineral products to armed conflicts (e.g. "Conflict Diamonds") or environmental disasters (e.g. "No dirty gold" campaign) (Bloomfield, 2014). As a consequence, big mining companies and jewellery sellers started voluntary CSR initiatives to label their production 'responsible' (e.g. the Responsible Jewellery Council and the Initiative for Responsible Mining Assurance issued in 2006). These initiatives differ from fair trade certification schemes as they apply the standard to the entire company (not to the product) and are not externally controlled. Efforts are published in corporate reports but are not visible for consumers on the product. Compared to fair trade, CSR initiatives are more common in large-scale settings; similar initiatives also exist in the agricultural sector (for more details see Sydow, in this volume; Hafner and Coy, in this volume).

Contrary to CSR, fair trade initiatives are oriented to artisanal and small-scale miners (ASM) in the Global South which "produce just 15\% of the global gold supplies, but make up as much as $90 \%$ of the labour force 
in the gold industry" (FLO, 2014). They are characterized by high levels of illegality, poverty, and exploitation (see Crawford and Botchwey, in this volume). The first programme targeting ecological and social certification of gold was Oro Verde in 2000, which can be seen as the inspiration for the later Fairtrade and Fairmined certification labels (Cardiff, 2010; Sarmiento et al., 2013). In 2003, the world's first independently certified environmentally and socially responsible wedding rings were launched. In 2006 , in collaboration with miners' organizations and stakeholders in Latin America the Alliance for Responsible Mining (ARM) developed Fairmined, the first standard for fair trade mining. In 2011, in cooperation with Fairtrade International, gold was introduced under 'fair' certification to the UK and Canadian market. A true milestone was the first selling of Fairtrade certified gold in Switzerland in 2014, representing one of the most important jewellery markets in the world.

However, not many miners have reached fair trade certifications yet. Currently, only two mining organizations are certified by Fairtrade (both in Peru) and four by Fairmined (in Peru, Colombia, and Mongolia). Other ASM from Asia, Africa, and Latin America are working towards the certification. In doing so, they are, however, confronted with various challenges. To be part of the international fair trade market, the miners need to adapt to external standards that largely ignore the unfavourable socioeconomic and political contexts in producer countries (Childs, 2014). For example, the standards expect transparent management and work safety measures. However, many extraction sites are located in areas with armed conflicts, safety issues, and high levels of corruption. Producers are highly affected by these circumstances but have little influence to change them.

\section{Comparative analysis of 'fairer' trading initiatives}

We argue that a key reason for the disparities of the successful implementation of fair trade standards in the small-scale agricultural and mining sector lies in the different structures of the value chains. The main differences are varying preconditions for successfully applying fair certification schemes. In this section, we evaluate the necessary structure of GVC/GPN in order to implement 'fair' certification mechanisms in a widely unregulated global market. The analysis is divided into three dimensions: (1) producers and products, (2) GVC/GPN characteristics, and (3) consumers and their influence.

To facilitate the comparability, we focus on small-scale farming and small-scale mining. The analysis is based on empirical studies on food products certified by the Fairtrade standard carried out in Germany (end of 2013) and Nicaragua (2014) as well as on literature research and media analyses of existing experiences of 'fair' certification efforts in the mineral sector, such as Fairtrade Gold (FLO) and Fairmined (ARM). 
Fairtrade-certified products in the agricultural sector

\section{Producers and products}

The Fairtrade approach puts producers first. Certification principally leads to reduced health risks, better education, and optimized working procedures among the producers involved. Great effort is also expended on the organizational structures in the producers' surroundings. As a framework for the producers, local cooperatives of economically independent working family farms are preferred. These cooperatives have to have elected controlling bodies and a general assembly, guaranteeing democratic organization and financial integrity. Cooperatives work on gender issues and on improving farmers' and communities' wellbeing, and they offer farm services and beneficial common purchasing and marketization. The producer cooperatives work together with certified exporters. In the case of Nicaragua, local cooperatives established top-level cooperatives operating on a regional scale. In many cases these structures cover further processing and exporting activities.

\section{GVC/GPN characteristics}

The complexity of the value chain can differ significantly depending on the product. Agricultural products (e.g. coffee, cocoa, tea, sugar) are low processed goods comparable to raw materials that may undergo final processing, blending, and packaging in the market area. Nevertheless, cooperatives have made efforts to add value in the producer region through labourintensive processing steps.

Market access is provided through certified fair trade buyers in most countries in the Global North. Usually, national import organizations, founded in the late 1970s and followed by other companies fully dedicated to fair trade, buy large amounts of the harvest. However, conventional companies that sell fair trade products under their brands or in their stores have expanded in the fair trade segment.

In general, the value chain of fair trade products is kept simple, as the target is to avoid intermediaries. Interactions between the actors are characterized by solidarity and partnership. While the importer in the Global North is governing the chain, the aim of the movement is to empower the small-scale producers in the Global South. Transactions include a pre-fixed fair minimum price and social premium. Constant knowledge exchange, pre-financing, or initiated social projects in local communities support trustful interactions. Power asymmetries can be detected where certification leads to transactions connecting producer cooperatives to powerful conventional wholesalers, as these companies do not consider fair trade principles as their core company goal. 


\section{Consumers and their influence}

Goodman (2004) sees Fairtrade stakeholders integrated in a common network, built on shared ethical and moral principles. Consumers and producers are no longer divided in 'us' and 'them' but combined in a 'we', "embedding the actions of both consumption and production in the creation and politics of fair trade" (907). Consuming fair trade products becomes a political statement and is an expression of values and defining a lifestyle (Ermann, 2006; Zick Varul, 2009). Moreover, Fairtrade has always been backed by an active and conscious alternative consumers group considering itself part of the social movement.

Assigning consumers an important role for making Fairtrade successful, the products show growing consumer orientation. The product range has been diversified, the quality has improved, and Fairtrade offers more and more mixed products and processed goods (e.g. biscuits and chocolate bars). These products show high complexity in the value chain by, for example, adding ingredients produced in the market region. Consequently, shifts of value creation processes into the market region can be observed (Kister, 2013).

\section{'Fair' initiatives in the mineral sector}

\section{Producers and products}

ASM in the Global South are the most vulnerable group in mining activities, working under conditions of exploitation and dangerous circumstances for health and safety (see e.g. Hentschel et al., 2002; Spiegel, 2009; OECD, 2013). Most mining laws in the Global South - principally the regulations influenced by neoliberal politics implemented from the 1990s onwards - favour large-scale and industrial mining, thus excluding smallscale mining operations (Childs, 2014). This leads or even forces many artisanal miners into informal and illegal set-ups with risky conditions. Environmental and health risks are mostly linked to the use of mercury, which is frequently released into the environment, for the separation of gold from other particles. Mining also changes the physical environment, removing large amounts of material which is discharged into rivers and creeks (Heemskerk, 2001: 306). The increasing use of more powerful mining equipment in ASM goes along with a considerable growth of sediment spillages.

The high market value of minerals like gold or diamonds makes them attractive for smuggling and can be used to finance war or terrorist activities. The minerals can be capitalized without big investments and are easy to transport. Minerals are usually extracted in remote regions with relatively low state monitoring or media scrutiny (O’Higgins, 2006: 241). Consequently, the predisposition for both miners and controllers to take 
a gamble for a one-time high-value transaction is big and stimulates corruption.

Small-scale miners are usually not organized in cooperatives or other forms of association. Most ASM activities are uncoordinated, "with miners working essentially independently or in small partnerships" (Hinton, 2005: 103). Therefore, the first step towards certification usually provides support for an improved organizational structure at the community level.

\section{GVC/GPN characteristics}

The complexity of the GVC/GPN of mineral products has been seen as a profound challenge for fair trade certification (Brown, 1993). As the ASM production sites are generally located in remote areas, the supply chain of artisanal gold is characterized by numerous intermediaries (transport, local dealers, exporters), decreasing profits for miners. Furthermore, gold undergoes complex processing steps - especially the final production of the jewel - until it reaches the final consumer. Similar to the agricultural sector, the target of fair trade gold is to simplify the value chain and to avoid intermediaries. The organizational structure of cooperatives as well as long-term exporter-buyer partnerships enable direct marketing to the exporter and facilitates the tracing back of the mineral.

\section{Consumers and their influence}

The lifestyle of the precious metals and gems consumer group differs considerably from the typical fair trade consumer of agricultural products. This makes it difficult for fair trade standards in the mineral sector to gain ground as consumers eventually influence the determination of fair trade standards, that is, they directly depend on the ethical and moral principles that guide their consumption. Slogans like 'gold to be proud of' or 'the best gold story in the world' try to encourage the consumption behaviour of the end-user about the jewel they are wearing.

The challenges of the fair trade certification of ASM today are various. The context in which ASM takes place is not undergoing fundamental changes, in relation to environmental impact, informality, and transparency. The retailers and consumers are generally not informed about these conditions and there is a lack of emotional proximity, leading to low levels of awareness compared to traditional agriculture fair trade standards.

\section{Similarities and differences}

Is the Fairtrade system as a well-known standard in the agricultural sector applicable to the mining sector and under which conditions? Based on the comparison above, we recognize similarities in the GVC structure in agriculture and mining, which would make a transfer possible, but also see 
differences that may explain the challenges faced by the existing fair trade initiatives in the mineral sector.

First, focussing on the similarities, the production primarily takes place in the Global South, while consumers are mainly located in the Global North. Lead firms in control of the global value chains are predominantly also located in the Global North.

Second, the increasing globalization of markets for raw materials, the falling transport costs, and technological innovations facilitate the access and trade of those resources. The globalization of the Western mode of living, which is based on the unlimited and permanent availability of cheap resources (Kulke, 2009) and the rapid economic growth of emerging countries, contribute to increasing demand. The spatial distance between the origin of the producer and the end-consumer has almost become insignificant.

Third, the growing global demand for resources leads to an increasing competition for the access to natural resources. This aspect is stronger for strategic mineral resources (e.g. lithium, see Anlauf, in this volume), but is also increasingly observable in the agricultural sector. Competition between local food and cash-crop production over access to factors of agricultural production (land, soil, or water) is increasing (see Schmitt, in this volume). The economic asymmetry of power is used to guarantee this access.

Fourth, in both sectors we must distinguish between small-scale production (ASM and peasant agriculture) and large-scale production (mining TNCs and agribusiness), with considerable differences concerning fair trading possibilities. We see parallels in the kind of certifications in largescale productions, oriented towards CSR, and the fair trade orientation of small-scale production, with the emphasis on the social aspects of trade relations.

In our comparison we also see notable differences. First, concerning the production forms: In the agricultural sector, a certain degree of organization and infrastructure is needed to be able to manage the cultivation and harvesting process and to persevere unproductive seasons. Agricultural production is a renewable activity and can be increased through intensification or the expansion of the acreage. In the mining sector, production directly depends on the amount and quality of the mineral deposit. Mining quantities can only be increased through technological advance or higher investment, usually not accessible for small-scale miners.

Second, forms of organization in cooperatives and inclusion into the local community have great significance in the agricultural sector. In contrast, an important percentage of ASM miners work individually or in small groups, often in temporary camps and far away from home. The informal character of the activity and the lack of transparency and control make it difficult to achieve the degree of organization and the social stability needed for fair trade certification. A suitable size and production volume is required for participating in international fair trade markets. 
Third, in the case of precious metals and gems, the considerably higher market value compared to agricultural products enhances the predisposition to illegal economic activities such as corruption, smuggling, and even the financing of armed conflicts. As a result, in these conditions of illegality the access to certification mechanisms is much more difficult if not impossible. Furthermore, the difference in market value between both product groups affects the chances of success in the fair trade market. While most agricultural products are mass consumption products, the possibility for jewellery to enter the mass market is strongly limited.

Fourth, if we look into the value adding steps we also find important differences. In many agricultural products, the processing steps are few and the small-scale producers are able to invest in value chain upgrading by carrying out some processing activities. In the ASM, the miners are not very powerful in relation to intermediaries and international buyers, and they are not capable of assuming the further processing of the minerals.

Finally fifth, there is a time delay in which the sectors (both participants and industry structures) have started to introduce fair trade aspects into the supply chain. According to Davies (2007), fair trade in the agricultural sector has already reached an "institutionalisation era", with stabilized markets and being well-known by end-consumers in the Global North (455). The mineral sector can still be seen in an initial phase where the niche market must be established, making the first steps and beginning with ASM precious metals and gems.

\section{Conclusion}

The chapter discussed opportunities and limitations of private fair trade standards to support a 'fairer' trading process of agricultural products and mineral resources. In analysing and comparing the GVC/GPN structures of agricultural and mineral products, we presented similarities but also differences which make the use of fair trade initiatives in the small-scale mining sector challenging. However, ASM is an important economic sector for many regions and countries. Despite many constraints on fair certification in the small-scale mining sector, efforts have to be made to achieve better resource fairness. As observed, the challenges to reach the level of certified fair production are enormous in this context. In particular, long-term planning and increased organizational structures are necessary to develop a more viable ASM sector which is necessary for fair trade to be effective.

The main requirements for the implementation of certification schemes, where small-scale producers attempt trading into global markets, are legalized access to land, property, and mining rights. Producers further have to adapt to specific organizational structures which are transparent and consist in terms of delivering of a relevant size. Reduced complexity of the GVC/GPN enables effective trading conditions that are traceable, and avoid losses to intermediaries. Formalized, certified, and controlled formal 
structures are capable to exclude violence, illegal production, open up formalized global markets to small-scale producers, and improve social outcomes for producers.

In fair trade, standards are able to set minimum criteria for the benefit of small-scale producer groups. Still, standards are oriented towards the desires of the consumer region. Fair trade standards are thus not protected from their dilution by powerful actors from the conventional market. While value-based niche markets can open up adequate market opportunities for small-scale producers, simultaneously, the specifications of certification schemes can build up trade barriers and hamper participants from the Global South.

Although respective regulations and norms exist on a global level, they often do not come into effect in the regional setting of the producer. Especially in developing countries, deregulation is problematic, and in many cases compliance with legislation is not sufficiently monitored. Standards and certification schemes may compensate for the lack of regulation and enforcement to a certain degree, but they do not replace national regulation as they are quite selectively effective on the producing sites integrated in certified value chains.

This chapter showed that fairness is a matter of perspective. Corresponding to our investigation, standards are framed among the participants embedded in the powerful Northern consumer region, while producers in the Global South must adapt their understanding of 'fairer' trade. Cross regional influences show the impact of these standards on the producers' region. It remains important to keep the question of definitive power in mind, particularly when it comes to the implementation and control mechanisms of standards in global value chains.

In fairer trade initiatives, actor groups that are outside the value chain have a crucial influencing role and are capable of raising additional demand and opening up a market niche. Awareness raising, educational campaigns, and information among civil society are important factors to increase consumers' interest and to exert pressure on importers, wholesalers, and retailers. Indisputably, consumers' conscience is easier to influence with products that are eaten or worn. With the growing use of mineral components in technical devices - even in sustainable forms of driving and energy production - it becomes, however, increasingly necessary and possible to achieve 'fairer' conditions in the mineral sector.

The predominant GVC/GPN structure in the mineral sector is unlikely to be changed in the near future. However, there still exist many starting points to increase fairness through the implementation of standards, improving the situation for small-scale producers. Therefore, it remains important to increase consumers' consciousness, backed up with an engaged network of societal actors (e.g. NGOs and media). Much like in the agricultural sector, it is important to enable and extend the fairness discourse around production and trade of mineral resources. 


\section{Notes}

1 We use 'Fairtrade' when we refer to the certification of Fairtrade Labelling Organizations International (FLO) (www.fairtrade.net), controlled by FLOCERT (www.flocert.net). We use 'fair trade' to refer to the market segment in general, which is not homogenous and involves a larger group of products, companies, and actor groups. In many cases, they identify themselves as part of the 'fair trade movement'.

2 For more information about standards in global trade, see Nadvi and Wältring, 2002; Bernzen, 2014.

3 For a comparison of GVC and GPN, see Hess, 2008; Fischer et al., 2010; Coe, 2012.

4 For more information about alternative food systems, see Goodman and Watts, 1997; Raynolds, 2000; Barrientos and Dolan, 2006; Fold and Pritchard, 2005; Goodman et al., 2012.

5 Many studies about private standards concentrate on the impacts on farmer households (see Becchetti and Costantino, 2008; Valkila and Nygren, 2010; Raynolds and Bennett, 2015; Chiputwa et al., 2015).

\section{References}

Barrientos, S. and Dolan, C. (eds) (2006) Ethical Sourcing in the Global Food System: Challenges and Opportunities to Fair Trade and the Environment, Earthscan, London.

Bathelt, H. and Glückler, J. (2002) Wirtschaftsgeographie: Ökonomische Beziebungen in räumlicher Perspektive, Ulmer, Stuttgart.

Becchetti, L. and Costantino, M. (2008) 'The effects of fair trade on affiliated producers: an impact analysis on Kenyan farmers', World Development, vol. 36, no. 5, 823-842.

Bernzen, A. (2014) 'Global food trade beyond the "standards" debate: conventions, institutions and uncertainties in organic food imports to Germany and Australia', PhD thesis, University of Cologne, Germany.

Bernzen, A. and Dannenberg, P. (2012) 'Ein "Visum" für Obst: Umwelt- und Sozialstandards im internationalen Lebensmittelhandel', Geographische Rundschau, vol. 64, no. 3, 44-52.

Bloomfield, M. J. (2014) 'Shame campaigns and environmental justice: corporate shaming as activist strategy', Environmental Politics, vol. 23, no. 2, 263-281.

Bridge, G. (2013) 'Resource geographies II: the resource-state nexus', Progress in Human Geography, vol. 38, no. 1, 118-130.

Broome, J. (1990) 'Fairness', Proceedings of the Aristotelian Society, vol. 91, 87-102.

Brown, M. B. (1993) Fair Trade: Reform and Realities in the International Trading System, Zed, London.

Brown, O. (2005) 'Supermarket buying power, global commodity chains and smallholder farmers in the developing world', Human Development Report 2005, UNDP, New York.

Cardiff, S. (2010) 'The quest for responsible small-scale gold mining: a comparison of standards of initiatives aiming for responsibility', www.earthworksaction.org/ files/publications/Small-scale-gold\%20mining-initiatives-comparison-2010.pdf [accessed 14 January 2016]. 
Childs, J. (2008) 'Reforming small-scale mining in sub-Saharan Africa: political and ideological challenges to a Fair Trade gold initiative', Resources Policy, vol. 33, 203-209.

Childs, J. (2014) 'From "criminals of the earth" to "stewards of the environment": the social and environmental justice of Fair Trade gold', Geoforum, vol. 57, 129-137.

Chiputwa, B., Spielman, D. J., and Qaim, M. (2015) 'Food standards, certification, and poverty among coffee farmers in Uganda', World Development, vol. 66, 400-412.

Clark, P. and Hussey, I. (2016) 'Fair trade certification as oversight: an analysis of fair trade international and the small producers' symbol', New Political Economy, vol. 2, no. 2, 220-237.

Coe, N. M. (2012) 'Geographies of production II: a global production network A-Z', Progress in Human Geography, vol. 36, no. 3, 389-402.

Coe, N. M., Dicken, P., and Hess, M. (2008) 'Introduction: global production networks. Debates and challenges', Journal of Economic Geography, vol. 8, 267-269.

Dannenberg, P. (2012) Standards in internationalen Wertschöpfungsketten: Akteure, Ziele und Governance in der Obst- und Gemüse-Wertekette Kenia EU, Lit, Berlin.

Davies, I. A. (2007) 'The eras and participants of fair trade: an industry structure/ stakeholder perspective on the growth of the fair trade industry', Corporate Governance, vol. 7 , no. 4, 455-470.

Ermann, U. (2006) 'Geographien moralischen Konsums: Konstruierte Konsumenten zwischen Schnäppchenjagd und fairem Handel', Berichte zur deutschen Landeskunde, vol. 80, no. 2, 197-220.

Fischer, K., Reiner, C., and Staritz, C. (eds) (2010) Globale Güterketten. Weltweite Arbeitsteilung und ungleiche Entwicklung, Promedia/Südwind, Vienna.

FLO (2014) 'Fairtrade Gold and Precious Metals Q\&A', http://wordpress.p20126. webspaceconfig.de/q-a/ [accessed 9 January 2016].

Fold, N. and Pritchard, B. (eds) (2005) Cross-Continental Food Chains, Routledge, New York.

Franz, M. and Hassler, M. (2010) 'The value of commodity biographies: integrating tribal farmers in India into a global organic agro-food network', Area, vol. 42, no. 1, 25-34.

Fridell, G. (2007) Fair Trade Coffee: The Prospects and Pitfalls of Market-Driven Social Justice, University of Toronto Press, Toronto.

Gendron, C., Bisaillon, V., and Otero Rance, A. I. (2009) 'The institutionalization of fair trade: more than just a degraded form of social action', Journal of Business Ethics, vol. 86, no. 1, 63-79.

Gereffi, G. and Korzeniewicz, M. (1994) Commodity Chains and Global Capitalism, Greenwood Press, Westport, CT.

Gereffi, G., Humphrey, J., and Sturgeon, T. (2005) 'The governance of global value chains', Review of International Political Economy, vol. 12, no. 1, 78-104.

Gibbon, P., Bair, J., and Ponte, S. (2008) 'Governing global value chains: an introduction', Economy and Society, vol. 37, no. 3, 315-338.

Gibson-Graham, J. K. (2006) A Postcapitalist Politics, University of Minneapolis Press, Minneapolis, MN.

Giese, E., Mossig, I., and Schröder, H. (2011) Globalisierung der Wirtschaft, UTB, Stuttgart. 
Goodman, D. and Watts, M. J. (eds) (1997) Globalising Food: Agrarian Questions and Global Restructuring, Routledge, New York.

Goodman, D., DuPuis, E. M., and Goodman, M. K. (eds) (2012) Alternative Food Networks: Knowledge, Place and Politics, Routledge, New York.

Goodman, M. K. (2004) 'Reading fair trade: political ecological imaginary and the moral economy of fair trade foods', Political Geography, vol. 23, no. 7, 891-915.

Heemskerk, M. (2001) 'Do international commodity prices drive natural resource booms? An empirical analysis of small-scale gold mining in Suriname', Ecological Economics, vol. 39, 295-308.

Henderson, J., Dicken, P., Hess, M., Coe, N., and Yeung, H. W.-C. (2002) 'Global production networks and the analysis of economic development', Review of International Political Economy, vol. 9, no. 3, 436-464.

Hentschel, T., Hruschka, F., and Priester, M. (2002) 'Global report on artisanal \& small-scale mining', IIED and WBCSD, http://pubs.iied.org/pdfs/G00723.pdf [accessed 14 January 2016].

Hess, M. (2008) 'Governance, value chains and networks: an afterword', Economy and Society, vol. 37, no. 3, 452-459.

Hinton, J. (2005) 'Communities and small scale mining: an integrated review for development planning', World Bank, Washington, DC, www.eisourcebook. org/cms/June \%202013/CASM,\%20an \%20Integrated \%20Review\%20for\%20 Development \%20Planning.pdf [accessed 9 January 2016].

Hutchens, A. (2009) Changing Big Business: The Globalisation of the Fair Trade Movement, Edward Elgar Publishing, Cheltenham.

Jaffee, D. and Howard, P. H. (2015) 'Who's the fairest of them all? The fractured landscape of U.S. fair trade certification', Agriculture and Human Values, online first, http://link.springer.com/article/10.1007/s10460-015-9663-2/fulltext.html [accessed 3 November 2015].

Kister, J. (2013) 'Fair trade in Germany left the niche market: power shifts observed in global fair trade value chains', Economia Agro-Alimentare, no. 3, 35-54.

Kulke, E. (2009) Wirtschaftsgeographie, UTB, Stuttgart.

Low, W. and Davenport, E. (2005) 'Postcards from the edge: maintaining the "alternative" character of fair trade', Sustainable Development, vol. 13, no. 3, 143-153.

Morgan, K., Marsden, T., and Murdoch, J. (2006) Worlds of Food, Oxford University Press, Oxford.

Nadvi, K. (2008) 'Global standards, global governance and the organization of global value chains', Journal of Economic Geography, no. 8, 323-343.

Nadvi, K. and Wältring, F. (2002) 'Making sense of global standards', INEF Report, no. 58, Gerhard-Mercator-Universität, Duisburg.

OECD (2013) 'OECD due diligence guidance for responsible supply chains of minerals from conflict-affected and high-risk areas', OECD Publishing, Paris.

O'Higgins, E. (2006) 'Corruption, underdevelopment, and extractive resource industries: addressing the vicious cycle', Business Ethics Quarterly, vol. 16, no. 2, 235-254.

Ponte, S. (2009) 'Governing through quality: conventions and supply relations in the value chain for South African wine', Sociologia Ruralis, vol. 49, no. 3, 236-257. 
Raynolds, L. T. (2000) 'Re-embedding global agriculture: the international organic and fair trade movements', Agriculture and Human Values, vol. 17, 297-309.

Raynolds, L. T. (2009) 'Mainstreaming fair trade coffee: from partnership to traceability', World Development, vol. 37, no. 6, 1083-1093.

Raynolds, L. T. (2012) 'Fair Trade: social regulation in global food markets', Journal of Rural Studies, vol. 28, no. 3, 276-287.

Raynolds, L. T. and Bennett, E. A. (eds) (2015) Handbook of Research on Fair Trade, Edward Elgar, Cheltenham.

Renard, M.-C. (1999) 'The interstices of globalization: the example of fair coffee', Sociologia Ruralis, vol. 39, no. 4, 484-500.

Renard, M.-C. (2003) 'Fair trade: quality, market and conventions', Journal of Rural Studies, vol. 19, 87-96.

Sarmiento, M., Ayala, H., Urán, A., Giraldo, B., Perea, J., and Mosquera, A. (2013) 'Legitimidad e innovación: el caso del Programa Oro Verde', Letras Verdes. Revista Latinoamericana de Estudios Socioambientales, vol. 14, 284-303.

Schamp, E. W. (2008) 'Globale Wertschöpfungsketten: Umbau von Nord-SüdBeziehungen in der Weltwirtschaft', Geographische Rundschau, vol. 60, no. 9, 4-11.

Schulz, C. and Affolderbach, J. (2015) 'Grünes Wachstum und alternative Wirtschaftsformen', Geographische Rundschau, vol. 67, no. 5, 4-9.

Schulz, C. and Bailey, I. (2014) 'The green economy and post-growth regimes: opportunities and challenges for economic geography', Geografiska Annaler: Series B, Human Geography, vol. 96, no. 3, 277-291.

Smith, D. M. (2000) Moral Geographies: Ethics in a World of Difference, Edinburgh University Press, Edinburgh.

Spiegel, S. J. (2009) 'Resource policies and small-scale gold mining in Zimbabwe', Resources Policy, vol. 34, 39-44.

Ungericht, B. (2010) 'Die Regulation transnationaler Wertschöpfungsketten als interessenpolitisch umkämpftes Terrain', in K. Fischer, C. Reiner, and C. Staritz (eds) Globale Güterketten. Weltweite Arbeitsteilung und ungleiche Entwicklung, Promedia/Südwind, Vienna, 58-75.

Valkila, J. and Nygren, A. (2010) 'Impacts of Fair Trade certification on coffee farmers, cooperatives and laborers in Nicaragua', Agriculture and Human Values, vol. 27, no. 3, 321-333.

Wade, R. H. (2004) 'Is globalization reducing poverty and inequality?', World Development, vol. 32, no. 4, 567-589.

WFTO and FLO (2009) 'A Charter of Fair Trade Principles', www.wfto.com/sites/ default/files/Charter-of-Fair-Trade-Principles-Final\%20\%28EN\%29.pdf [accesed 4 April 2016].

Wright, C. (2009) 'Fairtrade food: connecting producers and consumers', in D. Inglis and D. Gimlin (eds) The Globalisation of Food, Bloomsbury Academic, Oxford, 139-157.

Zick Varul, M. (2009) 'Ethical consumption: the case of fair trade', in J. Beckert (ed.) Wirtschaftssoziologie, Verlag für Sozialwissenschaften, Wiesbaden, 366-385. 


\title{
9 The soy-production fair $(y)$ tale? \\ Latin American perspectives on globalized dynamics, territoriality, and environmental justice ${ }^{1}$
}

\author{
Robert Hafner and Martin Coy
}

\section{Introduction}

Over the last three decades, the production of soy has become an increasingly lucrative business in Brazil and Argentina. Now fully incorporated in globalized production networks, local consequences of global activities are observed; socio-territorial fragmentation, increasing vulnerability, rising polarization between socio-spatial inclusion and exclusion, and the manifestation of socio-ecological conflict constellations become core problems of investigation. In this context, discussions on fairness have become increasingly relevant in the production of and discourse on soy (e.g. RTRS, 2015).

In this chapter, we compare two soy frontiers: the Mato Grosso Region in Brazil and the Argentine Chaco. At first glance, the two regions seem to undergo similar patterns of development, experience the same challenges and conflicts, and deal with issues of (un)fairness and (in)justice in similar ways, that is, mostly in the form of non-response and non-articulation of environmental justice claims. However, on a closer look, there are important differences in the two countries related to different national agendas, foci, and socio-environmental frameworks, for example, fiscal export policies or migration and spatial reconfiguration patterns. These differences are also reflected in the multiplicity of approaches and meanings of 'fairness'.

The objective of the chapter is twofold. First, the two soy frontiers are compared in order to unearth particular regional characteristics. Second, it is shown that fairness should be treated more as a 'conception' (an individual or group's perception of a concept) than as a 'concept', since the understanding of what is considered 'fair' is context-related and perspective-based. In this vein, activist-driven environmental justice concepts help to develop arguments of what fairness could look like in different contexts and from different perspectives. However, they are limited in analytical scope since situations of non-articulation of socio-ecological claims are not considered. Such elements, however, are of high importance in our case studies. 
We start by putting fairness and environmental justice into perspective by developing our understanding of the two concepts/conceptions. The concept of territoriality is introduced in order to bridge the gap between intangible theory and the tangible materiality of the case studies. Two axes of investigation are proposed: (1) territoriality, contextualizing the two regions in relation to non-articulation of conflicts, and (2) discourse, highlighting the different conceptions of what is considered fair by three main groups of actors in the two regions. After the conceptual section, we analyse the two case studies and compare them along the axes of investigation. The last section concludes with a focus on what can be learnt for resource fairness.

\section{Fairness, environmental justice, and territoriality}

In the context of soy production in Brazil and Argentina, it is vital to conceptualize the term 'fairness' as well as environmental justice (EJ). 'Fairness' is an intuitive and highly normative term; it is often used as an example of a concept that is clear unless defined. However, in order to be able to empirically work with the concept, an attempt to define and classify has to be undertaken. Hooker (2005) offers an interesting approach by distinguishing between formal and substantive fairness. Formal fairness' central feature is its non-normativity and impartial applicability, without claiming that those rules of fairness should be good or bad, moral, or context- or subject-sensitive (Hooker, 2005: 329).

Substantive fairness expands formal fairness to the extent that context and side-conditions are taken into account: "People get what they deserve" (Hooker, 2005: 330), although it becomes blurry how it is decided what people should deserve. Important in this way of thinking is Rawls' consideration that unfairness per se is of no importance; his understanding of fairness is highly theoretical-utopian and consequentialist, that is, the consequences of a process should be fair, fairness of the process itself is secondary (Rawls, 1999: 114). One can argue, however, that the actual realization of substantively unfair situations is already a form of consequence and has, therefore, to be dealt with. Fairness itself has to be considered an ideal situation (much in the cosmopolitan liberal sense of Rawls' intentions; see also Nili, in this volume).

Hooker and Rawls should be considered as examples of how fairness is defined. The direct application of their fairness concepts - the main considerations of which are theoretical and abstract - in our empirical analysis is questioned, since - as will be shown - the local, regional, and (supra-) national actors each work with their particular interpretations of the concept of fairness. Unearthing and comparing these conceptions of fairness both within as well as among the case studies offers new insights into the regional frontier dynamics.

Going beyond a mere theoretical or social discussion and introducing the biophysical environment as a medium, EJ offers the potential to 
analyse power relationships and interdependencies among different actors (Wapner and Matthew, 2009). Hence, both human and natural variables are considered in order to deal with three intertwined questions: (1) how do humans' actions impact particular attributes of nature (interest and action); (2) how are people affected/conditioned by (changing) biophysical variables (effect and consequence); and (3) what should be altered in the human-nature interplay in order to deal with possible injustices (reaction located on the normative level, see Drummond, 2008: 181). Thus, unlike fairness, EJ has always had a strong link to the local level (with possible supra-local origins of environmental injustice), while being - in the tradition of political ecology - conscious of the fact that " 'nature' or 'environment' - in both their 'materiality' and social construction cannot easily be used in immaterial abstraction" (Debbané and Keil, 2004: 210).

Over the recent years, EJ research has developed its focus from analysing the distribution of environmental risks (through quantitative methods) to include dimensions of responsibility, recognition, and participation (qualitative methods) (Stanton et al., 2007; Holifield et al., 2009: 599). The openness and diversity of the concept is also reflected in the fact that researchers increasingly combine EJ with other approaches, such as capabilities (Schlosberg and Carruthers, 2010; Nussbaum, 2013; Groves, 2015) and sustainability (Agyeman and Evans, 2004), or refer to different scales beyond the local (e.g. global environmental justice; Agyeman, 2014; Martin et al., 2014; Mehta et al., 2014), including aspects of climate change (Okereke, 2010; Wilson et al., 2010).

Particularly in a Latin American context, research goes beyond traditional EJ studies (e.g. on the effects of toxic landfills or air pollution) and deals with conflicts with international oil, mining, and agribusiness companies in the context of development challenges (Martínez-Alier, 2003; Roberts and Thanos, 2003; Schlosberg and Carruthers, 2010). Even though research on supra-national capitalist influence on frontiers of globalization can be found (particularly in Brazil; Gerber et al., 2009; Acselrad, 2010; Porto, 2012; Coy, 2013), up-to-date empirical in-depth analyses from Latin America are scare (for an exception see Reboratti, 2012; for implicit examples of EJ research see Hufty, 2008; García-López and Arizpe, 2010). One particular characteristic in Latin America lies within the alternative framing (Taylor, 2000) of EJ, such as context-based initiatives in the form of networks (e.g. Rede Brasileira de Justiça Ambiental), the inclusion of socio-ecological approaches (Gudynas, 2013), or the discussions of risk (Coy, 2010). This chapter focuses in particular on the work of Flitner (2007) who established an analytical matrix of scales of meaning and regulation (see Towers, 2000; Urkidi and Walter, 2011: 685), as well as of justice of distribution and recognition. In so doing, material (distribution of environmental goods and bads), symbolic (thought styles in the Flecksian interpretation on said distribution ${ }^{2}$ ), procedural (form 
of actors' inclusion in the process of decision making and action), and cultural (socio-cultural background of actors being part in conflicting situations) justice put focus on socio-ecological conflicts at hand (Flitner, 2007: 50).

So far, it has been shown that theoretical discussions of fairness concepts are hard to transfer to contextual empirical studies; we consider the actors' interpretations and definitions (i.e. conceptions) of fairness more fruitful. The analytical basis is laid with EJ, since it is a more tangible form of dealing with justice and the environment. Then, introducing territoriality as an underlying concept enables the inclusion of multi-scalar perspectives in terms of global production networks and the materialization of socio-economic change in socio-ecological conflicts. The physical components of the soybean frontier are reinforced in the analysis and put in an analytical framework of complex interactions and dynamics of the relationship between space and human agency (Agnew and Muscarà, 2012: 60).

Particularly in the discipline of geography, territoriality has often been used to analyse the national state and its execution of power within and beyond its borders (Kythreotis, 2012: 462). However, recent studies have shown that a more relational definition is preferred: territoriality as a fluid and historically grown, complex process (e.g. Elden, 2010; Agnew and Muscarà, 2012), where certain interdependences and their normative interpretations overlap (Agnew and Corbridge, 1995; Brenner, 1998). We understand territoriality, in short, as "a strategy of social power, by gaining control over a certain area" (Jerneck, 2000: 29).

As an addition to EJ, the concept of territoriality goes beyond claimsmaking as an indicator of socio-ecological unfairness. Therefore, it is highly suitable in our case studies, since the sole focus on justice claims would leave out the multifaceted realities of Latin American soy frontiers. Power relations do play a role in the concept of territoriality: they are not limited to the political sphere, but also include socio-economic as well as socio-ecological and spatial perspectives. Henceforth, focus has recently been laid on topological scalar terms, rather than areal ones (see Herod and Wright, 2002; Antonsich, 2009: 796), allowing for a contextual understanding of global-local interplays and dependencies.

Summing up, we use 'fairness' as a conception relating to varying actors' interpretations of the consequences of the same socio-ecological and economic processes. EJ offers an analytical frame to unearth and investigate conflict situations. With the inclusion of territoriality in the EJ debate, we avoid the EJ trap of needing the analytical trigger of claims-making, but still have a tool to analyse power relations materialized in the bio-physical regions. Hence, in order to visualize different aspects of fairness and EJ in the context of Latin American soy production, two axes of investigation are proposed: (1) territoriality and (2) discourse. The goal of the first axis is to contextualize the two case studies and to identify underlying 
mechanisms of (non-)conflict handling. The second axis highlights discursive elements of different conceptions of fairness according to varying settings and thought styles.

\section{Soy frontiers: Brazilian Mato Grosso and Argentine Chaco}

In this section, we analyse two soy frontiers, the Brazilian Mato Grosso Region and the Argentine Chaco along the axes of territoriality and discourse. The first case has been the major part of a research agenda over decades, with long-term stays in the region, allowing for first-hand observations and mappings of soy expansion, enriched by focussed and expert interviews. The second case has been studied via 14 months of fieldwork in 2013 and 2014, predominantly working with Jazz Methodology, a context-based approach combining sensory ethnography, participatory methods (e.g. Jane's Walks, workshops, netmaps), expert and focussed interviews.

\section{Territoriality: or, where are the conflicts?}

Soy production is a vital economic activity in Brazil and Argentina, with the second and third largest production worldwide, respectively (FAO, 2014). High levels of change (especially surface expansion) have been experienced in both countries over the last 20 to 30 years. Two of the most dynamic soy frontier regions are the Brazilian Mato Grosso and the Argentine Chaco.

\section{Brazilian Mato Grosso}

For a long time, the state of Mato Grosso was one of the most peripheral and 'underpopulated' regions of Brazil. At the beginning of the 1970s, much like the Brazilian Midwest and Southern Amazonia, the region became a priority region for agricultural colonization. The military regime promoted land distribution at the frontiers of settlement as a double strategy: for the expansion of agricultural production, and for the creation of alternatives to the solution of land conflicts in the core regions of Brazil. Thus, the new Mato Grosso frontier formed part of a re-territorialized response to socio-ecological conflict situations (dealing with distribution of environmental goods, interest, and actions). Instead of agrarian reforms, national avoidance strategies led to the implementation of settlement schemes for small farmers, organized by the state or private firms from Southern and South-Eastern Brazil. The expansion of modernized agriculture in the South had caused deep structural changes through land concentration and expulsion of small farmers in the South. In the form of an economically-driven exit strategy, business was made on the expelled people's hopes for a better life at the pioneer front in Mato Grosso. 
Three development phases are observed: First, an occupational phase of Northern Mato Grosso (especially the region of influence of the BR-163 highway from Cuiabá to Santarém) was dominated by small farmer immigration during the 1970s and the first years of the 1980s. Second, a phase of extractivism was dominated by timber and gold extraction during the late 1980s and the 1990s (shifting the focus from people to commodities). Third, a very dynamic expansion of large soybean farms implemented on large estates in Cerrado areas has substituted failed small farmers in the settlement schemes. This markedly altered the socio-economic and sociocultural structure of the region (Coy and Klingler, 2011), causing increasing regional vulnerabilities due to world market oscillations and the concomitant agribusiness reactions (Coy, 2005).

Hence, due to its high absorption of land and its high demand for investment (machinery, seeds, agrochemicals), the soybean boom contributed over the last 30 years to a marked process of land concentration and agro-social exclusivity by privileging highly capitalized farmers and gradually excluding small-scale farmers. Viewed from outside of the region, social-environmental questions of territoriality, exclusion, and environmental (in)justice (particularly in terms of effects and consequences) have to be raised.

At the same time, the soybean boom left its marks in regional settlement structures, inscribing its social exclusiveness and its local-global logics in the new and highly dynamic pioneer towns (e.g. the 'boom towns' along the BR-163 road, developed by private settlement companies). Some of these towns are now the 'wealthiest' municipalities in Brazil. They are economically dominated by the agribusiness sector (e.g. silos, traders, banks, implement merchants) and socio-culturally driven by farmers who increasingly prefer to live in an urban context.

Summing up, the development of Mato Grosso unearths plenty of contradictions: an impressive economic 'success story' on the one hand and a story of social (and economic) exclusion as well as of ecologic risks (e.g. destruction of the Cerrado vegetation, reduction of biodiversity, erosion, contamination by agrochemicals) on the other (Nepstad et al., 2014). Questions of distribution and concentration (now favouring the 'Big Four' producers ADM, Bunge, Louis Dreyfuss and Cargill as well as some big national companies, such as Amaggi) have to be raised, particularly in the context of EJ spheres of regulation. However, this call is very little - if at all - answered within the region.

\section{Argentine Chaco}

In the Argentine Chaco, the beginning of soy production can be dated to the 1970s, while a major increase has been experienced the mid-1990s, due to the adaptation of production modes towards direct seeding and the use of genetically modified crops. Nowadays, the Gran Chaco Region faces the 
highest deforestation rate worldwide (Hansen et al., 2013), while the Argentine Chaco being most affected by soybean expansion (Gasparri et al., 2013). In previously deforested areas, the new production scheme acts in strong competition with traditional forms of agri- and horticulture; new actors enter local markets, scales of production increase; land tenure and increasing land concentration and privatization occurs.

Considering the region from an outside perspective, certain potentials for socio-ecological conflicts can be identified: the application of pesticides/ herbicides close to settled areas, the privatization of land, the displacement of puesteros (small-scale farmers living in the Monte, i.e. land covered with trees and bushes), and deforestation (i.e. restriction of access to forestland), among others. Three main results are observed: First, the thought style of 'progress' is omnipresent. Even though locals may not directly benefit from increased soy production, the overall perception in villages surrounded by soy fields is surprisingly positive. This feature is highly represented in casual language of locals when talking about deforestation: "Han limpiado el campo" - "They have cleaned the field". Even though approximately 26 per cent of the people living in the Argentine Chaco use firewood from the Monte as a primary source of combustion for cooking (Krapovickas et al., 2016: 228), it is astonishing how far the positive outlook on frontier expansion is present in the local community.

Second, this one-term event changes local-regional territorialities, introducing new and predominantly extra-regional actors through moving the centres of their lives to the Chaco region. However, these actors came without their families. Coupled with the fact that workforce in the new soy agribusiness is not needed (in general, one skilled employee per 1,000 hectares of cultivated land is required), the advancement of the soy frontier has occurred without migration towards the region. Since locals living in the Monte were forced to leave for villages and local urban centres, an increasing disconnection between urban areas and rural surroundings occurs. Thus, it goes without saying that the most prominent sources of friction (if not to say conflict) arise from predominantly urban problems.

Third, the major results of several workshops carried out with young adults in three different locations show that socio-ecological problems circulate around the following themes: waste management, soy silos within urban areas, and increased motorization of the area (mostly trucks). Even though clear signs of - often unlawful - fumigation are observed in the vicinities of the villages (the minimum distance between urban areas and fumigated land has been observed to be less than two metres), fumigation, however, does not play a major discursive role.

\section{Comparison}

As Table 9.1 shows, the Mato Grosso Region shows more characteristics of a state-encouraged expansion, accompanied by new settlements, thus 
Table 9.1 Territoriality - comparison between Brazilian Mato Grosso and Argentine Chaco

\begin{tabular}{|c|c|c|}
\hline & Mato Grosso & Argentine Chaco \\
\hline $\begin{array}{l}\text { Development of } \\
\text { frontier }\end{array}$ & $\begin{array}{l}\text { From land colonization to } \\
\text { large-scale farming }\end{array}$ & $\begin{array}{l}\text { From local peasantry to large- } \\
\text { scale farming }\end{array}$ \\
\hline Migration patterns & $\begin{array}{l}\text { Migration from South Brazil } \\
\text { to Mato Grosso }\end{array}$ & $\begin{array}{l}\text { No significant migration to the } \\
\text { Chaco region, but increased } \\
\text { sub-regional migration to } \\
\text { urban areas }\end{array}$ \\
\hline $\begin{array}{l}\text { Form of frontier } \\
\text { expansion }\end{array}$ & State encouraged & State tolerated \\
\hline $\begin{array}{l}\text { Role of the state in } \\
\text { frontier expansion } \\
\text { process }\end{array}$ & $\begin{array}{l}\text { Facilitator (active): } \\
\text { - Provision of administrative } \\
\text { support at municipal level } \\
\text { - Public agro-research (e.g. } \\
\text { EMBRAPA, the Brazilian } \\
\text { Agricultural Research } \\
\text { Corporation) } \\
\text { - Distribution of production- } \\
\text { oriented information }\end{array}$ & $\begin{array}{l}\text { Beneficiary (passive): } \\
\text { - No/little explicit support for } \\
\text { agribusinesses }\end{array}$ \\
\hline Regional control & New regional elites & $\begin{array}{l}\text { Extra-regional control by } \\
\text { members of national/ } \\
\text { international agribusinesses }\end{array}$ \\
\hline $\begin{array}{l}\text { Concentration of } \\
\text { production }\end{array}$ & $\begin{array}{l}\text { Very high towards the Big } \\
\text { Four (ADM, Bunge, Cargill, } \\
\text { Louis Dreyfus) market } \\
\text { leaders in agribusiness }\end{array}$ & $\begin{array}{l}\text { Medium concentration, still } \\
\text { small- and medium-scale } \\
\text { farmers }\end{array}$ \\
\hline $\begin{array}{l}\text { Frontier's global } \\
\text { relevance/influence }\end{array}$ & $\begin{array}{l}\text { Very high visibility of soy- } \\
\text { related activity; leads to more } \\
\text { restrictions locally }\end{array}$ & $\begin{array}{l}\text { Still more peripheral frontier } \\
\text { with little visibility on a global } \\
\text { scale; facilitates more flexible } \\
\text { practices for agribusiness }\end{array}$ \\
\hline $\begin{array}{l}\text { Conflict handling } \\
\text { with local } \\
\text { community }\end{array}$ & \multicolumn{2}{|c|}{$\begin{array}{l}\text { Non-/low-level materialization of unfairness or injustice; } \\
\text { EJ claims are hardly voiced within the frontier region }\end{array}$} \\
\hline
\end{tabular}

Source: authors' own analysis.

focussing on an expansion with people rather than a mere commodification of land as experienced in the Argentine Chaco. Remaining in the economic realm, it is observed that the concentration of land towards the 'Big Four' in Mato Grosso is not that well pronounced in the Argentine counterpart, due to already-institutionalized conflicts between the Argentine government and the agrarian sector.

Both case studies show that the primary thought style revolves around the notion of 'progress', the accompanying thought collective within the region is represented by what Fleck (2011) describes through esoteric 


\section{R. Hafner and M. Coy}

(inner; made of key stakeholders in the soy-agribusiness) and exoteric (outer; other actors related to the issue of soy expansion, be it first or second hand) circles. The esoteric circle defines the circumstances of 'progress' in the region. The exoteric circle - through territorial power relations - is willingly or unwillingly drawn to the pre-set notions and modes of action to the extent that articulated forms of fairness claims - and thus the creation of conflicts - are hardly observed.

This interesting characteristic can be visualized through two often-heard quotes by locals: (1) "We will not bite the hand that feeds us"; and (2) "Nothing can be done". While (1) represents a clearly perceived dependence of locals on soy-related stakeholders - be it legitimized or not, (2) reflects some sort of resignation towards the dominant thought style and form of superimposed actions. This feature in particular goes along with the theoretical discussion of socio-cultural aspects of justice (see Flitner, 2007), where context, tradition, and modes of living are crucial. These remarks refer to frontier-internal perspectives.

From outside perspectives on the case studies, however, socio-ecological conflicts rather than previously discussed notions of 'progress' are central. Two potential sources of socio-ecological conflicts can be characterized as either one-off events (such as deforestation), or repetitive events (like fumigation). Both of them can be put in Flitner's (2007) EJ matrix under distributive justice. However, the main obstacle here is the non-/or low-level materialization of formal unfairness (Hooker, 2005). This interesting aspect can be coupled with changing territorialities and asymmetrical forms of procedural (in)justice (see Flitner, 2007). Simply put, participation in decision making on environmental issues related to soy expansion and its effects is close to non-existent, even though small-scale attempts of public participation on local levels exist. For example, some environmental secretaries try to supervise agriculture-related activities according to legal regulations.

\section{Discourse: or, the justification of fairness?}

Since it has been shown that conflict articulation does not play a pivotal role in terms of the relation between local, regional, and extra-regional actors, the second axis focuses on examples of how fairness and soy production is dealt with by different organizations. Three actor groups and their perspectives will be presented: the national government, nonproduction-related NGOs, and producer-driven actors.

\section{Brazilian Mato Grosso}

The Brazilian soybean economy has been legitimated by its obvious economic dynamism, putting the country on the top of the world producers and exporters of agricultural raw products. This is a constitutive part of a 
long-lasting Brazilian discourse of 'agricultural vocation', integrating Brazil's frontiers into global commodity chains and production networks.

In Brazil, national politics and agribusiness are intrinsically linked. The perception of agribusiness as a national 'growth engine' is discursively and politically supported by the powerful and growing representation of agribusiness interests in the Brazilian parliament (so-called bancada ruralista); national and regional governments reinforce agribusiness and the soybean sector by a decisive growth- and modernization-oriented policy, including large-scale infrastructural investments. The soybean sector has developed a very professional 'machinery' of self-representation, of political lobbying, and of image and discourse building. Aprosoja (Association of Soy and Corn Producers) has become a professional and powerful instrument of the sector in all kinds of political debates. Its main field of action is to claim logistical improvements (e.g. reduced transport costs, road infrastructure) and to politically safeguard an entrepreneurial friendly (neo-liberal) framework for investment. Simply put, the discourse is linked to a linear form of argumentation: soy expansion is considered part of progress and growth, which secures sustainability. Sustainability is seen positive and fair, making the circular assumption that soy expansion is fair. As a result, farmers' immediate economic interests are put first, setting back issues such as socio-ecological governance, an intrinsic aspect related to EJ. Nevertheless, Aprosoja's own visions of 'social and ecological responsibility' have meanwhile become a visible part of its discourses (e.g. Aprosoja's CSR-activities 'AçãoVerde' or 'AgroSolidário').

In this vein, in 2006 the soy processing agroindustries, together with different NGOs and other actors, agreed for a so called soy moratorium which should have guaranteed that soybeans produced on recently cleared forest land in the southern part of the Amazon should not be commercialized. This moratorium proved to be relatively efficient, aggravating and breaking, for instance, the expansion of soybean cultivation along northern parts of the BR-163 corridor (Nepstad et al., 2014). Despite all such initiatives for certification or for the implementation of rules aiming at a 'greening' of soy production, the greatest obstacles for such initiatives are, nowadays, shifts in global demand structures. China, specifically, as not only an emerging, but increasingly dominating, market is not very interested in socially or ecologically certified products. Therefore, producers do not feel any pressure, at the moment, to comply with changing production standards, notwithstanding all discursive-contrary declarations.

Nevertheless, the soy production sector is faced with resistance by national and international civil society activism. The BR-163 region in Mato Grosso became a 'hot spot' of disputes in this sense. The plans for the conclusion of road pavement towards Santarém required by the representatives of Mato Grosso's agribusiness (e.g. Aprosoja) in order to guarantee competitive transport costs and market conditions, prompted resistance from ecologists and social movements. Against this conflicting 
situation, the Lula government (2003-2011) intended to frame the plans for road building at the BR-163, for the first time, with a programme (Plano BR-163 Sustentável) containing measures of participatory planning, ecological governance, protection of natural and indigenous areas, and a whole package of measures towards sustainable regional development. In a certain sense those plans were promising concerning a fairer and just regional development. In more recent years, however, those plans were substituted by the merely modernization- and growth-oriented national investment programmes PAC1 and PAC2, highlighting the aforementioned national discourse.

Thus, the recent regional incorporation of Mato Grosso into the globalized market was based discursively on social development and economic opportunities of the soy frontiers for all people (colonization as an 'alternative' to agrarian reform), but in reality, the capitalist interests of private firms dominated from the beginning. Therefore, 'fairness' and (socioeconomic as well as environmental) 'justice' were never valuable concepts within the (societal, economic, and socio-ecological) context of Mato Grosso development. Thus, the dominant thought style driven by market forces shows an implicit understanding of libertarian fairness where those who invest get the returns.

\section{Argentine Chaco}

Unlike in Brazil, in Argentina the relationship between the government and the agrarian sector has been fraught with tensions for the last 60 years, culminating in the agrarian crisis in 2008 (Reca, 2010: 435). This tense relationship is manifested in one particular form of taxation on exports, particularly of soy-related products. While from 1993 to 2001 export taxes (retenciones) amounted to only 4 per cent of the commodity's value, the retenciones were increased to 35 per cent by 2007 (Reca, 2010: 440). Since the internal market for soy is not considered relevant, the vast majority of producers have been affected negatively. Since then, Argentina's government under Néstor Kirchner and Cristina Fernández de Kirchner (2003-2015) has radicalized its discourse against agrarian monopolies, defaming soy as being yuyo (i.e. weed; La Nación, 2008).

Nevertheless, a fundamental piece of information here is the actual discrepancy between promoting negative publicity against soy production and the application of the high-value retenciones. ${ }^{3}$ Taking into account the various forms of social plans existing in Argentina, it would be impossible to finance those plans without the existence of the globalized soy market. A clear form of action-oriented pragmatism is observed. Following neoextractivist thought styles, the redistribution of funds coming from extractive industries (here particularly including the agribusiness) establishes an approximation towards formal fairness of secondary income distribution due to soy expansion. Thus, the government's form of applying fairness 
(also in relation to Flitner's (2007) symbolic justice) goes towards the maximization of people's benefits (through a mixture of egalitarian and utilitarian fairness) in monetary terms, thereby neglecting the locally based negative effects of soy expansion. This feature becomes particularly important in the Argentine Chaco since - as the previous section described - local forms of resistance/articulation and materialization of fairness claims are not accentuated. Thus, as a first critical remark, it becomes clear that theoretical concepts of fairness have to include scalar dimensions, since what may be fair on the national level, can be considered unfair on the local scale.

The second critical perspective on fairness should be highlighted with the example of Greenpeace's activities in the Argentine Chaco. From an outside perspective, it would be expected that NGOs engaged a lot in local struggles, be they ecological or socio-ecological. However, from a regional inside-perspective, clear critique from locals in the Argentine Chaco is voiced. The presence of NGOs, particularly Greenpeace, is seen as practically non-existent by locals. The locals' anger at the perceived NGO's noncommitment in the region is constantly being expressed. Confronted with this accusation, a representative of Greenpeace in Buenos Aires elaborated the organization's focus on deforestation. This anecdote highlights the problem of the Chaco region of being an area out of focus for (inter-) national activist groups.

The third actor group, representing a group of farmers in Las Lajitas (Grupo Las Lajitas), is a mix of locally and regionally rooted, but also globalized, producers streamlining their technical expertise in the area. This is of particular importance, since - unlike in many production areas in the US - technical state support for farmers focuses primordially on smallscale (often self-subsistent) agri- and horticulturalists. Thus, the autoorganization of groups of middle-to-large-scale farmers occurs out of necessity to create parallel support structures for day-to-day business; the organization's principles are clearly defined by libertarian thought styles. When dealing with fairness on a discursive level, action-oriented pragmatism is very prominent. Once again, it is seen that from a national level, Argentina is more critically minded towards agribusiness activities, also articulating fairness claims on a national and supra-regional level, even though state incomes critically depend on agriculture.

\section{Comparison}

As shown in Table 9.2, in both our cases we have seen different modes of interpretation of fairness, owed to national structures as well as socioeconomic patterns and traditions. The most obvious difference between the two regional examples lies in the states' discursive approaches towards agricultural activity: Brazil shows a continuation of the positive outlook on agriculture, while Argentina radicalized its discourse, particularly 
Table 9.2 Discourse - comparison between Brazilian Mato Grosso and Argentine Chaco

\begin{tabular}{|c|c|c|}
\hline & Mato Grosso & Argentine Chaco \\
\hline $\begin{array}{l}\text { Overall } \\
\text { agribusiness } \\
\text { discourse in favour } \\
\text { of soy production }\end{array}$ & \multicolumn{2}{|c|}{$\begin{array}{l}\text { - Stop hunger } \\
\text { - Creation of employment } \\
\text { - Strengthen regional/national development }\end{array}$} \\
\hline $\begin{array}{l}\text { Official national } \\
\text { discourse }\end{array}$ & $\begin{array}{l}\text { - Agribusiness equals } \\
\text { economic growth } \\
\text { - Mato Grosso is a success } \\
\text { story } \\
\text { - Critical in terms of } \\
\text { environmental problems } \\
\text { (deforestation, climate } \\
\text { change) and Environmental } \\
\text { Governance }\end{array}$ & $\begin{array}{l}\text { - Increased radicalization of } \\
\text { discourse against } \\
\text { agribusiness } \\
\text { - Redistribution of wealth is } \\
\text { necessary and has to be } \\
\text { carried out by the national } \\
\text { government (neo-extractivist } \\
\text { thought style) }\end{array}$ \\
\hline $\begin{array}{l}\text { Frontier-internal } \\
\text { view of regional } \\
\text { development }\end{array}$ & \multicolumn{2}{|c|}{$\begin{array}{l}\text { Positive; the overall agribusiness discourse is fully } \\
\text { internalized }\end{array}$} \\
\hline $\begin{array}{l}\text { Frontier-external } \\
\text { view of regional } \\
\text { development }\end{array}$ & $\begin{array}{l}\text { - Critical by national and } \\
\text { international NGOs } \\
\text { - Positive by business sectors }\end{array}$ & $\begin{array}{l}\text { - Critical/indifferent, } \\
\text { particularly by non-soy } \\
\text { related NGOs }\end{array}$ \\
\hline Certification & \multicolumn{2}{|c|}{$\begin{array}{l}\text { - Important for large-scale producers and core regions of } \\
\text { production } \\
\text { - Predominantly relevant for export to the EU }\end{array}$} \\
\hline
\end{tabular}

Source: authors' own analysis.

against soy production, but still heavily relies on its revenues. This feature is prominently reflected in the establishment and level of formalization of agricultural lobbying groups in both regions.

One great commonality of both regions is the aspect of certification of soy production. Certification is intrinsically important. As confirmed by brokers in Buenos Aires, the current standards for exporting to the Netherlands (and thus the EU) say that certified soy and soy related products are an added benefit but are not a primary necessity. However, it is believed that the current status is only one step towards making certification obligatory, intensifying the pressure on producers to follow stricter norms in relation to legal compliance and good business practices, labour conditions, responsible community relations, environmental responsibility, and good agricultural practices (see RTRS, 2015); thus highlighting the 'fairness of soy'.

Another interesting aspect in this context deals with business size. In both regional cases, small or medium scale farmers do not see the necessity for certification since their visibility (on all scales) is fairly limited, thus reducing the need for better corporate social responsibility. Large-scale 
companies, however, are frequently faced with criticism in relation to their production modes and are thus more willing to participate in certification programmes (as confirmed through informal talks with RTRS representatives). Another vital argument in this context deals with the growth of new soy markets (predominantly China), where the core purchasing reason is defined by pricing rather than socio-ecological standards.

Summing up, in both regions, certification only plays a role for large companies with high visibility on a global scale, who are influenced by the opinion-formation of potential customers. As a result, the dichotomy of perception of the 'big and bad multinationals' vs. the 'small and good farmers' has to be broken up and re-evaluated; visibility can thus be seen as an indicator for global pressure towards fairness. Furthermore, certification - from the point of view of soy farmers - is predominantly an act of marketing rather than an actual statement towards fairer production.

\section{Conclusion}

Soy production and fairness discussions are clearly context dependent. While Brazil and Argentina show two different forms of discourse regarding agriculture, it has become apparent that both countries rely on the production of soy; Argentina, in particular, may be even more dependent on this commodity. The chapter has shown that the concepts of fairness are difficult to operationalize in empirical research. Therefore, we have looked for alternatives and have applied an EJ approach that was extended with the concept of territoriality. This allowed us to unearth underlying conceptions and situations of fairness.

Taking up two axes of investigation - territoriality and discourse major differences in perspective, from within the case studies and from the outside, are observed. Fairness per se is not discussed in the research areas unless open conflicts arise. In this case, particular understandings of fairness are instrumentalized to legitimize actors' strategies. Referring to our first axis of investigation, (1) territoriality, both regions have it in common that open conflicts between members of the agribusiness and locals/local (environmental) groups are hardly found. Two reasons are the thought style of 'progress', dominated by leading actors of the agribusiness that constantly overwrite the articulation of fairness claims and the perceived dependence on the new dynamisms of the agribusiness (particularly in terms of job creation). The second axis, (2) discourse, is less physioregionally attached but deals more with how different thought styles towards soy production are presented. Taking three different actor groups and their specific discourses into account, certification proved to be a major issue in the debates on soy-related fairness. Here, examples have shown that the motivation for certification (of all actors involved) depends, once again, on pragmatic reasoning of output maximization. This shows yet again that fairness is not a value per se but becomes relevant when 
extra benefits are obtained (in terms of publicity, marketing, and the use of protest resources).

Finally, it has been shown that the combination of EJ and territoriality can be fruitful for empirical cases dealing with resource fairness, since they facilitate profound insights into the underlying structures of socioecological conflict situations and their territorial as well as discursive framings. Hence, we conclude that for global topics such as resource fairness, regional contexts are of great importance. Therefore, regional comparisons help to deconstruct common fair(y) tales and substitute them with multifaceted and multileveled perspectives towards reality.

\section{Notes}

1 We thank the Austrian Agency for International Cooperation in Education and Research (OeAD-GmbH) for awarding Robert Hafner a Marietta Blau grant, financed by the budget of the Federal Ministry of Science, Research and Economy (bmwfi). Furthermore, thanks go to the Austrian Academy of Science for Robert Hafner's DOC Fellowship at the Institute of Geography, Innsbruck University.

2 Ludwik Fleck (e.g. 1980) has elaborated the concept of 'thought styles' in order to study the way in which cognition and thinking is formed in a community. The advantage of using thought styles rather than paradigms lies in the fact that they are procedure-oriented and constantly changing, based on the members within the community but also highly influenced by its surroundings.

3 In November 2015, with the election of Mauricio Macri, the Kirchner era came to an end. Thus, changes in the retenciones regime in favour of Argentine producers are already announced and partly implemented.

\section{References}

Acselrad, H. (2010) 'Ambientalização das lutas sociais - o caso do movimento por justiça ambiental', Estudos Avançados, vol. 24, no. 68, 103-119.

Agnew, J. A. and Corbridge, S. (1995) Mastering Space: Hegemony, Territory and International Political Economy, Routledge, London.

Agnew, J. A. and Muscarà, L. (2012) Making Political Geography, Rowman \& Littlefield, Lanham.

Agyeman, J. (2014) 'Global environmental justice or le droit au monde?', Geoforum, vol. 54, 236-238.

Agyeman, J. and Evans, B. (2004) “ "Just sustainability”: the emerging discourse of environmental justice in Britain?', The Geographical Journal, vol. 170, no. 2, 155-164.

Antonsich, M. (2009) 'On territory, the nation-state and the crisis of the hyphen', Progress in Human Geography, vol. 33, no. 6, 789-806.

Brenner, N. (1998) 'Between fixity and motion: accumulation, territorial organization and the historical geography of spatial scales', Environment and Planning D: Society and Space, vol. 16, no. 4, 459-481.

Coy, M. (2005) 'Between globalization and regionalization. The political ecology of pioneer fronts in the South-West of the Amazon', in A. Hall (ed.) Global Impact, Local Action, Institute for the Study of the Americas, London, 13-35. 
Coy, M. (2010) 'Los estudios del riesgo y de la vulnerabilidad desde la geografía humana. Su relevancia para América Latina', Población y Sociedad, vol. 17, 9-28.

Coy, M. (2013) 'Environmental Justice? Sozialökologische Konfliktkonstellationen in Amazonien', in H. Burchardt, K. Dietz, and R. Öhlschläger (eds) Umwelt und Entwicklung im 21. Jahrhundert: Impulse und Analysen aus Lateinamerika, Nomos, Baden-Baden, 121-133.

Coy, M. and Klingler, M. (2011) 'Pionierfronten im brasilianischen Amazonien zwischen alten Problemen und neuen Dynamiken. Das Beispiel des "Entwicklungskorridors" Cuiabá (Mato Grosso) - Santarém (Pará)', in Innsbrucker Geographische Gesellschaft (ed.) Innsbrucker Jahresbericht 2008-2010, Innsbrucker Geographische Gesellschaft, Innsbruck, 109-129.

Debbané, A. and Keil, R. (2004) 'Multiple disconnections: environmental justice and urban water in Canada and South Africa', Space and Polity, vol. 8, no. 2, 209-225.

Drummond, J. (2008) 'What I would like to see published in environmental justice', Environmental Justice, vol. 1, no. 4, 179-182.

Elden, S. (2010) 'Land, terrain, territory', Progress in Human Geography, vol. 34, no. $6,799-817$.

FAO (2014) 'Faostat', http://faostat.fao.org/site/567/DesktopDefault.aspx?PageID =567\#ancor [accessed 12 November 2015].

Fleck, L. (1980) Entstehung und Entwicklung einer wissenschaftlichen Tatsache, Suhrkamp, Frankfurt am Main.

Fleck, L. (2011) 'Wie entstand die Bordet-Wassermann-Reaktion und wie entsteht eine wissenschaftliche Entdeckung im allgemeinen?', in S. Werner and C. Zittel (eds) Denkstile und Tatsachen: Gesammelte Schriften und Zeugnisse, Suhrkamp, Berlin, 181-210.

Flitner, M. (2007) Lärm an der Grenze: Fluglärm und Umweltgerechtigkeit am Beispiel des binationalen Flughafens Basel-Mulhouse, Steiner, Stuttgart.

García-López, G. A. and Arizpe, N. (2010) 'Participatory processes in the soy conflicts in Paraguay and Argentina', Ecological Economics, vol. 70, no. 2, 196-206.

Gasparri N. I., Grau, H. R., and Gutiérrez-Angonese, J. (2013) 'Linkages between soybean and neotropical deforestation: coupling and transient decoupling dynamics in a multi-decadal analysis', Global Environmental Change, vol. 23, no. $6,1605-1614$.

Gerber, J.-F., Veuthey, S., and Martínez-Alier, J. (2009) 'Linking political ecology with ecological economics in tree plantation conflicts in Cameroon and Ecuador', Ecological Economics, vol. 68, no. 12, 2885-2889.

Groves, C. (2015) 'The bomb in my backyard, the serpent in my house: environmental justice, risk, and the colonisation of attachment', Environmental Politics, vol. 24 , no. $6,1-21$.

Gudynas, E. (2013) 'Die neue alte Entwicklungsstrategie Lateinamerikas: der Extraktivismus und seine Folgen', in H. Burchardt, K. Dietz, and R. Öhlschläger (eds) Umwelt und Entwicklung im 21. Jahrhundert: Impulse und Analysen aus Lateinamerika, Nomos, Baden-Baden, 33-46.

Hansen, M., Potapov, P. V., Moore, R., Hancher, M., Turubanova, S. A., Tyukavina, A., Thau, D., et al. (2013) 'High-resolution global maps of 21st-century forest cover change', Science vol. 342, no. 6,160, 850-853. 
Herod, A. and Wright, M. W. (2002) Geographies of Power: Placing Scale, Blackwell, Malden, MA.

Holifield, R., Porter, M., and Walker, G. (2009) 'Introduction spaces of environmental justice: frameworks for critical engagement', Antipode, vol. 41, no. 4, 591-612.

Hooker, B. (2005) 'Fairness', Ethical Theory and Moral Practice, vol. 8, no. 4, $329-352$.

Hufty, M. (2008) 'Pizarro protected area: a political ecology perspective on land use, soybeans and Argentina's nature conservation policy', in M. Galvin and T. Haller (eds) People, Protected Areas and Global Change: Participatory Conservation in Latin America, Africa, Asia and Europe, NCCR North-South, Swiss National Centre of Competence in Research North-South, University of Bern, Bern, 145-173.

Jerneck, M. (2000) 'Europeanization, territoriality and political time', Yearbook of European Studies, vol. 14, 27-49.

Krapovickas, J., Sacci, L., and Hafner, R. (2016) 'Firewood supply and consumption in the context of agrarian change: the North Argentine Chaco from 1990 to 2010', International Journal of the Commons, vol. 10, no. 1, 220-243.

Kythreotis, A. P. (2012) 'Progress in global climate change politics? Reasserting national state territoriality in a "post-political” world', Progress in Human Geography, vol. 36, no. 4, 457-474.

La Nación (2008) 'La Soja no es un yuyo', 2 April, www.lanacion.com.ar/ 1000732-la-soja-no-es-un-yuyo [accessed 14 January 2016].

Martin, A., Gross-Camp, N., Kebede, B., McGuire, S., and Munyarukaza, J. (2014) 'Whose environmental justice? Exploring local and global perspectives in a payments for ecosystem services scheme in Rwanda', Geoforum, vol. 54, 167-177.

Martínez-Alier, J. (2003) 'Scale, environmental justice, and unsustainable cities', Capitalism Nature Socialism, vol. 14, no. 4, 43-63.

Mehta, L., Allouche, J., Nicol, A., and Walnycki, A. (2014) 'Global environmental justice and the right to water: the case of peri-urban Cochabamba and Delhi', Geoforum, vol. 54, 158-166.

Nepstad, D., McGrath, D., Stickler, C., Alencar, A., Azevedo, A., Swette, B., Bezerra, T., et al. (2014) 'Slowing Amazon deforestation through public policy and interventions in beef and soy supply chains', Science, vol. 344, no. 6,188, 1118-1123.

Nussbaum, M. M. (2013) 'Embedding issues of environmental justice in the mainstream curriculum', Environmental Justice, vol. 6, no. 1, 34-40.

Okereke, C. (2010) 'Climate justice and the international regime', Wiley Interdisciplinary Reviews: Climate Change, vol. 1, no. 3, 462-474.

Porto, M. (2012) 'Complexity, vulnerability processes and environmental justice: an essay in political epistemology', RCCS Annual Review, vol. 4, no. 4, https:// rccsar.revues.org/420 [accessed 14 January 2016].

Rawls, J. (1999) A Theory of Justice, Belknap Press of Harvard University Press, Cambridge, MA.

Reboratti, C. (2012) 'Socio-environmental conflict in Argentina', Journal of Latin American Geography, vol. 11, no. 2, 3-20.

Reca, L. G. (2010) 'Retenciones a las exportaciones agropecuarioas: medio siglo de conflictos y una crisis', in L. G. Reca, D. Lema, and C. Flood (eds) El Crecimiento de la Agricultura Argentina Medio siglo de logros y desafíos, Universidad de Buenos Aires, Buenos Aires, 435-449. 
Roberts, J. T. and Thanos, N. D. (2003) Trouble in Paradise: Globalization and Environmental Crises in Latin America, Routledge, New York.

RTRS (2015) RTRS Standard for Responsible Soy Production, Sao Paulo.

Schlosberg, D. and Carruthers, D. (2010) 'Indigenous struggles, environmental justice, and community capabilities', Global Environmental Politics, vol. 10, no. 4, 12-35.

Stanton, E. A., Boyce, J. K., and Narain, S. (2007) Reclaiming Nature: Environmental Justice and Ecological Restoration, Anthem Press, London.

Taylor, D. E. (2000) 'The rise of the environmental justice paradigm: injustice framing and the social construction of environmental discourses', American Behavioral Scientist, vol. 43, no. 4, 508-580.

Towers, G. (2000) 'Applying the political geography of scale: grassroots strategies and environmental justice', The Professional Geographer, vol. 52, no. 1, 23-36.

Urkidi, L. and Walter, M. (2011) 'Dimensions of environmental justice in antigold- mining movements in Latin America', Geoforum, vol. 42, no. 6, 683-695.

Wapner, P. and Matthew, R. A. (2009) 'The humanity of global environmental ethics', The Journal of Environment \& Development, vol. 18, no. 2, 203-222.

Wilson, S. M., Richard, R., Joseph, L., and Williams, E. (2010) 'Climate change, environmental justice, and vulnerability: an exploratory spatial analysis', Environmental Justice, vol. 3, no. 1, 13-19. 


\title{
10 Greening the imperial mode of living?
}

\author{
Socio-ecological (in)justice, \\ electromobility, and lithium mining \\ in Argentina
}

Axel Anlauf

\section{Introduction $^{1}$}

How can we reach a wide-ranging de-carbonization within the twentyfirst century? Obviously, the transport sector is of particular importance.

(German Chancellor Angela Merkel (Bundesregierung, 2015, author's translation))

This quote from a speech by Angela Merkel held at the National Conference on Electromobility in Berlin in June 2015 demonstrates the importance major policy makers attribute to electric vehicles as a 'green' alternative to fossil fuels in the context of climate change and peak oil. Within the discourse of a Green Economy (UNEP, 2011), these vehicles might invoke the image of environmentally friendly technologies and sustainable transport solutions. This chapter challenges these assumptions from a political ecology perspective (see Pichler, in this volume), focusing on asymmetries of power and transnational justice implications with regard to a specific commodity: lithium. Although the metal has been exploited for several decades for a variety of applications (e.g. lubricants and ceramics), current battery systems for electric vehicles make lithium an indispensable resource, leading to a "lithium rush" (Koerner, 2008). The primary targets of this rush are the salt brines of the 'lithium-triangle' in the Andean highland plateau between Bolivia, Chile, and Argentina, where the majority of the world's lithium deposits are located (and where the extraction is most profitable). Argentina is of particular importance as it is home to a number of emerging lithium extraction projects that receive major investments from car and battery producers and/or their suppliers. To better understand the local implications of the global lithium rush, the chapter analyses the Olaroz lithium project in the province of Jujuy, and reflects on its socio-ecological impacts and transnational connections. Drawing on the concept of the imperial mode of living (Brand and Wissen, 2013), I argue that green economy strategies are built on global and local 
asymmetries of power, and spatially and temporarily externalize ecological and social costs. Therefore, they fail to promote socio-ecological justice, but are rather 'greening' the imperial mode of living.

The research is based on a qualitative case study of the Olaroz project in which transnational corporations (TNCs) interact with the provincial state of Jujuy and local indigenous communities. During a two-month field research from March to May 2014, 22 semi-structured interviews were conducted with local government representatives, company managers and engineers, researchers, as well as local community representatives.

The chapter proceeds as follows: After clarifying the theoretical concepts and the political economic context of lithium extraction, I illustrate the actors involved in the project and demonstrate their interests and strategies in order to analyse socio-ecological conflicts against the backdrop of asymmetric power relations among these actors.

\section{Green economy, the imperial mode of living, and socio-ecological justice}

Amidst signals of multiple crisis dimensions (e.g. financial, economic, climate, energy), political parties and international organizations proposed various 'green' strategies. Among these strategies are the Green New Deal (Green European Foundation, n.d.), Green Growth (OECD, 2011), and a Green Economy (UNEP, 2011). ${ }^{2}$ The common element of these suggestions is to harmonize economic growth, poverty reduction, and ecological concerns, understanding the recent economic crisis as an opportunity for investment in 'green' sectors. While these sectors also include market-based conservation mechanisms or biotechnologies, the strongest emphasis is on reducing fossil fuel dependence with investments in alternative energy and technologies. I refer to this latter strategy by the terms 'green' and 'greening'. Viewing the "gross misallocation of capital" as the "common feature" causing different crisis dimensions (UNEP, 2011: 14), a green economy is to be achieved by changing taxes, subsidies, and investment incentives.

Electromobility is an important element of the envisioned green economy (UNEP, 2011: 404; OECD, 2011: 68-69; Green European Foundation, n.d.). Significant amounts of the thousands of billions of dollars that were spent to counter the 2007/2008 economic crisis were dedicated to support green technologies in the automotive industry in OECD countries (for an overview see OECD, 2009: 22-29). Whereas full electric cars still lack consumer acceptance due to low kilometre range and long charging times, hybrid cars in particular have already significantly contributed to regaining growth in the automotive industry. For example, in 20121.2 million out of 8.7 million cars sold by leading automotive manufacturer Toyota were hybrid vehicles (Toyota Motor Corporation, 2015).

While there is a growing agreement that "present patterns of transportation [...] are highly unsustainable" (UNEP, 2011: 380), the proponents of 
a green economy rarely consider the sustainability and justice implications of 'green' technologies. The concept of the "imperial mode of living", in turn, highlights these connections and the underlying modes of production and living:

Exclusive access to resources, guaranteed by contract or through open violence, and the externalization of the socio-ecological costs that using these resources entails, are the conditio sine qua non of the global North's mode of living, which we therefore call 'imperial'.

(Brand and Wissen, 2013: 699)

From a Gramscian perspective, Brand and Wissen (2013) introduced the concept referring not only to dominant fossilist patterns of consumption and production but also to the overarching orientation towards economic growth and competitiveness of state institutions, which shape the perceptions and actions of politicians. Adapting individual automotive mobility to renewable energies ${ }^{3}$ makes it possible to keep up a fossilist consumption pattern of symbolic significance for the imperial mode of living, including the built environments of streets, highways, and housing or working areas. Furthermore, electric vehicles provide new means of accumulation for a sluggish car industry. For their production, the industry not only requires new technologies but also a different supply of resources, among which lithium is crucial. The focus on the extraction of these resources allows us to cast a different light on the sustainability implications promoted by the proponents of a green economy.

Building on Pichler's political ecology perspective on socio-ecological justice (this volume), I highlight unequal power relations and the structural conditions of resource extraction for electromobility. While green economy strategies might promote sustainability with regard to fossil fuel dependence and $\mathrm{CO}_{2}$ emissions, they are far from promoting socio-ecological justice as "self-determination and equality in the access to and control over nature and natural resources" (Pichler, in this volume, 48). Crisis strategies such as a green economy are notably silent on the issues of power and democracy. A very well-referenced report by the ETC-Group (2011) argues that a green economy, as it is currently unfolding, will lead to the concentration of market shares and power of those companies already dominating the global economy. In the transport sector, Toyota Motors, one of the major players of the 'brown' automotive industry, is also positioning itself to become a leader of electromobility. At the same time, new 'green' capital fractions such as Tesla Motors emerge.

A focus on actors involved in resource extraction and processing is a fruitful point of entry for understanding the injustices on which the imperial mode of living is based and which are reproduced through its greening. Bryant and Bailey (1997) developed an actor-oriented political ecology approach to study the unequal power relations in socio-ecological conflicts. 
They define power as the "ability of an actor to control their interaction with the environment and the interaction of other actors with the environment" (Bryant and Bailey: 1997: 39). From this perspective, socioecological conflicts, particularly those publicly expressed, are "important moments when underlying structures of power and real interests are most revealed" (Turner, 2004: 864). ${ }^{4}$

\section{The political economic context of lithium extraction}

Lithium technologies have become dominant in batteries for electric cars and other applications due to their advantages regarding costs, capacity, and efficiency (Roland Berger Strategy Consultants, 2012). While lithiumion batteries are well-established, competing technologies - such as fuel cells - that might become more attractive in the mid- to long term, have only recently entered consumer markets. The raw material lithium carbonate represents about 2 per cent of the value of a battery cell and the overall market volume was relatively small at US\$2,200 million in 2012 (COCHILCO, 2013: 1). However, lithium is becoming a resource of strategic importance for battery technologies due to its high electrochemical potential (Roland Berger Strategy Consultants, 2012: 35-37). Against this background, various (inter)governmental and independent reports highlight the strategic importance of the metal (e.g. European Commission, 2014: 24; Gunn, 2014). Currently, portable electronics (e.g. smartphones or notebooks) are driving the lithium demand. However, the required lithium input per unit for a hybrid or electric car is 100 to 1,000 times higher than for a smartphone or a notebook which helps to anticipate possible long-term trends and interests in lithium deposits (SignumBOX, cited in Fox-Davies Capital 2013: 7-8).

South America is of particular importance for the lithium market since it hosts the majority of lithium deposits and has the lowest production costs at about US\$2,000 per ton (Orocobre, 2013: 13). With world market prices at over US\$6,000 per ton that are projected to remain stable (Villaroel, 2014), investing in these projects provides an opportunity to gain high returns on investments for surplus capital that is seeking realization in the context of a crisis of over-accumulation. Hence, a multitude of new projects has started in South America, with different political and legal conditions. While Bolivia pursues a strategy of state-led industrialization, Chile has a restrictive legal framework that makes it difficult for companies to receive concessions for lithium resources (COCHILCO, 2013). Argentina, in turn, has a relatively business-friendly mining legislation and large amounts of high quality resources. This combination has attracted many companies that started lithium extraction projects in the different salt lakes or salares of the Andean Northwest. This chapter focuses on the Olaroz project which entered commercial production in December 2014 as the first of these new projects (Orocobre, 2014). Due to these projects, 
Argentina is expected to become the leading producer of lithium compounds by 2020 (COCHILCO, 2013: 20; Villaroel, 2014) or in investment-market words "the global powerhouse of lithium mining" (Filice, 2013). The lithium boom in Argentina is located within a general expansion of the mining frontier. A number of neoliberal reforms in mining regulation that came into effect in the mid-1990s during the presidencies of Carlos Menem have facilitated this expansion. Back then, Menem introduced regulations to attract transnational capital for investment that have not changed since the ascent of the Kirchner administration. In fact, in 2004, then-president Néstor Kirchner evaluated the prevailing legislation as "very positive" and aimed to "consolidate the process of mining investment and development in Argentina" with his National Mining Plan (cited in Svampa et al., 2009: 36). The administrations of Néstor Kirchner and his widow Cristina Fernández de Kirchner are seen as part of a wider Latin American phenomenon of "post-neoliberal" governments (Grugel and Riggirozzi, 2010). While these governments claim an increased share of export revenues for social redistribution and even promote selective reindustrialization, they rarely question the extractivist model of exporting raw materials in the context of a robust resource boom (Gudynas 2009).

Mirroring national policies, the provincial governors of Jujuy, Eduardo Fellner and Walter Barrionuevo from Kirchner's Justicialist Party, have, since 2003, developed new alliances and social policies since 2003 which are mostly directed towards marginalized urban classes (Battezzati, 2012). Similar to other provinces of the Andean northwest, Jujuy's economic dynamic stems from the appropriation of natural resources and their insertion into global value chains (Paolasso et al., 2013). Seventy-eight per cent of the province's exports are primary products, and the mining sector makes up more than half of exports (Ministerio de Economia y Finanzas Publicas, 2011: 2-3). Securing the valorization of natural resources for capital accumulation is therefore of particular importance for the political project of social redistribution in the absence of other significant economic activities.

\section{Actors, interests, and strategies in the Olaroz project}

The Olaroz project is operated by the company Sales de Jujuy, a joint venture of the Australian mining company Orocobre, the Japanese Toyota Tsusho Corporation, and Jujuy's state-owned mining and energy enterprise Jujuy Energía y Minería Sociedad del Estado (JEMSE). The salar de Olaroz is located in the Andean highland plateau, called puna, near the Chilean and Bolivian borders at approximately $3,900 \mathrm{~m}$ above sea level. Although the installations for extracting and processing the minerals are relatively small, the project affects a number of indigenous communities in the surrounding area, mainly due to hydrological dynamics. 


\section{The Australian mining company Orocobre}

As the name indicates, the Australian mining company Orocobre originally planned to exploit gold (Spanish: oro) and copper (Spanish: cobre) in Argentina because of a "highly prospective" geology, and Argentina's "standardised federal mining framework and attractive investment regime" (Orocobre, 2009a: 3). In May 2009, however, after the chaotic breakdown of the 2007/08 crisis, Orocobre started to exclusively focus on lithium, when US-based Lithium Investors invested US\$5.4 million into the "rapid development of the Olaroz Lithium-Potash Project" (Orocobre, 2009b). In the wake of the economic crisis and an emerging green mobility sector, financial capital identified lithium as a sector with high profit margins. As secured funding is a major issue for junior mining companies (Filice, 2013), Orocobre was obliged to please its investors and secure their participation by completing the rapid development of the Olaroz project.

\section{The Japanese Toyota Tsusho Corporation (TTC) and associates}

TTC is part of the Japanese Toyota group and provides material supplies to its parent conglomerate as well as to other East Asian companies such as Panasonic and Sanyo (Toyota Tsusho Corporation, 2014). Toyota Motors and Panasonic formed a joint venture to develop and produce battery packs for hybrid cars which had recently shifted to lithium technologies. In the wake of growing demand, Toyota Motors and Panasonic plan to increase the production of lithium-ion batteries by six times at their Omori plant in Japan (Filice, 2014). When entering into an agreement with TTC, Orocobre (2010) stated: “Toyota Tsusho's interest in the project stems from the desire to increase its exposure to reliable and diversified lithium supplies as global demand for lithium batteries in the automotive sector continues to grow" (2). According to Kentaro Tanimoto, mining manager at TTC, the company will obtain all but 5 per cent of the lithium carbonate produced at Olaroz (Interview 1). The mother company Toyota Motors is to become the "first and potentially the primary customer" (Dowling, 2010).

The strategic importance of lithium is emphasized by the fact that the Japanese government's Japan Oil, Gas and Metals National Corporation (JOGMEC) assisted TTC with initial surveys and debt guarantees for the Olaroz project. According to TTC, "for Japan, with its sparse energy resources, securing stable resource supplies is a core part of national strategies" (Toyota Tsusho Corporation, 2014). The Olaroz project shows both the importance of the material resource base for green technologies as well as the willingness of state institutions to secure strategic resources for domestic industrial production beyond its own territory in the wake of increasing competition for the earth's resources (Brand and Wissen, 2013). 


\section{The provincial state of Jujuy - JEMSE}

In March 2011, the provincial government declared lithium a strategic resource to "generate socio-economic development in the whole province of Jujuy" (Gobierno de Jujuy, 2011). While it remains unclear what precisely this means or how it will be realized, the state defined new rules of legality, making an association with the simultaneously-created state enterprise JEMSE a necessary condition for the approval of lithium projects in the province. JEMSE would obtain an 8.5 per cent share of the lithium companies operating in Jujuy as well as 5 per cent of the produced lithium carbonate. Orocobre (2012) views the JEMSE agreement as an "important milestone for the Company, closely aligning the interests of the Province of Jujuy with those of Orocobre and its project partners" (10). By national law, the provinces can charge a maximum royalty rate of 3 per cent. Against this background, Javier Elortegui, mining director of the provincial government, describes the creation of JEMSE as a means of increasing the income gained from the mining operations without violating national norms (Interview 2). The expansion of lithium mining is of particular importance for the province of Jujuy. First, lithium carbonate could become its single most important export good, increasing the total export value by 50 per cent. Second, the provincial government aims at creating local added value in the lithium battery value chain with the 5 per cent of the product it obtains from the lithium projects. Currently, the government is preparing to build a pilot plant in an old steel factory near the provincial capital of San Salvador de Jujuy (Interview 2). At the moment, however, there is no local company with the technological know-how or capital to join the project and the provincial state faces the technological challenge of installing a highly complex plant that has to be competitive with cathodes, cells, or batteries of leading international firms who are constantly investing in product improvement. For example, with an investment of US\$4 billion Tesla's Gigafactory exceeds the annual budget of the entire provincial state by a factor of 4 (Ministerio de Hacienda, 2013). Despite a strong discourse on industrializing lithium resources (La Gaceta, 2014) and several research and development initiatives in cooperation with national entities, these asymmetries are currently deepening Jujuy's dependence on lithium extraction and the export of natural resources (Anlauf, 2014, Chapter 8).

\section{Local communities}

The adjacent salt lakes of Olaroz and Cauchari are located in the centre of the department of Susques which is inhabited by almost 4,000 people, who live spatially dispersed in a total of ten communities of up to several hundred people each. According to official data, in Susques 67 per cent of the households lack basic necessities (Garcia Moritán and Cruz, 2011: 15). 
Basic infrastructure is often absent and Göbel (2013) even speaks of a "historic vacuum of the state" (145) in this peripheral region. The whole department of Susques is located in the Puna de Atacama, which is among the most arid regions in the Andean highlands, having only scattered grass and shrub vegetation while water sources are scarce (Göbel, 2008: 223-224). These conditions require extensive areas for the main economic activity: pastoral farming of llama, goat, and sheep. Livestock are mainly used for wool, leather, and meat production, either for subsistence or for trade. Although many families deploy flexible income strategies, including (temporary) wage labour, this does not imply any intention to give up pastoral farming, since it is of great cultural significance. According to Göbel (2013: 143), the close interaction with nature and the resulting knowledge are fundamental parts of an identity of difference. This Atacama identity (re-)surged in a politicization process in the 1990s, alongside political selforganization with broad social participation. As a result, the communities received legal recognition as aboriginal communities with juridical personality in the early 2000s. Based on the ILO Convention 169 that Argentina ratified in 2000, these communities also received communal land rights, and created an autonomous community administration. While this reorganization took place without any official funding, the old structures of the state, namely the municipal commission which is tied to political parties and funded by the state, continued to exist (Göbel, 2013: 143-144). The companies took advantage of the ill-designed autonomous administration as well as the historical vacuum of the state. While local residents, particularly those engaging in pastoralism, have a strong interest in a sound environment, many also feel an urgent need for (immediate) improvements of their material well-being.

\section{Territorial transformation and socio-ecological conflicts}

In order to better understand the socio-ecological conflicts around lithium extraction, this section starts with a brief hydrological excursus. Beneath the salt surface crust of the salar de Olaroz is a deep basin containing the salt brine which has developed over thousands of years. For the production of 17,500 tons of lithium carbonate per year, 2401/sec of salt brine are extracted by a number of wells. The brine is then concentrated in evaporation basins before it is introduced to a chemical plant where lithium carbonate is produced. With the help of fresh water, the lithium carbonate is washed to the required purity of $>99.5$ per cent (Interview 3). The environmental impact report of the Olaroz project considers the impact of the fresh water extraction of up to $201 / \mathrm{sec}$, which may lower the level of the aquifer (Ambiental, 2011: section 5.3). According to the report, this would be the only lasting impact of the project, which will be reversed in the medium term after the operations have ceased. The report, however, fails to mention the extraction of salt brine, which exceeds the former 
extraction of salt brine by the factor of 12 . Although the impacts of brine extraction are not mentioned, one has to consider that at the margins of the salar, the brine is also in contact with a layer of fresh water located above the brine because of its lower density. While the fresh water discharges towards the surface because of pressure, extracting huge amounts of brine has the risk of lowering the groundwater level and reducing the pressure. This could lead to the disappearance of wetlands and lagoons, which are mainly nurtured by subterranean waters instead of rain. These wetlands and lagoons are central for flora and fauna habitats and thus for human life, particularly for pastoralism (Messerli et al., 1997: 235; Gallardo, 2011). A significant amount of these subterranean waters are considered fossil water, which is "renewed extremely slowly, or [is] even non-renewable" (229). Considering this matter, mining geologist Diana Mutti comments that "no one knows how much fossil water the companies are extracting and no one knows how this will affect the hydrological system of fossil water in the Puna" (Interview 4)..$^{5}$ Against the backdrop of the water consumption and its effects on the ecosystem, the geologist Fernando Díaz concludes:

This exploitation affects the ecosystem, the fauna, the migration of birds, the camelids, and also the human population. Even if they are not many in number, they have particular ethnic characteristics and any exploitation that doesn't preserve the communities is to be considered ethnocide.

(Cited in Gallardo, 2011: 29, author's translation)

While the term ethnocide may seem dramatic, the lithium extraction indeed threatens the very existence of the local communities, particularly their ancestral form of production which is central for their identity. While the direct land use changes are relatively small and only affect a number of families from specific communities, a bigger impact on a much larger area occurs in the process of valorization, once the identified and secured resource (lithium) is extracted. The extraction of lithium reconfigures the use of water (salt brine or fresh waters), hitherto an essential part for the equilibrium of an extremely arid ecosystem, for the production for external markets. Hence, lithium mining intervenes in the communally managed territory and claims disproportionate, exclusive usage of the scarce resource water. Since pastoralism is highly dependent on the equilibrium of the ecosystem and the availability of water sources, lithium extraction is likely to influence a far greater territory than that affected by direct land use changes.

Up to now, however, neither the mining companies nor the provincial government have integrated the concerns of local people into the project development. For Orocobre, the rapid development of the Olaroz project became imperative in mid-2009. Hence, respecting the valid norms 
regarding indigenous rights, including appropriate consultations with potentially slow community procedures - not to mention a potential rejection of the project - are not conducive to the company's interests. The following statement by Alejandro Calpanchay, a resident of the community Susques, who used to work on the construction of the Olaroz plant reflects this process:

Two or three years ago we didn't want to [approve the project] because we didn't know about the topic, we didn't know what was going to happen over time. We had our doubts. And afterwards, people from Jujuy were coming [to say] that we should hurry [...]. The company Sales de Jujuy came on strong, it wanted to start working right away(!), right away and well we didn't want to, we didn't want to, we didn't want to, and finally we agreed. I don't know where this is taking us, I don't know!

(Interview 5)

This statement reveals that while there was formal community approval, local decision-makers were pressured to make a decision without being provided with sufficient information that would have been necessary for a democratic negotiation. Although the valorization of the lithium resources was formally open for contestation, the minutes of those meetings held to approve the project show that in various communities, these meetings were attended by less than 20 people, even in the community of Susques, where almost 1,000 people live. Critics such as Carlos Guzmán denounce the irregularity of this approval since the statute of the community says that at least 50 per cent of the community has to approve projects affecting all the inhabitants (Interview 6). The approval therefore has an undemocratic character, as the public sphere was explicitly closed to those whose participation would have been legally required. Furthermore, the question of how the valorization of lithium would occur, that is, under which circumstances and with which consequences (see above), was never open for contestation as the uncertainty and lack of information in the above-cited statement shows. This uncertainty is very common among local residents even people in the community leadership such as Josefa Barrios from Puesto Sey answered questions about their opinion on the project with "I don't know, I don't know. I know they are working there, but, [...] I don't understand a lot of this" (Interview 7).

Instead of informing the population and respecting community procedures on decision making, the company mostly negotiated with the municipal commission, a state institution dependent on political parties. Sales de Jujuy found stable partners among local leaders who were willing to cooperate and helped to get them into key positions in the municipal commission. These relatively young leaders, often re-migrants from the cities, accepted jobs in the companies and hence developed a self-interest in successful 
project development. Furthermore, the lithium company gained a relatively high degree of legitimacy by (at least temporarily) filling the historic vacuum of the state. It provided free services, including transport, health care (e.g. ophthalmology and dentistry), as well as education (e.g. metallurgy training and a school library). However, many of these services stopped once the project was approved (Göbel, 2013; Anlauf 2014, Chapters 7-8).

Although these procedures are in clear violation of the legal norms regarding indigenous peoples' rights to prior consultation and participation in the management of their resources, the provincial state authorities regarded these procedures as legal. It is precisely the capacity of the state to define legality that constitutes its main power dimension. The mining companies, in turn, did not only have the financial and organizational capacity to co-opt local leaders. They also possessed the necessary technology and capital to enable new rounds of accumulation via the valorization of natural resources which generates export revenues needed for the political project of the provincial and national state. The provincial state is therefore actively encouraging the extraction of lithium within its territory and does not intervene in the conflict between lithium companies and local communities. Historically marginalized, not accustomed to Western knowledge systems, and without means to access important information (e.g. through the internet), most residents of the indigenous communities in the department of Susques had to rely on partial information provided by companies and the government. This lack of information and access largely excluded them from the decision-making process, which has resulted in highly unequal access to and control over natural resources, especially water. Despite their legal personality and communal land holdings, the company's strategy was largely successful in defusing protest by filling the vacuum of the state, while local leaders also saw the company's presence as an opportunity to improve the material well-being of the communities.

The issue of water consumption and the conflict over the unequal distribution of water resources, however, led a group of pastoralist families to start organizing protest in the "Colectivo Apacheta". ${ }^{6}$ Their spokesperson Carlos Guzmán explains:

We formed the collective because of the fear of being left without water; because of not having consented [to the project]; because of not having had all the necessary conversations with us as small producers before they would take all of the water and all the minerals. [...] We want legal participation. We have been taking care of this land since our grandfathers and our great-grandfathers. We are the owners, but until now, [we haven't received] anything.

(Interview 6)

This quote demonstrates a great degree of awareness of the unequal allocation of costs and benefits, but also the aforementioned exclusion that is 
perceived as injustice, because local residents are losing access to and control over the critical resource of water. While bearing this cost, they are largely excluded from the benefits that are not only obtained by the mining companies. As discussed above, the production of electric and hybrid vehicles helped to regain growth in the global North in times of economic crisis. The massive valorization of lithium resources in South America for electromobility also helps to keep up the imperial mode of living with regard to mobility in times of peak oil and climate change. While car producers and consumers in the global North pride themselves on the implementation of cleaner technologies, these are produced at the expense of livelihoods of marginalized people in the global South. If socio-ecological justice was established and these people could exercise democratic control over their environment, it would be more difficult to find socially and environmentally just solutions in the mobility sector. Such solutions would require the reorganization of consumption patterns, built environments, production patterns, etc.: in short, the abandonment of the imperial mode of living, because it is built on the exclusive access to these resources. It is precisely the marginalized people's demand of the "right to equality" that "renders visible and exposes the 'wrongs' of the existing [socio-political] order" (Swyngedouw, 2009: 606). To claim their participation in the reordering of arrangements of ownership, control, and distribution, the Colectivo Apacheta has initiated a number of legal initiatives. For example, together with a lawyer from San Salvador de Jujuy, they denounced the validity of the approval process. They support this legal initiative with direct action, such as road blockades. Hitherto the alliance of TNCs and state apparatuses, however, has successfully resisted a democratization of society-nature relations towards a more equal access to and control over natural resources.

In the course of the conflict, "the naming of different possible socioenvironmental futures" (Swyngedouw, 2010: 228) becomes an important moment of democratization and socio-ecological justice as the selfdetermination over natural resources. First and foremost, the Colectivo Apacheta wants to strengthen pastoralism. Susques-based pastor Irma Soriano highlights the importance of this form of production against Western visions of 'development':

A thousand times, I prefer my field over cars or money. [...] If you are going to the city everything is money. If you have cattle, you already have everything. You have something to eat, you have something to weave, you have something to sell, everything!

(Interview 8)

As parts of an alternative future, Carlos Guzmán also envisions the (re-)introduction of agricultural crops such as quinoa or potato and community-controlled tourism. The Colectivo's initiative to receive funding 


\section{A. Anlauf}

for nightposts and other improvements for pastoralism, however, was denied by the national ministry of social development as "not viable" (Interview 6). In contrast to the mining activities in the area which are actively encouraged by state-apparatuses, small-scale pastoral production does not receive support. This makes it even more difficult for the local residents to exercise democratic control over natural resources, but it is precisely the vision of self-determination that becomes a foundational part of socio-ecological justice for the Colectivo Apacheta: "It's enough of them making money with what belongs to us. We will defend and fight until we have our land as it is, because we already know how to live" (Interview 6).

\section{Conclusion}

Taking up the case of lithium, this chapter has demonstrated that a shift from fossil fuelled to electric cars still relies on the exclusive access to (strategic) resources. Based on a green economy strategy and corresponding regulation, societal nature relations are moving away from the dependence on fossil fuels and becoming 'greener'. However, there is no significant alteration in the patterns of production and consumption which structure societal nature relations. The analysis of the impacts of lithium extraction in Argentina shows that - facilitated by asymmetric power relations - these green technologies spatially and temporarily externalize socio-ecological costs and constitute a continuation of the Global North's imperial mode of living. While a Green Economy might promote more sustainability in the sense of lowering fossil fuel consumption and $\mathrm{CO}_{2}$ emissions, it is by no means promoting socio-ecological justice. The case study of lithium extraction in the province of Jujuy shows that most parts of the affected local population were excluded from the decision-making process, that is, the valorization of lithium resources for capital accumulation was never really open for political contestation. Hence, in association with the provincial state of Jujuy and those states hosting their production facilities, TNCs have the power to control the environment of local communities, appropriating them of local resources for transnational cycles of accumulation. These resources are feeding an emerging green economy that is promoting sustainability without questioning the dynamics fostering environmental degradation and social inequalities at the local level. The exclusive access to fresh water and salt brine for lithium extraction marginalizes other forms of societal nature relations such as pastoralism which relies on the integrity and reproduction of the ecosystem. With a high awareness of this process, a small group of pastoralists started to organize protest, claiming their 'right to equality' through participation and control of local land and water resources. Although they have not been able to influence the operations at the salar de Olaroz yet, their claims to equality and selfdetermination allow us to grasp the flaws of a green economy from the 
perspective of socio-ecological justice. This shows that we need to think a socio-ecological transformation beyond a 'greening' of current modes of production and living to include the claims of the most marginalized.

\section{Notes}

1 Field research for this chapter was generously supported by the Rosa Luxemburg Foundation in Germany.

2 For the remainder of this chapter, I use the term green economy to refer to this bundle of strategies.

3 The energy source fuelling electric vehicles obviously depends on the respective electricity supply, which is still dominated by fossil fuels, such as coal. However, electromobility can potentially be powered by renewables.

4 For an overview of the field, see Pichler, in this volume.

5 All direct interview quotes were translated by the author from Spanish to English.

6 Apacheta is a mound of rocks, constructed by the indigenous peoples of the Andean highlands as an offer to Pachamama (mother earth) or other goddesses.

\section{References}

Ambiental (2011) Primera Actualización del Informe de Impacto Ambiental Etapa de Explotación del Salar de Olaroz, Departamento Susques, Provincia de Jujuy, Ambiental, Buenos Aires.

Anlauf, A. (2014) 'Towards mining development with environmental provision and social inclusion? The political ecology of lithium extraction in Jujuy, Argentina from a global perspective', MA thesis, Roskilde University, Denmark.

Battezzati, S. (2012) 'La Tupac Amaru: intermediación de intereses de los sectores populares informales en la provincia de Jujuy', Desarrollo Economico, Revista de ciencias sociales, vol. 52, no. 205, 147-171.

Brand, U. and Wissen, M. (2013) 'Crisis and continuity of capitalist society-nature relationships: the imperial mode of living and the limits to environmental governance', Review of International Political Economy, vol. 20, no. 4, 687-711.

Bryant, R. and Bailey, S. (1997) Third World Political Ecology, Routledge, London.

Bundesregierung (2015) 'Rede von Bundeskanzlerin Merkel zur Nationalen Konferenz "Elektromobilität - Stark in den Markt" am 15. Juni 2015 in Berlin', www.bundesregierung.de/Content/DE/Rede/2015/06/2015-06-15-elektromobilitaet.html [accessed 31 August 2015].

COCHILCO (2013) 'Compilación de informes sobre: mercado internacional del litio y el potencial de salares en el norte de Chile', www.minmineria.gob.cl/wpcontent/themes/minmineria/documentos/InformeLi.pdf [accessed 26 June 2014].

Dowling, N. (2010) 'Toyota powers up on Aussie lithium project for future electric and hybrid cars', Perth Now, 20 January, www.perthnow.com.au/business/ toyota-powers-up-on-aussie-lithium-project-for-future-electric-and-hybrid-cars/ story-e6frg2qc-1225821608841 [accessed 17 October 2014].

ETC Group (2011) 'Who will control the green economy', www.etcgroup.org/sites/ www.etcgroup.org/files/publication/pdf_file/ETC_wwctge_4web_Dec2011.pdf [accessed 30 August 2015]. 
European Commission (2014) 'Report on critical raw materials for the EU', http:// ec.europa.eu/enterprise/policies/raw-materials/files/docs/crm-report-on-criticalraw-materials_en.pdf [accessed 17 October 2014].

Filice, L. (2013) 'Argentina: home to emerging lithium producers', Seeking Alpha, 8 December, http://seekingalpha.com/article/1883921-argentina-home-toemerging-lithium-producers [accessed 26 June 2014].

Filice, L. (2014) 'Toyota's lithium-based future', Seeking Alpha, 3 March, http:// seekingalpha.com/article/2062623-toyotas-lithium-based-future? source=google_ news [accessed 26 June 2014].

Fox-Davies Capital (2013): 'The lithium market', www.globalstrategicmetalsnl. com/_content/documents/405.pdf [accessed: 26 June 2014].

Gallardo, S. (2011) 'Extracción de litio en el Norte argentine: la fiebre comienza', EXACTAmente - La revista de divulgación científica, vol. 18, no. 48, 26-29, http://revistaexactamente.wordpress.com/2011/10/25/extraccion-de-litio-en-elnorte-argentino/ [accessed 17 October 2014].

García Moritán, M. and Cruz, M. B. (2011) 'Comunidades originarias y grupos étnicos de la provincia de Jujuy', http://proyungas.org.ar/wp-content/uploads/ 2014/12/Cartilla_Etnias_Jujuy.pdf [accessed 26 June 2014].

Göbel, B. (2008) 'Dangers, experience, and luck: handling uncertainty in the Andes', in M. Casimir (ed.) Culture and the Changing Environment. Uncertainty, Cognition, and Risk Management in Cross-Cultural Perspective, Berghahn, Oxford, 221-250.

Göbel, B. (2013) 'La minería del litio en la Puna de Atacama: Interdependencias transregionales y disputas locales', Iberoamericana. América Latina - EspañaPortugal, vol. 49, 135-150.

Gobierno de Jujuy (2011) 'Decreto-Acuerdo No. 7592/2011', http://cdn.ipernity. com/118/03/99/10150399.525cb637.pdf [accessed 17 October 2015].

Green European Foundation (n.d.) 'Green new deal', http:/greennewdeal.eu/ [accessed 17 October 2015].

Grugel, J. and Riggirozzi, P. (2010) 'Post-neoliberalism in Latin America: rebuilding and reclaiming the state after crisis', Development and Change, vol. 43, no. $1,1-21$.

Gudynas, E. (2009) 'Diez tesis urgentes sobre el nuevo extractivismo: contextos y demandas bajo el progresismo Sudamericano actual', in J. Schuldt, A. Acosta, A. Barandiarán, A. Bebbington, M. Folchi, CEDLA - Bolivia, A. Alayza, et al. (eds) Extractivismo, Politica y Sociedad, CAAP and CLAES, Quito, 187-225.

Gunn, G. (2014) Critical Metals Handbook, Oxford, Wiley.

Koerner, B. I. (2008) 'The Saudi Arabia of lithium', Forbes, 6 October 2008, www. forbes.com/forbes/2008/1124/034.html [accessed 24 June 2014].

La Gaceta (2014) 'Giorgi: "La producción de litio es clave para el desarrollo industrial de la región del NOA", www.lagaceta.com.ar/nota/589520/economia/ giorgi-produccion-litio-clave-para-desarrollo-industrial-region-noa.html [accessed 17 October 2015].

Messerli, B., Grosjean, M., and Vuille, M. (1997) 'Water availability, protected areas, and natural resources in the Andean desert altiplano', Mountain Research and Development, vol. 17, no. 3, pp. 229-238.

Ministerio de Economia y Finanzas Publicas (2011) 'Fichas provinciales: Jujuy', www.mecon.gov.ar/peconomica/dnper/fichas_provinciales/Jujuy.pdf [accessed 24 June 2014]. 
Ministerio de Hacienda (2013) 'Presupuesto sintético 2013', www.hacienda.jujuy. gov.ar/wpcontent/uploads/presupuesto/sintetico/sintetico2013.pdf [accessed 26 June 2014].

OECD (2009) 'Responding to the economic crisis: fostering industrial restructuring and renewal', www.oecd.org/industry/ind/43387209.pdf [accessed 26 June 2014].

OECD (2011) 'Towards green growth', www.oecd.org/greengrowth/48224539.pdf [accessed 26 June 2014].

Orocobre (2009a) 'A lithium and potash producer in the making', Company presentation, 17 February, http://orocobre.com.au/PDF/ASX_17Feb09_Company\%20 Presentation.pdf [accessed 26 June 2014].

Orocobre (2009b) 'Placement to strategic cornerstone investor', ASX announcement, 11 May, http://orocobre.com.au/PDF/ASX_11May09_Placement\%20 to \%20Strategic\%20Cornerstone \%20Investor.pdf [accessed 26 June 2014].

Orocobre (2010) 'Orocobre and Toyota Tsusho announce JV to develop Argentine lithium project', ASX Announcement and Media Release, 20 January, http:// orocobre.com.au/PDF/ASX_20Jan10_Orocobre $\% 20$ and $\% 20$ Toyota $\% 20$ Tsusho\%20Announce\%20JV.pdf [accessed 26 June 2014].

Orocobre (2012) 'Annual report 2012', http://orocobre.com.au/PDF/29Oct12_ 2012AnnualReport.pdf [accessed 26 June 2014].

Orocobre (2013) 'Investor update May 2013', www.orocobre.com.au/PDF/ 9May13_InvestorPresentation.pdf [accessed 26 June 2014].

Orocobre (2014) 'Opening ceremony of Olaroz lithium project', http://orocobre. com.au/PDF/ASX5Dec14_Olaroz_Opening.pdf [accessed 28 August 2015].

Paolasso, P., Rainer, G., Ruiz Peyré, F., and Coy, M. (2013) 'Entwicklungstendenzen im ländlichen Raum Nordwestargentiniens', Geographische Rundschau, vol. 65 , no. $12,14-21$.

Roland Berger Strategy Consultants (2012) 'The lithium-ion battery value chain', www.icatconf.com/Sunumlar/SESSION4/3_LiB-Market-Overview-SHORT_ 2012-08-03_TR\%20version.pdf [accessed 27 June 2014].

Svampa, M., Botaro, L., and Sola Álvarez, M. (2009) 'La problemática de la minería metalífera a cielo abierto: modelo de desarrollo, territorio y discursos dominantes', in M. Svampa and M. Antonelli (eds) Minería Transnacional, Narrativas del Desarrollo y Resistencias Sociales, Buenos Aires, Editorial Biblos, 29-50.

Swyngedouw, E. (2009) 'The antinomies of the postpolitical city: in search of a democratic politics of environmental production', International Journal of Urban and Regional Research, vol. 33, no. 3, 601-620.

Swyngedouw, E. (2010) 'Apocalypse forever? Post-political populism and the spectre of climate change', Theory, Culture \& Society, vol. 27, no. 2-3, 213-232.

Toyota Motor Corporation (2015) 'Vehicle production, sales and exports by region', www.toyota-global.com/company/profile/figures/vehicle_production_ sales_and_exports_by_region.html [accessed 30 August 2015].

Toyota Tsusho Corporation (2014) 'Stable provision of a crucial resource for next-generation automobiles', www.toyota-tsusho.com/english/about/project/04/ [accessed 23 October 2014].

Turner, M. D. (2004) 'Political ecology and the moral dimensions of "resource conflicts": the case of farmer-herder conflicts in the Sahel', Political Geography, vol. 23, no. 7, 863-889. 


\section{A. Anlauf}

UNEP (2011) 'Towards a green economy: pathways to sustainable development and poverty eradication', www.unep.org/greeneconomy/Portals/88/documents/ ger/ger_final_dec_2011/Green\%20EconomyReport_Final_Dec2011.pdf [accessed 26 June 2014].

Villaroel, F. (2014) 'Escenarios en Sudamérica de la minería del litio: mercados', presentation at the international seminar Lithium in South America, Catamarca, Argentina, 9 April.

\section{List of interviews}

Interview 1: Kentaro Tanimoto, mining manager at TTC, San Salvador de Jujuy, 6 May 2014.

Interview 2: Javier Elortegui, director of mining and energetic resources in the provincial government, San Salvador de Jujuy, 5 May 2014.

Interview 3: Osvaldo Zambrano, chemical engineer at Sales de Jujuy, Olaroz plant, 29 April 2014.

Interview 4: Diana Mutti, professor for mining geology at Universidad de Buenos Aires, Buenos Aires, 30 September 2014.

Interview 5: Alejandro Calpanchay (pseudonym), former worker at the Olaroz plant, Susques, 23 April 2014.

Interview 6: Carlos Guzmán, spokesperson of the Colectivo Apacheta, San Salador de Jujuy, 27 March 2014.

Interview 7: Josefa Barrios, assesor of the comunero of Puesto Sey, Puesto Sey, 28 April 2014.

Interview 8: Irma Soriano, Susques-based small producer, Susques, 5 April 2014. 


\title{
11 Foreign involvement in small-scale gold mining in Ghana and its impact on resource fairness
}

\author{
Gordon Crawford and Gabriel Botchwey ${ }^{1}$
}

\section{Introduction}

Ghana is well known for its gold production, the second largest in Africa, with both large-scale and small-scale gold mining. While large-scale gold mining is dominated by transnational mining corporations, artisanal and small-scale mining (ASM) has been a traditional and indigenous activity for centuries, commonly using rudimentary means of extraction, and an activity that by law is reserved for Ghanaians (Parliament of the Republic of Ghana, 2006: sec 83). As in other African countries, ASM takes licensed and unlicensed forms, with the latter predominating - such illicit miners are known in Ghana as galamsey, an adulterated version of the English phrase "gather them and sell" (Aubynn et al., 2010: 3). In contemporary times, ASM in Ghana has become an increasingly important means of livelihood for many rural dwellers, often turning to mining to supplement or replace farming incomes (Jonsson and Fold, 2011: 480; Hilson and Garforth, 2012).

The last decade has seen two other major and interrelated changes in the ASM sector in Ghana. One is that gold production from small-scale mining has increased spectacularly, both by volume and as a proportion of total gold production. Official figures show that the volume of gold from small-scale mining has increased seven-fold from 225,411 ounces in 2005 to $1,576,478$ ounces in 2013 , and that the percentage of total gold production from small-scale mining (in comparison with large-scale mining) has increased from 11 per cent in 2005 , to 15.2 per cent in 2008 , and to a remarkable 36 per cent in 2013. ${ }^{2}$ Such phenomenal growth can be accounted for partly by the rise in rural households that are involved in ASM activities, and partly by the next change.

The second development has been more controversial due to the questions of legality and resource sovereignty that it raises. The last decade has seen a large increase in foreign involvement in the ASM sector, especially miners from China. From 2006 onwards, small numbers of Chinese and other foreign miners started coming to Ghana to engage in artisanal gold mining. The hike in gold prices from 2008 then led to a veritable gold rush 
and the arrival of substantial numbers of foreign miners, all working on an illicit basis given that small-scale mining can legally be undertaken only by Ghanaian citizens. Foreign miners came from nearby countries in West Africa as well as more distant parts of the world such as Armenia and Russia, but by far the largest concentration was from China (Interview 1). Indeed, in 2013 at the height of foreign involvement, a Chinese newspaper reported that an estimated 50,000 miners had left China for Ghana (Kane, 2013). The Chinese miners introduced new technology and machinery which increased the scale of mining, leading to larger areas of land being turned over to mining and to a consequent increase in environmental degradation.

By 2013, the participation of Chinese nationals in informal mining in Ghana had grown to such proportions, with adverse media coverage of 'illegal Chinese miners' and of conflicts between local and Chinese miners, that the Government of Ghana was forced to act. On 15 May 2013, President Mahama finally acknowledged that "We do clearly have a problem" and established a high-level Inter-Ministerial Task Force to combat illegal small-scale mining. While the President was careful to include all illegal mining activities in its remit, the sub-text was clear that this was a measure primarily aimed at foreign miners, especially Chinese nationals. The Task Force was essentially a military operation undertaken by the army and police, referred to as the 'flushing out' of illegal miners, and led to the deportation of 4,592 Chinese nationals, of whom 571 had been arrested and the rest had 'turned themselves in', as well as smaller numbers of other foreign nationals from Russia, Togo, and Niger (Modern Ghana, 2013).

Although the scale of foreign involvement in ASM has declined postTask Force, we argue here that this short but intense episode of foreign involvement, especially the role of Chinese miners, has brought about significant and irreversible changes in this traditional economic sector. What are the implications of such changes for the questions of resource fairness being examined in this volume? Traditionally, ASM has provided economic opportunities for low-income Ghanaians in rural areas (Akabzaa, 2009: 59; Jonsson and Fold, 2011: 480). This is in contrast to large-scale mining where benefits have been "disproportionately appropriated" by transnational mining corporations (Akabzaa, 2009: 29), with limited revenue to national government, and often negative livelihood impacts for communities affected by mining (Akabzaa, 2009: 58; Anyidoho and Crawford, 2014). In fact, official Ghanaian government policy has specifically promoted licensed ASM as a means of poverty reduction (Aryee, 2003), especially through rural employment creation and reduced rural-urban migration (Minerals Commission, 2009). Similarly, the restriction by law of small-scale mining to Ghanaian citizens would appear to be an attempt to enhance resource fairness, as reflected in a statement by the deputy minister for lands and natural resources that the law is intended to enable relatively low-income Ghanaian citizens "to benefit from the country's 
mineral resources" (Asamoah, 2014). However, the apparent flouting of this law by large numbers of foreign miners in the last decade could undermine this intent. Therefore, we explore two main questions in this chapter. What has been the impact of foreign involvement in small-scale mining in Ghana? And what are the consequences for issues of resource fairness?

Before turning to address these questions, it is necessary to define what we mean by resource fairness in this context. We examine the concept in four interrelated ways: resource sovereignty; state revenue collection; the distribution of benefits; and the issue of externalities and environmental degradation. Resource sovereignty refers to national control over a country's mineral resources, and the extent to which benefits from natural resource extraction are retained internally or subject to external capture and flight. Such questions are closely related to the issue of revenue collection and the degree to which the state is able to gain tax revenue from resource extraction for use in service provision and infrastructural development. The distribution of benefits concerns the question of who benefits directly and indirectly from resource extraction in terms of incomegenerating activities, and the extent to which benefits are enjoyed by lowincome Ghanaians or subject to elite capture. The issue of fairness in the distribution of benefits also involves a gender dimension, and the extent to which benefits are shared by both women and men. Finally, the issue of (negative) externalities concerns the question of who benefits from mining and who bears the costs of the associated environmental degradation.

Fieldwork was undertaken by the authors in July and August 2014 in the Upper Denkyira East Municipality in the Central region, bordering with the Ashanti and Western regions, one year after the Task Force's operations. Although the presence of foreign miners was much less by then, we were able to gather data on the preceding period and the concerns, issues, and changes that had emerged during this time. This municipality was chosen as it is in the heartland of the main alluvial gold mining area in southern Ghana, and a centre of Chinese involvement in small-scale mining. Data collection methods involved: semi-structured interviews with government officials at regional and municipal levels, chiefs and local politicians, local journalists, and local Ghanaian miners; and focus group discussions in two mining communities. In addition, visits were undertaken to ASM sites, both legal and illegal, to observe mining processes at first hand, including the degree of environmental degradation. National level interviews were conducted both prior to and after fieldwork to validate the initial findings, involving Ghanians and Chinese citizens resident in Ghana.

The chapter proceeds in six main sections. After this introduction, the second section provides background information on small-scale gold mining in Ghana. The third examines the rise of foreign involvement, especially by Chinese miners. The fourth section looks at the impact on the ASM sector of foreign involvement, while the fifth considers the implications for issues of resource fairness. Finally, the conclusion summarizes the 
findings and reflects on why this situation was allowed to happen, given the illegalities involved, and what this tells us about the nature of the state in Ghana.

\section{Artisanal and small-scale mining in Ghana}

ASM in Ghana has a very long history which can be dated back at least to the fifteenth century, when mercury was first used in gold extraction (Dummett, 1998; Tsuma, 2010: 10). With regard to the legal framework, there are three key provisions. The first applies to both large-scale and small-scale mining, while the other two pertain to ASM only. First, constitutionally, all minerals in Ghana are the property of the state, vested in the president: "Every mineral in its natural state [...] is the property of the Republic and is vested in the President in trust for the people of Ghana" (Republic of Ghana, 1992). This empowers the state to acquire mineralrich lands and to give them out as concessions for mining purposes both to large-scale mining companies and to registered small-scale artisanal miners, with limited compensation rights to farmers and traditional land users. One consequence has been the dispossession of land from many rural households, especially by the large concessions provided to mining corporations, which has, somewhat paradoxically, led to their increased dependence on ASM activities as a livelihood strategy (Tschakert and Singha, 2007: 1305; Hilson and Garforth, 2012).

Second, ASM was formally illegal in Ghana until 1989, although widely practised. The Small-Scale Gold Mining Law 1989 (PNDCL 218) legalized and attempted to regulate small-scale mining by introducing a registration and licensing process. This was then incorporated into the current Minerals and Mining Act 703 (Parliament of the Republic of Ghana, 2006). This formalization process enabled artisanal miners to apply to the Minerals Commission for a concession of 25 acres maximum in designated mining areas and then to acquire a licence to mine. However, this process is criticized as lengthy, bureaucratic and very expensive, including a range of official and unofficial fees. As such, it precludes most low-income miners from registering (Tschakert and Singha, 2007: 1306; Tsuma, 2010: 21; Hilson et al., 2014: 297-298), and therefore galamsey activities have continued to proliferate. One report states that, out of an estimated 250,000 ASM operators, "less than 30 percent [...] are duly registered and licensed" (Aubynn et al., 2010: 3). An earlier report estimated that 85 per cent operated without a licence (Carson et al., 2005). Therefore, the large majority of ASM operators remain informal and illicit.

The main advantage for licensed miners is that they have security of tenure and a legal entitlement to mine on their 25 acre concession (Carson et al., 2005), can apply for loans from banks and other financial institutions (Hilson et al., 2014: 299), and are not subject to the occasional crackdowns by the state on illegal mining (Hilson and Yakovelva, 2007). 
They also pay little to no taxes or royalties, with exemption for the first three years of operation, with the law on both royalties and income tax described as "ambiguous" by the National Association of Small-Scale Miners, indicating that tax is rarely paid (Interview 2). The key source of government revenue from small-scale gold mining is through sales of gold to the Precious Minerals Marketing Company (PMMC), a state agency responsible for gold exports. The Government of Ghana takes 0.5 per cent of the value of gold exported by PMMC as revenue (Interview 3). Smallscale miners, including galamsey operators, sell gold to licensed gold buyers, who in turn, and by law, sell the gold to PMMC. Interestingly, in buying gold, PMMC does not differentiate in sales from legal or illegal miners, a policy driven by the reality of illicit mining, but also indicating a degree of state tolerance of galamsey activities.

However, despite the attempt to formalize and regularize small-scale mining from 1989 onwards, there is a strong argument that the state has actually neglected the ASM sector for decades and simultaneously prioritized the large-scale sector dominated by transnational corporations. Clearly, this has an adverse effect on prospects for greater resource fairness through engagement in ASM. Hilson et al. (2014: 298-299) make the case forcefully that the long delays in applications for licences, at times taking years, coupled with a lack of state financial and technical support to licensed ASM operators, amounts to neglect and maintains the sector's "perpetual informality" (Hilson et al., 2014: 292; see Jonsson and Fold, 2011: 485 for similar problems regarding ASM licensing in sub-Saharan Africa generally). Tschakert and Singha (2007) also highlight processes of marginalization of the ASM sector in Ghana, including the leasing of large areas of land to large-scale mining corporations and the criminalization of galamsey. Such processes in their view are "in stark contrast to the official rhetoric of poverty reduction" (Tschakert and Singha, 2007: 1306). Further, Hilson et al. (2014: 301) argue that it is precisely this state failure to provide appropriate support that led ASM operators, both licensed and unlicensed, to be open to opportunities for collaboration with migrant Chinese miners when they arose.

Third, as indicated in the introduction, according to the law, licensed small-scale mining can only be undertaken by citizens of Ghana. There has certainly been some disjuncture between the law and the reality on the ground, with non-Ghanaian miners involved in galamsey activities. Yet, until recently such 'foreigners' were almost entirely from neighbouring countries in West Africa - for instance, Burkina Faso and Togo - having migrated across porous borders in search of economic opportunities. This situation changed dramatically in the last decade with the influx of large numbers of foreign miners into the small-scale sector, most notably from China. 


\section{Rise of foreign involvement in ASM}

Until about ten years ago, two points could be made with certainty about artisanal gold mining in Ghana. First, it was a traditional activity, often using the same rudimentary means of extraction (pick, shovel, and bowl) for centuries. Second, it was almost entirely an indigenous activity, apart from those few miners from neighbouring countries. However, the last decade has seen rapid and interrelated changes to both these aspects. As indicated above, foreign miners from China and other faraway places started coming to Ghana to engage in small-scale gold mining from 2006 onwards, which turned into a gold rush with the hike in gold prices from 2008. It is stated that many Chinese miners came into Ghana via Togo, which had a 'no visa required' arrangement with China, and then crossed the border unofficially, while others came in on tourist visas (Interview 1). The exact numbers of such irregular migrants is not known, due to the evasion of immigration laws, but it can be safely stated that the number of Chinese miners was in the tens of thousands, with the large majority coming from Shanglin County in Guangxi province and known as the 'Shanglin gang' (Huifeng, 2013). All such irregular migrants were working on an illicit and illegal basis given that the sector is reserved for Ghanaian citizens by law.

The Chinese miners had a major impact, however. They transformed the artisanal nature of mining through the introduction of a much higher level of mechanization, notably the use of excavators, bulldozers, and wash plants. Much of this equipment was also sold or hired out by Chinese traders. One particular innovation introduced by Chinese miners was direct mining within rivers by means of a barge or platform fitted with suction equipment, despite the illegality of mining in rivers or indeed within 100 metres of a river bank (Interviews 4, 5, and 6). River mining, or dredging mining as it is known, was subsequently adopted by Ghanaian miners and has resulted in rivers becoming severely polluted, with disastrous consequences for the aquatic eco-system and for the provision of potable water for local communities (CSIR Water Research Institute, 2013), consequences that are difficult and very costly to reverse (Interview 7).

How did such large numbers of foreign miners, particularly from China, come to be involved in ASM in Ghana? This research identified both contingency and structural factors, as well as external and internal aspects. The main contingency factor was the meeting in 2006 between a Chinese national, resident in Ghana and involved in the small-scale mining sector, and a Chinese miner from Guangxi province. This led to the introduction of the 'trommel' machine, or wash plant, for use in alluvial gold mining (Interview 8). It vastly increased the grams of gold that could be extracted on a daily basis. Each machine required a team of eight workers to operate in a cooperative manner, and therefore groups of eight Chinese migrants 
started to come into the country. Large sums of money were being made, especially as the world market price of gold rose rapidly from 2010 onwards, and news spread quickly by word-of-mouth back in China, particularly in Shanglin County where that technique had been used for more than 30 years. Another driver was the economic boom in China which made it possible for lower-class Chinese citizens to borrow sums of US $\$ 25,000$ from the bank, providing groups of eight Chinese nationals with approximately 200,000 dollars for investment in ASM activities (Interview 8).

However, this account only tells part of the story. How could tens of thousands of Chinese and other foreign nationals be working in an industry that, by law, is restricted to Ghanaian citizens? Further, how could Chinese miners in particular operate in a country that is so different from their own in many respects? It appears that collusion in illegality occurred from the local level to high levels of government. On entry into the country, bogus visas and work permits were issued unlawfully to some Chinese miners by corrupt immigration officials for a fee (Interview 9). We were informed that Chinese migrants from Shanglin County were relatively poor people, not highly educated, and rarely able to speak English (Interview 8). They were unfamiliar with Ghanaian culture and traditions, especially regarding land ownership, and guidance and assistance in entering local communities was essential. Accounts of chiefs disbursing land to Chinese miners for significant sums of money as well as allegations of official corruption were recurring themes (Focus groups 1 and 2). Not least, the Chinese miners undertook mining in close collaboration with Ghanaian miners, either with licensed concession holders or in galamsey activities.

It is evident that the influx of Chinese miners into small-scale gold mining in Ghana, and the new methods that they introduced, did not simply lead to conflict over resources, as was reported in newspaper headlines, but to significant levels of collaboration with Ghanaians. Such collaboration was particularly attractive when large sums of money could be made very quickly, given the combination of more efficient extraction methods and the very high price of gold. Many Ghanaians were keen to take advantage of their positions either to facilitate Chinese mining, for instance, through provision of access to land, or to allow illegal mining to occur through 'turning a blind eye' in return for financial inducements. Issues of state corruption are discussed further below.

\section{Impact of foreign involvement in ASM}

Over a short period from 2008 to 2013, the impact of Chinese involvement in ASM has been very significant, with considerable implications for issues of resource fairness. This section looks at the different areas of impact while the next discusses the consequences for resource fairness. 


\section{Mechanization and intensification of small-scale mining}

Chinese involvement has transformed the small-scale mining sector through the introduction of new technology and machinery. From traditional and artisanal production using rudimentary methods, the sector, or at least a significant part of it, has become highly mechanized, and indeed can no longer be described as artisanal. Chinese miners also brought considerable amounts of capital, and the combination of new technology and capital has led to a huge intensification of production both on smallscale concessions and on other lands where mining is carried out illicitly. Areas of land that previously would have taken years to mine using the traditional methods are now mined in weeks, and the amount of land that is acquired from land owners for mining purposes has increased enormously (Interview 10). The mechanization and intensification of production involves irreversible changes to the nature of small-scale mining.

\section{Small-scale mining becomes big business (for some)}

A consequence of mechanization and intensification of mining is that the economic rewards are now much greater for concession holders, foreign miners, and galamsey operators alike. Although it is illegal to sub-let, one common model involves licensed miners turning over their concessions to foreign miners, invariably Chinese in our experience, and splitting the value of the gold produced, commonly 15 per cent to the concession holder(s) and 85 per cent to the Chinese miners who effectively do all the mining (Interview 11). We were informed by concession holders that a 15 per cent stake can amount to an income of 15,000 to 25,000 Ghana cedis per week, or approximately 3,000 to 5,000 British pounds per week. These are huge incomes in a sector mainly associated with the survival strategies of poor rural households (Bush, 2009; Hilson and Banchirigah, 2009). Although the Chinese miners bear the cost of production, it is also evident that they have made large amounts of money on these deals. One Chinese respondent, who had Chinese miners as business clients, stated that "in four to five years, a lot of Chinese millionaires, even billionaires" were created, adding that they "had worked very hard" often in tough conditions "in the bush" (Interview 6).

Chinese media reports also confirmed the huge amounts of money that Chinese miners were making from small-scale gold mining in Ghana. In a story that followed President Mahama's announcement of the InterMinisterial Task Force, the 21st Century Business Herald, a Chinese business daily newspaper, reported on the riches made by the estimated 50,000 Chinese miners in Ghana, the so-called 'Shanglin gang' (GhanaWeb, 2013). The headline figure was that US\$500 million had been made, citing stories of gold bars brought home as gifts and Ferraris being ordered from the proceeds. The report cited one local bank source as stating that in May 
and June 2011, more than 1 billion Chinese yuan (approximately US\$150 million) was wired into Shanglin from abroad. They reported that 100,000 Chinese yuan could be made in gross profit daily (approximately US $\$ 15,000$ per day), presumably per small-scale mining operation of about eight miners.

However, small-scale gold mining is only a lucrative business for a small proportion of those involved. Indeed, the stratification and inequalities amongst Ghanaians involved in small-scale mining has significantly increased, inclusive of a gender dimension, which addresses one element of our 'resource fairness' criteria. While male concession holders at the apex of the small-scale mining industry can now earn significantly more than the President's official salary, in contrast women, children and many youths are now left to extract remnants of gold by re-washing the gravels that are left in heaps of 'tailings' at sites abandoned after intensive mining has been completed. This is known locally as 'doing pooley' and described by lowincome women as backbreaking work (Focus group 3).

\section{Environmental degradation (for all)}

A further consequence of mechanization and the intensification of production has been much larger-scale environmental degradation in areas of alluvial mining, inclusive of both land and water bodies. Regarding land, many abandoned pits are left uncovered and become flooded, posing a danger to local residents, especially children, and to livestock (Focus groups 1 and 2). Additionally, extensive damage to farm lands and forests has occurred with the rush to acquire land, mostly illegally, for small-scale mining. Loss of farm lands has adversely affected both cocoa production and food crop production.

The destruction of river systems has been a new and catastrophic form of environmental degradation that has occurred precisely due to the introduction of dredging mining within rivers by Chinese miners, subsequently adopted by Ghanaian miners. Main rivers are now severely polluted, notably the river Pra and its tributaries such as the Offin, with high levels of water turbidity, loss of aquatic life, and contaminated drinking water. The river Offin was described by a local journalist as "now looking like coffee with milk" (Interview 12). The degree of water pollution has very severe consequences for local communities, including those served with piped water, increasing the cost of chemical treatment to make such water potable (CSIR Water Research Institute, 2013).

\section{Local conflict and increased insecurity}

The increased competition for resources has also led to issues of law and order. This has related not only to direct conflicts between miners and to incidences of robbery of Chinese miners, but to increased security 
problems for all citizens. In the Central region, it was stated by the police that armed robberies had increased, and that such robberies often occurred with guns originally brought in by the Chinese to protect themselves while mining in the bush (Interview 6). These weapons had been abandoned during the operations of the national Task Force and had fallen into criminal hands (Interview 13). Local conflicts between Chinese and Ghanaian miners over access to gold resources were reported in the national press from mid-2012 onwards, with deaths and injuries on both sides $(B B C$ News, 2012). Disputes have also arisen between Ghanaians, and in particular between young people in communities and the traditional authorities (chiefs), often accused of 'selling land' to Chinese miners (Boadi, 2013; Frimpong, 2013).

\section{Lost revenue}

Significant opportunities for revenue collection by the Government of Ghana have been lost, a particular concern from a resource fairness perspective. While the government gets some revenue from small-scale gold mining through sales of gold to PMMC, the state's gold-buying agency, there are strong suggestions that gold is being smuggled out of the country, with a significant loss of foreign exchange to the state (Interviews 1 and 2). Although this research has no direct evidence of how gold produced by foreign miners was sold, it would seem likely that a significant proportion of such illicit production has not gone through official channels, but has been taken illegally out of the country. Indeed, a knowledgeable source at national level stated that this is "a widely-held view" (Interview 2), while an informed source in Dunkwa-on-Offin, a licensed concession holder who had worked with Chinese miners, expressed the view that "gold was sent directly to China" or smuggled out to China, with "so many ways" of doing so (Interview 11). We have no means to verify the accuracy of this, but equally no reason to doubt the veracity of this first-hand information from different sources.

Aside from gold sales, very little revenue would seem to be collected from ASM activities, despite the extremely large sums of money being made by those involved at the apex of the business. Clearly, irregular Chinese migrants are paying no taxes to the government. Similarly, unlawful galamsey operators pay no tax, yet their operations have increased in scale with foreign involvement or adoption of Chinese technology and practices. Legal concession holders pay little or no taxes or royalties, despite the potential for concession holders to now gain very high incomes (Interview 9). Concession owners are obliged to pay a small annual fee to the local government for a business operations permit, yet, according to a local government official, "some do and some don't, as they are so powerful"(Interview 14). 


\section{Legal impunity}

Despite the various elements of illegality in foreign involvement in smallscale mining, these have frequently been ignored and the law not enforced - for example, the purchasing of small-scale concessions from Ghanaians; mining in rivers; and the allegations that gold produced is not going through the PMMC. Clearly, local Ghanaians were also collaborating in such unlawful practices, inclusive of both licensed miners and local galamsey operators. But the scale of legal impunity increased greatly during this period of substantial foreign involvement in small-scale mining, and the consequences are much more significant in terms of environmental degradation. It is also extraordinary that foreign involvement in ASM was allowed to escalate over a period of years to such a level that tens of thousands of foreign miners were operating illegally within the country, yet with no government action.

The situation prior to the establishment of the Task Force in May 2013 was described as a "culture of impunity" (Interview 15), where small-scale mining was being undertaken collaboratively by Chinese and Ghanaians in a "free-range" manner that was "out of control" (Interview 9) with little or no respect for the law by those mining or, disturbingly, by the relevant authorities. Although foreign involvement has decreased post-Task Force, the fact that it was allowed to develop and reach such proportions raises fundamental questions about the nature of the Ghanaian state. It is also the case that the Task Force was a one-off crackdown targeted at foreign miners, and Ghanaian miners continue to undertake illegal operations, such as mining in rivers, with relative impunity, as observed during fieldwork.

\section{Institutional failure and corruption}

Why was this culture of impunity allowed to develop? And why did it take so long for the government to act? The endemic nature of corruption is central to any answer.

During fieldwork, we were constantly hearing allegations of various individuals taking bribes and/or being bought off. This extended from immigration officials to local chiefs, and from local government officers to high-ranking central government personnel. We were informed by lone voices in the public sector that foreign miners, especially from China, were protected by "big shots in government" in return for payments (Interview 14). As well as private benefits, it was also suggested that various politicians were protecting the Chinese, especially in the run-up to the December 2012 general elections, in return for financial support to sponsor their campaigns. Such accusations were corroborated by a Chinese respondent with first-hand experience of incoming Chinese miners as business clients (Interview 6). He noted that "money talks" and Chinese miners had made payments to both high-level government officials and those at ground level, 
with the latter also expected to channel money to senior officials. He alleged that "many [government] people were involved", including officials from key government agencies, and that they had effectively provided protection to Chinese miners. Yet post-Task Force, he noted that a fundamental shift had occurred and Chinese miners were "no longer protected by the [Ghanaian] government", and therefore most had moved on to other countries in the region or returned to China (Interview 6).

This view was corroborated by a Ghanaian mining source, himself involved with Chinese miners. He stated that those very officials who had previously colluded with and accepted payments from Chinese miners, such as immigration officials, subsequently denied all knowledge of them at the time of the Task Force, to the surprise of the Chinese miners, and condemned as 'fake' those same work permits that they had previously issued unlawfully (Interview 9). Although the Inter-Ministerial Task Force eventually brought an end to this free-for-all ravaging of Ghana's gold resources, the allegations of corruption also extended to the Task Force itself. Significant payments by Chinese miners to Task Force members in order to avoid arrest were reported, as well as the theft of gold and property from Chinese miners, in the course of the military-style crackdown. Indeed, we were told that those Chinese who were arrested and deported were precisely those who "could not pay" (Interview 11).

\section{Consequences for resource fairness}

We have defined resource fairness in four interrelated ways: resource sovereignty; the distribution of benefits amongst the populace; state revenue collection; and the issue of externalities and environmental degradation. We now examine the longer-term implications of this episode of foreign involvement in ASM in Ghana for these four dimensions. The consequences would appear to be largely negative.

First, if the rationale for legally restricting small-scale mining to Ghanaian citizens is understood as an assertion of resource sovereignty, enabling relatively poor citizens "to benefit from the country's mineral resources", as stated by the deputy minister, then clearly this has failed. Over a period of a few years, many foreign miners, especially Chinese nationals, have made large amounts of money very quickly from the extraction of Ghanaian gold (Interviews 9 and 6). Depressingly, this illegal capture of Ghana's resource wealth has been facilitated by relatively powerful Ghanaians in government and in chieftaincy institutions, eager to grab a personal share of the 'quick money' being made. It is impossible to estimate the value of the gold that has been extracted, but it is clearly a multi-million, if not multi-billion, dollar sum that has been appropriated into private pockets and removed from the country in a process of informal capital flight.

Second, in terms of the distribution of benefits, the introduction of increased mechanization and intensification of production by Chinese 
miners has brought irreversible changes to the ASM sector, and intensified the inequalities amongst Ghanaians, inclusive of a gender dimension. On the one hand, for those concession holders and galamsey gang leaders who are now mining using Chinese technology and techniques, small-scale mining has become a highly lucrative business. Invariably men, they have become wealthy individuals in their communities, using their capital to develop other businesses, such as hotel ownership and mining equipment hire. Such individuals remain a minority in the sector, however. Others are left in a worse position - for instance, the women directly involved in ASM, now forced to eke out livelihoods by re-washing gravels to extract any remaining traces of gold at already mined and abandoned sites. Thus, the degree of stratification amongst small-scale miners has intensified, inclusive of a marked gender dimension, due to the differential access to the benefits of intensified small-scale gold mining.

Third, if an essential aspect of resource fairness entails revenue collection which the state can use to provide services and infrastructure for the collective benefit of all, then the loss of potential revenue through smuggling of gold and the lack of an effective tax regime is another adverse consequence. The allegations of smuggling of gold out of the country are a particular concern. If correct, this deprives the Ghanaian government not only of tax revenue, but much-needed foreign exchange. In effect, it is theft of Ghana's sovereign resources in what was undeniably an unregulated free-for-all scramble. The smuggling of gold is an area in itself that requires further research. Another area of potential revenue generation that is not realized concerns the lack of royalties and income tax paid by licensed small-scale miners, despite current earnings that, at times, dwarf the President's official salary. This is clearly unsatisfactory and requires legal reform to clarify this so-called "ambiguous" situation and ensure the state collects appropriate tax payments (Interview 2).

Fourth, the environmental degradation associated with intensified alluvial mining also impacts adversely on resource fairness in terms of negative effects on local people's access to land and water. Large tracts of land have become lost to farming with the top soil removed by excavators to a depth of over six metres. This results in land becoming completely degraded, inclusive of abandoned pits of stagnant water. With land reclamation rarely undertaken, the loss of farm land is thus long-term. There are consequent adverse effects on incomes and on local food production, with increased reliance by rural folk on purchasing food products from urban markets, requiring in turn greater cash income (Focus group 3). This forces many farmers, especially women, into undertaking small-scale mining themselves as a means of income generation, in difficult and hazardous circumstances, often in abandoned pits, as described above. Rivers and streams have also become so heavily polluted from intensified mining that they can no longer be used as sources of drinking water in situations where other sources such as boreholes and wells are not available. There are 
negative externalities, as those benefiting from gold mining are not paying for the associated environmental costs. On the contrary, despite collecting limited revenue from small-scale mining, the government is faced with an enormous, and indeed incalculable, bill to remedy the environmental damage caused by intensified ASM operations, while many of those responsible have left the country.

In sum, despite the legal framework around small-scale mining that asserts resource sovereignty and a notion of resource fairness in which the state and its citizens benefit from Ghana's mineral endowments, foreign involvement in the ASM sector has led to a privatization of benefits to individual miners, inclusive of foreign nationals and an elite fraction of Ghanaian ASM operators. The capture of such mineral wealth is illegal in many instances, including all operations where foreign nationals are directly involved in mining. In terms of benefits and costs to the state, it is evident that the state has failed to regulate the sector sufficiently, which has led to a failure to collect the revenue that is core to a resource fairness agenda, while incurring the huge costs required to repair the environmental damage. Most depressing, however, is the evidence that indicates that this free-for-all scramble for Ghana's gold occurred with the active collusion of state officials, politicians, and traditional authorities, all eager to gain a private share of the wealth produced, whatever the public costs. This is clearly the antithesis of any resource fairness agenda.

\section{Conclusion}

This chapter has examined the recent and controversial phenomenon of foreign involvement, especially of Chinese miners, in the ASM sector in Ghana. It posed two questions: What has been the impact of foreign involvement in small-scale mining? And what are the implications for issues of resource fairness? The findings suggest that the impact of this short period of intense foreign involvement, at most from 2008 to 2013, has been very significant. Indeed, it is argued that, with mechanization and the application of new technology, ASM in Ghana has changed irrevocably, and in such cases can no longer be described as artisanal. Although since 2013, the presence of foreign miners is no longer so evident, the equipment and methods introduced by Chinese miners are now being used by Ghanaian miners. In terms of resource fairness, findings show an intensification of resource unfairness or resource injustice. Resource sovereignty is undermined by foreign miners making 'quick money' from Ghana's gold and there is greater inequality in the distribution of benefits amongst Ghanaians. Even more troubling is that the state has gained very little revenue while it is left with incalculable environmental costs. While ASM has the potential to contribute significantly to Ghana's development trajectory both directly through income generation for relatively poor Ghanaians and indirectly through government revenue collection, this has palpably not 
occurred. We conclude by attempting to analyse why this situation has occurred, and indeed been allowed to happen, given the illegalities involved.

The role of the state is key to understanding this situation. What is most striking about this case-study is that a situation developed to the stage where it was described by a senior official in environmental protection as "out of control" and characterized by a "culture of impunity" (Interview 1). This peaked in 2012 and 2013 with tens of thousands of foreign miners, mainly Chinese nationals, engaged in an illegal free-for-all for Ghanaian mineral resources. Where was the state in this context? The state was very slow to respond, despite increasing media coverage of local conflicts and environment destruction, until finally President Mahama established an Inter-Ministerial Task Force. Yet, the state was not absent in the preceding years. We argue that this phenomenon of foreign involvement in the ASM sector in Ghana was allowed to occur, despite the legal prohibitions, due to a combination of rent-seeking by those in positions of authority and the "persistent informality" (Van Bockstael, 2014) of the sector.

The Ghanaian state is not a weak state, as became evident when the Task Force was eventually put in place. Yet, this example has also shown that it is a state, like others in sub-Saharan Africa, which is increasingly characterized by "everyday corruption" and the rent-seeking behaviour of public officials (Blundo and Olivier de Sardan, 2006). Similarly, traditional authorities in Ghana, the hierarchy of chiefs and sub-chiefs, have used their positions of authority in mining localities to personally benefit from galamsey activities (see Hilson et al., 2014: 301). It would appear that foreign miners, especially from China, were able to operate with impunity for so long because they were actually protected by those in authority - public officials, politicians, and chiefs - in return for private payments. Various state institutions have clearly failed in their responsibilities to maintain the law. Yet, this is not due to weakness or issues of capacity. Rather, public officials have 'turned a blind eye' to illicit mining in return for a share in the large sums of money being made from gold extraction. Similarly, chiefs have seen an opportunity for personal gain, especially by selling land for mining. Those in public positions, including traditional authorities, have become increasingly oriented to pursuing private accumulation rather than public service. Significantly, corrupt behaviour and opportunism was even evident in the Task Force's activities, with army and police personnel taking advantage of their power to pursue private gain at the expense of the Chinese miners.

Clearly, corrupt and rent-seeking behaviour by those in authority has had an adverse effect on prospects for a fairer use of Ghana's gold resources in the small-scale sector. Furthermore, the concept of informality is key here, both the informality of the state's functioning and the informality of the ASM sector. We argue that the combination of the two has enabled illicit foreign involvement in small-scale mining to occur in a 
manner that has intensified resource unfairness. Blundo and Olivier de Sardan (2006) emphasize the significance of the concept of informality in relation to everyday corruption. They note that "the 'real' function of the state is very removed from its 'official functioning'" (Blundo and Olivier de Sardan, 2006: 5) in terms of laws and regulations, and describe this 'real' function as the "generalized informal functioning" of the state (Blundo and Olivier de Sardan, 2006: 5), facilitating corrupt practices and private accumulation by public officials. This is heightened by the informality of the ASM sector itself, described by Hilson et al. (2014) as its "perpetual informality" (292). This is precisely due to the state's failure to legalize and formalize the sector through access to licences and to provide the necessary support to licensed operators, despite its official policy rhetoric. Given the increasing reliance of many rural dwellers on ASM as a means of livelihood, often due to land loss to large-scale mining operations, this has inevitably meant an increase in unlicensed and informal mining. Foreign miners have been able to take advantage of this informality in an unregulated sector, and indeed have provided some of the financial and technical support that many ASM operators have lacked. However, the negative consequences of foreign involvement in such informal and mainly illicit mining, including the environmental impact, have become much greater than in traditional ASM due to the intensification of production through mechanization. The sector's informality combined with the 'informal functioning' of the state, where state officials and traditional authorities can easily be bought off, has enabled the plunder and appropriation of Ghana's gold resources by foreign miners in a neocolonialist manner and in stark contrast to any notion of resource fairness. Conclusions therefore are that the recent phenomenon of foreign involvement in ASM has further intensified issues of resource unfairness in smallscale gold mining in Ghana.

How can such issues be addressed and a greater degree of resource fairness achieved? Whereas the state has been identified as the problem, it is also crucial to any potential solution. Formalization of the sector is needed if income generation opportunities for low-income Ghanaians and revenue collection for the government are to be enhanced. This requires viable and effective state institutions, ones that are able to develop and enforce a regulatory system for natural resource management in the ASM sector. How such institutions can be achieved is a much bigger question, beyond the scope of this short chapter, but one which challenges the dominant neoliberal paradigm and its construction of a limited, pro-market state (Harrison, 2004). It is clear that creating institutions and laws that work will require the state to adopt a much more pro-active and interventionist role to ensure that resource extraction is organized and regulated in ways that enable low-income Ghanaians to share in the benefits in a manner more congruent with the concept of resource fairness. 


\section{Note}

1 The authors would like to thank the International Growth Centre, Ghana, for financial support for this project.

2 These numbers were taken from a document obtained from the Minerals Commission in Accra in 2014, thought to be the small-scale mining section extracted from the annual report.

\section{References}

Akabzaa, T. (2009) 'Mining in Ghana: implications for national economic development and poverty reduction', in B. Campbell (ed.) Mining in Africa: Regulation and Development, Pluto Press, London, 25-65.

Anyidoho, N. A. and Crawford, G. (2014) 'Leveraging national and global links for local rights advocacy: WACAM's challenge to the power of transnational gold mining in Ghana', Canadian Journal of Development Studies, vol. 35, no. 4, 483-502.

Aryee, B. N. A. (2003) 'Small-scale mining in Ghana as a sustainable development activity: its development and a review of the contemporary issues and challenges', in G. M. Hilson (ed.) The Socio-Economic Impacts of Artisanal and Small-Scale Mining in Developing Countries, A. A. Balkema Publishers, Lisse, 379-418.

Asamoah, B. S. (2014) 'Small-scale mining in Ghana', presentation at the Growth Week 2014, 23 September, International Growth Centre, LSE, www.theigc.org/ multimedia/growth-week-2014-country-session-ghana/?back=3837 [accessed 21 December 2015].

Aubynn, T., Andoh, T. A., Koney, S., Nantogmah, A., Yennah, A., Menkah-Premo, S., and Tsar, J. (2010) 'Mainstreaming artisanal and small-scale mining: a background to policy advocacy', draft report, Ghana Chamber of Mines, Accra.

BBC News (2012) 'Ghana probes death of “illegal Chinese gold miner", 15 October, www.bbc.co.uk/news/world-africa-19946787 [accessed 21 December 2015].

Blundo, G. and Olivier de Sardan, J.-P. (2006) Everyday Corruption and the State: Citizens and Public Officials in Africa, Zed Books, London.

Boadi, S. (2013) 'Illegal Chinese, Indian miners take over Minti', Modern Ghana, February, www.modernghana.com/thread/202201/444393/1 [accessed 21 December 2015].

Bush, R. (2009) " "Soon there will be no-one left to take the corpses to the morgue": accumulation and abjection in Ghana's mining communities', Resources Policy, vol. 34, no. 1-2, 57-63.

Carson, M., Carson, M., Cottrell, S., Dickman, J., Gummerson, E., Lee, T., Miao, Y., et al. (2005) 'Managing mineral resources through public-private partnerships: mitigating conflict in Ghanaian gold mining', Working paper WWS591c, Woodrow Wilson School of Public and International Affairs, Princeton University, Princeton, NJ.

CSIR Water Research Institute (2013) 'Impact of small-scale mining on the water resources of the Pra River basin', CSIR, Accra.

Dummet, R. E. (1998) El Dorado in West Africa: The Gold-Mining Frontier, African Labor, and Colonial Capitalism on the Gold Coast, 1875-1900, Heinemann, Athens. 
Frimpong, E. D. (2013) 'Chinese arrested for shooting three Manso Abodom youth', Graphic Online, 11 February, http://graphic.com.gh/news/general-news/ 9076-chinese-arrested-for-shooting-three-manso-abodom-youth.html [accessed 21 December 2015].

GhanaWeb (2013) 'Chinese strike about $\$ 500 \mathrm{~m}$ worth of Gold in Ghana with secret method', 17 May, www.ghanaweb.com/GhanaHomePage/NewsArchive/ artikel.php?ID=274243 [accessed 15 December 2015].

Harrison, G. (2004) The World Bank and Africa: The Construction of Governance States, Routledge, London.

Hilson, G. and Banchirigah, S. M. (2009) 'Are alternative livelihood projects alleviating poverty in mining communities? Experiences from Ghana', Journal of Development Studies, vol. 45, no. 2, 172-196.

Hilson, G. and Garforth, C. (2012) "Everyone now is concentrating on the mining": drivers and implications of rural economic transition in the eastern region of Ghana', Journal of Development Studies, vol. 49, no. 3, 348-364.

Hilson, G. and Yakovelva, N. (2007) 'Strained relations: a critical analysis of the mining conflict in Prestea, Ghana', Political Geography, vol. 26, no. 1, 98-119.

Hilson, G., Hilson, A., and Adu-Darko, E. (2014) 'Chinese participation in Ghana's informal gold mining economy: drivers, implications and clarifications', Journal of Rural Studies, vol. 34, 292-303.

Huifeng, H. (2013) 'Low costs and huge profits irresistible lure for Chinese to mine Ghana's gold', South China Morning Post, 7 June, www.scmp.com/news/china/ article/1255126/low-costs-and-huge-profits-irresistible-lure-chinese-mine-ghanasgold [accessed 21 December 2015].

Jonsson, J. B. and Fold, N. (2011) 'Mining "from below": taking Africa's artisanal miners seriously', Geography Compass, vol. 5, 479-493.

Kane, M. (2013) 'Ghana takes action against illegal Chinese miners', Institute for Security Studies, 23 August, www.issafrica.org/iss-today/ghana-takes-actionagainst-illegal-chinese-miners [accessed 15 December 2015].

Minerals Commission (2009) Designated Areas for Small-Scale Gold and Diamond Mining in Ghana, Minerals Commission, Accra.

Modern Ghana (2013) '4,500 Chinese leave Ghana after illegal mining crackdown', 12 July, www.modernghana.com/news/474808/1/4500-chinese-leaveghana-after-illegal-mining-crackdown.html [accessed 21 December 2015].

Parliament of the Republic of Ghana (2006) The Minerals and Mining Act, 2006, Act 703, Accra.

Republic of Ghana (1992) 'The constitution of the Republic of Ghana 1992', www.judicial.gov.gh/constitution/chapter/chap_1.htm [accessed 21 December 2015].

Tschakert, P. and Singha, K. (2007) 'Contaminated identities: mercury and marginalization in Ghana's artisanal mining sector', Geoforum, vol. 38, no. 6, 1304-1321.

Tsuma, W. (2010) Gold Mining in Ghana: Actors, Alliances and Power, ZEF Development Studies, Lit Verlag, Berlin.

Van Bockstael, S. (2014) 'The persistence of informality: perspectives on the future of artisanal mining in Liberia', Futures, vol. 62, 10-20. 


\section{List of focus groups and interviews}

Focus group 1: youth (involved in ASM, Pokukrom, Upper Denkyira East Municipality, 27 July 2014.

Focus group 2: men and women (involved in ASM), Pokukrom, Upper Denkyira East Municipality, 27 July 2014.

Focus group 3: women (involved in ASM), Buabenso, Upper Denkyira East Municipality, 29 July 2014.

Interview 1: director for planning, programming, monitoring, and evaluation at Environmental Protection Agency, Accra, 9 April 2014.

Interview 2: national administrator of the Association of Small-Scale Miners, Accra, 13 August 2014.

Interview 3: official at Precious Minerals Marketing Company, Accra, 13 August 2014.

Interview 4: municipal director at the Minerals Commission, Dunkwa, 24 July 2014.

Interview 5: regional programme officer at Environment Protection Agency, Cape Coast, 30 July 2014.

Interview 6: principal consultant at a Chinese financial and legal consultancy firm, Accra, 12 January 2015.

Interview 7: deputy executive director at Environmental Protection Agency, Accra, 9 January 2015.

Interview 8: vice-chairman of the Ghana-China Business Chamber of Commerce, Tema, 13 August 2014.

Interview 9: acting managing director at Akonta mines in Ghana, Accra, 14 August 2014.

Interview 10: small-scale concession holder at Nayak Mining Enterprise, Buabenso, Upper Denkyira East Municipality, 29 July 2014.

Interview 11: concession holder and member of local Small-Scale Miners Association, Dunkwa, 26 July 2014.

Interview 12: radio journalist at Solar FM, Dunkwa, 23 July 2014.

Interview 13: municipal police commander at the Ghana Police Service, Dunkwa, 24 July 2014.

Interview 14: administration official at Upper Denkyira East Municipal Assembly, Dunkwa, 28 July 2014.

Interview 15: deputy technical director for mining at the Ministry of Lands and Natural Resources, Accra, 9 April 2014. 


\title{
12 Elite capture and the development of natural resource linkages in Mozambique
}

\author{
Lars Buur and Celso Marcos Monjane
}

\section{Introduction}

Since the end of the 16-year, devastating civil war in 1992, Mozambique has enjoyed a remarkable turnaround, with strong and sustained economic growth averaging approximately 7 per cent per year. But as "the low hanging fruits from post-war reconstruction were reaped" (IIM, 2012: 11), growth has largely been driven by overseas development assistance (Jones and Tarp, 2012) and mega-project investments in the form of large, capital-intensive, and foreign-owned operations, without any clear signs of a structural transformation taking place (Whitfield et al., 2015). ${ }^{1}$

Since the first democratic elections in 1994, mega-projects have functioned as 'showcases' for successive Mozambican governments, exposing Mozambique to potential investors. Mega-projects have been considered important for investors and donors for at least two reasons. First, foreign investment-driven mega-projects have counteracted the negative, investorhostile image of the country's post-independence socialist period (Buur and Baloi, 2009). Second, the successful attraction and protection of large-scale foreign investments have been seen as a litmus test showing potential investors the Mozambican government's readiness to act in an open liberal economy and as a catalyst for investment in much-needed infrastructure development (Clément and Peiris, 2008).

However, while mega-projects account for most of the overall growth in industrial manufacturing and exports, this has been growth with little sustained formal employment creation or broad-based poverty reduction, as investments have led to little or no development of national entrepreneurialism or capabilities of substance in the productive sectors of the economy. This is somehow surprising, as in many ways there has indeed been a push to make sure that investments have a positive impact on the Mozambican economy, as well as a strong drive towards poverty alleviation. It has generally been acknowledged in key government documents that Mozambique faces three key challenges: “(a) to diversify its economy, (b) to begin the process of structural transformation, and (c) to achieve broad-based gains in living standards" (IIM, 2012: 11). 
The paradox is that, even though relatively elaborate official organizational and institutional arrangements based on policies, strategies, and units have emerged over time in order to reap the benefits, particularly in terms of linkages of large-scale investments in the extractive sectors to local firms and the economy more broadly, such linkages rarely take place. Linkages are important because they can form part of triggering the economic transformation processes of resource-rich developing countries if foreign investments succeed in linking up to local firms so that domestic firms are upgrading, transfer of technology, knowledge, and skills are facilitated, business and management practices are improved, and access to finance and markets are eased. Strong linkage creation can as such promote "production efficiency, productivity growth, technological and managerial capabilities, and market diversification in local firms" (UNCTAD, 2013: 1). For poor but resource rich countries like Mozambique the importance of creating linkage development related to resource investments is pertinent, as it seems, besides taxation, to be the most important avenue for reaping the fruits of its rich natural resource endowment. It is only by linking the national economy to extractive investments that the economy can move from extreme dependence to a more fair engagement with the global economy.

However, the shift to natural resources that Mozambique has experienced over the last decade has not played a pivotal role in the transformation of the economy. Instead, economic growth has increased the already enormous disparity in wealth that sustains the political-cum-economic elite coalition linked to the Frelimo Party that has increased its grip over power in the two decades since the peace accord of 1992. In important ways this seems to reproduce Mozambique's predicament, mentioned by CastelBranco (2010), that the country has become an extractive service economy, bucking the formal imperative of industrial and economic transformation that has been the policy of the Frelimo party since independence. Consequently, the present development pattern seems to be making the Mozambican economy even more of an "enclave economy" (Morrisey, 2012), thus mirroring key features of the critique of foreign direct investment (FDI)-driven development and the 'resource curse' literature's quite negative assessment (Killick, 2004) of the potential for abundant natural resources economies to break the logjam of economic transformation and inclusive growth.

This chapter explores these broader processes from the perspective of linkage creation in Mozambique related to mega-projects in natural resource extraction and development from a political economy perspective. From a resource fairness perspective, linkage creation is essential as it allows for a more fair distribution of opportunities for local firms to gain from large-scale natural resource investments and for learning and spillover effects to other parts of the economy. In a longer term perspective, it is a potential key source of economic transformation towards higher value 
added activities and more and better local employment, therefore reducing dependence on resources.

The chapter proceeds as follows: the first section briefly considers the scope of mega-investments and their relation to Mozambique's economic structure. The second section describes how linkage development has been pursued in relation to mega-investments and explores the organizational and institutional realm that has developed over the last 15 years. The third section reviews the limitations to linkage development and analyses why the present wave of mega-investments in the extractive natural resource economy is struggling to engage in linkage formation. A brief conclusion ends the chapter.

\section{Extractive FDI investments in Mozambique}

Mozambique's history of natural resource extraction is relatively recent. Mozambique opened up the economy after the General Peace Accord in 1992. From 1997 to 2009, mega-projects generated FDI inflows amounting to approximately US $\$ 8.4$ billion (Mwanza, 2012: vii). Since the end of the 1990 s, it has seen investments in aluminium processing, gas extraction, heavy sand flow, and most recently coal-mining (see Buur et al., 2013). The first large extractive investment was the MOZAL aluminium smelter outside Maputo which went online in 2001. ${ }^{2}$ At present, the government has already granted more than a hundred coal exploration licences, even though production has only started for nine main extraction projects. The biggest coal investor is the Brazilian company Vale, which is "expecting to invest into the total project up to US\$8.2 billions" (MCMP, 2013: 74). Nevertheless, this is far below future investments in gas and liquid natural gas (LNG) facilities, which are expected to exceed US\$50 billion over the next ten years (Besseling, 2013; Ledesma, 2013). Mozambique is expected to become one of the world's largest producers of LNG and is aiming at the Asian growth markets. In contrast, the biggest agricultural investments in the sugar sector amounted to the much lower figure of approximately US $\$ 400$ million after the programme was initiated in 1996, with another US\$300-400 million after the millennium (see Buur et al., 2012a). Moreover, Mozambique's GNP lingers around approximately US\$13 billion, so foreign investment in the extractive natural resource industries is considered a 'game changer'.

Castel-Branco $(2010,2012)$ argues that mega-investments in Mozambique are a continuation of a far longer history of an extractive development economy characterized by considerable path dependencies. The Mozambican extractive development economy is characterized by an extreme concentration on a limited set of export products, services and firms in the energy and extractive sector that account for most of the economic growth. The economy is also a typical consumption economy rather than an economy based on investments for production. Urban centres rely 
on imported consumer goods of everything from hardware to foodstuffs. This has been exacerbated by the service economy, which has dominated more than 50 per cent of GDP from 1994 onwards. The service aspects of the economy have undergone dramatic structural change, as it is no longer the regionally oriented transport subsector that dominates, but rather the growth of banking, insurance, and telecommunications, as well as air travel, domestic transport, and tourism.

While agriculture's contribution to GDP has fallen significantly over the past 30 years, from 35 per cent in the 1980s to approximately 20 per cent at the beginning of the new millennium, this is due to a fall in agriculture's relative weight since the MOZAL and following extractive investments. The changing status of agriculture is therefore not attributable to a process of economic maturation of the economy based on an increase in agricultural productivity and linkages to the processing industries (Whitfield et al., 2015). Agriculture has remained important for the economy because this is where most people find employment and make their livelihood. Industry's contribution to GDP was only 21.1 per cent (KPMG, 2013). From 2000 onwards, mega-projects such as the MOZAL aluminium, coal and mineral sands exploitation accounted for the majority of growth in the 'industry' component of GDP, with MOZAL alone accounting for twothirds. Besides mega-projects, the other major industries include beverages, tobacco, sugar, and more recently the re-emergence of cashew processing (Hanlon and Smart, 2008). In terms of exports, the MOZAL aluminium smelter alone accounted for 31.38 per cent of all exports in 2012, followed by coal ( 12.52 per cent), electricity (6.73 per cent), tobacco (6.57 per cent), gas, and sugar. ${ }^{3}$

In other words, the extractive development economy that has evolved in Mozambique is an economy that produces what is not consumed domestically, and consumes what it does not produce (Weimer et al., 2012). One important implication of the extractive nature of the economy is that domestic capitalist class accumulation and income are based not on production in productive sectors, but on the rents of the services linked to extractive economies, while the economy is heavily dependent on external capital inflows, with a tendency to generate cyclically negative capital outflows. The economy's extractive nature creates a mode of accumulation that relies on natural resources and existing infrastructure, as well as creating structural inequalities in capitalist development across the different regions of the country (Castel-Branco and Ossemane, 2010: 143).

The dependence on the extractive sectors and related FDI investment can be seen in the incentive packages provided for the first and second generation of mega-investments. Even though there are vast differences between what has been granted as tax breaks and holidays in order to attract FDI, a clear pattern has developed. According to the African Peer Review Mechanism (APRM, 2009: 163-164), as a first mover, MOZAL was granted Africa's most generous tax exemption benefits. Added to this 
is the "preferential treatment" by government agencies establishing "task forces" catering for permits, licences, and non-standard procedures in order to compensate for cumbersome standard procedures (Krause and Kaufmann, 2011: 49). Moreover, both the SASOL gas investment and the Kenmare heavy sand investments have received generous tax holidays. Calls for contracts to be re-negotiated have therefore been made. But since the content of most contracts is not made available, the issues of incentives granted for investing in Mozambique and possible links to the ruling political elite are wide-ranging.

However, in contrast to what one would expect, and based on its low position on all governance indexes, Mozambique has formally developed an organizational and institutional setup linking the extractive economy to the national economy and small and medium sized enterprises (SME) development in response to the first wave of mega-investments from the mid-1990s and the second, intensified, wave since 2005.

\section{FDI-driven linkages: the institutional and organizational realm}

Since 1998, the key driver of linkage and local content awareness and promotion in Mozambique has been intimately related to the experience of the US\$2.4 billion MOZAL aluminium smelter outside Maputo, until recently the single biggest FDI investment in Mozambique and its first megainvestment. ${ }^{4}$ MOZAL has been used as an 'ideal model' showing investors that investments in risky destinations such as post-conflict Mozambique are possible, as well as being a 'best practice' example of the promotion of linkages between FDI mega-investments and SME and local content development. Whereas the first assumption is difficult to assess, the veracity of the second assumption has been thoroughly evaluated in multiple studies, assessments and manuals (see Castel-Branco and Goldin, 2003; Jaspers and Mehta, 2007; Robbins et al., 2009; Sonne-Schmidt et al., 2009; Ernst and Young, 2010; Krause and Kaufmann, 2011; Da Costa, 2012). While some studies herald MOZAL as a prime example of investor commitment and the power of following best practice blueprints, other studies have marked out the limitations of this type of investment.

The MOZAL investment had two phases of construction: MOZAL I was initiated in 1998 and took two and a half years, while the MOZAL II expansion was initiated in 2001 and took only one and a half years to be completed. Four steps can be identified in which linkages and local content provisions have been promoted in relation to MOZAL's construction and operational phases.

Identification: From 1997, the Mozambican state, through the Centre for the Promotion of Investments (CPI) and with support from the International Financial Corporation (IFC) and the World Bank, carried out a study as part of preparations for the participation of domestic SMEs in the 
construction of MOZAL and its subsequent production. A study screening 370 enterprises in 1997 found that "99\% had serious problems with product quality" and generally lacked experience, did not have the necessary portfolio of projects, operated with out-dated and depleted equipment and technology, and had serious management shortages (Castel-Branco and Goldin, 2003: 24). With very low levels of intra- and inter-firm linkages and technological capabilities, and a very thin and dispersed formal enterprise base, there was very little MOZAL could do to tap into and link up with local SMEs. So while opportunities would emerge, there were very few domestic enterprises that could engage with MOZAL. What became particularly clear to CPI and MOZAL was that the "standard contract format" MOZAL brought with it from South Africa was too large and technologically advanced for Mozambican companies to engage with (Robbins et al., 2009: 28). One consequence of this was that Mozambican participation in the construction of MOZAL I was limited.

SME Empowerment Linkages programme (SMEELP): Since 2001, there has been a joint MOZAL, CPI, and IFC programme that attempted to develop Mozambican firms so they could become eligible for participation in the enlargement of the MOZAL plant (MOZAL II) through matching grants. This was based on the creation of a Mozambican firm database and the vetting of the potential of enterprises to engage with MOZAL. This was followed up by the redesign and unbundling of MOZAL standard contracts, in addition to the reformulation of procurement standards so that they would better fit Mozambican business realities. Finally, the project engaged in the facilitation, information exchange, and training of the Mozambican SMEs that were considered the most capable candidates for MOZAL bidding, including when they were contracted for follow up through mentoring. In total, 16 SMEs were trained and, over time, 28 contracts worth just over US\$5 million were awarded.

Mozlink I: From 2003, SMEELP continued from the construction to the operational phase of the smelter, with a particular focus on banks and financial institutions providing loans to SMEs and the provision of technical capacity training. The linkage programme culminated in 2005 with the opening of the Beluluane Industrial Park next to MOZAL, which enjoys 'Industrial Free Zone' status and aims at creating clustering effects (Robbins et al., 2009: 22), with CPI and IFC being the key drivers. The programme trained 45 SMEs, and Mozlink enterprises gained contracts worth US\$13 million out of a total expenditure on local content of 180 million dollars, in which electricity and water combined accounted for 96 million dollars (Krause and Kaufmann, 2011: 51).

Mozlink II: This expanded Mozlink I in 2006 from being tied to MOZAL to including other FDI-driven investments, primarily in the gas (SASOL in 2002) and beverage sectors (Coca-Cola and South African Breweries). These were three-year supply-chain programmes aimed at strengthening the business and technical capabilities of SMEs so that they 
could compete for industry contracts (Ernst and Young, 2010). The key driver was the IFC's Private Enterprise for Africa (IFC PEP Africa). The IFC boasts that Mozlink II (IFC, n.d.; Jaspers and Mehta, 2007; Ernst and Young, 2010) has trained 75 SMEs and secured US $\$ 20$ million in revenues for them, with a 40 per cent growth in contract development by Mozlink corporate partners and providing employment for 3,000 employees.

Following in the slipstream of new mega-investments and the attempt to create linkages between the first generation of extractive industry megainvestments, new legislation emerged. Most importantly, at least in name, were the "Industrial Policy and Strategy" (GoM, 2007a) and the related "Strategy for the Development of Small and Medium Size Enterprises in Mozambique" from 2007 (GoM, 2007b). Among other issues, the Industrial Policy formulated mainly by the Mozambican state and government (GoM, 2007a: 4) highlighted the development of linkages between the beneficiaries of industrial development, encouraging them to organize themselves into productive clusters in order to increase the productivity and efficiency of the entire value chain. The policy also suggested that industries should focus on areas with a major economic and social impact, ${ }^{5}$ permitting the promotion of vertical and horizontal integration as well as of industries able to exploit productive resources and capacities adequately and sustainably. ${ }^{6}$ If the hallmarks of good industrial policies are the targeting, prioritization, and enforcement of the conditions for productivity, then the Industrial Policy was rather vague, because it did not provide guidance on how to link up with mega-investments (Krause and Kaufmann, 2011: 28 , nor clearly provide strategic guidance on how, for example, an investment like MOZAL could be used to boost economic development in the future (APRM, 2009: 165).

In contrast to the overall Industrial Policy, the specific strategy for SME development does set out key priorities and objectives while also proposing a certain sequencing of actions, including the establishment of an Institute for the Promotion of Small and Medium-sized Enterprises (IPEMA). While IPEMA was established in 2008 to drive implementation of the SME strategy, it largely relies on external funding for implementation, as is common for most organizational developments in Mozambique. The general idea was for IPEMA to take over from earlier institutions such as the Foundation for the Promotion of Small Industries and the Institute for the Development of Local Industries, which had some state funding, their own staff, and were implementation-oriented. As few initiatives supported by donor funding have been established by IPEMA, they do not seem to have provided any particular foundation for developing SMEs.

The three key pillars of the strategy - improving the business environment for SMEs, strengthening their technological and management capacity, and the provision of strategic support - depend on changing the overall business environment by "creating a level playing field and reducing transaction costs for SMEs" (Krause and Kaufmann, 2011: 29). 
In this sense, IPEMA's role primarily becomes one of facilitation, as its results depend on general policy reform and on support and resources, principally from donor organizations. However, while donor organizations are supportive of IPEMA, they have largely focused on running, establishing, or renewing their own organizations and institutional linkage programmes. Programmes such as the World Bank's Project for Entrepreneurial Development (PODE), which operates its own matching grant scheme for co-financing training sessions, consultancies, export promotion, and so forth, is a good example and is indeed keen on linking Mozambican enterprises to current mega-investments. In 2009, the Bank added the New Mozambique Competitiveness and Private Sector Development Project, whose US $\$ 25$ million budget is far larger than the budget of the Ministry of Trade and Industry (MIC), not to mention IPEMA. In addition, most national donor agencies, such as Danida, NORAD, and SIDA, run their own support mechanisms for private-sector, SME, and linkage development.

A particularly important point is that, at least to date, no specific legislation on local content for Mozambique exists, although some provisions can be found in different laws. ${ }^{7}$ Local content policies, understood as the extent to which investors have to purchase inputs and services locally, are contentious in regard to which criteria are used to define a Mozambican company as a firm. The Investment Law (No. 3/1993) suggests that a company or firm is Mozambican when it is formed and registered under Mozambique law, with headquarters in the Republic of Mozambique, and in which the respective capital share belongs at least 50 per cent to Mozambican citizens, companies, or institutions, whether private or public. But what constitutes 'capital' can be interpreted in different ways with the implication that local content provisions can de facto be provided by foreign companies with sleeping Mozambican partners that operate as 'fronts' for foreign companies. Another contentious issue has been that local firms will only be preferred under certain conditions, based on the quality of products and services offered locally, as they must be comparable to those offered internationally (Petroleum Law, No. 21/2014, Art. 41). This may as such be 'fair' if the aim is to promote competition, but it has the potential to reduce the participation of local firms, which can rarely comply, given their low capabilities and the relatively low quality of local products and services.

Finally, the legislation described so far overwhelmingly effects backward linkages, those links related to the supply of inputs to the commodity sector. Importantly, the regulatory frameworks also envisage the development of forward linkages, where outputs from the commodity sector are used as inputs to other industries. For example, the Mining Law (No. 20/2014) states that "mineral resources should be used where appropriate for power generation in order to achieve national energy security or as raw material for the manufacturing or other applications in the country" 
(Art. 21). This means that the state can buy mining products at market prices to use in the local industry whenever the commercial interests of the country require: "whenever possible, treatment and processing of ores exploited in Mozambique must be carried out within the country" (Art. 57).

If this is the institutional and organizational set-up for support to domestic SMEs that came out of the first and second generations of megainvestments, beginning with MOZAL in 1998 and the subsequent specific legislation related to extractive industries, the broader question is, what has been the actual experience of linking domestic firms to megainvestments?

\section{Limitations to linkage creation: the political economy of linkages}

Compared to the quantity of investments in which MOZAL has been involved, the results of the efforts to build linkages were rather meagre. Although no one has disputed the importance of the linkage programmes that emerged in the slipstream of the MOZAL investment, there were important limitations that are worth examining, as this experience is intimately related to how natural resource linkages are being pursued today in Mozambique.

First, as Krause and Kaufmann (2011) argue,

the effects have been quite limited in number and scope, as well as structure. The results are limited to the creation of a small market niche for local firms that depend almost completely on MOZAL and have not contributed to the development of an industrial cluster of innovative SMEs.

Second, in most cases the companies that received grants during the first generation of linkage programmes were the same as those in the following stages, with each company providing an increased number of services and supply functions (Jaspers and Mehta, 2007). This left a distinct impression that the linkage programmes that emerged from the MOZAL slipstream were helping a small, favoured number of enterprises instead of enlarging the general SME pool (Krause and Kaufmann, 2011: 51). This has clear historical origins, but there are also clear political and economic reasons for this concentration and favouritism. Over time, MOZAL created more than 200 suppliers of inputs to its operations in metallurgical services, transportation, auto-mechanical and electrical products and services, construction, security, cleaning, catering, and laundry. However, the majority of the enterprises were linked in one way or another to South African companies related to the South African aluminium establishment in Richards Bay and elsewhere (Castel-Branco and Goldin, 2003: 6) that reallocated 
with MOZAL. They also established subsidiaries over time and in many cases entered partnerships with well-placed Mozambicans. This seems to be a logical outcome, as MOZAL, through its main investor Billiton, came to Mozambique with an established business structure and model developed in South Africa. This had clear advantages, as an entire package of companies that could be subcontracted and that could establish links with Mozambican partners over time, though it also created rather limited and narrow linkage effects in Mozambique itself.

Third, this linkage model had few spillover effects to the Mozambican economy regarding technological capabilities and learning. Although it catered for some infrastructure development in energy, transport, and site and service development of an industrial area, in addition to the creation of around 1,100 jobs, the development impact as such was rather limited. Even though MOZAL worked with suppliers in a broad spectrum of services, most of the more genuine Mozambican owned and steered enterprises were in the low hanging fruits service sectors related to security, cleaning, and transport with limited knowledge and technological transfers.

Fourth, the concentration and monopolization of opportunities had the potential to trigger the establishment of new enterprises that were better geared and attuned to exhausting the opportunities emerging from the extractive natural resource industry, which does, however, not seems to have happened thus far. Research suggests that the Mozambican enterprises that came out of the MOZAL linkages programmes in fact became specialized and upgraded, being able to satisfy ISO and similar international standard requirements for safety, but also that they struggled to find new companies they could link up with until the recent wave of coal, gas, and energy mega-investments. Initially due to upgrading, they lost access to "traditional markets, or [lost] some space and ability to work with the traditional market" (Castel-Branco and Goldin, 2003: 29) as they became too expensive and advanced for the Mozambican economy. In this context, the enterprises that emerged in the shadow of MOZAL began a process of de-specialization in order to obtain enough domestic contracts to survive. One of the consequences has been that relaxed company practices needed for survival have spread to the specialized domain of the company, hence undermining gains in productivity and technological capability. This then caused problems when the recent wave of megainvestments into coal, gas, and energy came on stream after 2007 as the cluster of smaller enterprises that had evolved out of the MOZAL experience struggled to get contracts with the new investors due to despecialization.

Finally, while the intention behind the SME programme was to create forward linkages when possible, experience from the first generation of mega-investments spearheaded by MOZAL suggests that this has not happened because of the limited technical capacity of Mozambican companies 
and the lack of specific policies 'forcing' forward linkages. The expectation that the mere existence of MOZAL would create a manufacturing cluster based on aluminium ingots, or that SASOL would create forward linkages in which gas would be used as the raw material for a local industry, has until recently proved elusive (Warren-Rodriguez, 2008). For example, gas from the Pande and Tamano fields in Mozambique was transmitted to South Africa, from where it returned as value-added gas for household consumption in Mozambique until a new, smaller plant was set up in Mozambique in 2012 (Nhancale and Vilanculos, 2010).

Hence, where all the first-generation mega-investments were first-mover investments (aluminium, gas, and heavy sand) and therefore had special government attention - often with special institutional arrangements such as generous tax, customs, and import agreements (Castel-Branco and Goldin, 2003: 23) - there were also disadvantages and first-mover costs such as the lack of infrastructure investments and institutional and technical capacity. The hope was that the first generation of mega-investments would transform the general business landscape, making it easier for the second generation to link up to the Mozambican economy. However, second-generation investments have neither been as smooth as anticipated nor had the expected outcomes so far. Investments have generally found it very difficult to find small and medium sized Mozambican companies outside a small pool of companies to link up to. One reason remains the underlying problems of lack of capacity to meet the standards the new extractive mining and energy companies require. A second reason is that the national economic policy environment generally failed to give SME's sufficient attention during implementation despite the official focus on local linkages and SME development.

To understand these issues and the earlier and current challenges of linkages creation more generally it is crucial to take into account the often overlooked - political economy context and consequently the political forces that shape linkage development in Mozambique. This is important as industrial policy inevitably will be about distributing economic benefits and favouring certain economic factions or actors in contrast to other factions or actors. In this regard, the dynamics of linkages related to the new extractive economy must be placed within a broad political economy context in order to understand the nature of the domestic capitalists who have emerged over the last three decades and the scant attention seemingly given to emerging SMEs.

Interestingly, Mozambique was one of sub-Saharan Africa's eight most industrialized countries, at least until its independence in 1975 (Torp, 1979), but "after independence in 1975, the majority of fearful settlers fled back to Portugal and the industry was largely left alone" (Hanlon and Mosse, 2010: 2). With many businesses abandoned, "inexperienced and often poorly educated Mozambicans had to fill the gaps to avoid economic collapse, and five years after independence, Frelimo remained immensely 
popular, both for ending colonial oppression and for the expansion of health and education" (Hanlon and Mosse, 2010: 2).

At that time, it was believed that an honest and hard-working elite could develop the country, but the escalating civil war undermined the project of building a new developed state. The mid-1980s saw a shift to a mixed economy under the tutelage of the World Bank, even while the war continued. Liberal economic reforms took place, and state assets, except for strategic enterprises, were largely privatized. On top of access to property, officials and newly emergent business people were also given special access to dollar loans and credits by the state. As Pitcher (2003) argues, the fifth Frelimo Congress in 1989 had eliminated the restrictions imposed on party members, giving them an allowance to participate in the private sector. By doing so, the Congress gave the Frelimo state the power to reward its supporters by giving them state enterprises, while politicians viewed privatization as an opportunity for wealth accumulation.

This history of accumulation suggests that the most recent national capitalists are members of the ruling Frelimo coalition, which includes former government officials, administrators of state enterprises, and members of the security complex. Indeed, "these new capitalists started their careers in the government and in politics and owe their existence or economic expansion to patron client networks" (Pitcher, 2003: 807). The result was that

more than $40 \%$ of the new firms went bankrupt within five years of privatization, more than half of the remainder were traded for cash or shares or transformed into warehouses, and the state could not raise the expected additional revenue from massive selling of its property.

(Castel-Branco, 2014: 29)

Related to this, the Mozambican structure is highly skewed, consisting of a few big enterprises owned in part by foreign capital and in part by the state or members of the ruling elite; a few formally registered SMEs owned by both foreign and domestic capital, but with little clustering effect; and a large stratum of informal micro-enterprises owned by domestic entrepreneurs that comprise 98.6 per cent of all enterprises (Krause and Kaufmann, 2011: 13-14).

Key Frelimo elites have been known to win contracts as a way of making sure that economic opportunities are restricted and do not benefit or assist the opposition (Weimer et al., 2012). This created various 'bottlenecks' as 'point resources', and key service domains related to knowledge and consultancies, transport and port handling, access to finance and currency, imports of foodstuffs and consumer goods, machinery and technical appliances, and the export of natural resources were monopolized by Frelimo elites or Frelimo-supporting trade houses acting as cartels and monopolies. This includes the capture of the local content market in services and linkages by certain Frelimo factions. 


\section{L. Buur and C. M. Monjane}

The SMEs that were created during the first generation of linkage programmes in Mozambique in connection with MOZAL, as well as the various companies linked to members of the ruling elite coalition that emerged after the liberalization of the economy during the early 1990s, often in joint ventures with foreign companies, therefore became part of the cartel and monopsony economy. Over time a relationship evolved between the Frelimo ruling elite and the international donor community that supported the coalition with aid that has been characterized as a "pathological equilibrium" (Renzio and Hanlon, 2007: 6), allowing Frelimo to use the state to secure its dominant position and win elections as long as political stability was maintained. A tacit assumption is that mega-projects and foreign companies are in a secret alliance with the top political leadership of Frelimo. The paradox is that this alliance between Frelimo and mega-projects (or FDI more generally) are strongly supported by the international financial institutions and donors that aim at promoting good governance and democratization, while at the same time such investments buttress the Frelimo regime and its capacity to monopolize the democratic space in Mozambique.

As Buur et al. (2012b) observed, party coalition members who are engaged in economic activities are rarely found in the productive sectors but rather where easy rents can be deducted, as in trade and imports, communications, transport, and banking, often protected by state barriers of entry in one way or another. This is compounded by a limited manufacturing base in which few economic entrepreneurs having the required capabilities. Hence, when opportunities arise, they will nearly always be easy to monopolize, with the only people with capabilities, if any, coming from the ruling elite. Further, smaller entrepreneurs will try to stay 'under the radar' and spread out their activities in order not to attract the attention of politically connected business groups that could feel under threat, as one business man and representative from CTA phrased it in 2012. Thus, even though new opportunities have been made available by the present wave of mega-investments little happens. As a World Bank official noted in 2013:

There are opportunities. There is also a lot of talk and conferences at Indy Village [referring to the much used venue for donor and state promotion of governance, where at one conference in 2012 discussing SME opportunities related to mega-investments eight ministers participated]. They say that we need to 'take the opportunities' megainvestments provide, that there is enough for all, but then there is silence and nothing happens.

(Interview with Lars Buur, Maputo, March 2013)

One consequence of such monopolization and elite capture is that foreign companies begin to develop their own programmes for local content 
development. For example, former Rio Tinto Coal Mining (RTCM) argued that, while they obviously liked working with foreign companies of a certain standing that they had established links with from other contexts, they were becoming increasingly interested in attracting competition for service contracts and hence also work with a larger pool of local firms. The reason was simple: the price level was artificially high, as a small group of companies had ring-fenced port-handling, transport, imports of machinery, and the various types of services they depended on. The mapping of potential new enterprises that RTCM had commissioned from a consultancy company, and the setting up of a training facility in Maputo that aimed to empower companies so they could win procurement contracts over time, was all done in order to create competition and challenge the established monopolies. Thus, instead of using the structures created by the first generation of investments, including the state's organizational and institutional framework related to IPEMA, they were in the process of establishing their own linkage programmes in an attempt to challenge the tacit monopoly and monopsony status of a group of companies that restricted competition.

Another example of elite capture is the Norwegian Oil for Development Programme (OfP), which is generally acknowledged to have been successful in supporting demand-driven capacity-building, with its focus on technical capabilities being greatly appreciated by counter-party institutions (NORAD, 2012: 1). After 2006, when support was provided through the OfD programme umbrella, the majority of the funding was used to provide institutional support for the National Institute for Petroleum (INP), with smaller components of institutional development and capacity-building for the state-owned oil company (ENH) and the Ministry of Environment. The fact that more or less all people with knowledge of the oil and gas sector have been involved with the OfD programme means that a situation has evolved where there are overlapping relationships between members of the sector, the Frelimo government, and business (CIP, 2010; 2012). It seems like all the top senior government officials and bureaucrats in the INP, $\mathrm{ENH}$, and related ministries have launched companies to service the oil and gas sector because they enjoy "privileged access to information on the country's natural resources" (CIP, 2010: 1). Where such close networks and relations between political and technocratic elites and international business are inevitable in a country with a very limited private sector and a recent history of state-led development, they may be the foundation for a greater ability in the future to manage resources. But so far much suggests that Mozambique seems to be heading in the direction of inefficient rent usage with little ability to manage its rich resource endowment securing a more fair distribution and use of resources. 


\section{L. Buur and C. M. Monjane}

\section{Conclusion}

This chapter has argued that large-scale FDI in Mozambique's natural resource endowments from the mid- to late-2000s has created fewer linkage opportunities than expected and that access to these opportunities has been monopolized. The tendency for linkage formation to be driven towards monopolies or what we have called "linkage patronage" (Hansen et al., 2015) has major consequences for realizing the potential of linkages in extractives for development. The groups that become the main beneficiaries when foreign investors involved in extractive industries link up with or move import functions to domestic entrepreneurs will be those who already control the economy. In Mozambique, this means elite groups closely related to Frelimo. Once such easy rents from 'low-hanging' linkage promotion have been captured by key ruling elite coalitions, it is very difficult to change the distribution of economic opportunities and benefits from linkage policies. The dangers of capture are very real and not conducive to linkage promotion and by implication productive transformation, as the ruling elite focus on trade and service.

One implication of the findings from this chapter is that broader questions related to fairness and a more equal distribution of potential benefits from natural resource exploitation are not solely related to external factors, such as FDI dominance, that create an uneven playing field for least developed economies, but are also intimately related to internal political economy factors, which implies that the political incentives - be they direct, as part of industrial policies, or less steered - that motivate elites to pursue linkage development need to be taken seriously. Here, contexts such as institutions and politics matter, as they impact on the political incentives that influence political, bureaucratic, or economic elites in formulating and implementing policies. Only by taking such considerations into account can one begin to understand how, and whether, linkage development is exercised, and who ultimately gains, and, hence, if these policies and processes provide support or limits to resource fairness.

\section{Notes}

1 In Mozambique, investments that exceed 500 million US dollars are referred to as mega-investments.

2 It is owned by the Australian based BHP Billiton Ltd, the Industrial Development Corporation of South Africa Ltd, the Japanese Mitsubishi Corp, and the Mozambican government (with less than 4 per cent).

3 Before the mega-investments began to change the composition of exports, Mozambique had a chronic balance of payments problem. However, the economy is dependent on a small number of export commodities, and it imports a significant amount of goods and services for extraction purposes that are consumed or used domestically, making the economy extremely vulnerable to external price shocks for oil and food.

4 The construction of MOZAL was followed by the US\$1.4 billion SASOL pipeline from the Pande and Tamana gas fields in the Inhambane province in the 
south of the country from 2002 and the construction of the Kenmare/Moma heavy sand plant in Nampula in the north of country from 2003, coming into operation in 2006/7.

5 The examples were very specific, such as "the food-processing industry, with its capacity to maximize agricultural and fishery potential, and in turn providing multi-sectorial linkages, employment and import substitution, as well as increased and diversified exports" (GoM, 2007a: 4).

6 Again, the examples were specific, "such as industries for the processing of timber and its derivatives, and industries producing construction materials, among others" (GoM, 2007a: 4).

7 Five pieces of legislation have various provisions of relevance to this chapter: the Investment Law (Law No. 3/93 of 24 June, Mozambique), the Law on PublicPrivate Partnerships of Large Scale Projects Business Concessions (Law No. 15/2011 of 10 August, Mozambique), the Mining Law (Law No. 20/2014 of 18 August, Mozambique), the Petroleum Law (Law No. 21/2014 of 18 August, Mozambique), and the Policy and Strategy of Mineral Resources (Resolution No. 89/2013 of 31 December, Mozambique).

\section{References}

APRM (2009) Country Review Report: Republic of Mozambique, African Peer Review Secretariat, Country Review Report 11, Midrand.

Besseling, R. (2013) 'Mozambique: political dynamics, regulatory outlook and infrastructure risks', http://macua.blogs.com/files/exclusive-analysis_africa_moz. pdf [accessed 23 December 2015].

Buur, L. and Baloi, O. (2009) 'The Mozambican PRSP initiative: moorings, usage and future', DIIS Working Paper, no. 35, Danish Institute for International Studies, Copenhagen.

Buur, L., Mondlane, C., and Baloi, O. (2012a) 'The white gold: the role of government and state in rehabilitating the sugar industry in Mozambique', Journal of Development Studies, vol. 48, no. 3, 349-362.

Buur, L., Mondlane, C., and Baloi, O. (2012b) 'Mozambique synthesis analysis: between pockets of efficiency and elite capture', DIIS Working Paper, no. 1, Danish Institute for International Studies, Copenhagen.

Buur, L., Therkildsen, O., Hansen, M., and Kjær, M. (2013) 'Extractive natural resource development: governance, linkages and aid', DIIS Report, no. 28, Danish Institute for International Studies, Copenhagen.

Castel-Branco, C. N. (2010) 'Economia extractiva e desafios da industrialização em Mozambique', in L. de Brito, C. Castel-Branco, S. Chichava, and A. Francisco (eds) Economia Extractiva e Desafios de Industrialização em Mozambique, IESE, Maputo, 19-109.

Castel-Branco, C. N. (2014) 'Growth, capital accumulation and economic porosity in Mozambique: social losses, private gains', Review of African Political Economy, vol. 41, no. 1, 26-48.

Castel-Branco, C. N and Goldin, N. (2003) 'Impacts of the MOZAL aluminium smelter on the Mozambican economy. Final report', www.iese.ac.mz/lib/cncb/ Mozal_and_economic_development.pdf [accessed 10 October 2013].

Castel-Branco, C. N. and Mandlate, O. (2012) 'Da economia extractiva à diversificação da base produtiva: O que pode o PARP utiliizar da análise do mode de acumulação em Moçambique?', in L. de Brito, C. Castel-Branco, S. Chichava, 
and A. Francisco (eds) Economia Extractiva e Desafios de Industrialização em Mozambique, IESE, Maputo, 117-144.

Castel-Branco, C. N. and Ossemane, R. (2010) 'Crises cíclicas e desafios da transformação do padrão de crescimento económico em Moçambique', in L. de Brito, C. Castel-Branco, S. Chichava, and A. Francisco (eds) Economia Extractiva e Desafios de Industrialização em Mozambique, IESE, Maputo, 141-182.

CIP (2010) 'The business interests of public managers in the extractive industry: alliances with the stamp of trafficking in influence and conflicts of interest', www.cip.org.mz/cipdoc/130_Extractive \%20industry \%20conflicts $\% 20$ of $\% 20$ interest \%20in\%20Mozambique.pdf [accessed 10 October 2013].

CIP (2012) 'The business interests of public managers in the extractive industry', www.cip.org.mz/article.asp?lang=en\&sub $=c r r p \& d o c n o=130$ [accessed 10 October 2013].

Clément, J. and Peiris, S. (2008) 'Sustaining growth takeoffs: lessons from Mozambique', in Post-Stabilization Economics in Sub-Saharan Africa: Lessons from Mozambique, International Monetary Fund, Washington.

Da Costa, N. (2012) 'Are there spillover effects from foreign direct investment in Sub-Saharan Africa? Assessing the linkage effects in Mozambique', MA thesis, School of Oriental and African Studies, London.

Ernst and Young (2010) Final Report: Mozlink II Independent Evaluation, Ernst and Young, Lda Maputo.

GoM, República de Moçambique (2007a) Industrial Policy and Strategy, Maputo.

GoM, República de Moçambique (2007b) Estratégia Para o Desenvolvimento das Pequenas e Médias Empresas em Moçambique, Maputo.

Hanlon, J. and Mosse, M. (2010) 'Mozambique's elite: finding its way in a globalized world and returning to old development models', Working Paper, no. 105, UNU-WIDER, Helsinki.

Hanlon, J. and Smart, T. (2008) Do Bicycles Equal Development in Mozambique?, James Currey, Woodbridge.

Hansen, M., Buur, L., Kjær, A., and Therkildsen, O. (2015) 'The economics and politics of local content in African extractives: lessons from Tanzania, Uganda and Mozambique', Forum for Development Studies, vol. 42, no. 3, 1-28.

IFC (n.d.) 'The IFC MozLink program: supporting small business growth in Mozambique', www.commdev.org/userfiles/Mozlink_Factsheet.pdf [accessed 10 October 2013].

IIM (Inquérito às Indústrias Manufactureiras) (2012) 'Survey of Mozambican manufacturing firms: descriptive report', República de Moçambique, Ministério da Planificação e Desenvolvimento, Direcção Nacional de Estudos e Análise de Políticas, Maputo.

Jaspers, F. J. and Mehta, I. (2007) Developing SMEs Through Business Linkages: The MozLink Experience. A Manual for Companies, NGOs, and Government Entities Version 1.0., Mozal Aluminum and IFC, Maputo and Washington.

Jones, E. and Tarp, F. (2012) 'Jobs and welfare in Mozambique', Country case study for the 2013 World Development Report, http://siteresources.worldbank.org/ EXTNWDR2013/Resources/8258024-1320950747192/8260293-132095671227 6/8261091-1348683883703/WDR2013_bp_Jobs_and_Welfare_in_Mozambique. pdf [accessed 15 March 2013].

Killick, T. (2004) 'Politics, evidence and the new aid agenda', Development Policy Review, vol. 22, no. 1, 5-29. 
KPMG (2013) 'Monitoring Africa sovereign risk: Mozambican snapshot', www. kpmg.com/Africa/en/KPMG-in-Africa/Documents/2013\%20Q4\%20snapshots/ KPMG_Mozambique\%202013Q4.pdf [accessed 23 December 2015].

Krause, M. and Kaufmann, F. (2011) 'Industrial policy in Mozambique', Discussion Paper, no. 10, Deutsches Institut für Entwicklungspolitik, Bonn.

Ledesma, D. (2013) 'East Africa gas: potential for export', The Oxford Institute for Energy Studies, University of Oxford, www.oxfordenergy.org/wpcms/wp-content/ uploads/2013/03/NG-74.pdf [accessed 13 January 2016].

MCMP (2013) 'Final report', 27 May 2013, Maputo.

Morrissey, O. (2012) 'FDI in Sub-Saharan Africa: few linkages, fewer spillovers', European Journal of Development Research, vol. 24, no. 1, 26-31.

Mwanza, P. (2012) 'Mozambique business linkages review: an overview of key experience, issues and lessons', USAID Mozambique, www.speed-program.com/wpcontent/uploads/2012/11/2012-SPEED-REPORT-MOZLINKAGES-REVIEW-EN. pdf [accessed 15 January 2016].

Nhancale, C. and Vilanculo, H. (2010) Análise das Empresas Petroliferas e de Mineração Sul-Africanas em Moçambique: Mozal e Sasol, Southern Africa Resource Watch, SARW, Johannesburg.

NORAD (2012) 'Enhancing the integrity of the oil for development programme: assessing vulnerabilities to corruption and identifying prevention measures - case studies of Bolivia, Mozambique and Uganda', NORAD Report, no. 7, Norad, Oslo.

Pitcher, A. (2003) 'Sobreviver à transição: o legado das antigas empresas coloniais em Moçambique’, Análise Social, vol. 38, no. 168, 793-820.

Renzio, P. and Hanlon, J. (2007) 'Contested sovereignty in Mozambique: the dilemmas of aid dependence', GEG Working Paper, no. 25, Global Economic Governance Programme, Oxford.

Robbins, G., Lebani, L., and Rogan, M. (2009) 'TNC FDI firms and domestic SME linkages: reflecting on three SADC case studies', School of Development Studies Research Report, no. 82, University of KwaZulu-Natal, Durban.

Sonne-Schmidt, C., Arndt, C., and Magaua, M. (2009) 'Contribution of megaprojects to GDP in Mozambique', II Conference of IESE, 22-23 April, Maputo.

Torp, J. (1979) 'Industrial planning and development in Mozambique: some preliminary considerations', Research Report, no. 50, Scandinavian Institute of African Studies, Uppsala.

UNCTAD (2013) Commodities and Development Report: Perennial Problems, New Challenges and Evolving Perspectives, United Nations, Geneva.

Warren-Rodriguez, A. (2008) 'Linking technology development to enterprise growth: evidence from the Mozambican manufacturing sector', Department of Economics Working Papers, no. 160, School of Oriental and African Studies, University of London.

Weimer, B., Macuane, J., and Buur, L. (2012) 'A economia do political settlement em Moçambique: contexto e implicações da descentralização', in B. Weimer (ed.) Mocambique: Descentralizar o Centralismo. Economia Politica, Recursos e Resultados, IESE, Maputo, 31-75.

Whitfield, L., Therkildsen, O., Buur, L., and Kjaer, A. M (2015) The Politics of African Industrial Policy: A Comparative Perspective, Cambridge University Press, New York. 


\title{
13 The agrofuels project in Ukraine How oligarchs and the EU foster agrarian injustice ${ }^{1}$
}

\author{
Christina Plank
}

\section{Introduction}

Agrofuel politics have been highly contentious over the past decade. ${ }^{2}$ While agrofuels are widely held to contribute to energy security, local development, and the mitigation of climate change (European Union, 2009), environmental, development and human rights NGOs, as well as a growing body of academic opinion, question the benefits and point to the negative social and environmental impacts of these crops. Agrofuels erode biodiversity (Campbell and Doswald, 2009) and increase greenhouse gas emissions, rather than reducing them, by influencing land use (Searchinger et al., 2008), thus driving climate change (Fargione et al., 2008). They also pose a threat to local food security and cause changes in agricultural regimes (McMichael, 2010). The production of agrofuels has promoted the commodification of crops, the valorization of land and increased export dependency. By influencing land use it gives rise to land access conflicts (Borras et al., 2011; Dietz et al., 2015) and raises major resource justice issues.

The introduction and implementation of agrofuel policies by the EU has met with growing opposition. The Biofuels Directive adopted in 2003 set a blending target of 5.75 per cent of agrofuels to be added to conventional fuel by 2010 (European Union, 2003). The Renewable Energy Directive (RED) (European Union, 2009) adopted in 2009 raised this goal to 10 per cent, to be attained by all member states by 2020 . Although attempts were made to spin a strong 'win-win' narrative around the agrofuel drive, highlighting the supposed economic and environmental benefits, the backlash led to the introduction of sustainability criteria. However, these are strictly environmental and have no social dimension. Criticism has continued to mount, with the spotlight increasingly on indirect land use change, due to the additional greenhouse gas emissions occasioned by the cultivation of 'virgin' land needed for food production. In response, in 2015 the European Parliament (2015) reduced the blending target in the RED to 7 per cent for the so-called 'first generation' agrofuels produced from food crops. Nevertheless, what is by now a firmly entrenched agrofuel industry still enjoys strong policy and government support. 
This chapter examines the political and economic implications of agrofuel production, and its related transformation of the agricultural system. McMichael (2009) refers to the rise of the agrofuel industry as that of the "agrofuels project", which he describes as a state-capital nexus. "The rush to agrofuels, under the guise of policies geared to alternative energy and reducing carbon emissions, opens up new profit frontiers for agribusiness, energy and biotechnology corporations" (McMichael, 2009: 826). Agrofuel crops - notably rapeseed, soya beans, and palm oil, but also wheat, maize, and sugar cane - should therefore be seen as part of an expanding "flex crops" industry (Borras et al., 2016). This term points to the fact that oilseeds and starches are subject to multiple use - as feedstock for agrofuels, but also as food, animal feed, or inputs for other industrial products such as cosmetics. This flexibility enhances the security of demand for these crops, making their cultivation more economically appealing.

This chapter analyses the transnational impact of the EU's agrofuel politics on Ukraine and their consequences for agrarian justice. The EU relies on imported feedstock to meet its blending target. Ukraine possesses over 32 million hectares (ha) of fertile farmland and is a major feedstock exporter to the EU, in line with its traditional role as the "breadbasket of Europe". Ukraine's expanding rapeseed output primarily reflects the rising demand for agrofuel feedstock in the EU (Schaffartzik et al., 2014), while corn, soya beans, sunflower, and wheat are also exported to the EU as 'sustainable' agrofuel feedstock (ISCC, n.d.). From an agrarian justice perspective, the crucial questions are "the collective struggles of rural working people to democratise access, ownership, and control of land, water and other natural resources" (TNI, 2015), as well as the opportunities to shape and take part in the decision-making process (see Pichler, in this volume). An agrarian movement capable of articulating such demands has yet to emerge in Ukraine. The prevalent oligarchical structures are an obstacle to grassroots organization. The agrofuels project, and the active support of the EU, reinforces the oligarchic system and agribusiness. A full picture of agrarian justice, in terms of access, distribution, and representation, would need to take account not just of small farmers and their representation but also of influence of the Ukrainian oligarchs and the ruling class as a whole.

Drawing on McMichael (2009), I argue that the agrofuels project in Ukraine should be viewed as an oligarchic project supported by the EU. The state sets the stage for societal nature relations. In Ukraine, the oligarchs - understood as internal bourgeoisie - dominate the state. Agrofuels are an opportunity for them to make profits by engaging in agribusiness. I examine the capital-state nexus by focusing on internalization - the interplay of internal (here, the Ukrainian oligarchs) and external actors (multinational agribusiness corporations, funds and traders, as well as the EU and member states) - in a situation where there are aspects of both conflict and cooperation with respect to the control of land, trade, and sustainability certification among the ruling class. The German government has 
been particularly keen to promote the production of supposedly 'sustainable' biomass in Ukraine in order to obtain agrofuel feedstock. Exporting this feedstock does not contribute to agrarian resource justice in Ukraine but strengthens the country's agribusiness and oligarchs.

The analysis is based on qualitative expert interviews, conducted in Ukraine in winter 2011 and 2012, and on documents, including different draft bills, adopted laws, agreements, position papers, online portals, and newspaper articles. The experts interviewed were representatives of ministries, renewable energy and agricultural pressure groups, international organizations and financial organizations, NGOs, agribusiness, farmers, agrofuel producers, the EU and its member states in Ukraine, and agricultural experts.

The second section draws on political ecology and introduces internalization as a theoretical framework in the context of the Ukrainian state and oligarchs. The next section gives an overview of agrofuel consumption in the EU and related feedstock production in Ukraine. The fourth reviews the interconnection of the Ukrainian state, oligarchs, and agribusiness. The fifth explores the realms of land, trade and sustainability certification, and conflict and cooperation among the ruling class. The final section looks at the implications of the agrofuel project for agrarian justice in Ukraine.

\section{Understanding the Ukrainian state: oligarchic projects and internalization}

The following analysis treats the agrofuels project as an oligarchic project. It draws on the debate about the role of the state in "societal nature relations" (German: gesellschaftliche Naturverhältnisse) (see Brand and Wissen, 2012; Brand and Görg, 2013) and gives prominence to the concept of 'internalization', that is, the interplay of 'internal' and 'external' social forces. Since the economic and the political spheres cohere in the persons of the oligarchs, in Ukraine internalization is inseparable from personal relationships. The interplay between these social forces shapes the agricultural sector and, in turn, agrarian justice.

The agrofuels project in Ukraine and related agrarian justice issues can only be understood in the light of societal nature relations. A political ecology perspective not only reveals the power relations that are inscribed in societal nature relations, it also demonstrates how nature is appropriated and transformed, and how this is feeds back into society. Identifying the winners and losers in the transformation process sheds light on agrarian justice (see Pichler, in this volume). Social inequality is one of the keys to an understanding of the Ukrainian agrofuels project (see Wissen, 2015).

The state has a decisive influence on societal nature relations in Ukraine, and this has been true of the agrofuels project and related questions of agrarian justice (see Pichler, in this volume). Defining the state as a social relation (Poulantzas, 1978) underlines its contested character - the 
conflicts, social forces, and various capital factions that mould it. Similarly, according to this reading, the ruling class is not a unified bloc but is constituted of a number of factions. Poulantzas (1976) not only differentiates between a national and a comprador bourgeoisie (i.e. one that is dependent on external capital) but also introduces the term "internal bourgeoisie". The internal bourgeoisie is interwoven with international capital but still has a strong material base in the country.

Depending on the prevalent politico-economic conditions, the state will be more accommodating to some interests than to others. This is highlighted by Jessop's "Strategic-Relational Approach". "A given type of state, a given state form, a given form of regime, will be more accessible to some forces than others according to the strategies they adopt to gain state power" (Jessop, 1990: 1873). Rather than treating the Ukrainian state as "weak" (Kuzio, 2012) or "captured" (Hellman and Kaufmann, 2001), as many authors do, I believe that it is more productive to focus on the politico-economic interaction of the Ukrainian oligarchs, viewed as an internal bourgeoisie. In Ukraine, the oligarchs have a massive influence on the post-Soviet space, constitute the Ukrainian state, and are at the same time interwoven with the world market. Due to their political and economic power, exercised through Finance Industry Groups, they are the doorkeepers to all socio-ecological and economic influence in Ukraine (Plank, 2015a). The apparatus of the state is dominated by the economic power of the ruling class; what Poulantzas calls "relative autonomy" (Poulantzas, 1978) is virtually non-existent in Ukraine (Becker, 2015: 409).

This makes it difficult, if not impossible, for foreign actors to directly engage with or intervene in the Ukrainian state and economy without cooperating with the oligarchs. I show how foreign players frame their interests and strategies to obtain sustainable certified feedstock. The Poulantzian concept of internalization draws attention to the connection between 'internal' and 'external' political and economic dynamics and social forces, and thus makes it possible to examine agents of internationalization such as the Ukrainian oligarchs (Poulantzas, 1976: 22). Since individuals (or clans) hold the economic and political reins, personal relationships are especially vital to internalization in Ukraine. By drawing on Jessop's "Strategic-Relational Approach" (Jessop, 1990), I show how foreign actors - in the development aid community, science, agribusiness, and government - can only pursue their interests by joining forces with the Ukrainian oligarchs. Cooperation within the ruling class reinforces social inequality and agrarian injustice.

\section{EU agrofuel industry targeting Ukraine's agricultural potential}

The EU's demand for agrofuel feedstock is driven by existing refining capacity and the mandatory blending target. Despite the reduction of the target 
to 7 per cent for 'first generation' agrofuels in the RED, the demand for feedstock remains high. The EU agrofuel industry depends both on domestically sourced feedstock and on imported flex crops. For instance, 20 per cent of the feedstock for agroethanol and 40 per cent of that for agrodiesel had to be imported in 2010 (Gerasimchuk, 2013: 5). Most cars in the EU are diesel fuelled, and agrodiesel consumption is some four times higher than agroethanol use by volume, as shown by Table 13.1. The share of renewables in fuel consumption has increased since 2009 but has remained below the blending target, standing at 5.4 per cent in 2013. More domestically grown and imported feedstock will be needed in future to attain even the reduced target.

The largest consumers of transport agrofuels in the EU in 2014, in order of volume, were France, Germany, the United Kingdom, Italy, and Spain, while Germany is the leading producer (EurObserv'ER, 2015: 14). In Germany, agrofuel moved from small-scale to large-scale production when the government changed its support policy from tax-free payments to a blending target in 2006. Small-scale producers were pushed off the market by the oil companies because they were unable to supply the large volumes required (Vogelpohl, 2014: 22-26). Today, the largest agrodiesel producers in Germany are transnational corporations such as ADM Germany, Verbio AG, and Petrotec (EurObserv'ER, 2015: 12). In the case of agrodiesel in particular, there is still unused capacity because the producers rely on sustainable certified feedstock. Although certification as such is voluntary for agrofuel producers, and is carried out by private schemes, it is mandatory for anyone wishing to make output count towards the RED blending target and thus qualify for the financial incentives. In line with its history as a renewable energy pioneer, Germany was one of the first countries to insist on compliance with sustainability criteria (Biofuel Sustainability Order, 2009). The order requires companies to supply certified agrofuels in order to obtain state subsidies. The International Sustainability

Table 13.1 Agrofuel consumption in the EU 28*

\begin{tabular}{llll}
\hline Year & $\begin{array}{l}\text { Agrodiesel ('000 tonnes } \\
\text { of oil equivalent [toe]) }\end{array}$ & $\begin{array}{l}\text { Agroethanol } \\
\text { ('000 toe) }\end{array}$ & $\begin{array}{l}\text { Renewable energy as a share of } \\
\text { transport fuel consumption** (\%) }\end{array}$ \\
\hline 2009 & $8,013.0$ & $1,719.3$ & 4.3 \\
2010 & $8,934.6$ & $1,991.0$ & 4.8 \\
2011 & $8,493.5$ & $1,763.7$ & 3.4 \\
2012 & $9,209.5$ & $2,056.0$ & 5.1 \\
2013 & $9,868.5$ & $2,580.8$ & 5.4 \\
\hline
\end{tabular}

Sources: Eurostat, 2015a, 2015b.

Notes

* The shares of biogas and other liquid agrofuels are insignificant (at $1 \%$ or less of agrofuel consumption).

** Including electricity. 
and Carbon Certification (ISCC) system is one of the main certification schemes backed by the German Federal Ministry of Food, Agriculture and Consumer Protection via the Agency for Renewable Resources (FNR) (European Commission, 2011). Germany is a key agrofuel producer, consumer, and certifier and has, as I will show in more detail below, a strong interest in Ukraine as a source of feedstock.

Against the backdrop of an expanding EU agrofuel industry, various studies and government documents have highlighted Ukraine's agrofuel potential. This has been examined by research on land availability and greenhouse gas emissions (Van der Hilst et al., 2014). Some studies have also focused on the economic viability of agrofuel production in Ukraine (Lakemeyer, 2007; Strubenhoff, 2009). For example, a "Market Scan Bioenergy Ukraine" was carried out for the Dutch government in 2009; this recommended exchanging feedstock for knowledge and technology (Elbersen et al., 2009). There has been repeated discussion as to whether land around Chernobyl could be used for agrofuel production. This would permit the utilization of contaminated land that is off limits for food production (edie.net, 2009). All these studies point to the country's great agricultural potential, particularly as an exporter. In the words of two authors, "Ukraine has all preconditions to become one of the largest sustainable biomass suppliers" (Ogarenko and Nivievskyi, 2012: 2).

Indeed, Ukraine is already an important feedstock supplier to the EU agrofuel industry. While it exports a variety of flex crops, rapeseed production is largely driven by agrodiesel demand. Ukraine is among the world's leading rapeseed exporters (Gerasimchuk, 2013: 7-8). Conversely, the EU is the main export market for Ukrainian rapeseed, with over 90 per cent of the output going to EU member states (Schaffartzik et al., 2014). Besides rapeseed, Ukraine exports soya beans, sunflower seeds, wheat, maize, and sugar beet for agrofuel production in the EU. However, these products' share of the agrofuel market lags far behind that of rapeseed (Gerasimchuk, 2013: 7-8; ISCC, n.d.).

\section{The Ukrainian state, the oligarchs, and agribusiness}

Oligarchs play an important role in the economic and political life of Ukraine, and are closely interwoven with the state. Oligarchic clans emerged as a national bourgeoisie in the metals, energy, and banking sectors after the waves of privatization under President Leonid Kuchma (1994-2005). They do not constitute a single capital faction, but their groups should be seen as Finance Industry Groups that are strongly rooted in the domestic economy. These Finance Industry Groups have grown from regional bases - Kyiv, Donetsk, and Dnipropetrovsk - and there are strong rivalries between them. A common feature of the oligarchs is their desire to remain powerful in the country and extend their power there, and this is the motive that guides their decisions to support the West and/or the East. 
As members of parliament or ministers, as well as via their political parties, they are more or less able to directly influence the state apparatus. In addition, they influence Ukrainian society via the media (Plank, 2015a: 595-597).

Since the financial and economic crisis, the renascent farming industry has played an important role for Ukraine and its oligarchs because agriculture is a stable export sector and is now very profitable. Agriculture's huge untapped potential has been noticed by the oligarchs, and it has been carved up among them. During Janukovych's presidency (2010-2013) members of his Party of the Regions, many of whom are involved in agribusiness, played a prominent part in parliamentary decisions of importance to the sector. For instance, Oleg Bakhmatyuk, the owner of UkrLandFarming, the largest agricultural holding company in Ukraine, controlling 654,000 ha, is a member of the Janukovych 'family'. The richest and most influential oligarchs, Rinat Achmetov (Donetsk clan) and Ihor Kolomoyskyi (Dnipropetrovsk clan) have also diversified by setting up their own agricultural holding companies, HarvEast (170,000 ha) and PrivatAgroHolding (116,000 ha), respectively (Plank and Plank, 2014: 56-58; Latifundist, n.d.a). In the current parliament, agriculture is the most coveted committee among the party's members (Leshchenko, 2015). Meanwhile, in the person of Petro Poroshenko, the new President elected in 2014 after the events on the Maidan, for the first time an oligarch is ruling the country, and Poroshenko, too, has major holdings in the food and agriculture industry (Samaeva, 2015).

Not only local oligarchs, but also Western capital, are seeking to gain from the revival of Ukrainian farming. The change of government from President Yushchenko (2005-2010) to Janukovych (2010-2013) had a considerable influence on the investment climate for Western companies. After Ukraine opened up to Western capital in the aftermath of the Orange Revolution in 2004 it was easier for European companies to gain a foot in the door, and this also applied to the agricultural sector. However, under Janukovych this changed, and Western interests found it increasingly difficult to win a hearing from his government. With the protests on the Maidan, Janukovych's fall, and the signing of the Association Agreement and the Deep and Comprehensive Free Trade Agreement with the EU, the politico-economic balance has again tilted towards the West. The new proWestern government envisages a sell-off of state agricultural enterprises and energy companies, and is encouraging Western companies to take part in the privatization process. The changes of government from Yushchenko to Janukovych, and now to Poroshenko, have thus profoundly altered social, political, and economic relations between Ukraine and the West (Plank, 2015a). 


\section{Internalization through land, trade, and sustainability certification}

I shall now set out to show how the oligarchic agrofuels project fosters agribusiness, thereby reinforcing resource injustice, and how the EU is promoting this trend. Land concentration, the creation of a farmland market, export quotas and RED sustainability certification are all arenas of conflict and cooperation among the ruling class, and shape the agricultural sector and hence agrarian justice.

\section{Land concentration and the creation of a farmland market}

The land reform ushered in by Ukrainian independence transformed the agricultural sector. The collective and state farms were dissolved, and the land distributed to the workers on them. Most of the beneficiaries do not work their land but lease it out, because neither the means of production nor financial support were provided when the change in ownership took place (Allina-Pisano, 2008). As long ago as the 1990s, the EU, the World Bank, and USAID began pushing for the creation of a land market in Ukraine. For example, they offered aid for the establishment of a land registration system and cadastre (Roth and Valetta, 2006; World Bank, 2016). Germany's longstanding cooperation with Ukraine has had a strong focus on the agricultural sector. It has actively advised on the transformation process in Ukraine, providing information on 'best practice' in the West. This advice has come from both the public and the private sector (Deutscher Bundestag, 2015). Today, the EU twinning programme, under which expertise is provided by Germany, the Netherlands, and Lithuania, is attempting to transfer 'best practice' regarding the liberalization of the land market to Ukraine. However, the privatization of the farmland market remains controversial because most of the rural population and the domestic agribusiness sector oppose it (Plank, 2015b). As a result, the moratorium on the sale and purchase of farmland has again been extended - this time until 1 January 2017 (Drannik, 2015).

A dualistic farm structure inherited from the Soviet Union - subsistence farming and former kolkhozes (collective farms) - is still characteristic of the post-Soviet sector. ${ }^{3}$ The old collective farms are now increasingly grouped under big umbrella companies known as 'agroholdings'. The latter are horizontally and vertically integrated agricultural companies that control not only much of Ukraine's farmland but also the whole supply chains of various agricultural and food products. Some, like Kernel (390,000 ha) and Nibulon (82,500 ha), are major grain traders. Ukrainian oligarchs increasingly own 'agroholdings', meaning that the agribusiness sector is dominated by domestic capital (Plank and Plank, 2014; Latifundist, n.d.a). The chief executive of a large foreign agroholding that is invested in Ukrainian agribusiness told me: "There are actually very few 
agro-companies managed by foreigners. Very few. You know, the oligarchs buy them. But it's actually not that important, to be frank. If the land is well managed it doesn't matter" (Interview 1). The political structures favour large agroholdings against smallholdings, and the former dominate the agricultural sector. Ukrainian oligarchs prefer large units because they are easier to control.

Despite the dominance of the oligarchs, the increasing demand for feedstock and the low cost of leasing land in Ukraine have prompted some European investors and managers to begin investing in Ukrainian agriculture, due to their belief that the European agrofuel market offers bright prospects for profits (Plank and Plank, 2014). However, only a few mostly people with experience of operating in the country - have remained on the market. In 2007 Britain's Landkom International PLC and France's AgroGeneration, two European agroholdings, began growing rapeseed, wheat, barley, maize, soya beans, and sunflowers in Ukraine for the EU food and agrofuel markets (AgroGeneration, 2015; Bloomberg, n.d.). Both were the objects of friendly takeovers. Sweden's Alpcot Agro, subsequently renamed as Agrokultura, bought Landkom in 2012 and swapped its farmland in Ukraine (in the Lviv, Ternopil and Ivano-Frankivsk regions) with the Ukrainian agroholding and large-scale poultry producer Myronivsky Hliboproduct (MHP) for land in the Voronezh region in Russia (Concorde, 2015). The challenges of Ukrainian agriculture tend to prompt foreign investors to withdraw again.

Despite the fact that agroholdings from EU member states have difficulty in gaining entry to the agricultural sector and Western governments have met with obstacles to the creation of a Ukrainian land market, the EU supports agribusiness via loans extended by the European Bank for Reconstruction and Development (EBRD). The EBRD has a strong preference for funding agribusinesses rather than smallholders. For example, it only provides limited credit in local Ukrainian currency (EUUKRAINECOOP, 2015). At the same time, Ukrainian agroholdings are listed on EU stock exchanges, and are often registered in offshore tax heavens like Cyprus or Luxembourg. Foreign funds (e.g. the Dutch Pension Fund for Care and Well-Being and Sweden's AP3 pension fund) sometimes own shareholdings in Ukrainian farming groups. Investments by foreign financiers, including pension funds and listings on foreign stock exchanges, mean that ownership is increasingly intertwined and there is a trend towards the financialization of the sector (Plank and Plank, 2014).

\section{Trade barriers}

Along with the concentration of land, trade disputes are another major area of conflict among the ruling class. Along with the control and cultivation of land, trade is a major field of activity for agribusinesses. The agroholdings aim to control the whole supply chain from seed production 
through to land, storage, and trade facilities. At the same time trading companies also engage in the cultivation of land. International traders such as Cargill, Dreyfus, Serna (the Ukrainian subsidiary of Glencore), Toepfer (now owned by ADM) and Suntrade (Bunge's Ukrainian subsidiary) have all been active in Ukraine since the 1990s, and export flex crops to the EU for agrofuel production (ISCC, n.d.). As mentioned above, Ukraine's Kernel and Nibulon control large areas of farmland. Multinationals also engage in agriculture in Ukraine; for instance, Glencore holds 70,000 ha of land there, while Cargill acquired a 5 per cent interest in UkrLandFarming in 2014 (2015). International traders have been trying to extend their influence over the Ukrainian agricultural sector.

The introduction of export quotas for some crops caused regular conflicts between the Ukrainian government and international agribusinesses especially multinational traders - during the Janukovych era. Ukraine has frequently introduced export restrictions since 2006 (EBRD, 2014). World Trade Organization (WTO) regulations only permit this at times of economic difficulties. However avoiding domestic grain shortages is crucial to keeping the price of bread down. The Ukrainian government regulates the price of wheat, which is regarded as a strategic crop, using administrative measures including export barriers (Interview 2). ${ }^{4}$

The introduction of export quotas led to a major dispute under Janukovych during the 2010/2011 grain export season. Export quotas for wheat were introduced when world prices rose. This step met with strong resistance from international traders. Export licences were awarded to the newly founded state company, Khlib Investbud, which belonged to Janukovych's 'family', and the international traders came away empty handed. Consequently, the multinational traders protested - supported by the international community in the shape of the EBRD, the European Business Association, the US-Ukraine Business Council, and the American Chamber of Commerce in Ukraine - and called for the abolition of the quotas (Olearchyk, 2011; Interview 3).

Unlike wheat, which is one of Ukraine's most important export crops by volume, rapeseed is not a cause of friction among or with the traders because there are no export controls. The agroholdings value this absence of trade barriers.

There are no customs, no duties on rapeseed and no regulation. That's another reason why it's an attractive product. It's because the state doesn't regulate the volume. The state doesn't see it as a strategic crop like wheat. With wheat it's much more complicated. That's why we are decreasing the number of hectares given over to wheat.

(Interview 4)

This difference explains why the share of rapeseed production relative to total agricultural output has surged since 2004. The Ukrainian government 
regards rapeseed as a 'technical crop' without a strategic bearing on food production. It can therefore be exported to the EU as agrofuel feedstock. While only Janukovych's 'family' gained from the export quotas, low bread prices benefited the population at large.

\section{Sustainability certification}

Germany takes a particularly close interest in the Ukrainian agricultural sector. The German government has played a major role as an adviser on Ukraine's economic transformation process. Germany operates at an institutional level to promote agricultural cooperation in general and agrofuel production in particular. ${ }^{5}$ The "sustainable biomass" project launched by Germany's GIZ development agency and run by the German-Ukrainian Agricultural Policy Dialogue (APD) - a lynchpin of German-Ukrainian bilateral cooperation based at the Institute for Economic Research (IER) in Kyiv - acts as a focal point for institutional support for the agrofuels project in Ukraine. A look at the project's aims and the parties involved reveals how strong the links between the German government and agrofuel industry, and Ukrainian agribusiness are.

In line with the 'win-win' claims on behalf of the RED, the GIZ development project sells agrofuels as a response to climate change and 'peak oil', and a means of fostering local development. As part of the project workshops have been held in various parts of Ukraine with a view to enforcing sustainability criteria for agrofuel feedstock, and a handbook on the certification process has been produced. Agricultural experts from the International Finance Corporation (IFC) and Toepfer have commented on the handbook, and training programmes have been held in cooperation with Agrivent, which belongs to the Ukrainian Agribusiness Club (UCAB) (Interview 5).

UCAB is a crucial partner for the GIZ project. Together with the Ukrainian Agricultural Federation and the Ukrainian Grain Association, it is one of the three big lobbying organizations that have a say in agricultural politics. UCAB is the only lobbying group that knows how to work with Western companies. The organization has strong ties with Germany through its director Alex Lissitsa, who is a former senior researcher at the Leibniz Institute of Agricultural Development in Transition Economies (IAMO). Lissitsa also worked for Yuriy Melnyk when he was Minister of Agriculture under President Yushchenko (Latifundist, n.d.b). Today Melnyk is on the board of UCAB and is the Chief Operational Officer of the MHP agroholding (UCAB, 2015). These examples illustrate the role of personal relationships in Ukraine, and the close ties between business and politics.

Despite these workshops problems with sustainability certification have emerged because in some cases it only exists on paper. Under the RED, the sustainability criteria include an obligation to reduce greenhouse gas emissions. They also exclude the use of land converted from areas with 
previously high carbon stock, such as wetlands and forests, or land of high biodiversity such as primary forests or highly biodiverse grassland, for agrofuel production (European Union, 2009). The RED does not impose any social criteria. The ISCC scheme works on a self-declaration basis, which can result in compliance problems. Little is done to monitor conformity, and sustainability is sometimes being claimed in the absence of compliance. As an interviewee put it: "I think that there [in the EU] everything is OK. But Ukraine has problems with peat land. In Poltava oblast they plant crops on peat land. That's against the criteria but they are still certified" (Interview 6). He added that sustainable cropping was being circumvented in other ways:

There can also be the case that one company really operates according to the criteria. But this company is supplied by smaller companies which are not certified, and only the big one gets checked. [...] But you know that's business. If business can avoid something then it will do so.

(Interview 6)

There is only an incentive for sustainability certification if it brings higher prices. If producers and traders will receive the same price regardless there will be no reason to seek certification (Interview 7). Certification schemes favour large-scale companies over smallholders because of the administrative red tape (Interview 5). Certification for sustainable biomass is controversial in Ukraine, both because it sometimes amounts to no more than window-dressing and because it puts small farmers at a disadvantage.

To sum up, the EU and the USA have so far been unsuccessful in their efforts to promote liberalization of the Ukrainian farmland market. A fully privatized land market would give them easier access to land. To date, most of the agroholdings active in the country are owned by Ukrainian capital, and Ukrainian oligarchs are increasingly controlling land via agroholdings. The latter are supported by credit from international financial institutions, and foreign funds hold shares in them. Ukrainian farming companies and traders have strong ownership links, making them still more powerful players in the agricultural sector. The imposition of export quotas for wheat spawned conflicts between the internal and external factions of the ruling class. By contrast, certification according to the RED sustainability criteria does, indeed, represent a win-win situation for agroholdings, traders, and the EU agrofuel industry.

\section{Implications of the agrofuels project for agrarian justice in Ukraine}

This last section looks at the social and environmental consequences of the agrofuels project in Ukraine, and shows how, in terms of access, distribution, 
and representation, the agrofuels project fosters agrarian injustice in the post-Soviet space. Generally, the export of feedstock for agrofuels supports agribusiness in the form of the agroholdings; it tends to marginalize rural communities and strengthen the oligarchs.

The post-Soviet dualism of agricultural holding companies and small farmers has persisted down to the present. However, if the tendency for these large-scale farming groups to control and consolidate ever more acreage continues a growing number of small farmers will probably be driven off the land. The agroholdings are increasingly making it impossible for small farmers to keep their land, let alone expand production. However, according to official statistics, small farmers still account for the production of most of the food consumed in Ukraine. In 2014 they harvested 98 per cent of all potatoes, 86 per cent of all vegetables, and 85 per cent of all fruit and berries in the country. They contributed 52.7 per cent of gross agricultural output (UkrStat, 2014). Visser et al. (2015) call the importance of small-scale producers in the post-Soviet space "quiet food sovereignty". They carry out labour intensive work and produce the majority of potatoes, other vegetables and fruit whereas the agribusiness sector focuses on exporting flex crops. However, the small farmers are not organized as a political movement. The agrofuels project endangers their "quiet food sovereignty" by furthering the interests of the agribusiness sector.

Another feature of the post-Soviet system is the fact that so far the state has played no part in rural development. There is no distributive mechanism in place that would enable the state to provide support for rural communities. Neither is there a strategy to maintain the livelihood, quality of life, and standard of living of the rural population. Under the Soviet system, kolkhozes were the heart of the villages, and were responsible for providing infrastructure and social services. Today the agroholdings have corporate social responsibility (CSR) policies. For instance, Landkom and AgroGeneration have built roads, schools, hospitals, and orphanages in order to win the support of local people (Miller, 2008; AgroGeneration, 2015). However, these CSR measures are no substitute for the absent state. Moreover, the contribution of the agroholdings to employment is disputed. They require few employees, and the workforce is often brought in from outside (Interview 8).

There is no pressure group capable of effectively representing small and medium sized farmers, and of fighting for agrarian justice in Ukraine. Oligarchs dominate not only the economic but also the political sphere. They are represented in person or via their parties in parliament and/or government, and the three large agrarian pressure groups also defend their interests. The oligarchs are not interested in agricultural and rural development, but regard agriculture as just another source of profits. Likewise, the EU supports large-scale agriculture by providing EBRD loans for agribusinesses. Member states, and especially Germany, are preoccupied with obtaining 'sustainable' flex crops from Ukraine, and this is the one priority 
for Germany's bilateral development assistance effort. In consequence, EU development aid does little for agrarian justice.

Neither have environmental NGOs raised the issue of agrarian justice, and they have only recently begun looking at the social and environmental impact of large-scale agriculture at all. The CEE Bankwatch Network has, however, pointed to the severe consequences of the agribusiness activities of MHP, the acquirer of Agrokultura's land in Ukraine. A report from Bankwatch shows that people in the countryside around Vinnytsia have been forced to lease their land to MHP. Other impacts are poultry waste production, odour nuisance, and increased truck traffic. MHP has been unwilling to engage with local residents about these issues. The source of such problems lies in the unquestioning overall support for agribusiness (Kolomiets and Bacheva McGrath, 2015), due to the close links between economic and political interests.

\section{Conclusion}

In this chapter I have discussed the consequences for Ukraine of the agrofuels blending goal set by the Renewable Energy Directive. The EU's agrofuel industry targets Ukraine as a feedstock producer. The characteristics of, and conditions for the agrofuels project in Ukraine are determined by the state, which is dominated by the Ukrainian oligarchs. This constellation of social forces strengthens Ukrainian agribusiness, and with it the export of flex crops. Foreign players, such as farming companies, funds and traders, are attempting to cash in on the agrofuel boom by engaging in feedstock production and trade in Ukraine. However, they are compelled to compete with local oligarchs for control of farmland and trade. Germany is attempting to encourage 'sustainable' production of biomass from the Black Earth region by providing development assistance designed to feed the German and European agrofuel industries. This results in internalization processes that are reinforcing existing agrarian injustice. The reality of the EU's agrofuels drive on the ground is an oligarchic project that is hindering small farmers' access to land. The Ukrainian state offers no help for rural communities and smallholders, and rural communities lack an effective pressure group or political movement. The focus on the production of agrofuel feedstock does not contribute to a more just agrarian sector but instead reinforces existing inequalities.

\section{Notes}

1 I thank Ulrich Brand and the two reviewers for their comments. I should also like to thank the Austrian Academy of Sciences, the University of Vienna, and the Austrian Marshall Plan Foundation for their financial support.

2 I use the term 'agrofuels' instead of 'biofuels' to highlight their agrarian origin and its controversial character. The international peasants' movement La Via Campesina has coined this term and critical scholars have adopted it. 
3 In Ukraine, the farm structure is as follows: there are corporate farms with an average of 1,700 hectares, less than 400 state farms, about 50,000 family farms with an average of 80 hectares, and household plots with an average of 2.5 hectares (Lerman, 2007).

4 This regulation was introduced because of memories of the great famine of the early 1930s, known as the 'Holodomor', where millions of Ukrainians starved to death. Regulating the price of wheat and thus of bread remains an important task of every Ukrainian government (Interview 2).

5 While the Netherlands are also involved in biomass production and sustainability certification in Ukraine - the Dutch government, for instance, issued a Biomass Action Plan for Ukraine in conjunction with the Ukrainian government (SEC Biomass, 2009) - they focus mainly on solid biomass.

\section{References}

AgroGeneration (2015) 'AgroGeneration', http://agrogeneration.com/ [accessed 9 December 2015].

Allina-Pisano, J. (2008) The Post-Soviet Potemkin Village. Politics and Property Rights in the Black Earth, Cambridge University Press, Cambridge, UK.

Becker, J. (2015) 'Oligarchie - eine Form bürgerlicher Herrschaft. Das Beispiel osteuropäischer semi-peripherer Kapitalismus', Prokla, vol. 180, no. 45, 409-432.

Biofuel Sustainability Ordinance (2009) 'Verordnung über Anforderungen an eine nachhaltige Herstellung von Biokraftstoffen', www.gesetze-im-internet.de/ bundesrecht/biokraft-nachv/gesamt.pdf [accessed 7 January 2016].

Bloomberg (n.d.) 'Company overview of Landkom International PLC', Bloomberg Business, www.bloomberg.com/research/stocks/private/snapshot.asp?privcapid= 38801770 [accessed 8 December 2015].

Borras Jr., S. M., McMichael, P., and Scoones, I. (2011) The Politics of Biofuels: Land and Agrarian Change, Routledge, London and New York.

Borras Jr., S. M., Franco, J. S., Isakson, R. S., Levidow, L., and Vervest, P. (2016) 'The rise of flex crops and commodities: implications for research', The Journal of Peasant Studies, vol. 43, no. 1, 93-115.

Brand, U. and Görg, C. (2013) 'Regimes in global environmental governance and the internationalization of the state: the case of biodiversity politics', International Journal of Social Science Studies, vol. 1, no. 1, 110-122.

Brand, U. and Wissen, M. (2012) 'Global environmental politics and the imperial mode of living: articulations of state-capital relations in the multiple crisis', Globalizations vol. 9, no. 4, 547-560.

Campbell, A. and Doswald, N. (2009) 'The impacts of biofuel production on biodiversity: a review of the current literature', UNEP-WCMC, Cambridge, www. cbd.int/agriculture/2011-121/UNEP-WCMC3-sep11-en.pdf [accessed 7 December 2015].

Concorde (2015) 'MHP swaps Russian land for Agrokultura's Ukrainian assets', 10 June, http://concorde.ua/en/research/daily/mhp-swaps-russian-land-foragrokultura-ukrainian-assets-14147/ [accessed 9 December 2015].

Deutscher Bundestag (2015) 'Antwort der Bundesregierung auf die Kleine Anfrage der Abgeordneten Niema Movassat, Wolfgang Gehrcke, Christine Buchholz, weiterer Abgeordneter und der Fraktion DIE LINKE. Landgrabbing in der Ukraine', Drucksache 18/3925. 
Dietz, K., Engels, B., Pye, O., and Brunnengräber, A. (2015) The Political Ecology of Agrofuels, Routledge, London and New York.

Drannik, A. (2015) 'Week's balance: tariffs for population, moratorium on land, and Ukraine's distinguished guests', 15 November, Unian, www.unian.info/ economics/1184096-weeks-balance-tariffs-for-population-moratorium-on-landand-ukraines-distinguished-guests.html [accessed 11 January 2016].

EBRD (2014) 'The EBRD's experience with policy dialogue in Ukraine. Case study - grain sector', London.

edie.net (2009) 'Chernobyl-blighted land to be used for biofuel crops', edie newsroom, 10 July, www.edie.net/news/3/Chernobyl-blighted-land-to-be-used-forbiofuel-crops/16683/ [accessed 11 January 2016].

Elbersen, W., Wiersinga, R., and Waarts, Y. (2009) 'Market scan bioenergy Ukraine. Report for the Dutch Ministry of Agriculture, Nature and Food Quality', www. biofuel.agroexpo.de/News/2009_Market_Scan_Bioenergy_Ukraine.pdf [accessed 8 December 2015].

EurObserv'ER (2015) 'Biofuels barometer', www.eurobserv-er.org/biofuelsbarometer-2015/ [accessed 8 December 2015].

European Commission (2011) 'Memo: certification schemes for biofuels', http://europa.eu/rapid/press-release_MEMO-11-522_en.htm?locale=en [accessed 7 January 2016].

European Parliament (2015) 'European Parliament legislative resolution of 28 April 2015 on the Council position at first reading with a view to the adoption of a directive of the European Parliament and of the Council amending Directive 98/70/ EC relating to the quality of petrol and diesel fuels and amending Directive $2009 / 28 / \mathrm{EC}$ on the promotion of the use of energy from renewable sources (10710 /2/2014-C8-0004/2015-2012/0288(COD))', http://biofuelstp.eu/downloads/ilucdirective/201504_final_version_iluc_directive_en.pdf [accessed 8 December 2015].

European Union (2003) 'Directive 2003/30/EC of the European Parliament and of the Council of 8 May 2003 on the promotion of the use of biofuels or other renewable fuels for transport', http://eur-lex.europa.eu/legal-content/EN/TXT/H TML/?uri=CELEX:32003L0030\&from=en [accessed 7 December 2015].

European Union (2009) 'Directive 2009/28/EC of the European Parliament and of the Council of 23 April 2009 on the promotion of the use of energy from renewable sources and amending and subsequently repealing Directives 2001/77/EC and 2003/30/EC', http://eur-lex.europa.eu/legal-content/EN/TXT/HTML/?uri=C ELEX:32009L0028\&from=EN [accessed 7 December 2015].

Eurostat (2015a) 'Share of renewable energy in fuel consumption of transport', http://ec.europa.eu/eurostat/tgm/table.do?tab=table\&init=1\&language=en\&pcod $\mathrm{e}=$ tsdcc340\&plugin $=1$ [accessed 5 January 2016].

Eurostat (2015b) 'Primary production of renewable energy by type', http://ec. europa.eu/eurostat/tgm/refreshTableAction.do?tab=table\&plugin=1\&pcode=ten 00081\&language =en [accessed 5 January 2016].

EUUKRAINECOOP (2015) 'EBRD official: “we invest $€ 1$ billion to Ukraine every year” , EU-Cooperation News, 29 January, http://euukrainecoop.com/2015/01/29/ ebrd/ [accessed 11 January 2016].

Fargione, J., Hill, J., Tilman, D., Polasky, S., and Hawthorne, P. (2008) 'Land clearing and the biofuel carbon debt', Science, vol. 319, no. 5,867, 1235-1238.

Gerasimchuk, I. (2013) 'Biofuel policies and feedstock in the EU', Energy, Environment and Resources EER PP 2013/04, Chatham House, www.chathamhouse. 


\section{C. Plank}

org/sites/files/chathamhouse/home/chatham/public_html/sites/default/files/Nov13 Gerasimchuk.pdf [accessed 8 December 2015].

Hellman, J. and Kaufmann, D. (2001) 'Confronting the challenge of state capture in transition economies', Finance Development, vol. 38, no. 3, www.imf.org/ external/pubs/ft/fandd/2001/09/hellman.htm [accessed 7 December 2015].

ISCC (n.d.) 'All certificates', www.iscc-system.org/en/certificate-holders/all-certificates/ [accessed 7 December 2015].

Jessop, B. (1990) State Theory: Putting the Capitalist State in its Place, Polity, Cambridge, UK.

Kolomiets, N. and Bacheva McGrath, F. (2015) 'Black Earth. Agribusiness in Ukraine and the marginalisation of rural communities', http://bankwatch.org/ sites/default/files/BlackEarth-UAagri.pdf [accessed 11 December 2015].

Kuzio, T. (2012) 'The Ukrainian immobile state two decades after the disintegration of the USSR', Communist and Post-Communist Studies vol. 45, no. 3-4, 413-415.

Lakemeyer, E. (2007) Die Produktion von Biokraftstoffen und insbesondere Biodiesel in der Ukraine und die Entwicklung des Rapsmarktes. Eine Betrachtung mit Hilfe der Politik Analyse Matrix, Cuvillier Verlag, Göttingen.

Latifundist (n.d.a) 'Top 100 latifundistov Ukrainy', http://latifundist.com/rating/ top100\#100 [accessed 11 January 2016].

Latifundist (n.d.b) 'Lissitsa Aleks Nikolaevich', http://latifundist.com/dosye/lissitsaaleks-nikolaevich [accessed 9 January 2016].

Lerman, Z., Sedik, D., Pugacov, N., and Goncharuk, A. (2007) 'Rethinking agricultural reform in Ukraine', www.iamo.de/fileadmin/documents/sr_vol38.pdf [accessed 11 January 2016].

Leshchenko, S. (2015) 'Ukraine between corruption and reform', lecture at the Institute for Human Sciences (IWM), Vienna, 7 May, www.youtube.com/ watch?v=fcr1SMLEWyY [accessed 11 January 2016].

McMichael, P. (2009) 'The agrofuels project at large', Critical Sociology, vol. 35, no. $6,825-839$.

McMichael, P. (2010) 'Agrofuels in the food regime', The Journal of Peasant Studies, vol. 37, no. 4, 609-629.

Miller (2008) 'In Ukraine, mavericks gamble on scarce land', Wall Street Journal, 12 May, http://farmlandgrab.org/post/view/7338-in-ukraine-mavericks-gambleon-scarce-land\#sthash.2zYaNhBG.dpuf [accessed 10 December 2015].

Ogarenko, Y. and Nivievskyi, O. (2012) 'EU biofuels policy: Repercussions on Ukraine', Agri-Food Policy Review, www.ier.com.ua/files/Regular_products/ Agro_review/2012/APD_AFPR_2012_03_en.pdf [accessed 8 December 2015].

Olearchyk, R. (2011) 'Ukraine removes grain export quotas', Financial Times, 25 May.

Plank, C. (2015a) 'Kapitalistische und territorial-geopolitische Logiken der Macht: die Rolle der EU im Ukraine-Konflikt', Prokla, vol. 181, 593-608.

Plank, C. (2015b) 'Liberalization of the Ukrainian land market: a threat to the right to food', in Brot für die Welt, FIAN, ICCO (eds): Right to Food and Nutrition Watch. Peoples' Nutrition is not a Business, www.rtfn-watch.org/en/home/ watch-2015/ [accessed 15 January 2016].

Plank, C. and Plank, L. (2014) 'The financialisation of farmland in Ukraine', Austrian Journal of Development Studies, vol. 30, no. 2, 46-68.

Poulantzas, N. (1976) The Crisis of the Dictatorships. Portugal, Greece, Spain, NLB, London. 
Poulantzas, N. (1978) State, Power, Socialism, Verso, London.

Roth, M., and Valetta, W. (2006) 'Land reform and land market development in Ukraine. Findings of the Ukraine land titling initiative (uti) project assessment and strategies for future USAID intervention', www.usaidlandtenure.net/sites/ default/files/USAID_Land_Tenure_Land_Reform_and_Land_Market_Development _in_Ukraine.pdf [accessed 11 January 2016].

Samaeva, Y. (2015) 'Navstrechu Agrokolonializmu', Zerkalo nedeli, 24 April, http://gazeta.zn.ua/macrolevel/navstrechu-agrokolonializmu-_.html [accessed 11 January 2016].

Schaffartzik, A., Plank, C., and Brad, A. (2014) 'Ukraine and the great biofuel potential? A political material flow analysis', Ecological Economics, vol. 104, 12-21.

Searchinger, T., Heimlich, R., Houghton, R. A., Dong, F., Elobeidi, A., Fabiosa, J., Tokgoz, S., et al. (2008) 'Use of U.S. croplands for biofuels increases greenhouse gases through emissions from land-use change', Science, vol. 319, no. 5,867, 1238-1240.

SEC Biomass (2009) 'Biomass action plan for Ukraine', http://biomass.kiev.ua/ images/library/info-materials/bap_en.pdf [accessed 10 December 2015].

Strubenhoff, H. (2009) 'Perspektiven der Biomassenutzung in der Ukraine - Zeit für Investitionen?’, Ukraineanalysen, vol. 63, 6-7.

TNI (2015) 'About agrarian justice', www.tni.org/en/page/stub-22 [accessed 11 January 2016].

UCAB (2015) 'Presidium', http://ucab.ua/en/pro_ukab/prezidiya/ [accessed 9 January 2016].

UkrLandFarming (2015) 'History', www.ulf.com.ua/en/company/history/ [accessed 9 December 2015].

UkrStat (2014) 'Reports', www.ukrstat.gov.ua/ [accessed 11 January 2016].

Van der Hilst, F., Verstegen, J. A., Zheliezna, T., Drozdova, O., and Faaij, A. P. C. (2014) 'Integrated spatiotemporal modelling of bioenergy production potentials, agricultural land use, and related GHG balances; demonstrated for Ukraine', Biofuels, Bioproducts and Biorefining, vol. 8, no. 3, 391-411.

Visser, O., Mamonova, N., Spoor, M., and Nikulin, A. (2015) ' "Quiet food sovereignty" as food sovereignty without a movement? Insights from post-socialist Russia', Globalizations vol. 12, no. 4, 513-528.

Vogelpohl, T. (2014) “ "Das ist Wettbewerb. Und das ist normaler Strukturwandel.” Die Neoliberalisierung der deutschen Biokraftstoffpolitik', in B. Hirschl, K. Dietz, T. Vogelpohl, E. Dunkelberg, M. Backhouse, R. Herrmann, and M. Brüntrup (eds) Biokraftstoffe zwischen Sackgasse und Energiewende. Sozialökologische und transnationale Perspektiven, oekom, München, 15-39.

Wissen, M. (2015) 'The political ecology of agrofuels: conceptual remarks', in K. Dietz, B. Engels, O. Pye, and A. Brunnengräber (eds) The Political Ecology of Agrofuels, Routledge, London and New York, 16-33.

World Bank (2016) 'Rural land titling \& cadastre development project', www. worldbank.org/projects/P035777/rural-land-titling-cadastre-developmentproject?lang=en [accessed 11 January 2016]. 


\section{C. Plank}

\section{List of interviews}

Interview 1: chief executive of an agroholding, Kyiv, 28 November 2012.

Interview 2: employee of a development organization, Kyiv, 29 October 2012.

Interview 3: head of a business association, Kyiv, 9 November 2012.

Interview 4: employee of an agroholding, Lviv, 29 November 2012.

Interview 5: employee of a governmental organization, Kyiv, 1 December 2011.

Interview 6: national project coordinator of an international organization, Kyiv, 10 November 2012 (in Russian, translated by the author).

Interview 7: employee of an agrarian pressure group, Kyiv, 30 October 2012.

Interview 8: agricultural expert of an international organization, Kyiv, 13 November 2012 (in Russian, translated by the author). 


\title{
14 Price risks and resource fairness in commodity trading
}

The cotton and coffee sectors in sub-Saharan Africa

\author{
Cornelia Staritz, Bernhard Tröster, and \\ Karin Küblböck
}

\section{Introduction}

The sharp commodity price rise and heightened volatility between 2003 and 2013 have reignited academic and political discussions on the drivers of commodity prices and their consequences, particularly for commodity dependent developing countries. From a resource fairness perspective, the questions of how commodity prices are set and transmitted to actors involved in commodity production and how price risks are distributed among these actors are of crucial importance. Rather than focusing on price levels per se, this chapter focuses on the distribution of price risks across commodity chains. Despite the close interrelation between price levels and risks, the latter has not been a focus of resource fairness debates although it is a major concern for commodity producers and captures most clearly the growing interconnection of financial markets with physical commodity trade.

Commodity trade takes place in global commodity chains, that is, interfirm networks in which the production and trade of commodities is organized. In particular, the governance structure of such chains, and herein the strategies and practices of lead firms - that is, international extractive companies, commodity traders, manufacturers or retailers that extract, trade, process or sell the majority of internationally traded commodities - have an important impact on price setting, transmission and risks. Yet, global commodity chains are based in and react to institutional contexts at the global and local level: these contexts co-determine chain dynamics and governance and mediate outcomes for actors involved in commodity chains. In commodity sectors the institutional and policy context has changed significantly since the 1980s and 1990s - from stabilization of commodity prices and export earnings in producer countries to liberalization and marked-based instruments for price setting and price risk management (PRM) (World Bank, 2011; Nissanke, 2011).

At the global level, international commodity agreements (ICAs) were established in the 1950s and 1960s with the aim of stabilizing commodity prices that have been historically very volatile, including minimum price 
systems, buffer stocks, and export quotas (Küblböck, 2015). In addition, compensatory financing schemes such as the Compensatory Financing Facility of the International Monetary Fund and two facilities for the stabilization of export earnings, STABEX (for agricultural products) and SYSMIN (for mining products) agreed between the European Commission and the African, Caribbean and Pacific (ACP) group of countries under the Lomé and Cotonou agreements were put in place to ameliorate the adverse effects of fluctuating export earnings (Newman, 2009). Given a number of problems of the ICAs (e.g. related to the determination of a long-term price level, the high cost of maintaining buffer stocks, problems of cheating, rent-seeking, and free-riding) but also a general shift to market liberalization in order to 'get prices right', they were dismantled by the end of the 1980s. Simultaneously, access to the compensatory financing schemes had become more and more complicated. With increasingly tight conditionalities they lost their attractiveness (UNCTAD, 2008).

Subsequently, financial markets, that is, commodity derivative markets, have become the central pricing and risk management mechanism for international commodity trade (Nissanke, 2011). This shift was accompanied by a surge of liberalization and deregulation of financial markets, such as the liberalization of exchange rates and international capital flows, deregulation of the banking sector, and the removal of barriers for investors in commodity derivative markets. These developments have resulted in an increased importance of financial motives in commodity derivative trading through the dominance of financial investors and the expanded financial activities of large physical traders (Newman, 2009). These developments can be subsumed under the term 'financialization', that is, "the increasing role and dominance of financial motives, financial markets, financial actors and financial institutions in the operations of the domestic and international economies" (Epstein, 2005: 3). This has led to the increased interaction between financial and physical markets for commodities.

The collapse of ICAs and the deregulation of financial markets occurred concomitantly with widespread domestic liberalization in commodity sectors in the context of structural adjustment programmes supported by the World Bank and other donors. This involved the dismantling of national commodity marketing boards - remnants of colonial commodity marketing structures in Sub-Saharan Africa (SSA) that were carried over to the post-colonial era - that guaranteed minimum prices to farmers and controlled exports and stocks in accordance with ICA limits in many commodity producer countries. In the context of market reform, minimum prices and other price stabilization instruments were largely abandoned, thus shifting to more market-based price setting that has bound together producer prices with global futures prices. There remains, however, variety in local market structures and state involvement in producing countries with important implications on how price volatility is transmitted and how different actors experience and negotiate prices (Staritz et al., 2015). 
The main question of this chapter is: how does the current global commodity price setting mechanism based on derivative markets impact on the distribution of price risks in commodity chains? The analysis is based on four case studies of the coffee sector in Ethiopia and the cotton sector in Burkina Faso, Mozambique, and Tanzania. Coffee and cotton are the most important cash crops in SSA upon which millions of smallholder farmers and rural households depend for their livelihood. We assess how global and local institutional changes, particularly global liberalization and financialization and domestic market reform in producer countries, have affected price setting, transmission, and risks of different chain actors. In doing so, we connect global processes of liberalization and financialization to local outcomes in commodity producing countries and make inferences concerning the impact of these processes on the distribution of risks along commodity chains. The paper adds to resource fairness debates by focusing on commodity price risks and the role of financial markets in influencing distributional outcomes. In fairness debates there is often a focus on the real side of the economy, not taking into account the role of financial markets and actors which has become particularly important in the context of financialization.

We show that international traders generally use global prices, arising from commodity derivative markets in particular, as their reference point in commodity trading. So export prices in producer countries are linked to futures prices that are set on increasingly financialized derivative markets with implications on volatility and short-termism. However, national price setting arrangements still vary with important implications for producer prices and distribution of risks between international traders, national intermediaries or processors, and producers. They range from atomistic competition where individual producers negotiate prices with intermediaries or international traders, market-based contract farming arrangements with some sort of pre-determined prices, and national commodity exchanges to fixed seasonal producer prices negotiated among associations. In these systems access to PRM tools also varies. However, national actors in producer countries generally do not use hedging as they cannot deal with the involved risks and costs - even more so in the context of financialization - which contrasts with large international and financially adept actors that can benefit from hedging and other financial trading strategies (Newman, 2009).

We further argue that discussing commodity price setting and the distribution of price risk from a resource fairness perspective has to go beyond a focus on ensuring that prices are based on economic fundamentals (i.e. via reducing excess speculation) to questioning if markets and, in particular, derivative markets are a useful instrument to ensure the inclusion of economic and social criteria, including social costs, in price setting and risk distribution (see also the discussion on social costs in the chapter by Raza, in this volume). In this context, other factors such as distributional and 
poverty impacts, which are not usually reflected in markets - even less so in the very short term functioning of derivative markets - have to be taken into account. Exposure to risk is a particularly important dimension of poverty. Poor households in developing countries are typically more exposed and vulnerable to risk. Further, agriculture - on which the majority of poor people depend - involves particularly high risks, such as bad weather conditions, pests, or effects of climate change. Hence, commodity price risks add to these vulnerabilities, particularly those of the weakest group in the chain, namely, smallholder farmers in developing countries. These distributional outcomes are highly related to questions of representation, that is, the extent to which the interests of different actors are taken into account in establishing and regulating the institutional architecture of price setting and hence which actors can influence rule setting (see also Raza, in this volume, and Pichler, in this volume).

This chapter is based on trade, industry, and financial data and interviews with international commodity traders and financial investors conducted at commodity futures markets in New York and London and with local actors in the coffee and cotton commodity chain in Ethiopia, Burkina Faso, Mozambique and Tanzania. During fieldwork in the four SSA countries, semi-structured interviews were conducted with farmers' organizations, processors, processors' associations, relevant government institutions, and sector experts. ${ }^{1}$ The chapter starts with an analysis of global commodity markets with an emphasis on financialization dynamics followed by a discussion of price risks in global coffee and cotton commodity chains. The last section concludes at a conceptual and a policy level, focusing on implications for resource fairness and governance.

\section{Financialization and global commodity markets}

At the centre of financialization dynamics in commodity sectors are commodity derivative markets - their increasing importance in price setting and risk management on the one side and the increasing prominence of financial motives in trading on these markets through the dominance of financial investors and the expanded financial activities and practices of large physical traders on the other side.

A vast literature, based largely on econometric analysis, emerged in the context of the exceptional development of global commodity prices in the 2000s, often perceiving derivatives on commodities in the literal sense only, with futures conceptualized as investment vehicles disconnected from physical commodities (for an overview see Ederer et al., 2016). Yet, derivatives and their markets have become locked to physical markets in new and complex ways (Russi, 2013), being today the central mechanism for price discovery and risk management in physical commodity trading. Futures prices are generally used as a benchmark in contracts between physical traders as spot markets are often geographically dispersed and 
centralized futures markets are accepted as the best indicator for overall supply and demand conditions. ${ }^{2}$ Commodity derivative markets have also been promoted as insurance as physical traders can hedge against the risk of price fluctuations. ${ }^{3}$ Hence, commodity derivative markets have served as the linchpin between the financial and the physical sphere (Clapp, 2014).

The structure of commodity derivative markets and trading activities on these markets has changed, particularly in the 2000s. This involves, first, the increasing importance of financial markets for firms' decision making around the allocation of resources. The business models of international commodity trading houses shifted towards financial motives and activities, reflected in the restructuring of commodity trading companies to place 'risk management' at the centre of their core competencies, namely inhouse research departments and futures brokerages that cater to traders of physical commodities as well as financial investors. Commodity trading houses thus play the dual role of physical commodity trader and financial investor on commodity exchanges (Newman, 2009). While there is considerable variation among international traders, the increased role of large multi-commodity trading companies has led to financial trading strategies becoming more dominant alongside traditional physical commodity related hedging activities. Several large international traders have their own financial services units or hedge funds, investing on their own account, managing third party money, and selling investment products. While the proportion of company revenues coming from such financial activities has remained relatively small and variable, they have grown relative to revenues derived directly from the trading of physical commodities (Gibbon, 2014).

Second, and connected to the first, is the increase in activity on commodity derivative markets driven purely by financial interests. Initially, these markets were developed primarily to allow the management of risks for physical commodity traders, but they have increasingly become dominated by traders outside physical commodity markets, particularly financial investors. Speculators have always played a role in these markets by taking opposite positions to physical hedgers but they were largely specialized in the trading of few commodities. Financial investors, in contrast, trade in a large range of commodities as an asset class in order to derive profits from price changes - similar to stocks, bonds and real estate assets (Nissanke, 2011; UNCTAD, 2011). The 1990s saw an increase in hedge funds active on commodity exchanges in the context of deregulation and declining barriers with the transition from open outcry to electronic trading platforms. More recently, large institutional investors, pension funds in particular, have flooded commodity derivatives markets. Further, investment banks have increasingly offered diverse products for commodity derivative market investments to allow their clients to profit from commodity price developments, in addition to trading on their own account. This has increased, in particular after the dot-com crises (2000/2001) and 
in the context of the global economic crisis (2007/2008) as investors searched for new investment opportunities. Funds from financial investors in commodity futures markets have increased from US $\$ 13$ billion in 2003 to US\$411 billion in the first quarter of 2013 (Barclays Capital, 2013).

These developments have crucial implications on price discovery and volatility in international commodity trade and on the possibilities for accessing derivative markets for PRM. There is a controversial debate on the effects of financialization on commodity prices. Despite large differences, an increasing amount of research shows that trading strategies of financial investors have impacted on short term price developments in addition to fundamental factors (see also UNCTAD, 2011). In our own research, we test the impact of positions held by financial investors on monthly commodity prices in addition to fundamental demand and supply factors. We find that 50 per cent of variations in coffee prices and 15 per cent in cotton prices can be traced back to net long positions of financial investors, particularly money managers, in futures markets between 2006 and 2012 (Ederer et al., 2016). ${ }^{4}$ This means that, at least in the short term, financial investors' trading strategies disturb coffee and cotton prices which questions the extent to which commodity derivative markets fulfil their economic role of price discovery based on economic fundamentals.

In addition to price impacts, the functioning of these markets has also changed. Pronounced short termism and complexity have increased costs and risks of derivative trading, raising entry barriers for actors without access to financial resources and markets (Heumesser and Staritz, 2013). Trading strategies of financial investors and new investment products, together with electronic trading and extended trading hours have increased the speed, complexity and short-termism of derivatives trading - with intra-day volatility being a rather new phenomenon in markets for coffee and cotton. These changes make trading more flexible and allow for immediate reactions but also demand continuous awareness of the market and permanent access to finance in order to finance margin calls. ${ }^{5}$ For producercountry actors these markets were always difficult to access, involving high costs and risk and requiring permanent access to market information, finance, and brokers. For smaller physical traders that do not have the resources to interact actively with financial markets these developments have also made access to hedging more difficult, furthering the concentration process at the trader side. In contrast, large physical traders tend to profit from these developments, as they are increasingly involved in financial activities and own separate financial units in addition to physical commodity trading. 


\section{Price setting and risks in coffee and cotton commodity chains}

\section{Price setting}

The global coffee and cotton chains include actors in producing countries such as smallholder farmers or commercial farmers, processors, and exporters. The transactions among these actors might be mediated by local traders. The export of 'green' (or raw) coffee beans or of cotton lint runs through the hands of international traders, before downstream processing and final sale via various distribution channels. Generally, coffee involves minor processing in producer countries with green beans being exported to roasters that roast coffee or make instant coffee that is sold to retailers, super markets or coffee chains. Cotton involves more processing in producer countries as seed cotton needs to be ginned where the cotton lint is separated from the cotton seed - before exporting. Cotton lint is largely exported to textile mills that produce yarn and fabric for apparel production. International traders play a key role in global coffee and cotton trade with a few globally acting companies handling the large majority of internationally traded coffee and cotton. They act as intermediaries between producers/exporters and processors/manufacturers, providing purchasing and buying services, arranging transport and guaranteeing performance (Larsen, 2008). Some international traders have also invested upstream in local buying and processing to secure supply (ITC, 2013).

Physical coffee and cotton prices are generally determined by applying a differential to prices in futures markets. For cotton, futures and options contracts traded at the Intercontinental Exchange (ICE) in New York serve as a global benchmark - despite substantial basis risk as ICE futures contracts are limited to the delivery of U.S. cotton to U.S. locations. The Cotlook A Index, compiled daily by Cotton Outlook, a private company in Liverpool, by collecting quotations from traders, is also important. The Index is highly intertwined and correlated with ICE futures prices as traders take into account ICE closing prices for their quotations. For Arabica coffee, Coffee C futures traded on ICE serve as a global benchmark; for Robusta it is futures traded on the NYSE London International Financial Futures and Options Exchange (LIFFE). Prices in physical coffee and cotton contracts vary because of differences in quality, location, delivery schedule, local supply and demand conditions, and bargaining power. But global prices are used as a global benchmark or reference in physical trade, being the most important factor in price determination.

The importance of futures markets in price setting is related to the dismantling of national price stabilization systems in producer countries as well as to the trading practices of international traders. International traders increasingly prefer using futures prices as a reference in physical 
contracts as they use derivative markets for hedging. For hedging to be effective (by taking the opposite position to the physical position on derivative markets) physical prices have to reflect futures prices. This is done by either using forward contracts, where the price is fixed when signing the contract, or price to be fixed (PTBF) contracts where the volume and delivery date are fixed but the price is fixed on a later time contingent on the prevailing futures price. PTBF contracts only require hedging after prices have been fixed and allow for more sophisticated and flexible risk management. However, this advantage can only be used by actors with access to derivative markets, foremost international actors. For actors without access to derivative markets PTBF contracts transmit volatility even more directly to local prices (Newman 2009; Bargawi and Newman, 2013). In our cases, PTBF contracts are not widespread due to their less frequent use in the cotton sector and regulations in Ethiopia that only allow for export contracts with fixed prices.

The four case study countries have different market structures with Ethiopia and Tanzania being more liberalized and Mozambique and, particularly, Burkina Faso more regulated in terms of producer prices. Ethiopia introduced strict regulations in the coffee sector, including the exclusion of foreign companies and traders from coffee trading within the country. Ethiopia also established a central commodity exchange in 2008 one of the first countries in the SSA to do so - on which the majority of coffee production is traded. The Ethiopian Commodity Exchange (ECX) price system's focus is on price transparency, that is, the efficient transmission of ECX auction prices that are linked to global prices to the farm gate, without price stabilization measures or instruments to deal with price instability (Tröster and Staritz, 2015). The Tanzanian cotton sector is the most liberalized in SSA (arguably together with Uganda's). The sector is open to competition with no restrictions on farmers' and ginners' choice of trading partners and a large number of private companies active. An indicative producer price is set before the marketing season, based on a stakeholder consultation, but it can be revised during marketing if global prices should change. Thus it provides no stability to producers (Staritz et al., 2015).

In Burkina Faso and Mozambique, the cotton sector is organized through regional concession systems where ginners have to buy cotton from farmers in a particular region and have to provide inputs to them. Farmers, in turn, have to sell their cotton to the ginner. In Burkina Faso the system is concentrated with only three ginners and strong state involvement in the largest one. A fixed price is set before planting, negotiated amongst sector stakeholders. Two unique features of the system in Burkina Faso are the two tier price system with a potential premium paid to farmers at the end of the season and the existence of a smoothing fund that subsidizes local prices when world prices are low and is replenished in years when prices are high (Kaminski et al., 2011). In Mozambique, the 
regional concession system involves around 11 private ginners. The sector operates a national minimum price system for seed cotton negotiated between sector stakeholders. The minimum price is set in April/May, between six weeks and two months in advance of cotton marketing. In 2007 the system was amended by an indicative price set in October/ November, seven to eight months prior to purchasing and before planting. But this price is subject to change in the marketing season which reduces price stability for farmers. In both countries the price formula that is used as a basis for negotiations includes the Cotlook A index to capture global prices but there are discussions to adopt the ICE futures price.

Despite these differences, in all four systems coffee and cotton prices along the chain are increasingly co-integrated with global price benchmarks. Figure 14.1 shows the evolution of the annual average export and farm gate prices together with the relevant futures prices. It is seen that yearly export prices follow the volatility of global prices. Correlation coefficients show this close relation between global and export prices accounting for 0.83 in Tanzania, 0.90 in Burkina Faso and Mozambique, and 0.92 in Ethiopia for the period 2005 to 2013/2014. Yearly realized farm gate prices also follow global price dynamics. Correlation coefficients between farm gate prices and futures prices are around 0.70 in Mozambique and Tanzania and around 0.90 in Ethiopia. In Burkina Faso we find a correlation index of 0.58 ; however, once the second payment is taken into account the coefficient increases to 0.87 .

\section{Price risks}

The extent to which volatile international futures prices are transmitted to and lead to price risks for farmers depends on the national market and price setting structure. Price risks for coffee and cotton commodity chain actors can be differentiated in price fluctuations between seasons (interseasonal price risk) and within seasons (intra-seasonal price risk). Interseasonal price instability is a reality in all case study market structures as national prices are based on and increasingly aligned to global prices. This risk is largely born by farmers in all four countries as producer prices closely follow world prices through adoption of market-based producer price setting mechanisms in competitive systems (Ethiopia and Tanzania) as well as in regulated systems where price formulas have increasingly been based on world prices (Mozambique and Burkina Faso). Hence, in all market structures, producers bear the brunt of inter-seasonal price instability.

There are, however, differences concerning intra-seasonal price volatility in the four case study market structures. In contrast to most other commodities and countries, in the cotton sectors in Burkina Faso and Mozambique, there exist national producer price stabilization measures in the context of regional concession systems. Prices fluctuate between 

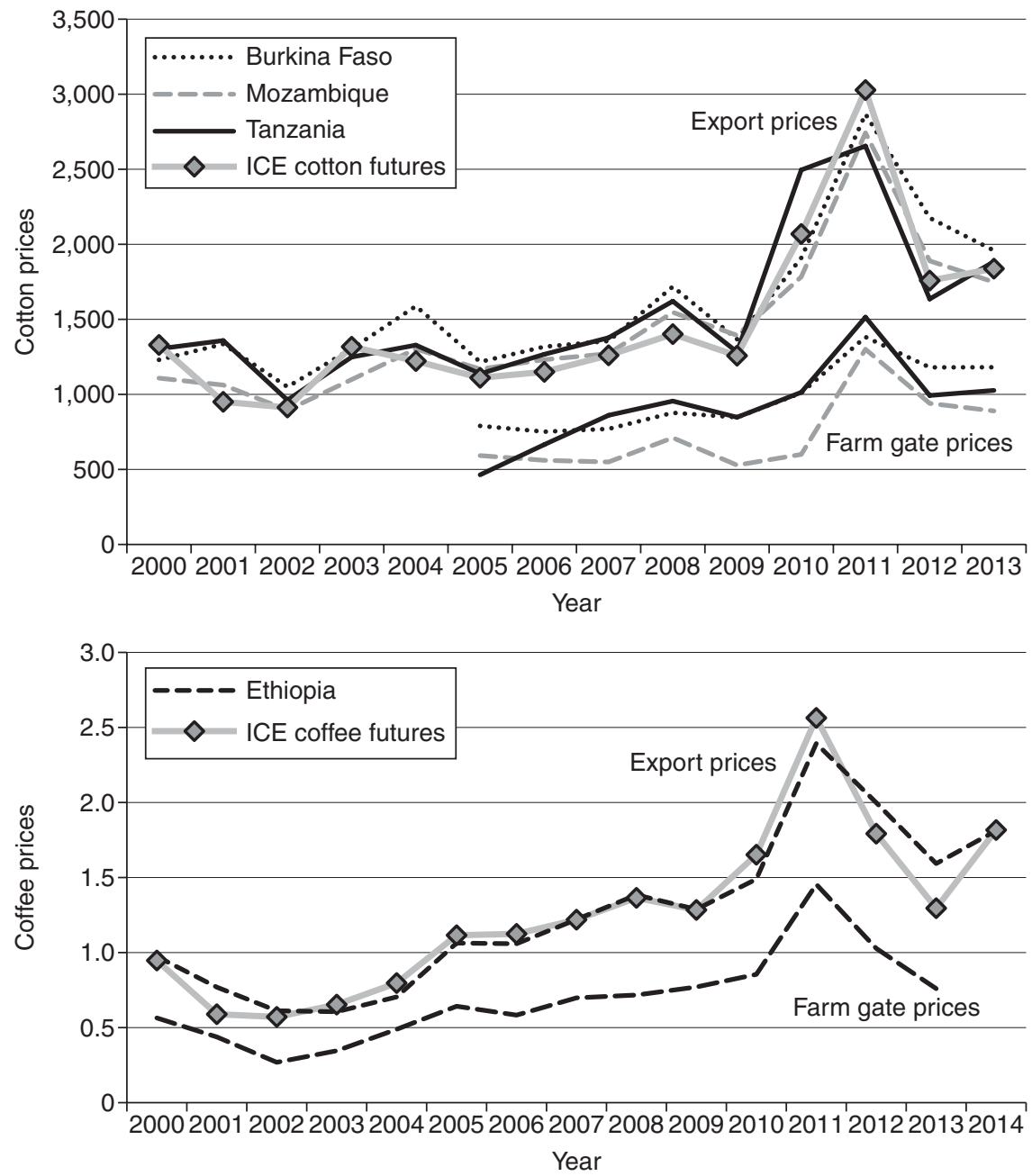

Figure 14.1 Futures prices, export prices, and farm gate prices for cotton (upper) and coffee (lower) (source: Futures prices from ICE; export prices from UN Comtrade, International Coffee Organisation, and Ethiopian Ministry of Trade; producer prices for cotton from MAFAP and FAO (compared with national sources - UNPCB in Burkina Faso, TCB in Tanzania, and IAM in Mozambique) and for coffee from International Coffee Organisation; exchange rate from WDI).

Note

In US dollar per tonne for cotton and in US dollar per $\mathrm{lb}$ for coffee; The export price value for 2003 is unrealistically low for Mozambique - hence, we excluded it from the analysis; A conversion factor from seed cotton to cotton lint of 0.42 was assumed for all countries; marketing year based on season in Burkina Faso. 
seasons, but for a season fixed producer prices are negotiated in tripartite structures between farmers, ginners, and the government based on a formula linked to global prices. In Burkina Faso, prices are fixed in advance of planting which helps to stabilize farmers' incomes by reducing uncertainty in planting decisions. In Mozambique, there are two price fixing meetings - one before the planting season and one before marketing starts where prices may be changed. Farmers are thus exposed to changes in the world price that occur between the meetings. ${ }^{6}$ In Burkina Faso, moreover, the smoothing fund partly compensates ginners should prices decline during the season. In return, a part of the price has to be contributed to the fund in high price years. The government also holds risks as it has a mandate to re-capitalize the fund if prices decline for an extended period, as occurred in 2007 (IMF, 2014).

The price systems in Burkina Faso and Mozambique are also different concerning the share of farmers' prices in export prices. The two tier price system in Burkina Faso ensures a relatively high farmers' price share. This is in contrast to Mozambique where the price share going to farmers is comparably low. This is related to Mozambique's incomplete price stabilization system that fixes a minimum price but does not ensure a second payment if prices should increase during the season. In a regional concession system higher prices can also not be secured through competition among ginners (as in Tanzania) as farmers have to sell to one ginner.

In Tanzania, farmers are exposed to world price volatility over the whole season although this is to a limited extent tempered by the - adjustable - indicative price setting at the start of the marketing season. World price movements are thus transmitted to Tanzanian producers within a season. This is exemplified in the following quote: "If NY goes up, you'll see the price goes up as well in the field. And if next day NY price goes down, you'll see the price going down later that day in the field" (local ginner, Interview 1). Since ginners can pass on world price movements to producers, the price risk they face on this side of the transaction is limited. Also, in Ethiopia global price volatility is transmitted to local processors and farmers through the EXC, leading to price fluctuations between and within seasons. Farmers bear the majority of the price risk as local processors and exporters can transfer export price volatility to farmers. The strong link to ICE futures notations in the ECX system is confirmed in the following interview quotes: "The benchmark is the NY futures price" (international NGO, Interview 2). "We are price takers, not decision makers. [...] The price is determined in New York" (local exporter, Interview 3). "The ECX price and the ICE price are highly correlated, but there are some circumstances where ECX price is lower than ICE price or - to a lesser extent - when ECX price is higher than ICE" (ECX representative, Interview 4). ${ }^{7}$

The PRM strategies employed by different actors along coffee and cotton chains depend, on the one hand, upon their exposure to world price 
movements and, on the other hand, their access to PRM strategies (see Figure 14.2 for a schematic representation on these two indicators). PRM strategies may be classified as physical or financial. Physical PRM strategies involve influencing the time of selling through storage, back-to-back trading, and fixed price forward contracts. ${ }^{8}$ Financial strategies involve hedging through futures and options on commodity derivative markets (Dana and Sadler, 2012). Although futures prices are used as a benchmark for local prices in all market structures, local actors do not use derivate markets for risk management. This is related to the high costs, risks and complexities involved - even more so given the increased speed and complexity of trading in the context of financialization. It also requires access to information, financial resources, and brokerage services. Further, trading on derivative markets is not adapted to the contexts of local actors in producing countries - for instance, the volumes of local exporters are often very small compared to lot sizes in futures markets. A particular problem is the increasing short-termism of trading and the related intraday volatility of commodity prices which leads to more frequent and unpredictable margin calls requiring permanent access to finance. For actors that do not have financial units and the resources and capacities to interact actively with derivative markets and weather any losses associated with sudden adverse price changes, hedging has become an even more difficult risk management instrument. Even Burkina Faso's Sofitex, the largest ginner in SSA, does not use futures or options. ${ }^{9}$

Farmers have also very limited access to physical PRM strategies. Storage and insurance are limited and costs are high. Only the wealthiest farmers are able to choose the time when they sell (Bargawi, 2008). Farmers have no possibility to use forward contracts since the marketing season is fixed by the government and transactions are conducted in cash. Hence, farmers have largely no alternative PRM option available other than adapting their production volumes and/or the use of inputs from season to season. The capacity of processors and exporters in producer countries to manage price risks varies depending on their size and expertise but most importantly on whether they are affiliated to international traders. Independent local exporters are restricted to physical PRM, most importantly selling at different points in time through fixed-price-forward contracts. As forward sales lead to production risks, because sales are often signed when actual production levels cannot be predicted, international traders only buy forwards from exporters if they are confident that volumes can be guaranteed (ITC, 2013). This is the case for all three ginners in Burkina Faso and the majority of exporters in Mozambique and Ethiopia where forward sales are used extensively. In Tanzania, larger ginners can also sell forward to international traders. But smaller independent ginners are generally not in a position to guarantee volumes or store lint for extended periods. They primarily deal with price risks by trying to secure large margins and adjusting their buying price over the course of the season. 
In contrast, international traders (and locally-based processors or exporters affiliated to international traders) hedge most of their trades through their headquarters which have specialized financial units. Hence, access to hedging gives multinational actors, that is, international traders, and their local affiliates an important advantage in dealing with price risks relative to local actors in producing countries and smaller traders (Dana and Gilbert, 2008). Hedging is increasingly required not only to reduce traders' internal price risk exposure but to be creditworthy for banks and other funders that require risk management as a prerequisite, even more so since the global economic crisis. However, the impact goes beyond price security as commodity derivative markets are not only used for hedging but also for speculative purposes. In particular, large multi-commodity traders, far from being concerned by the increasing presence of financial investors on these markets, have made speculative derivatives trading an important part of their business strategy, opening expanded profit opportunities. By contrast, smaller, traditional commodity traders have largely remained focused on physical trading activities with limited expansion into financial services.

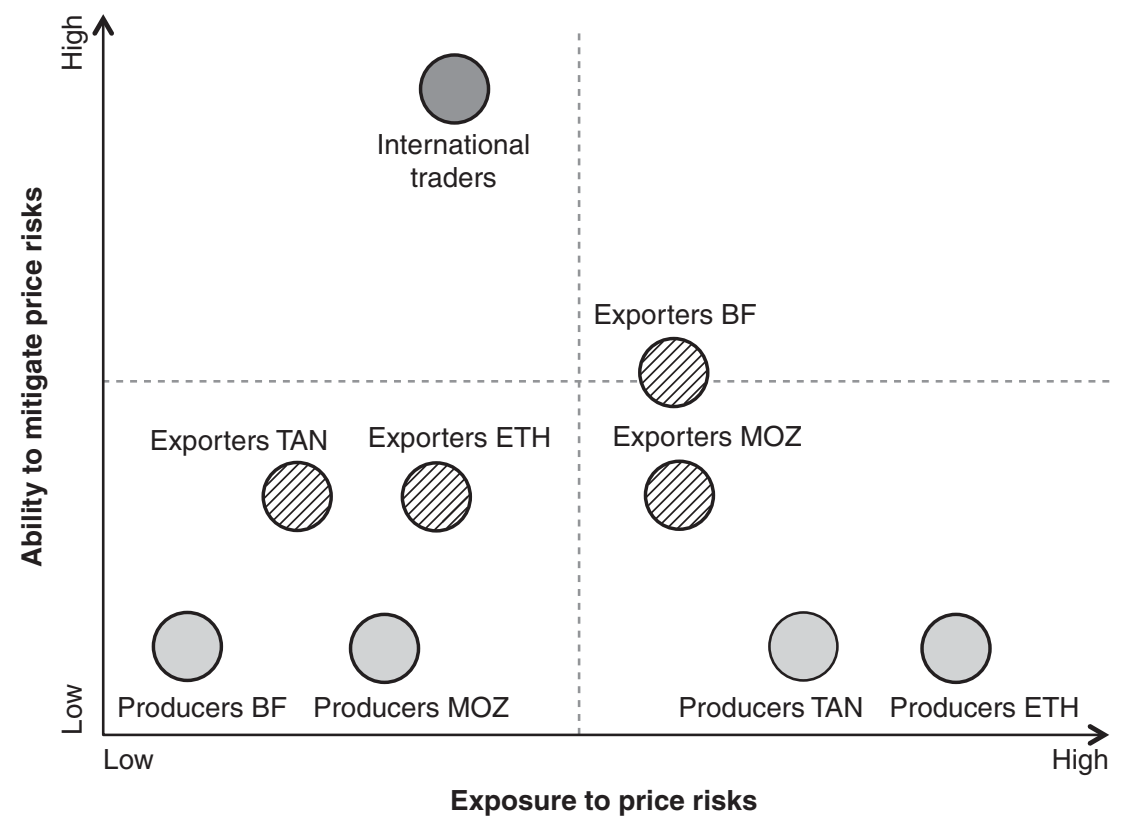

Figure 14.2 Intra-seasonal price risks and PRM for producers, local exporters, and international traders (source: authors' own analysis).

Note

$\mathrm{ETH}=$ Ethiopia; TAN = Tanzania; $\mathrm{MOZ}=$ Mozambique; BF = Burkina Faso. 


\section{Conclusion}

Price instability and related price risks are major concerns, particularly for smallholder farmers. Given the liberalization of price stabilization schemes in producer countries and international traders' practices, particularly the use of hedging, commodity derivative markets have become the central pricing mechanism for international coffee and cotton trade. Futures prices are increasingly transferred along the commodity chain to exporters and producers. This is particularly problematic in the context of the increased short-termism in derivatives trading and the limited PRM options for actors in producer countries. The extent to which unstable world prices are transmitted to producers depends, however, upon the national market structure and price setting arrangements. Inter-seasonal price instability is a reality in all countries studied since national prices are based on, and increasingly aligned to, global prices. This is the case under competitive price setting as well as in administered price setting systems. Withinseasonal price volatility is a greater concern for farmers in Ethiopia and Tanzania than in Burkina Faso and Mozambique given the existence of different types of national producer price stabilization schemes.

Uneven exposure to price instability and access to PRM strategies have important distributional and fairness implications. International traders have the capacity to deal with price risks through hedging in addition to expanding their activities and profit possibilities through pursuing financial trading strategies and providing financial services on commodity derivative markets. In contrast, local actors in producer countries face the challenge of price instability and increased short-termism with very limited access to PRM. Financialization has given rise to opportunities and challenges for actors in cotton and coffee commodity chains and, given the heterogeneity of actors, has tended to exacerbate existing inequalities. Large international and financially adept actors stand to benefit from opportunities for speculation alongside hedging activities on derivative markets while local actors in producer countries face greater challenges in an environment of price instability and short-termism (Newman, 2009; Staritz et al., 2015; Tröster and Staritz, 2015).

National market structures mediate uneven exposure to price risk and risk management but only to a certain extent. National structures can address and mediate local relationships and power asymmetries in producer countries by negotiating how price risks are shared amongst actors operating in the national marketing system. The national institutional context, particularly tripartite negotiation structures and processes and strong independent farmers' associations are crucial for outcomes that reflect farmers' interests. National structures alone, however, cannot fully address the major driver of inequality in incomes and risks, namely, unequal power structures in global commodity chains - the dominance of international traders, in particular, and their increasing links to commodity 
derivative markets (Newman, 2009; Staritz et al., 2015). Through acting on these markets they are in a position to determine prices along coffee and cotton chains, cope with price risks, and expand their financial activities and profit avenues.

In light of these conclusions, policy reforms are necessary at least at four levels - regulation of commodity derivative markets to reduce the dominance of financial motives (Staritz and Küblböck, 2013); establishment of national price stabilization schemes to ensure fair and stable prices in producer countries; development of alternative physical price determination beyond commodity derivative markets, such as an adapted version of collective price agreements that were created by ICAs; and reduction of dependence on international traders through developing marketing and trading capacities in producer countries and through furthering local and regional processing and other production linkages.

Re-regulation of commodity derivative markets would be an important step towards price stabilization. Despite some important steps (e.g. regarding transparency and position limits), attempts to re-regulate commodity derivative markets in the $\mathrm{EU}$ in the context of the economic crisis have, however, once more been strongly influenced and watered down by the financial industry (Küblböck and Staritz, 2014). Actors that bear the negative consequences from higher volatility and price risks lack the possibility of influencing regulation, which is highly problematic from a fairness point of view. Current efforts by some international organizations to deal with price risks of farmers and exporters through extending their access to hedging instruments is certainly not the policy answer. Commodity derivative markets are not an effective way to cope with commodity price risks for an important group of physical traders and particularly local actors in developing countries. Such efforts would intensify the impact of financialization on commodity chains and the uneven distributional implications discussed in this chapter.

Reforms beyond commodity derivative markets will be necessary to stabilize commodity prices and reduce vulnerability for local actors. Price stabilization schemes at the national or regional level are a useful instrument to cushion price risks for producers. Given asymmetric power structures between the involved parties, an important prerequisite for price negotiations is tripartite institutional structures as well as strong and independent farmers' associations. A main challenge for national and regional price stabilization funds is securing financing, particularly in the context of long-lasting low-price periods. Hence, stabilization funds could be coupled with an international counter-cyclical financing facility to mitigate income shocks from commodity price movements and ensure financial and policy space (Nissanke and Kuleshov, 2012). Ideally, such measures are complemented with new price stabilization mechanisms at the international level. In this regard, the re-establishment of ICAs, including supply and inventory management measures, could be an important 
step. However, lessons learnt from the past, such as flexibility and mediation procedures, definition of an appropriate price range compatible with market conditions, and creation of a compensation fund with sufficient resources would need to be incorporated in the design of ICAs (UNCTAD, 2010).

Ultimately, developing countries need to reduce their dependence on commodities and diversify their economies not only to deal with price instability and external vulnerability but to secure structural transformation to higher value added activities, better jobs and sustained growth (see also the dynamic conceptualization of resources presented in the chapter by Raza, in this volume). An important opportunity is productive linkages from commodity sectors to other sectors (Morris et al., 2012). This involves forward linkages to processing - roasting or instant coffee production in the case of coffee and spinning, weaving and apparel production in the case of cotton - with important potential for value addition and employment generation. But also backward linkages provide diversification possibilities in terms of input provision including pesticides, fertilisers, equipment, and various services from IT to transport. For diversification and commodity based development, price stabilization is an important prerequisite, but in addition it requires a broad set of industrial policies and capacities at the public and private sector as well as sufficient policy space.

On a conceptual level, our analysis reveals the necessity of considering the interdependencies between value chain governance and global macro and local contexts to assess distributional outcomes for local producers of export crops. In particular, the role of financial markets and financialization in determining prices and value, related risks and PRM options, and the structure of physical chains and the actions and motives of different actors are crucial. Not taking into account this additional dimension of power and its interrelations with traditional lead firm power in commodity chain analysis makes a distributional analysis incomplete. It circumvents the central question of how value is created or 'set' and income and risks distributed, which is strongly influenced - if not dominated - by financial markets and their interaction with the physical sphere of production and trade in the context of financialization.

\section{Notes}

1 In Ethiopia, we conducted interviews with six exporters, two cooperatives, one roaster and the Ethiopian Commodity Exchange (ECX). In Burkina Faso and Mozambique, we conducted interviews with seven ginners, two spinners, two input providers, farmers' unions and ginners' associations. We also interviewed representatives of the government institution responsible for the sectors, Ministries of Trade and Agriculture, international institutions, NGOs and sector experts. In Tanzania selected telephone and field interviews were conducted with two ginners, the Tanzania Cotton Board (TCB) and the Textile Development Union (TDU). 
2 Commodity derivatives can either be traded on regulated exchanges, called futures markets, that provide price information (i.e. futures prices) or bilaterally and unregulated over the counter (OTC) (Staritz, 2012).

3 For instance, a producer of wheat can sell futures contracts according to the amount of the expected harvest today, which secures today's price for wheat, while a consumer of wheat can buy futures contracts to secure input costs.

4 Financial investors can be differentiated into money managers that pursue active and short term, often trend following, trading strategies and index investors/ swap dealers that pursue longer term and passive long only trading strategies (Ederer et al., 2016).

5 Holding futures requires margins that are adjusted on a daily basis to reflect market movements. Margin calls take place when the current price falls outside the margin that is set below the original purchase price by the futures contract.

6 In practice, there has been no downward revision of prices following the second meeting to date.

7 Farmers being part of cooperatives get a higher share of export prices in Ethiopia due to a potential secondary payment if export prices increase during the marketing season as in Burkina Faso. However, only around 5 to 10 per cent of farmers are part of cooperatives.

8 There are also longer term strategies such as switching to niche and speciality product markets that are less affected by world-price instability and diversification through selling a larger variety of products or increasing local processing.

9 In Tanzania, the World Bank and CRDB promoted hedging through its "Kinga Ya Bei” project with very limited uptake (Newman, 2009). In Ethiopia, the access to financial derivative markets for hedging is also restricted for Ethiopian actors given foreign exchange controls.

\section{References}

Barclays Capital (2013) 'The commodity investor: still stop-go for commodities', October 2013, London.

Bargawi, H. (2008) 'Cotton price fluctuations at the ground-level: assessing the difference in impact in rural Tanzania', NCCR Trade Working Paper, no. 11, Bern.

Bargawi, H. and Newman, S. (2013) 'From futures markets to the farm-gate: assessing real price transmission along coffee chains', ISS Working Paper, no. 577, The Hague.

Clapp, J. (2014) 'Financialization, distance, and global food politics', The Journal of Peasant Studies, vol. 42, no. 5, 797-814.

Dana, J. and Gilbert, C. L. (2008) 'Managing agricultural price risk in developing countries', in H. Geman (ed.) Risk Management in Commodity Markets: From Shipping to Agricultural and Energy, Wiley Finance, Chichester, 207-307.

Dana, J. and Sadler, M. (2012) 'Market-based approaches to managing commodity price risk', Contribution to G20 Commodity Markets Sub Working Group, Washington, DC.

Ederer, S., Heumesser, C., and Staritz, C. (2016) 'Financialization and commodity prices: an empirical analysis for coffee, cotton, wheat and oil', International Review of Applied Economics, vol. 30, no. 4, 462-487.

Epstein, G. A. (2005) Financialization and the World Economy, Cheltenham, UK and Northhampton, MA. 
Gibbon, P. (2014) 'Trading Houses during and since the Great Commodity Boom: financialization, productivization or...?', DIIS Working Paper, no. 12, Copenhagen.

Heumesser, C. and Staritz, C. (2013) 'Financialization and the microstructure of commodity markets: a qualitative investigation of trading strategies of financial investors and commercial traders', ÖFSE Working Paper, no. 44, Vienna.

IMF (2014) 'Burkina Faso, selected issues', Country Report no. 14/230, Washington, DC.

ITC (2013) 'Improving Africa's cotton value chain for Asian markets', Technical Paper, Geneva.

Kaminski, J., Headey, D., and Bernard, T. (2011) 'The Burkinabé cotton story 1992-2007: sustainable success or Sub-Saharan mirage?', World Development, vol. 39, no. 8, 1460-1475.

Küblböck, K. (2015) 'Internationale Rohstoffpolitik: Vom Rohstoffimperialismus zur globalen Ressourcenfairness?', in ÖFSE (ed.) Österreichische Entwicklungspolitik 2015: Rohstoffe und Entwicklung, ÖFSE, Vienna, 19-26.

Küblböck, K. and Staritz, C. (2014) 'Regulation of commodity derivative markets: critical assessment of reforms in the EU', ÖFSE Policy Note, no. 12, Vienna.

Larsen, M. N. (2008) 'The global cotton market and cotton sector reforms in SubSaharan Africa', in N. Fold and M. N. Larsen (eds) Globalization and Restructuring of African Commodity Flows, Nordiska Afrikainstitutet, Uppsala, 156-183.

Morris, M., Kaplinsky, R., and Kaplan, D. (2012) 'One thing leads to another: promoting industrialisation by making the most of the commodity boom in SubSaharan Africa', Center for Social Science Research, Cape Town.

Newman, S. (2009) 'Financialization and changes in the social relations along commodity chains: the case of coffee', Review of Radical Political Economics, vol. 41, no. 4, 539-559.

Nissanke, M. (2011) 'Commodity markets and excess volatility: sources and strategies to reduce adverse development implications', Paper prepared for the Common Fund for Commodities (CFC).

Nissanke, M. and Kuleshov, A. (2012) 'An agenda for international action on commodities and development: issues for the EU Agenda beyond the MDG', European Report on Development, Background Paper.

Russi, L. (2013) Hungry Capital: The Financialization of Food, Zero Books, Winchester.

Staritz, C. (2012) 'Financial markets and the commodity price boom: causes and implications for developing countries', ÖFSE Working Paper, no. 30, Vienna.

Staritz, C. and Küblböck, K. (2013) 'Re-regulation of commodity derivative markets: critical assessment of current reform proposals in the EU and the US', ÖFSE Working Paper, no. 45, Vienna.

Staritz, C., Newman, S., Tröster, B., and Plank, L. (2015) 'Financialization, price risks, and global commodity chains: distributional implications on cotton sectors in Sub-Saharan Africa', ÖFSE Working Paper, no. 55, Vienna.

Tröster, B. and Staritz, C. (2015) 'Financialization and price risks in global commodity chains: the coffee sector in Ethiopia', ÖFSE Working Paper, no. 56, Vienna.

UNCTAD (2008) 'Trade and development report 2008', Geneva.

UNCTAD (2010) 'The least developed countries report 2010', Geneva. 
UNCTAD (2011) 'Price formation in financialized commodity markets: the role of information', Study prepared by the Secretariat of the UNCTAD, Geneva.

World Bank (2011) 'World Bank group announces new instrument to help food producers and consumers in developing nations deal with volatile prices', Press Release No: 2011/559/EXT, The World Bank, Washington, DC.

\section{List of interviews}

Interview 1: General Manager, Ginner, Dar el Salaam, Tanzania, August 2014.

Interview 2: Country Director, International NGO, Addis Ababa, Ethiopia, September 2014.

Interview 3: Export Manager, Coffee Exporter, Addis Ababa, Ethiopia, September 2014 .

Interview 4: Chief Strategic Officer, Ethiopian Commodity Exchange (ECX), Addis Ababa, Ethiopia, September 2014. 


\title{
15 Responsibility for financing biodiversity conservation
}

\author{
An analysis of the Convention on \\ Biological Diversity ${ }^{1}$
}

\author{
Ina Lehmann
}

\section{Introduction}

Biological diversity (biodiversity) provides numerous so-called ecosystem services for human material livelihoods. ${ }^{2}$ Among other things it supplies food, drinking water (through soil cycling functions), income (through the sale of nature-based products), and protection against floods and storms (provided by mangroves and coral reefs in coastal regions). Many ecosystem services transcend national or continental borders, including, inter alia, the climate-regulating effects of tropical forests and the medicinal properties of some tropical plants which benefit customers around the world (Millennium Ecosystem Assessment, 2005). Yet human economic activities significantly overexploit the earth's biological resource base and thereby threaten the very basis of human life (Rockström et al., 2009). In reaction to this, at the highest political level, the UN Convention on Biological Diversity (CBD) commits its signatory parties to the objectives of conservation and to the sustainable use of biodiversity, with the latter generally understood as part of the former (United Nations, 1992). ${ }^{3}$ Biodiversity conservation does not come for free, of course, and principles are thus needed to determine who should be responsible for bearing the costs of conservation. While these principles are in practice politically negotiated, ideally, they should be just. Ideals will hardly ever be reached in 'real world' politics, but they can operate as an important guidance for reform (Buchanan and Keohane, 2006: 406-410). Therefore, I consider it worthwhile to discuss how far the international conservation regime of the CBD provides for the just international allocation of responsibility for conservation-related costs. In order to keep the global ecological balance intact it is particularly urgent to conserve biodiversity in developing countries, where most biodiversity today is concentrated (Rosendal, 2000: 20). Hence, I focus on responsibility for conservation in developing countries.

Specifically, I ask who should be responsible for bearing the costs of biodiversity conservation in developing countries. The question about the just allocation of costs for international environmental policies has sparked a huge debate among global climate justice scholars (e.g. Shue, 1993; 
Neumayer, 2000; Caney, 2006, 2010; Page, 2016; Schuppert, 2016), but a similar discussion is still missing for other environmental policy fields. By singling out biodiversity conservation as a starting point, I hope to contribute to closing this gap. Moreover, by its very nature, the theoretical debate is focused on the principled normative question of who ought to bear what burden of global climate policies but rarely moves on to ask how actual policies fare in this light (for a recent partial exception see Armstrong, 2016). However, if political theory is to work as a practical discipline that helps in deciding what should be done, then it surely does need to engage with actual policies (Swift and White, 2008). A second objective and contribution of this chapter, therefore, is to empirically evaluate how far the policies adopted in the framework of the CBD live up to normatively justifiable principles of responsibility.

In order to address these twin objectives, the chapter proceeds as follows. In the first, theoretical, section, I argue for a combination of the contributor pays principle and the ability to pay principle. On this basis, I conclude that the least developed states should be exempted from conservation funding and all other states should bear a progressively increasing funding responsibility. In a second, empirical, section, I work out whom the CBD and finance-related decisions of its Conferences of the Parties (COPs) hold accountable for funding conservation in developing countries. I then evaluate these policies in the light of the normative principles discussed and conclude that the CBD itself is largely in line with my normative suggestions for the allocation of responsibility, but recent COP decisions diverge from this by attributing too much responsibility to developing countries. Finally, I highlight the increasing role of the private sector as an actor in biodiversity conservation that needs more attention in normative theorizing.

\section{Normative principles for the allocation of responsibility}

Before I embark on a discussion of principles for the just international allocation of responsibility for biodiversity conservation, it is necessary to briefly specify which kinds of agents ought to be responsible for what kinds of activities. Regarding agents, my argument is that responsibility for international environmental conservation policies ought to be borne by states because unsustainable resource-use patterns can ultimately be ascribed to them. By setting the legal and political framework for resource exploitation, states are the main agents that can steer resource-use patterns in one direction or another (Page, 2012: 302). Regarding activities, I think we need to separate the responsibility to undertake conservation measures from the responsibility to fund them (Page, 2016: 84). The two do not necessarily go together, and there are reasons why they should not. Conservation of its own biodiversity is a justice requirement for each state for two main reasons. First, species and ecosystem composition is very 
place-specific, so conservation activities have to be undertaken in the localities where biodiversity is threatened. Second, and relatedly, states should serve the function of realizing their citizens' basic interests and ought to avoid imposing harms on future generations and people in other countries. These duties apply to all states and are generally assumed to include the respect for ecological limits (Schuppert, 2016: 110-111). International sharing of responsibility can, then, only take the form of sharing the costs of conservation. The costs for conservation policies can be of various kinds. For instance, funds are needed for directly conservation-related measures, such as monitoring, threat control, and ecosystem rehabilitation. Funding also relates to stakeholder compensation for use restrictions, thus covering their opportunity costs (Hein et al., 2013: 89-90). In the specific context of the CBD, countries require funds for the institutional and administrative framework of conservation, for example, the development of national plans for biodiversity conservation and the build-up of national reporting systems (see e.g. COP Decisions IX/11 and XI/4).

\section{The contributor pays principle}

With these clarifications, I now turn to discussing two principles for the international sharing of the costs of biodiversity conservation in developing countries. ${ }^{4}$ The first principle is widely established in international environmental policy and law and has a strong appeal to most people's justice intuitions. According to this so called 'contributor pays principle' (CPP), agents are morally responsible for bearing the costs of mitigating environmental harm in relation to their contribution to causing the harm (Shue, 1999: 534-535; Neumayer, 2000: 187-188; Singer, 2002: 34). ${ }^{5}$ Biodiversity loss occurs through myriads of local, regional, and global processes, not all of which are yet fully understood or documented (Millennium Ecosystem Assessment, 2005: 36). Nevertheless, it is possible to identify a number of main drivers of biodiversity loss in developing countries, enabling us to spell out general principles for how to allocate conservation funding responsibility between countries.

To start with, developing countries themselves have historically overused significant parts of their biodiversity and are continuing to do so. In Southern Asia and parts of Latin America, for instance, large forest areas had been cleared for agricultural purposes long before the arrival of European settlers (FAO, 2012: 9, 13). In many tropical regions, moreover, deforestation rates have increased in recent decades, largely as a result of the growing population and its dependence on land-based economic activities as well as due to the pressure from commercial agriculture for export purposes (FAO, 2011: 5; 2012: 9-15). In some parts of Asia biodiversity loss rates due to agricultural intensification and nutrient exposure have also accelerated recently (Secretariat of the Convention on Biological Diversity, 2010: 59-60). Likewise, fish consumption levels and overfishing 
have increased in many developing countries, particularly in the emerging economies (FAO, 2014: 3). Moreover, in many developing countries rampant corruption provides a fruitful ground for illegal logging and wildlife trade of endangered species (Smith and Walpole, 2005: 252-253). Overall, these major trends illustrate that developing countries significantly fuel biodiversity loss. According to the CPP, they should therefore be held responsible not only for undertaking domestic conservation activities but also for bearing the financial burden of these activities. In line with the stronger contribution of emerging economies to at least some environmentally harmful activities such as overfishing, they should be allocated a somewhat greater responsibility than developing countries in general.

However, only considering the site of the problem, that is, the country in which environmental harm takes place, is not sufficient. Rather, one also has to ask who has (politically and/or economically) instigated the harmful action. For example, historically, a lot of colonial timber exploitation took place in Asia (FAO, 2012: 13) which certainly should be considered the moral fault of the colonial powers. Currently, consumers in developed countries instigate much biodiversity overexploitation in developing countries. For instance, although palm oil plantations significantly diminish local biodiversity, 10 per cent of the world's permanent cropland - in 43 developing and emerging countries - is cultivated by palm oil plantations (Koh and Wilcove, 2008), and large quantities of the palm oil produced are exported to developed countries. European long-distance fishing operations in the exclusive economic zones of West African countries serve as another example. Most of the fish is directly exported to Europe, with African countries receiving only little compensation for access by European fishers (Millennium Ecosystem Assessment, 2005: 62-63). Increasingly, emerging countries, like China, also import fish from developing countries, while people in developing countries themselves largely rely on local fish products (FAO, 2014: 3). One might argue that the producer countries retain political responsibility for the uses of their lands and waters. This, however, overlooks the fact that such poor countries are frequently economically dependent on agricultural exports, logging, and fishing right fees for economic growth. Their development trajectories take place within the context of a world economic system in which they operate first and foremost as natural resource exporters, and their opportunity to develop economically through environmentally harmful activities is fuelled by demands from developed countries. Developed countries, and also to some extent emerging countries, are thus not innocent bystanders but rather cocontributors to biodiversity loss in developing countries. Therefore they ought to take up a significant share of the costs of conservation measures in developing countries. ${ }^{6}$

As far as it goes, I think that the CPP's proposition that developing, emerging, and developed countries bear different degrees of responsibility for conservation funding in developing and emerging countries is right. 
However, the reach of the CPP is restricted in two respects. First, it does not discriminate on the basis of whether or not the environmental harm results from a morally wrong act. Some environmental resource use is clearly indispensable for people to lead a decent life and thus, although it may cause environmental harm, should not be considered as anybody's fault. In contrast, to the extent that resources are wasted or overused for what is clearly a luxurious lifestyle, the resulting environmental harm should be understood as a fault that needs to enter the determination of the responsibility for funding environmental policies (this draws on Henry Shue's (1993) account of responsibility for greenhouse gas emissions). This logic also has strong appeal for biodiversity conservation. Some biological resource use is necessary for people everywhere to meet their livelihood needs. In many developing countries, these subsistence uses alone may lead to significant resource overexploitation, because the poor directly depend on local ecosystems. Where people have no choice but to overexploit natural resources for their daily needs, this often leads to a downward spiral of increasing poverty and decreasing environmental quality (Millennium Ecosystem Assessment, 2005: 63). For example, in many forest regions in developing countries, bush meat is the major source of protein but as poor people hunt it at unsustainable levels, some forests become "virtually devoid of animal life", thereby bringing the entire forest ecosystem into imbalance (Secretariat of the Convention on Biological Diversity, 2010: 63). Such overexploitation should not count towards developing countries' moral responsibility for conservation costs. Certainly, in developing countries and even more so in emerging economies, the resourceintensive lifestyle of the elites and emerging middle classes is another important factor for biodiversity loss (e.g. through the intensification of agriculture or loss of land). Yet if only these latter contributions to environmental harm are to be considered as (morally) wrong and as therefore needing to enter the determination of conservation funding responsibility, all non-fault-based biodiversity loss remains unaccounted for.

Similar problems arise, second, with regard to past environmental harm. Holding states responsible according to their past contribution to an environmental problem is normatively problematic insofar as it holds these states' current citizens responsible for acts they did not commit and over which they had no (political) control. After all, it was their ancestors and not they who degraded the environment for most of history (Caney, 2005: 756; Gosseries, 2004: 41-42). Against this, states usually represent some form of legal and institutional continuity and one might therefore expect them to take over responsibility for past faults that have occurred under their jurisdiction (Zellentin, 2015: 259). The problem that this burdens those people alive today who had no say over past decisions remains, however (Caney, 2006: 468). Essentially, it is unfair to expect those who have not caused a problem to fix it (Shue, 1999: 536). ${ }^{7}$ Regardless of these objections, biodiversity loss in developing countries has accelerated 
tremendously over the past decades (for forests, see e.g. FAO, 2012: 9), and accordingly in the lifetime of the current generation, so that it can be held responsible for significant shares of biodiversity loss. Of course, this is by no means to imply that the accumulated loss of past centuries should be left unaccounted for.

These considerations are not intended to undermine the CPP; its strong intuitive appeal can hardly be denied. In this sense, the CPP is appropriate for dealing with those environmental burdens that have occurred in the lifetime of the current generation and that are not essential for immediate livelihood purposes. For all other causes of environmental degradation, which Simon Caney (2010: 213) calls the 'remainder', a complementary principle is needed.

\section{The ability to pay principle}

I suggest that the remaining costs should be covered by the 'ability to pay principle' (APP), according to which the rich states should bear the costs of environmental policies (Caney, 2005: 767-772; 2010: 213-218; Page, 2008: 561-562). Any international environmental agreement that asks the poor states to cooperate in solving environmental problems but overlooks the radical economic inequality among nations is grossly unfair (Shue, 1999: 544). The deeper justification for such an approach is that humane policies must take into account the actual living circumstances of people and should be guided by the ideal of a minimum level of wellbeing below which nobody may fall (Shue, 1999: 537, 540-544; Page, 2008: 559). Therefore, if a state cannot guarantee the material basis of life for large parts of its population, economically strong states are obliged to support it, which includes bearing the (financial) burden of international environmental policies. Imposing these obligations is justified because, and to the extent that, rich countries are able to divert some of their resources to addressing environmental damage in other countries without undermining the well-being of their own citizens (Caney, 2005: 769-770; Miller, 2007: 255; Page, 2008: 561). A crucial question, of course, is when countries should be considered unable to pay for environmental policies. Here, I follow Henry Shue's (1999) sufficientarian argument that the minimum that constitutes the threshold for the ability to pay is all people having the "essentials for at least a bit more than mere physical survival - for at least a distinctively human, if modest, life" (540-541).

Translating APP into international conservation policies means that the least developed countries should clearly be exempted from conservation finance requirements, because they are struggling to guarantee the majority of their citizens the bases for a decent livelihood. For all other countries the APP is open to progressive rates of payment. Thus, the richer a state, the more it can legitimately be asked to contribute to meeting the costs of mitigating global environmental change (Shue, 1999: 537-538; Caney, 
2010: 213). Beyond the sufficientarian threshold this thus allows for very modest contributions from slightly better off developing countries. Julian Culp (2014) has, moreover, presented a forceful normative argument that rising powers do indeed have some ability to pay for the alleviation of global poverty (even if within limits). Overall, however, just as with the $\mathrm{CPP}$, the bulk of financing responsibility lies with the rich developed states.

The key counter-intuitive drawback of APP is that it does not at all take fault into account as a basis for determining responsibility to pay. It thereby ignores one of the most fundamental moral considerations that people hold, that is, that those actors who do harm should be held responsible for it (Caney, 2010: 213-214). There is thus a normative tension here, and one that cannot, I think, be perfectly solved. On the one hand, the sources of harm should matter in the allocation of responsibility, while on the other hand, a clear commitment to humane living conditions demands that some actors ought to be exempted from financing responsibilities. For the share of financing responsibilities unaccounted for by CPP, I nevertheless argue that the priority should be placed on the ability to pay, even if that undermines intuitions about fault-based responsibility. It is not an option to leave costs unaccounted for by avoiding conservation action, since that would further destroy the basis of human life. In such a scenario it is ultimately the smaller injustice to make the rich pay even if some of the harm is not their fault whereas it seems morally intolerable to make the poorest pay and further undermine their livelihood bases. The APP thus leaves the advantaged to pay, and they have less cause to complain because they can still have an affluent life (Caney, 2010: 214).

The CPP and APP taken together largely correlate with regard to their overall arguments, concerning which groups of states should bear more or less responsibility for conservation finance. The least developed countries should be exempted from conservation funding requirements. All other countries should be subject to progressive rates of funding in accordance with their contribution to the problem as well as with their ability to pay and assuming that these two criteria are to some degree correlated. More specifically, this means that those developing countries that are not among the least developed might be asked to contribute some funding, emerging economies some more, and the bulk of funding for international conservation objectives should be attributed to the developed states. Within each of these groups of states, the more detailed allocation of responsibility should ideally follow a delicate balance between fault-based considerations and social wellbeing-based considerations, but it is practically impossible to translate this into a formula of responsibility. This is especially so given the many scientific uncertainties that still exist regarding processes of biodiversity loss and which do not allow for a precise ascription of fault. Nevertheless, the general benchmarks outlined here should be sufficient in the empirical analysis to assess whether the international conservation regime around the CBD has adopted normatively satisfying financing rules. 


\section{Funding responsibilities in the biodiversity regime}

\section{The CBD and the Strategy for Resource Mobilization}

The CBD is a framework convention that provides the overall structure for international cooperation in biodiversity conservation and stresses the importance of national implementation. In this spirit, it addresses financing only very briefly and in very general terms. Its preamble acknowledges "that economic and social development and poverty eradication are the first and overriding priorities of developing countries". This is, therefore, the overall normative guidance that the financing rules of the regime should live up to. More concretely, the key substantive provision with regard to financing is Article 20. First, it demands each signatory party to contribute financial resources for the achievement of the objectives of the Convention "in accordance with its capabilities" (United Nations 1992: Art. 20.1). In light of the developing countries' restricted financial capabilities, the developed countries are asked to provide developing countries with new and additional funding that covers the "agreed full incremental costs" of their measures and activities to implement the Convention obligations (United Nations 1992: Art. 20.2). ${ }^{8}$ Moreover, the Convention states that the "extent to which developing countries will effectively implement their commitments under this Convention will depend on the effective implementation by developed country Parties of their commitments under this Convention related to financial resources and transfer of technology" (United Nations 1992: Art. 20.4). The interpretation of this article is contested. It can either be a description of causal relations, or it can be interpreted to mean that financial and technical support to developing countries is a legal requirement for their implementation of the Convention (Loft, 2009: 66). In either case, a substantial share of the responsibility for biodiversity funding lies with the developed countries. In providing funds they should, moreover, "take full account of the specific needs and special situation of least developed countries" (United Nations 1992: Art. 20.5). Beyond that, the CBD does not specify any more concrete rules for sharing financial responsibility.

The weak guidance by the CBD accounts for the high policy relevance of the biennial COPs, as they explicitly serve to develop the regime further and - wherever possible - arrive at more substantial agreements. Provisions on funding are dispersed throughout the various substantive programme areas (e.g. agricultural, forest, or mountain biodiversity) under the CBD. Eventually, the Strategy for Resource Mobilization brought together and complemented these dispersed provisions at COP 9 in 2008. The Strategy's objective is to increase both international financial flows and domestic funding in order to secure the effective implementation of the Convention and to halt biodiversity loss (Decision IX/11). As such, it is a crucial attempt at putting the realization of the CBD's obligations on a 
more solid financial footing. Since then, each COP has reviewed the Strategy and sought to develop it further. Hence, the following analysis focuses on this strand of COP decisions because it consistently draws together the core principles of biodiversity finance under the CBD. Specifically, in line with my research question, I single out those stipulations that address states' obligations to fund conservation in developing countries. Moreover, at COP 10 in 2010, parties adopted the so-called Aichi Targets, which further specify the objectives of the Convention, including some quantified targets, such as halving the loss rates of natural habitats by 2020 (Decision X/2). These targets are currently the main reference point for decisions on financing.

Overall, the COPs have further established the particular responsibility for developed countries to fund conservation in developing countries. A first key, but non-specific, provision is that developed countries should increase biodiversity-related development assistance for developing countries (Decision IX/11B Para. 3.2) and promote measures such as debt-fornature swaps (Decision IX/11 B Para. 3.8). Only at COP 11 in Hyderabad in 2012 did parties agree on a basic quantitative framework for biodiversity funding for the achievement of the Convention's objectives and Aichi Targets. Taking the average of 2006 to 2010 annual biodiversity-related international financial flows as a baseline, developed countries were asked to double this funding for developing countries by 2015 and maintain this level at least until 2020 (Decision XI/4 Para. 6-7). This objective was recently reaffirmed at COP 12 in 2014 (Decision XII/3 Para. 1).

In addition to these financing requirements for developed countries, attempts have been formulated to make developing countries bear a share of the burden. First, one key objective of the Strategy for Resource Mobilization, which is reiterated in subsequent decisions, is to substantially increase domestic biodiversity funding. This should happen "as appropriate" (Decision IX/11 Annex Para. 3.7) or for countries "with adequate financial resources" (Decision X/3 Para. 9). This increased reliance on developing country funding has been given a further boost, as COP 12 has complemented COP 11's quantitative funding targets with an extra paragraph calling for domestic resource mobilization to meet identified biodiversity-related funding needs (Decision XII/3 Para. 1e). Second, the Strategy calls for developing country contributions through South-South cooperation as a complement to North-South cooperation (Decision IX/11B Para. 6.2; reiterated in Decision XII/3 Annex IV Para. 12). SouthSouth cooperation is generally considered to be a particularly efficient way of delivering technological support and capacity building to developing countries. However, in the context of the CBD COP decisions, it explicitly also includes the provision of loans and grants by developing countries (CBD, 2012a: 44).

The obligations established by the CBD and COP decisions are only partially mirrored in the actual provision of biodiversity funds. Detailed 
estimates of the resources required for meeting the Convention's objectives are not readily available (see also CBD, 2012b: 6; Parker et al., 2012: 18). A rough assessment by the CBD Secretariat assumes that the global costs for meeting the Aichi Targets will be in the range of US $\$ 150$ billion to 440 billion a year (CBD, 2012b: 12). Given a persistent deficiency in countries' reporting of their biodiversity-related expenditures, it is also difficult to assess the actual amount of funding (Waldron et al., 2013: 12144). Clearly, however, most funds for biodiversity conservation come from domestic government sources (Parker et al., 2012: 34). A recent estimate suggests that, globally, domestic funding accounted for approximately 21.5 billion dollars annually from 2001 to 2008 , with the bulk of this domestic spending clearly taking place in developed countries (Waldron et al., 2013: 12145). Nevertheless, in both developed and developing countries, even in those with major biodiversity, environmental protection expenditures remain insignificant in national budgets (CBD, 2010: 12). International biodiversity aid has recently been estimated to be around US $\$ 1$ billion per year (Waldron et al., 2013: 12145), with some recent increase being reported against the 2006-2010 baseline (Secretariat of the Convention on Biological Diversity, 2014: 123). South-South cooperation for biodiversity purposes has been estimated to fall in the range of US $\$ 200$ million per year (CBD, 2012a: 44). Even if all of these numbers are rough estimates, they clearly suggest that the funding available will not be sufficient to meet conservation targets (Secretariat of the Convention on Biological Diversity, 2014: 123). Many of the most severely underfunded countries are developing countries that are host to a significant proportion of globally threatened biodiversity. Here, a modest increase in absolute funding could generate relatively large impacts for conservation (Waldron et al., 2013: 12147).

\section{Normative justice assessment}

What, then, do the written policies and actual funding trends suggest with regard to the just allocation of funding responsibility in the international conservation regime under the CBD? The CBD is rhetorically much more strongly rooted in an ability to pay logic than in a contributor pays logic, as evidenced notably by the clear emphasis that countries' financial responsibilities depend on their capabilities (United Nations 1992: Art. 20.1). Nevertheless, its overall differentiated funding provisions are in line with the distribution of responsibility that I have derived above from a combination of the CPP and APP. Both my normative proposal and the CBD's policies justify the exemption of least developed countries from funding obligations. By highlighting the specific needs of least developed countries, the CBD clearly establishes that these countries should be the primary recipients of support. On the other end of the spectrum, the CBD affirms the special responsibility of the developed countries, as they are 
required to cover developing countries' incremental costs of implementing the Convention. Given the overall convergence of the CBD's financing requirements with the normative justice principles developed above, is it irrelevant that the CBD does not seem to incorporate fault-based considerations? I believe the answer is no, because within the broad lines of responsibility established by the $\mathrm{CBD}$, the single states will still have to decide how much exactly they will contribute to the global goal of biodiversity conservation. For reasons of justice, such a decision should also be influenced by the morally relevant contribution of the respective state to biodiversity loss.

Looking, then, at the specification of the funding rules through the COP decisions, the normative assessment is ambivalent. On the one hand, the decisions rightly reaffirm the special funding responsibility of the developed states - and what is more, they do so without recourse to weakening language (i.e. expressions such as 'as appropriate' etc.). The 2012 decision to double the flow of biodiversity-related funds from developed to developing countries gives the previously vague language about developed countries' obligations much more force. Moreover, the decision has been appreciated by developing countries as a necessary step to make progress in halting biodiversity loss (Tsioumani, 2012: 298). On the one hand, in light of the estimated funding needs, even a doubling of current international transfers will not be enough. Developing countries in particular have asked for a further increase in international support for meeting conservation targets (ENB, 2014: 24). Developed countries point to the recent financial crisis and global economic downturn to reject further funding commitments. But NGOs have strongly - and in my view, rightly - highlighted that the financial crisis does not limit developed countries' ability to pay, as they could easily free money by abandoning environmentally harmful agricultural subsidies (CBD Alliance, 2014a: 2). From the point of view of the normative principles I have discussed in this chapter, the empirically observable lack of funding for conservation is thus particularly the fault of the developed countries.

At the same time, the COP decisions reveal a normatively problematic attempt to shift responsibility from developed to developing and emerging countries. Moreover, while this was initially still tied to appropriateness and fit with countries' capacities, the most recent complementation of the quantitative international funding targets with domestic resource mobilization requirements and the call for South-South cooperation lacks such reservations. Thereby, developing countries especially are accorded too much responsibility. Yet South-South cooperation does not appear to me to be a generally unjust policy principle. Rather, I have argued above that, in light of their economic capacities and their contribution to global biodiversity loss, emerging countries should indeed bear some (limited) responsibility for global conservation funding. An example of such a justified South-South cooperation is the so-called "Hyderabad Pledge" through which India, in 
2012, allocated an additional US\$50 million over the next two years for the implementation of the CBD in India and to support capacity building in other developing countries (ENB, 2012: 21-22). It would, however, be more problematic if South-South financial transfers were required between much poorer countries. From a normative point of view, the limits of South-South cooperation should be clear, whereas observers of the field currently see a push by developed states to expand such forms of funding. NGOs and developing countries are thus understandably wary that developed countries are trying to shift their responsibility to developing (and emerging) countries (ENB, 2012: 6; CBD Alliance, 2014b: 2; Lovera and Wulf, 2014: 2).

\section{Conclusion}

This chapter started from the observation that, while biodiversity conservation is a global benefit, it carries with it considerable costs, especially in developing countries where most biodiversity is concentrated. This connection raises the question of who should bear the costs of conservation in developing countries. I initially illustrated that, to different degrees, all states have contributed to biodiversity loss but that poverty-related as well as past overuse cannot be used as a basis for holding them responsible for conservation funding. Thus, while the contributor pays principle provides a first important reference point for allocating responsibility among states in line with their overuse of biodiversity, the principle leaves some costs unaccounted for. This remainder, I argued from a normative justice perspective, should be covered by the ability to pay principle, that is, according to a country's economic capacity. The two principles largely point in the same direction, so that, overall, least-developed countries should be exempted from funding obligations for biodiversity conservation and all other countries should be subject to progressive rates of funding obligations with the bulk of the funding responsibility resting with developed countries. In the empirical analysis, I found that the provisions of the CBD strongly confirm this normative position, even though they are predominantly grounded in a country's ability to pay and leave aside questions of fault. Yet the decisions in the context of the 2008 Strategy for Resource Mobilization have increasingly shifted responsibility towards the emerging and developing countries through requirements of domestic resource mobilization and South-South cooperation without specific attention to the principles underlying either the CPP or APP. Especially insofar as these decisions are increasingly insensitive to these countries' limited financial capacities, this is a problem of justice. In practice, these problems related to the allocation of responsibility among groups of states are exacerbated by a generally too low level of spending. In particular, developed countries provide far too few funds to meet the needs for global conservation. It is foreseeable that biodiversity loss will thus continue, and with it, human wellbeing will be further put at risk. 
According to my normative and empirical discussion, an obvious reform requirement for subsequent COPs would be that developed countries reassume more funding responsibility. However, this does not seem realistic at the moment. Instead, besides the burden shift to developing and emerging economies, an additional trend is the call for the involvement of the private sector in biodiversity financing. Recent COPs have increasingly called for private sector contributions for global conservation purposes (e.g. Decision IX/11 Annex Para. 2.6, 3.4; Decision XI/4 \$14). To date, these make up only for a small share of global funding for biodiversity. Estimates suggest that US\$0.5 billion (Waldron et al., 2013: 12145) to 3 billion (Barbut, 2011: 189) a year are raised for biodiversity from private sources. Nevertheless, this practice has received fierce criticism, especially from NGOs. They fear that developed states use private funding to cast off some of their own responsibility and that, through private funding, private interests will enter conservation policies (e.g. Lovera and Paul, 2010: 7; CBD Alliance: 2012 , 1). The responsibility of the private sector for bearing the costs of environmental conservation has so far hardly been taken into account in normative environmental justice theory. Simon Caney (2006: 467-468) has suggested, but not further elaborated on, the idea that one might consider holding corporations responsible in addition to states because, even within a particular legal context, corporations have some of their own room for manoeuvre. Weighing this argument against the concerns brought forward by NGOs will be an important further step for empirical and normative research if we want to be better able to assess whether the adopted policies can be justified or should be reformed.

\section{Notes}

1 I would like to thank Tobias Weise and two reviewers for their comments on earlier versions of this chapter. Funding by the German Research Foundation (DFG grant no. DI1417/2-1) is gratefully acknowledged.

2 According to the standard definition, biological diversity covers genetic, species, and ecosystem diversity (United Nations, 1992) but most conservation policies primarily address species and ecosystem diversity. Ecosystem services are standardly defined as the "conditions and processes through which natural ecosystems, and the species that make them up, sustain and fulfill human life" (Daily, 1997). In fact, what people need for their livelihoods are ecosystem services rather than biodiversity directly. I nevertheless refer to the underlying concept of biodiversity as this terminology better captures the object of conservation policies.

3 The third CBD objective comprises fair and equitable access and benefit-sharing (ABS) from the commercial utilization of genetic resources. For reasons of space, I leave this aside, although some of the financing provisions discussed in the following also apply to ABS provisions.

4 Note that when I refer to developed countries in the following, these are by and large to be understood as OECD countries. This roughly coincides with the list of developed countries adopted by the parties to the CBD (Decision XIII/18). Note that the USA are not a party to the CBD. Justice would thus require them to live up to their responsibilities through other (multilateral or bilateral) channels. I generally refer to all other countries as developing countries and only 
differentiate further between emerging economies and least developed countries where this serves to make my argument more nuanced.

5 In the climate justice debate, this principle is better known as the 'polluter pays principle'.

6 Climate change, of course, is another important factor contributing to biodiversity loss and is also mainly caused by developed countries (IPCC, 2013). For reasons of simplicity, I do not discuss regime overlap here and argue for the time being that all responsibility for climate change should be dealt with in the context of the UN Framework Convention on Climate Change.

7 On a more general level, this argument is problematic in that it would also prohibit reparations after wars - which are, however, generally accepted (Neumayer, 2000: 188-189). The issue of why the responsibility 'inherited' from past generations should differ across policy fields certainly needs more discussion. Preliminarily, I posit that it makes a moral difference whether the harm committed by past generations was intentionally violent or whether it is an unintended consequence of a well-intended activity, such as economic development.

8 Incremental costs in this sense are the extra costs that countries incur by implementing the Convention. On the particular difficulty of determining the incremental costs of biodiversity conservation, see Biermann (1998: 249).

\section{References}

Armstrong, C. (2016) 'Fairness, free-riding and rainforest protection', Political Theory, vol. 44, 1, 106-130.

Barbut, M. (2011) 'The Global Environment Facility. Our catalytic role to sustain biodiversity', in F. Dodds and A. Djoghlaf (eds) Biodiversity and Ecosystem Insecurity. A Planet in Peril, Earthscan, London, 187-197.

Biermann, F. (1998) Weltumweltpolitik zwischen Nord und Süd. Die neue Verhandlungsmacht der Entwicklungsländer, Nomos, Baden-Baden.

Buchanan, A. and Keohane, R. O. (2006) 'The legitimacy of global governance institutions', Ethics \& International Affairs, vol. 20, no. 4, 405-437.

Caney, S. (2005) 'Cosmopolitan justice, responsibility, and global climate change', Leiden Journal of International Law, vol. 18, no. 4, 747-775.

Caney, S. (2006) 'Environmental degradation, reparations, and the moral significance of history', Journal of Social Philosophy, vol. 37, no. 3, 464-482.

Caney, S. (2010) 'Climate change and the duties of the advantaged', Critical Review of International Social and Political Philosophy, vol. 13, no. 1, 203-228.

CBD (2010) 'Global Monitoring Report 2010. Innovative Financing for Biodiversity', Secretariat of the Convention on Biological Diversity, www.cbd.int/ financial/doc/global-monitoring-report-en.pdf [accessed 11 February 2013].

CBD (2012a) 'State of financing for biodiversity. Draft global monitoring report 2012 on the Strategy for Resource Mobilization under the Convention', Secretariat of the Convention on Biological Diversity, Montréal, www.cbd.int/doc/meetings/ cop/cop-11/information/cop-11-inf-16-en.pdf [accessed 10 January 2016].

CBD (2012b) 'Report of the High-Level Panel on Global Assessment of Resources for Implementing the Strategic Plan for Biodiversity 2011-2020', Secretariat of the Convention on Biological Diversity, Montréal, www.cbd.int/doc/meetings/ cop/cop-11/information/cop-11-inf-20-en.pdf [accessed 10 January 2016].

CBD Alliance (2012) 'Opening statement of the CBD Alliance', Eco, vol. 40, no. $1,1-2$. 
CBD Alliance (2014a) 'Civil society concerns and aspirations for SBSTTA', Eco, vol. 48 , no. $1,1-2$.

CBD Alliance (2014b) 'What will be your next steps to protect biodiversity? CBD Alliance statement at the high-level segment', Eco, vol. 50, no. 9, 1-3.

Culp, J. (2014) 'Rising powers' responsibility for reducing global distributive injustice', Journal of Global Ethics, vol. 10, no. 3, 274-282.

Daily, G. C. (1997) Nature's Services. Societal Dependence on Natural Ecosystems, Island Press, Washington, DC.

ENB (2012) 'Summary of the eleventh conference of the parties to the Convention on Biological Diversity: 8-19 October 2012', Earth Negotiations Bulletin. A Reporting Service for Environment and Development Negotiations, www.iisd. ca/biodiv/cop11/ [accessed 22 October 2012].

ENB (2014) 'Summary of the fifth meeting of the working group on review of implementation and the eighteenth meeting of the subsidiary body on scientific, technical and technological advice to the Convention on Biological Diversity: 16-28 June 2014', Earth Negotiations Bulletin. A Reporting Service for Environment and Development Negotiations, www.iisd.ca/biodiv/wgri5-sbstta18/ [accessed 8 January 2015].

FAO (2011) The State of the World's Land and Water Resources for Food and Agriculture. Managing Systems at Risk, FAO, Rome.

FAO (2012) State of the World's Forests 2012, FAO, Rome.

FAO (2014) The State of World Fisheries and Aquaculture. Opportunities and Challenges, FAO, Rome.

Gosseries, A. (2004) 'Historical emissions and free-riding', Ethical Perspectives, vol. 11, no. 1, 36-60.

Hein, L., Miller, D. C., and de Groot, R. (2013) 'Payments for ecosystem services and the financing of global biodiversity conservation', Current Opinion in Environmental Sustainability, vol. 5, 87-93.

IPCC (2013) Climate Change 2013: The Physical Science Basis. Contribution of Working Group I to the Fifth Assessment Report of the Intergovernmental Panel on Climate Change, Cambridge University Press, Cambridge, UK.

Koh, L.P. and Wilcove, D. S. (2008) 'Is oil palm agriculture really destroying tropical biodiversity?', Conservation Letters, vol. 1, no. 2, 60-64.

Loft, L. (2009). Erhalt und Finanzierung biologischer Vielfalt. Synergien zwischen internationalem Biodiversitäts- und Klimaschutzrecht, Springer, Berlin.

Lovera, S. and Paul, H. (2010) 'Finance, economic instruments and biodiversity', in CBD Alliance (ed.) Top 10 issues for COP 10. Civil society at the 10th Conference of Parties to the Convention on Biological Diversity. Seeking biodiversity justice for all lives on earth, www.cbdalliance.org/en/images/Briefing_notes/ CBDA_10briefings_ENG_v8.pdf [accessed 21 January 2015].

Lovera, S. and Wulf, F. (2014) 'The Pyeongchang roadmap and the sustainable development goals. A renegotiation of the strategic plan in favor of industry and “protection-without-people" ?', www.cbdalliance.org/en/images/COP12/Briefing notesCOP12/Briefing_on_Pyeongchang_roadmap_and_SDGs.pdf [accessed 3 January 2015].

Millennium Ecosystem Assessment (2005) Ecosystems and Human Well-being. Synthesis. Island Press, Washington.

Miller, D. (2007) National Responsibility and Global Justice, Oxford University Press, Oxford. 
Neumayer, E. (2000) 'In defence of historical accountability for greenhouse gas emissions', Ecological Economics, vol. 33, 185-192.

Page, E. (2016) 'Qui bono? Justice in the distribution of the benefits and burdens of avoided deforestation', Res Publica, vol. 22, no. 1, 83-97.

Page, E. A. (2008) 'Distributing the burdens of climate change', Environmental Politics, vol. 17, no. 4, 556-575.

Page, E. A. (2012) 'Give it up for climate change: a defence of the beneficiary pays principle', International Theory, vol. 4, no. 2, 300-330.

Parker, C., Cranford, M., Oakes, N., and Leggett, M. (eds) (2012) The Little Biodiversity Finance Book. A Guide to Proactive Investment in Natural Capital (PINC), The Global Canopy Programme, Oxford.

Rockström, J., Steffen, W., Noone, K., Persson, Å., Stuart Chapin III, F., Lambin, F., Lenton, T.M., et al. (2009) 'A safe operating space for humanity', Nature, vol. 461, no. 7,263, 472-475.

Rosendal, G. K. (2000) The Convention on Biological Diversity and Developing Countries, Kluwer, Dordrecht.

Schuppert, F. (2016) 'Carbon sink conservation and global justice: benefitting, free riding and non-compliance', Res Publica, vol. 22, no. 1, 99-116.

Secretariat of the Convention on Biological Diversity (2010) Global Biodiversity Outlook 3, Montréal.

Secretariat of the Convention on Biological Diversity (2014) Global Biodiversity Outlook 4, Montréal.

Shue, H. (1993) 'Subsistence emissions and luxury emissions', Laws \& Policy, vol. 15 , no. $1,39-60$.

Shue, H. (1999) 'Global environment and international inequality', International Affairs, vol. 75, no. 3, 531-545.

Singer, P. (2002) One World. The Ethics of Globalisation. Yale University Press, New York.

Smith, R. J. and Walpole, M. (2005) 'Should conservationists pay more attention to corruption?', Oryx, vol. 39, no. 3, 251-256.

Swift, A. and White, S. (2008) 'Political theory, social science, and real politics', in D. Leopold and M. Stears (eds) Political Theory. Methods and Approaches, Oxford University Press, Oxford, 49-69.

Tsioumani, E. (2012) 'Beginning of the implementation era?', Environmental Policy and Law, vol. 42, no. 6, 298-303.

United Nations (1992) 'Convention on biological diversity', www.cbd.int/doc/legal/ cbd-en.pdf [accessed 6 September 2012].

Waldron, A., Mooers, A. O., Milleer, D. C., Nibbelink, N., Redding, D., Kuhn, T. S., Timmons Roberts, J., and Gittleman, J. L. (2013) 'Targeting global conservation funding to limit immediate biodiversity declines', Proceedings of the National Academy of Sciences, vol. 110, no. 29, 12144-12148.

Zellentin, A. (2015) 'Compensation for historical emissions and excusable ignorance', Journal of Applied Philosophy, vol. 32, no. 3, 258-274.

\section{List of COP decisions}

All COP Decisions available at: www.cbd.int/decisions/.

Decision XIII/18 [2006]: Guidance to the financial mechanism.

Decision IX/11 [2008]: Review of implementation of Articles 20 and 21. 
Decisions X/2 [2010]: The Strategic Plan for Biodiversity 2011-2020 and the Aichi Biodiversity Targets.

Decision X/3 [2010]: Strategy for resource mobilization in support of the achievement of the Convention's three objectives.

Decision XI/4 [2012]: Review of implementation of the strategy for resource mobilization, including the establishment of targets.

Decision XII/3 [2014]: Resource mobilization. 


\section{Index}

ability to pay principle (APP) 9, 257, 261-2, 267

agribusiness 78, 139, 154-5, 219,

223-4, 226

agricultural politics 43, 228

agricultural sector: fairtrade-certified

products in 136-7; fairtrade standard

in 132-4

agrochemicals 127-8, 151

agrofuel feedstock 219-21, 228, 231

agrofuel industry 218-19, 221-3, 229,

231; 'sustainable' agrofuel feedstock 219

agrofuels project, in Ukraine: Biofuels

Directive (2003) 218; 'first

generation' agrofuels 218; trade

barriers 226-8

agroholdings 225-30

agroindustries 127,155

Argentine Chaco 151-2, 156-7

artisanal and small-scale miners (ASM)

134, 137, 181, 196; fair trade

certification of 138 ; foreign

involvement 183, 186-92

Beitz, Charles 17, 34, 23, 27

biodiversity conservation: ability to pay principle (APP) 261-2; allocation of responsibility for 257-62;

contributor pays principle (CPP)

258-61; domestic resource mobilization for 264; funding

responsibilities for 263-7; Hyderabad

Pledge 266-7; non-fault-based

biodiversity loss 260; South-South

cooperation for 265-6

biodiversity loss 52, 258-9, 263; in

developing countries 260

biological diversity 256 biotechnologies 165, 219

Brazilian Mato Grosso 150-1, 154-6

capitalist development, model of 55 , 57, 66, 203

carbon dioxide $\left(\mathrm{CO}_{2}\right)$ emissions 166 , 176

carbon trading 43

civil society activism 155; organizations

(CSOs) 99-101, 103, 129

climate change $269 \mathrm{n} 6$; implications of 43,175 ; mitigation of 218

climate justice $2,5,43,256,269 \mathrm{n} 5$

commodity-exporting countries 55 , 64

commodity price boom 4, 65-6

commodity trade 237-8;

financialization and global

commodity markets 240-2;

financialization on commodity prices, effects of 242; multi-commodity trading companies 241; price instability in 250; price setting and risks in coffee and cotton commodity chains 243-9

company-community relations 8 , 111-12, 115, 122

Conflict Diamonds 96, 134

contributor pays principle (CPP) 9, 257, 258-61, 267

Convention on Biological Diversity (CBD) 9, 256; Corporate Social

Responsibility (CSR) 3, 5, 109, 230

cosmopolitan liberalism 35-6, 57; ownership 19

deforestation 152, 154, 157, 258

democracy: concept of 40; conflictoriented conception of 41 ; 
democracy continued deliberative 39 ; meaning of 41 ; process-oriented models of 39 ; radical 40-2; and socio-ecological conflicts 39-42

distributive justice, theory of 33,35 , $36,42,43,154$

Earth Summit (1992), Rio de Janeiro 76 ecological debts 56,63

ecological justice 43

economic justice, notion of 17-18

economic redistribution 58-9

electric cars 165-6; batteries for 167

electromobility 9, 165, 166, 175

enclave economy 201

energy production 2, 73, 141

environmental degradation 9, 54-5, 176, 182-3, 189, 191-3, 261

environmental governance, global 52

Environmental Impact Assessment 115; Environmental and Social Impact Assessments (ESIA) 98

environmental justice $6,33,43,146-7$, 268; movement 42-4; versus ecological justice 43

environmental pollution 99

environmental protection 195, 265; economic development with 52; priority of economic growth over 53; socio-economic development and 54-7

environmental sustainability 52

European agrofuel market 226

European Bank for Reconstruction and Development (EBRD) 226-7; loans for agribusinesses 230

Extractive Industry Transparency Initiative (EITI) 96, 114

fair trade gold 138; Fairtrade certified gold 135

Fairmined (standard for fair trade mining) 135

fairness and justice in resource politics, notions of 33

fairtrade-certified products, in the agricultural sector: consumers and their influence 137; GVC/GPN characteristics 136; producers and products 136

Fairtrade International 135

Fairtrade Labelling Organizations (FLO) 132-3, 142n1 'fairtrade' system (FLO) 127; certification schemes 127, 134-5, 139 ;

'fair' trading standards, global initiatives on: in agricultural sector 132-4; in mineral sector 134-5

Finance Industry Groups, Ukraine 218, 221, 223

financial markets, deregulation of $237-9,241-2,252$

food security, definition of 44

food sovereignty: concept of 42-4; network 44; "quiet food sovereignty" 230

food system, social control of 44

foreign direct investment (FDI) 115, 201, 212

foreign stock exchanges 226

fossil fuels 2, 164-6, 176

Fraser, Nancy 53, 73, 86, 91; justice, concept of 58-59, 65

free, prior, and informed consent (FPIC) 95

futures markets $240-3,248,253 \mathrm{n} 2$

galamsey (illicit miners) 181, 184-5, 187-8, 190-1, 193, 195

Global Compact 109, 112, 114, 122

global difference, principle of 19

global inequalities 19, 25, 128-9

global justice: challenging moral assumptions of 34-6; in liberal political philosophy 18-19

Global Production Network (GPN) $127,131,149$

global reforms: limitations of 29; moral principles underlying 28; Pogge's proposals for 26-7; self-referring 30 ; uncertainty in 27-30

Global Resource Dividend (GRD) 6, 35

global trade 128-30

Global Value Chain (GVC) 9, 127, 129, $131,133,135,137,138,141,168$

green economy $54,55,64,164,165-7$, 176

Green Growth 9, 11, 165

greenhouse gas emissions 2, 218, 223, 228,260

'greening' capitalism, idea of 52-4, 57

Green New Deal 165

'green' technologies 9, 166

hegemony, Gramscian concept of 84; gold mining in Ghana 41 
human-nature interactions 75,148

hybrid cars 165,169

imperial mode of living, concept of 53, 164, 165-7, 175

income redistribution, issues of 61

Institute for the Development of Local Industries, Mozambique 206; River

Basin Committees 78; river basin management 79; Users' Commissions 78

intellectual property: protection of 64; rights 24

Intercontinental Exchange (ICE), New York 243

international commodity agreements (ICAs) 237-8, 252

International Finance Corporation (IFC) 204, 228; Private Enterprise for Africa 206

International Monetary Fund (IMF) 24, 35; Compensatory Financing Facility 238

joint ventures 168-9, 212

justice, theory of $18,57-8$

Kapp, Karl William 61; social costs, notion of 53, 60

Kimberley Process 96

"Kinga Ya Bei” project, Tanzania 253n9

kolkhozes (collective farms) 225, 230

land market, liberalization of 225

La Vía Campesina (international peasant movement) 44

liquid natural gas (LNG) 202

lithium: case study of extraction 176 ; investors 169; lithium-ion batteries 167, 169; "lithium rush" 164; "lithium-triangle" 164; political economic context of 167-8

local-regional territorialities 152

London International Financial Futures and Options Exchange (LIFFE) 243

'Making Most of Commodities' project 65

marginalized people 40, 47, 175

market-based development cooperation 132

market prices $61,65,133,167,187$, 208
Mesas de Diálogo (Dialogue Tables) 10, 91, 98, 101

mineral sector: exporter-buyer partnerships 138; 'fair' initiatives in 137-40; fairtrade standard in 134-5

moral: concept of economy 131; concept of geography 131; idea of arbitrariness 17, 19; principles of moral justice 33

Mouffe, Chantal 34, 39, 41; conception of democracy 41

national ownership, idea of 19,28

national property rights, violation of 28

natural resource conflicts: actors involved in 90; claims for redistribution 94-5; Environmental and Social Impact Assessments (ESIA) 98; evolution of 90; Extractive Industries Transparency Initiative 96; governance initiatives in resolving 96-7; Kimberley Process 96; local justice claims in 93-6; local resource conflicts 91-3; Open Contracting Partnership 96; in Peru 97-9; recognition of 95; representation and equality 95-6 natural resource exports, growth of 21

natural resources: appropriation and control of 33; as collective asset 19; competition for access to 4; endowments of 20; exploitation of 52; global demand for 139; global distribution of 19, 28; ownership rights 38 ; power asymmetries associated with appropriation of 37 ; public revenue from 5; role of (state) institutions for the control of 35 ; rules allocating control over 24; unequal distribution of benefits from $4-5,35$

"No dirty gold" campaign 134

Observatory of Mining Conflicts in Latin America 92

Olaroz lithium project 164-5; actors, interests, and strategies in 168-71; territorial transformation and socioecological conflicts 171-6

oligarchs 223-4, 226

Orocobre (Australian mining company) 168, 169, 170, 172

Oro Verde programme 135 
"parity of participation" principles 58-9 peasant agriculture 139

pension funds 226, 241

Pogge, Thomas 17-18; on causal force of global institutions 26; global basic structure, notion of 23 ; on modifications in the global order 25; proposals for global reforms 26-7; on unequal distribution of natural resources 35; views on global justice 23-4

political ecology, tenets of $7,33-4$, 36-9, 43, 47, 148, 164, 166, 220

power relations, tenets of $7-11,33$, 36-9, 41, 47, 74-5, 77, 83, 128, 131, 149,165

precious metals and gems 138, 140

price instability $244-5,250,252$

price risks: in commodity chains 239 ; price risk management (PRM) 237, 239, 248, 252

public participation, definition of 79 , 120, 154

public standards 128

puesteros, displacement of 152

radical democracy 34, 40-3, 60

Rainforest Alliance 134

Rancière, Jacques 34, 39-41

Rawls, John 17-19; theory of justice 19, 34, 41; Theory of Justice, A (1999) 18

Renewable Energy Directive (RED, 2009) 218, 231

resource-abundant countries 22

resource-based development 57 ; strategies for 4-5

resource exploitation, benefits and costs of 57-9

resource-exporting countries 5,66 resource fairness: concept of 60-5, 196; framework for 57-60; and justice $1-3$; price risk from 239; resources as a process of creation 63-5; social costs of 60-3

resource injustices 2, 35, 194, 225

resource management $6,74,78,112$, 196

resource privilege $28-9$

resource redistribution, principle of 20 , 27

resource-related conflict 37

resources and scarcity, constitution of 74-6 resource sovereignty $3,9,11,181,183$, 192, 194

right to equality $41,175-6$

risk management 237-41, 244, 248-50

small and medium sized enterprises

(SME) 204, 206

social costs: of capitalist accumulation

60-3; notion of 60, 65; problems of

61

social inequality $85,120,176,220-1$

social justice system $6,18,86$; marketdriven 131

social licence to operate 5, 102, 104

social responsibility 96

social rights 62

societal nature relations $34,36,38$, 39-42, 47, 86, 176, 219-20;

democratization of 33

socio-ecological conflicts 33,38 ; concept of 37; and democratization 39-42; political ecology and power relations in 36-9; power relations in 166 ; in rural areas 43; territorial transformation and 171-6

socio-ecological justice 165-7, 176-7; concept of 34; distributional aspects of 44; political dimensions of 42-7; political representation in 44 ; transnational perspective on 45

South-South trading 132

soy-production, in Latin America 146; agribusiness 154; Brazilian Mato Grosso and Argentine Chaco 150-9; in context of fairness, environmental justice, and territoriality 147-50; economic activity of 150; Jazz Methodology 150

Structural Adjustment Programmes (SAPs) 4, 115, 238

Sub-Saharan Africa (SSA) 195, 210, 238

subsistence farming 46, 225

supply chain 138, 140, 205, 225, 226

"sustainable biomass" project 228

sustainable development 52, 133

technological innovation 52, 54, 63, 64, 139

technology transfer 55, 62

territoriality, concept of 149

toxic: landfills, effects of 148; waste, dumping of 2,42 
trade barriers $32 \mathrm{n} 3,129,141,226-8$

trading practice: forms of 132; of international traders 243

Transatlantic Trade and Investment Partnership (TTIP) 56

transnational corporations (TNCs) 5 , $96,128,165,185$

transnational mining corporations 181-2

Trans-Pacific Partnership (TPP) 56

unequal resource distribution, reasons of 36

United Nations (UN): Agenda for Sustainable Development 52; Convention on Biological Diversity (CBD) 256; Declaration for the Establishment of a New International Economic Order (1974) 3; Declaration on Permanent Sovereignty over Natural Resources (1962) 3; General Assembly 52; Global Compact see Global Compact; Universal Declaration of Human Rights (UDHR) 23, 25; Universal Declaration of the Rights of Mother Earth (2010) 43

value chain: characteristics of 131 ; complexity of 136 ; framework of 129-30; mapping of 128,129
Voluntary Principles on Security and Human Rights 109, 113

Wassa Association of Communities Affected by Mining (WACAM) 115, 117-18, 121

water: commercialization of 77 ; commodification of 77 ; concept of management 74 ; construction of infrastructure 84; discharges 84,172 ; distribution $8,78,84,86$; expansion of infrastructure 78 ; as a finite resource $76-7$; legislation 77,81 ; management in Brazil 73; participatory management 78 ; pollution $60,115,189$; redistribution of 79 ; users $74,79-80,83-4$; wateruse rights 100

World Bank 24, 78-9, 204, 211, 225 , 238; Project for Entrepreneurial Development (PODE) 207

World Trade Organization (WTO) 24, 27, 35, 56, 227

World Water Council (WWC) 73

Zimmermann, Erich 53-4, 60, 63, 74; functional theory of resources 54 


\section{Taylor \& Francis eBooks}

\section{Helping you to choose the right eBooks for your Library}

Add Routledge titles to your library's digital collection today. Taylor and Francis ebooks contains over 50,000 titles in the Humanities, Social Sciences, Behavioural Sciences, Built Environment and Law.

\section{Choose from a range of subject packages or create your own!}

\section{Benefits for you}

》) Free MARC records

》 COUNTER-compliant usage statistics

» Flexible purchase and pricing options

» All titles DRM-free.

\begin{tabular}{c|l}
\hline $\begin{array}{c}\text { REQUEST YOUR } \\
\text { FREE } \\
\begin{array}{c}\text { INSTITUTIONAL } \\
\text { TRIAL TODAY }\end{array}\end{array}$ & $\begin{array}{l}\text { Wree Trials Available } \\
\text { academic, corporate and } \\
\text { government customers. }\end{array}$ \\
\hline
\end{tabular}

Benefits for your user

» Off-site, anytime access via Athens or referring URL

»Print or copy pages or chapters

» Full content search

» Bookmark, highlight and annotate text

» Access to thousands of pages of quality research at the click of a button.

\section{eCollections - Choose from over 30 subject eCollections, including:}

\begin{tabular}{|l|}
\hline Archaeology \\
\hline Architecture \\
\hline Asian Studies \\
\hline Business \& Management \\
\hline Classical Studies \\
\hline Construction \\
\hline Creative \& Media Arts \\
\hline Criminology \& Criminal Justice \\
\hline Economics \\
\hline Education \\
\hline Energy \\
\hline Engineering \\
\hline English Language \& Linguistics \\
\hline Environment \& Sustainability \\
\hline Geography \\
\hline Health Studies \\
\hline History \\
\hline
\end{tabular}

\begin{tabular}{|l|}
\hline Language Learning \\
\hline Law \\
\hline Literature \\
\hline Media \& Communication \\
\hline Middle East Studies \\
\hline Music \\
\hline Philosophy \\
\hline Planning \\
\hline Politics \\
\hline Psychology \& Mental Health \\
\hline Religion \\
\hline Security \\
\hline Social Work \\
\hline Sociology \\
\hline Sport \\
\hline Theatre \& Performance \\
\hline Tourism, Hospitality \& Events \\
\hline
\end{tabular}

For more information, pricing enquiries or to order a free trial, please contact your local sales team: www.tandfebooks.com/page/sales
Routledge
Taylor \& Francis Grou
The home of 